\title{
WestVirginiaUniversity
}

THE RESEARCH REPOSITORY @ WVU

Graduate Theses, Dissertations, and Problem Reports

2009

\section{Ludwig van Beethoven's orchestration of the trombone}

Daniel R. Cloutier

West Virginia University

Follow this and additional works at: https://researchrepository.wvu.edu/etd

\section{Recommended Citation}

Cloutier, Daniel R., "Ludwig van Beethoven's orchestration of the trombone" (2009). Graduate Theses, Dissertations, and Problem Reports. 2917.

https://researchrepository.wvu.edu/etd/2917

This Dissertation is protected by copyright and/or related rights. It has been brought to you by the The Research Repository @ WVU with permission from the rights-holder(s). You are free to use this Dissertation in any way that is permitted by the copyright and related rights legislation that applies to your use. For other uses you must obtain permission from the rights-holder(s) directly, unless additional rights are indicated by a Creative Commons license in the record and/ or on the work itself. This Dissertation has been accepted for inclusion in WVU Graduate Theses, Dissertations, and Problem Reports collection by an authorized administrator of The Research Repository @ WVU.

For more information, please contact researchrepository@mail.wvu.edu. 


\title{
Ludwig Van Beethoven's Orchestration of the Trombone
}

\author{
Daniel R. Cloutier
}

\author{
Doctoral Research Project \\ submitted to the \\ College of Creative Arts \\ at West Virginia University \\ in partial fulfillment of the requirements \\ for the degree of
}

Doctor of Musical Arts
in
Trombone Performance

H. Keith Jackson, D.M.A., Chair

John Winkler, D.M.

George Willis, M.M.

Christopher Wilkinson, Ph.D.

Lee Blair, M.F.A.

Division of Music

Morgantown, West Virginia

2009 


\section{Abstract \\ Ludwig Van Beethoven's Orchestration of the Trombone \\ Daniel R. Cloutier}

Ludwig Van Beethoven is considered one of the first composers to fully realize the wideranging performance potential of the trombone. Although the instrument had already been scored in sacred and operatic works by major composers (and symphonies by lesser-known composers), it was Beethoven who was considered to be the first to truly emancipate the trombone from its sacred and operatic boundaries and write for it in various secular, choral, and even chamber music genres. In this paper, every composition of Beethoven's that includes trombones is examined. The historical context of each individual work will be established, along with any general trombone-related observations from the work in question. Musical examples from each work will be examined in detail, with the view of elucidating compositional techniques such as melodic and solo usage, doubling, range, dynamic range, percentage of measures actually played, and placement within orchestration. Comparisons between genres and time periods will also be made, with the objective being to establish patterns of musical evolution—if any—across time or between genres. 


\section{Dedication}

This Research Project is dedicated to the memory of my mother, Pauline J. Cloutier, who died unexpectedly during the last stages of this Project. She lived a full and active life, right up to her final days. She had been looking forward to this Research Project's completion, and it is my hope that her love of writing is reflected in the words found on these pages. 


\section{Acknowledgements}

Several people deserve thanks for their significant contributions to this effort. First, thanks goes to Dr. H. Keith Jackson for his unwavering support and encouragement, keen observations, and rejuvenating sense of humor. I am honored, not only to have him as a colleague, but to be able to call him friend. Thanks to Chris Durman and the rest of the staff at the University of Tennessee Music Library. Without their help with finding research materials, this project would have been significantly more difficult. Thank you to John Hagen, Manager of the West Virginia University Libraries Institutional Repository Program, for his flexibility, patience, and helpfulness. Thanks goes out to Dr. Richard Scruggs for his excellent work in translating the Urtext Commentaries from the German. Thanks to my dad, Robert Cloutier, for his unparalleled proofreading skills. Thanks also to my son Mitchell for encouraging me to keep working on this Research Project until it was done. And finally thank you to Glenda Cloutier, my life partner and wife of twenty-four years, my strongest supporter, my most truthful critic, and my dearest friend. Without your support, encouragement, and belief in me, this Research Project—and my Doctorate degree-would never have happened. 


\section{Table of Contents}

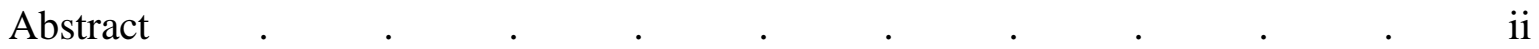

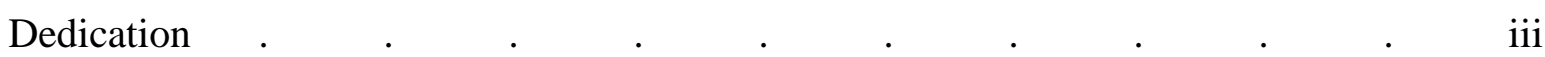

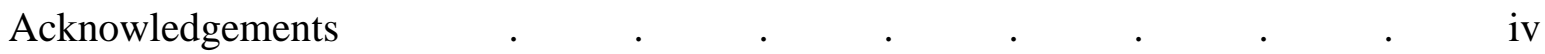

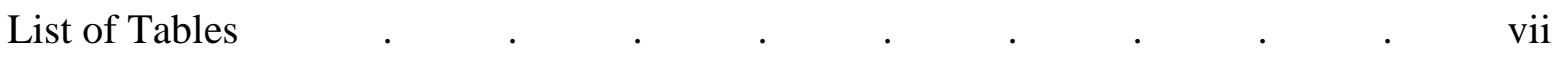

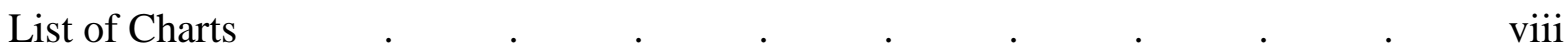

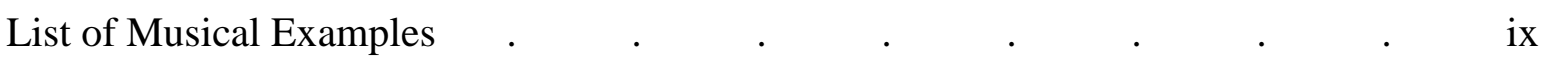

\section{Chapter}

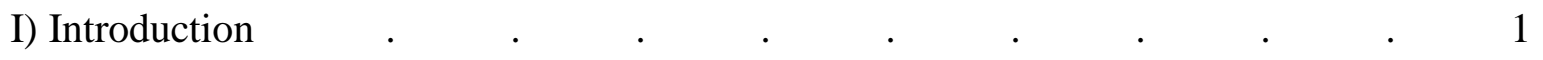

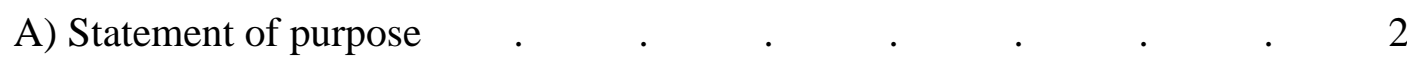

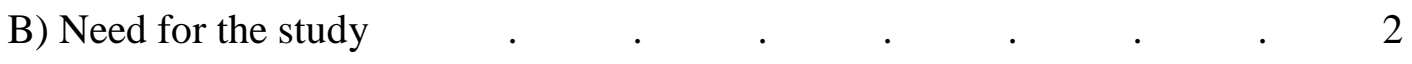

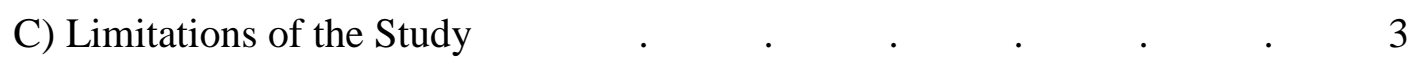

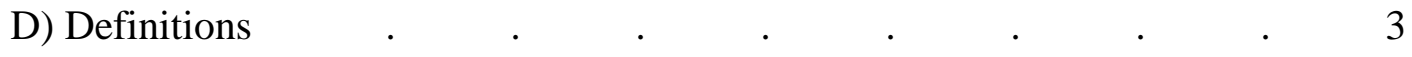

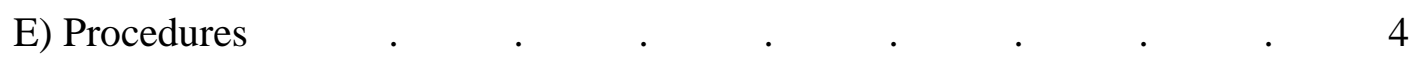

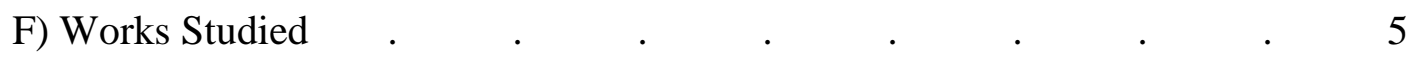

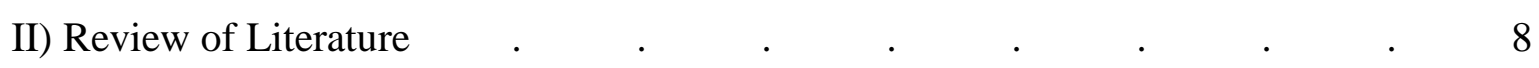

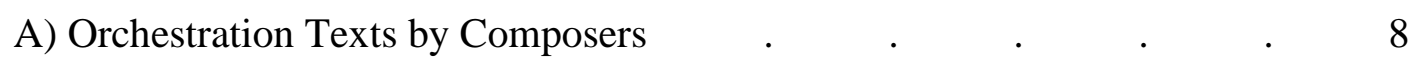

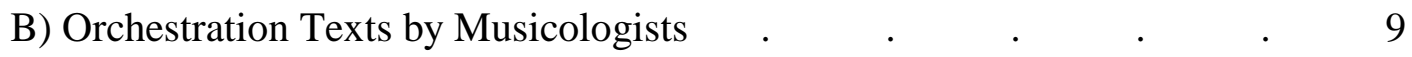

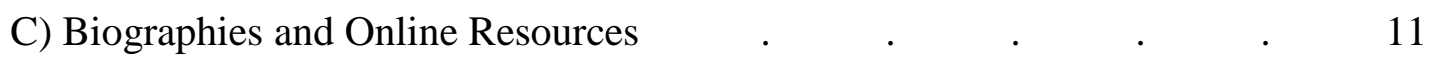

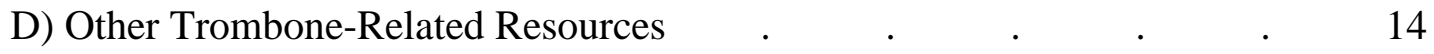

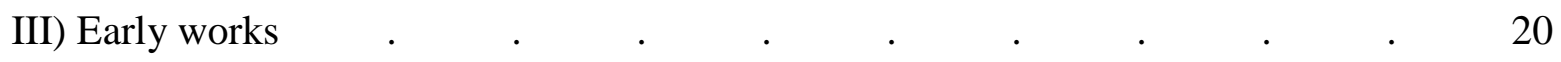

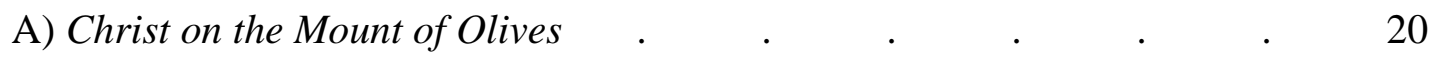

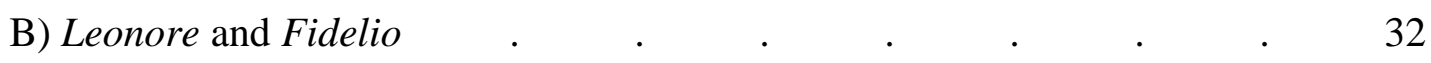




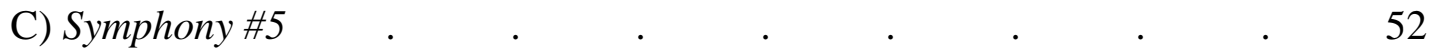

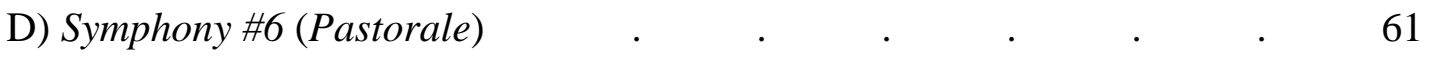

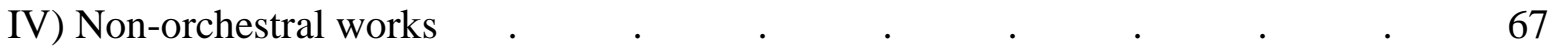
A) Three Equali
67

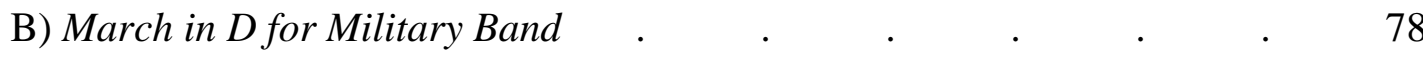

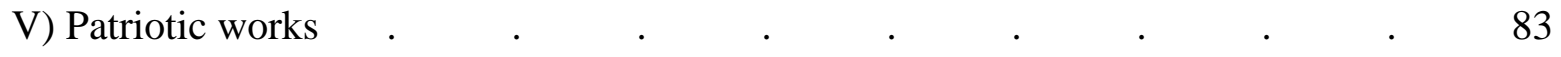

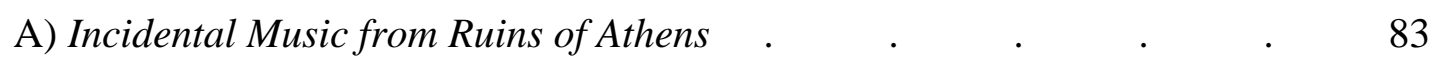

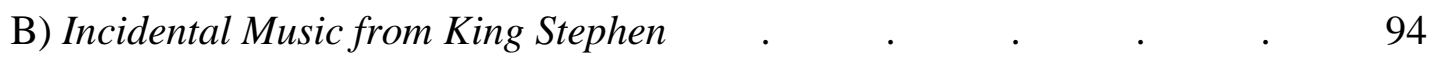

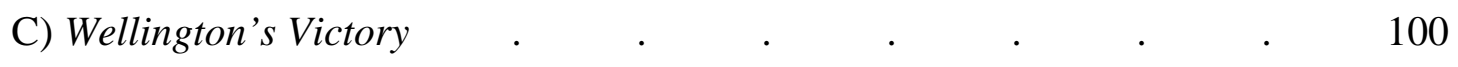

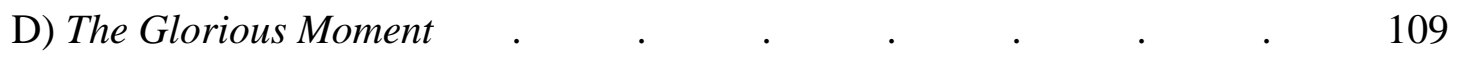

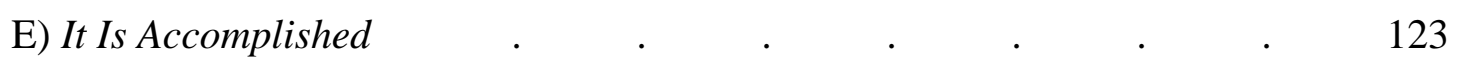

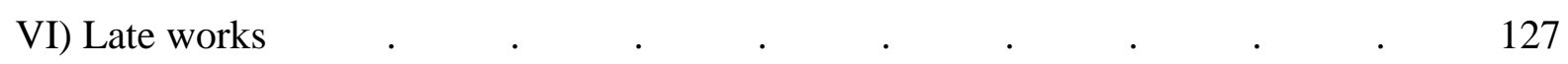

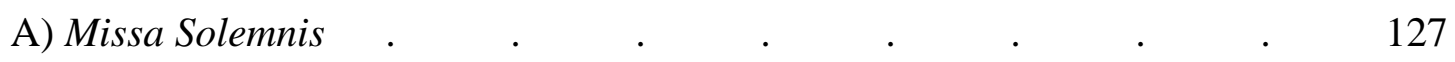

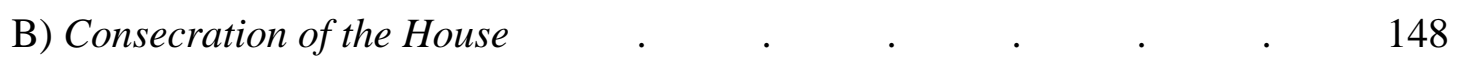

C) March and Chorus from Ruins of Athens $\quad . \quad$. $\quad . \quad$. $\quad$. 153

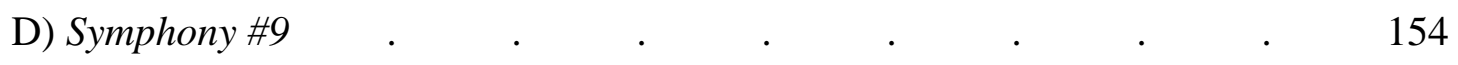

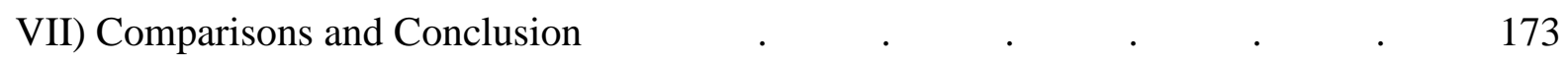
A) Between Genres

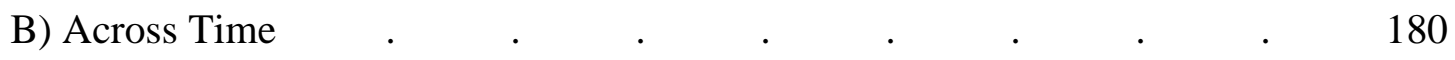

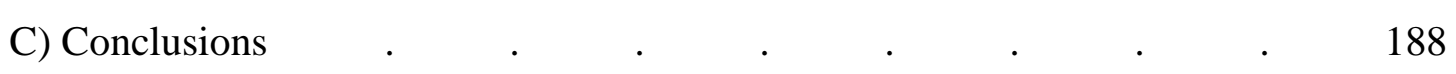

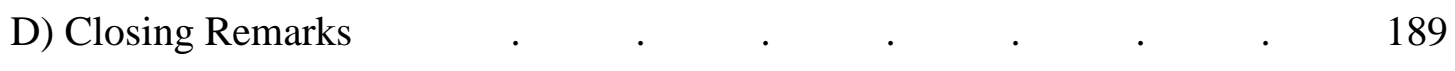

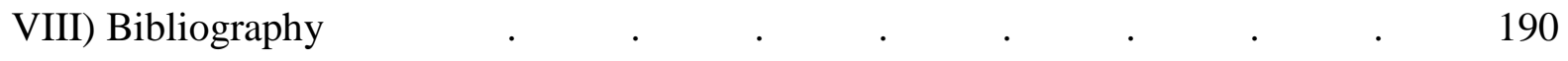




\section{List of Tables}

Table

Page

1: Works of Beethoven which Include Trombones $\quad \ldots \quad$. $\quad$ • $\quad$. 7

2: Trombone Statistics for Christ on the Mount of Olives, Opus $85 \quad$ • 32

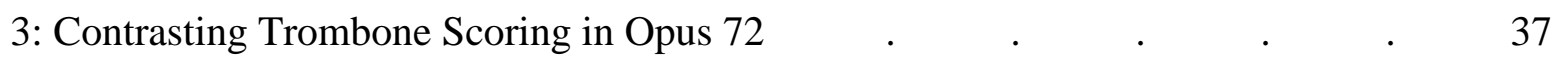

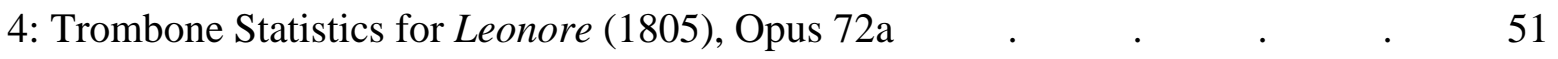

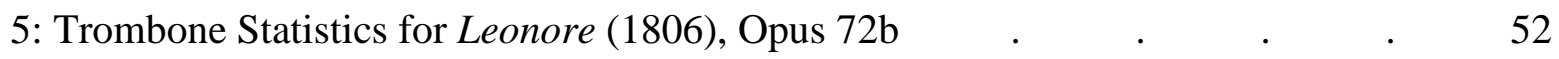

6: Trombone Statistics for Fidelio (1814), Opus $72 \quad$. $\quad . \quad$ • $\quad$ • 52

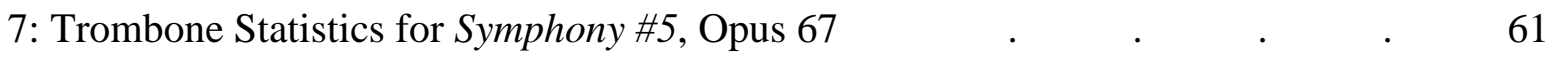

8: Trombone Statistics for Symphony \#6, Opus $68 \quad$. $\quad . \quad$. $\quad$ • $\quad 66$

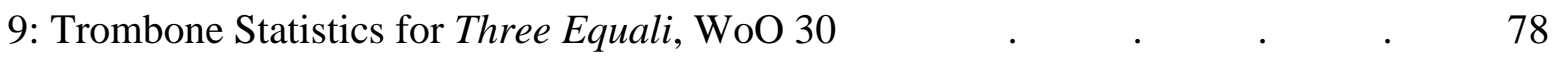

10: Trombone Statistics for Military March in D, WoO $24 \quad$ 82

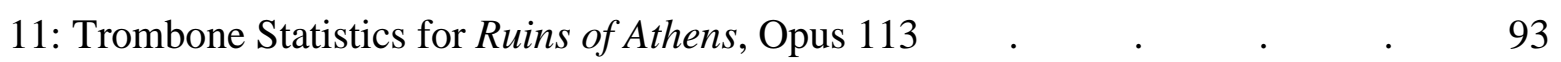

12: Trombone Statistics for King Stephen, Opus $117 \quad$ • $\quad$ • $\quad$ • $\quad$ • 99

13: Trombone Statistics for Wellington’s Victory, Opus $91 \quad$ • 108

14: Trombone Statistics for The Glorious Moment, Opus $136 \quad$ • $\quad$ • 123

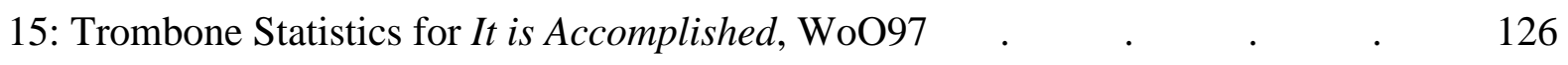

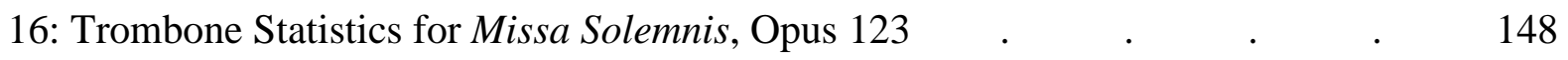

17: Trombone Statistics for Consecration of the House, Opus $124 \quad$ • 153

18: Trombone Statistics for March and Chorus from Ruins of Athens, Opus 114 • 153

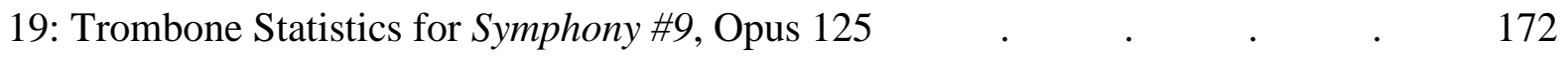

20: Genres of Beethoven’s Works which Include Trombones, by Opus 173

21: Trombone Statistics for Leonore and Fidelio Overtures $\quad$ • $\quad$ • 176 


\section{List of Charts}

Chart

Page

1: Average Percentage of Measures in Orchestral Works, Listed by Genre 178

2: Percentage of Measures in Works, Listed by Frequency

179

3: Percentage of Measures in Orchestral Works over Time

187 


\section{List of Musical Examples}

Example

Page

1: Christ on the Mount of Olives, Number 1, measures 1-2 $\quad$ . . . . 25

2: Christ on the Mount of Olives, Number 1, measures 23-24 26

3: Christ on the Mount of Olives, Number 1, measures 29 and $30 \quad$ • $\quad 27$

4: Christ on the Mount of Olives, Number 1, measures 67-70 $\quad$ • $\quad$ • $\quad 28$

5: Christ on the Mount of Olives, Number 2, measures 176-181 . $\quad$ • $\quad 28$

6: Christ on the Mount of Olives, Number 2, measures 207-213 _ 29

7: Christ on the Mount of Olives, Number 6, measures 160-164 . 29

8: Christ on the Mount of Olives, Number 6, measures 274-278 $\quad$. $\quad$ • $\quad 29$

9: Christ on the Mount of Olives, Number 2, measures 237-242 $\quad$ • $\quad$. $\quad 30$

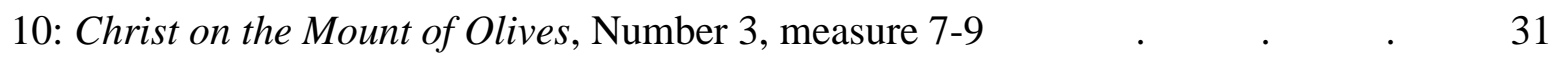

11: Fidelio, Number 8, measures 115 and $123 \quad$. $\quad$. $\quad$. $\quad$. $\quad$. 41

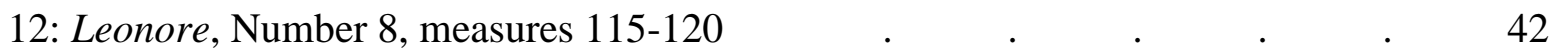

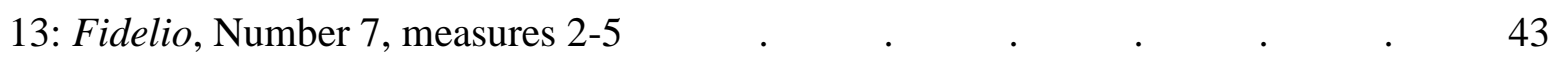

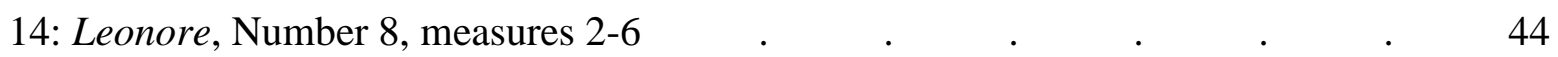

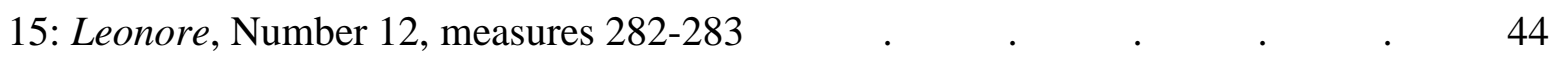

16: Fidelio, Number 10, measures 228-229 $\quad$. $\quad$. $\quad$. $\quad$. $\quad$. $\quad 44$

17: Leonore, Number 12 (Finale Act II), measures 459-463 45

18: Leonore, Number 18 (Finale Act III), measures 9-14 46

19: Leonore, supplemental fragment of Number 18, measures 336-340 46

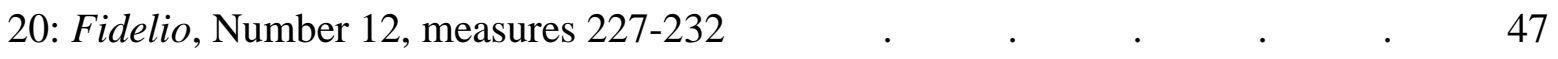

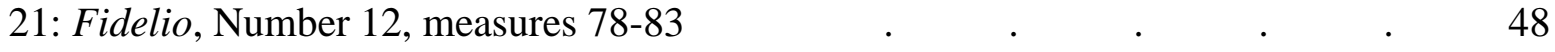




\section{Example}

22: Fidelio Overture, measures 230-233

23: Leonore Overture \#2, measures 89-95

24: Leonore Overture \#3, measures 70-76

25: Leonore Overture \#2, measures 236-244

26: Leonore Overture \#3, measures 104-112

27: Symphony \#5, Finale, measures 1-6

28, Symphony \#5, Finale, measures 32-37

29: Symphony \#5, Finale, measures 74-82

30: Symphony \#5, Finale, measures 12-17

31: Symphony \#3, Finale, measures 452-455; 464-465

32: Symphony \#5, Finale, measures112-118

33: Symphony \#5, Finale, measures 289-294

34: Symphony \#5, Finale, measures 386-390

35: Symphony \#6, Fourth movement, measures 106-111

36: Symphony \#6, Finale, measures 28-32

37: Symphony \#6, Finale, measures 46-49

38: Symphony \#6, Finale, measures 132-139

39: Equale 1 from Three Equali

40: Equale 2 from Three Equali

41: Equale 3 from Three Equali

42: Military March in D, measures 4-8 


\section{Example}

44: Military March in D, measures 28-33

45: Military March in D, measures 35-41

46: Military March in D, measures 49-55

47: Ruins of Athens, Number 3, measures 15-18

48: Ruins of Athens, Number 3, measures 21-29

49: Ruins of Athens, Number 6, measures 120-123

50: Ruins of Athens, Number 6, measures 129-134

51: Ruins of Athens, Number 6, measures 135-141

52: Ruins of Athens, Number 6, measures 157-161

53: Ruins of Athens, Number 7, measures 151-157

54: Ruins of Athens, Number 7, measures 186-193

55: Ruins of Athens, Number 8, measures 76-83

56: Ruins of Athens, Number 8, measures 143-150

57: King Stephen, Number 1, measures 13-20

58: King Stephen, Number 2, measures 20-27

59: King Stephen, Number 2, measures 28-32

60: King Stephen, Number 3, measures 13-20

61: King Stephen, Number 3, measures 38-46

62: King Stephen, Number 7, measures 1-7

63: King Stephen, Number 8, measures 28-34 


\section{Example}

66: Wellington’s Victory, Battle, measures 47-55 $\quad$. $\quad$. $\quad$. 105

67: Wellington’s Victory, Victory Symphony, measures 225-233 $\quad$ 106

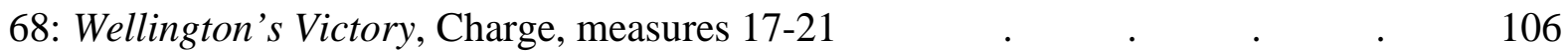

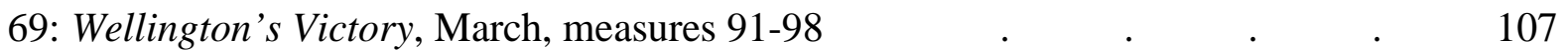

70: Wellington’s Victory, Victory Symphony, measures 288-292 $\quad$ 107

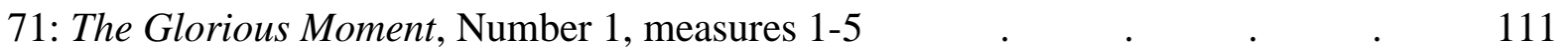

72: The Glorious Moment, Number 1, measures 98-103 112

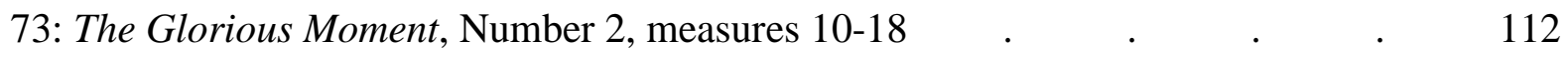

74: The Glorious Moment, Number 2, measures 46-65 113

75: The Glorious Moment, Number 3, measures 193-204 114

76: The Glorious Moment, Number 3, measures 205-212 115

77: The Glorious Moment, Number 3, measures 217-224 115

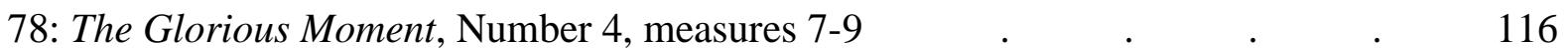

79: The Glorious Moment, Number 4, measures 55-74 . 117

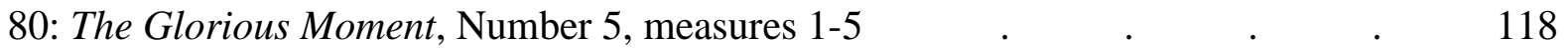

81: The Glorious Moment, Number 6, measures 121-140 119

82: The Glorious Moment, Number 6, measures 164-176 120

83: The Glorious Moment, Number 6, measures 216-225 121

84: The Glorious Moment, Number 6, measures 229-235 121

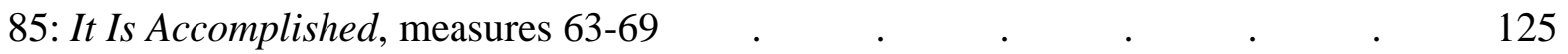

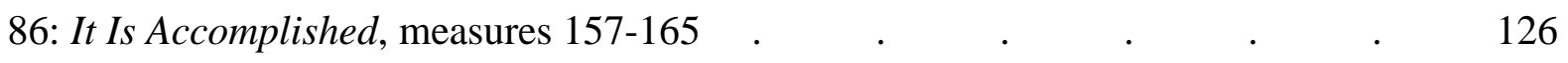

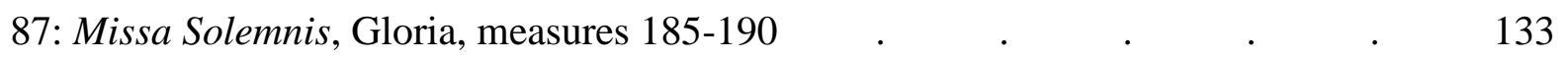




\section{Example}

Page

88: Missa Solemnis, Gloria, measures 292-295

134

89: Missa Solemnis, Credo, measures 11-15

135

90: Missa Solemnis, Gloria, measures 345-349

135

91: Missa Solemnis, Agnus Dei, measures.155-161

136

92: Missa Solemnis, Sanctus, measures 170-175

136

93: Missa Solemnis, Sanctus, measure 119-122

137

94: Missa Solemnis, Sanctus, measures 9-20

137

95: Missa Solemnis, Gloria, measures 360-373

138

96: Missa Solemnis, Agnus Dei, measures 216-229

140

97: Missa Solemnis, Gloria, measures 429-440

141

98: Missa Solemnis, Credo, measures 250-255

141

99: Missa Solemnis, Credo, measures 256-261

142

100: Missa Solemnis, Credo, measures 221-228

143

101: Missa Solemnis, Gloria, measures 381-392

145

102: Missa Solemnis, Agnus Dei, measures 235-240

145

103: Missa Solemnis, Sanctus, measures 216-222

146

104: Consecration of the House, measures 1-5

150

105: Consecration of the House, measures 8-21

151

106: Consecration of the House, measures 37-40

152

107: Handel, King Saul, Number 1, measures 18-23

152

108: Symphony \#9, Scherzo, measures 412-415

158

109: Symphony \#9, Scherzo, measures 475-484

159 


\section{Example}

Page

110: Symphony \#9, Scherzo, measures 496-507 $\quad . \quad$ •

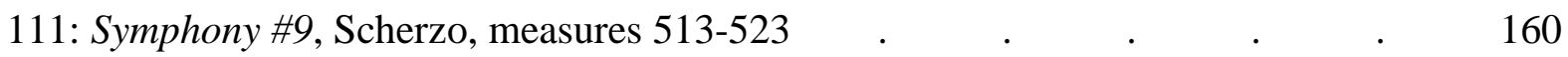

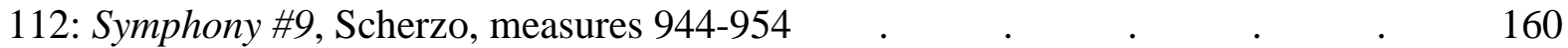

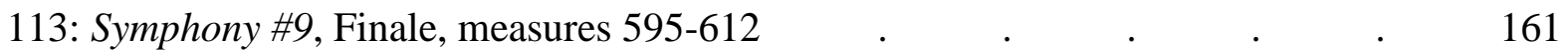

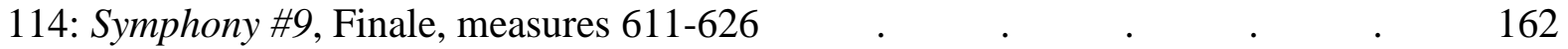

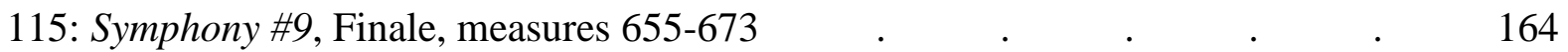

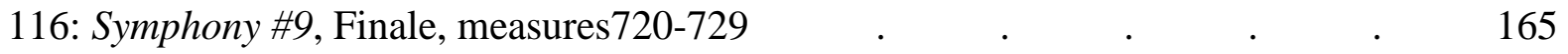

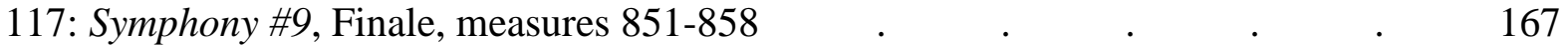

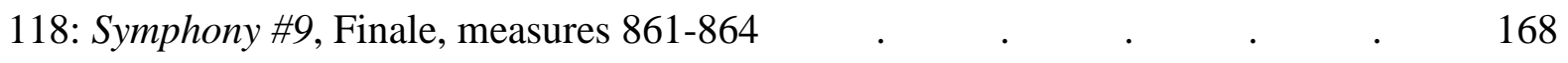

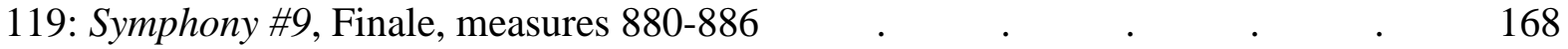

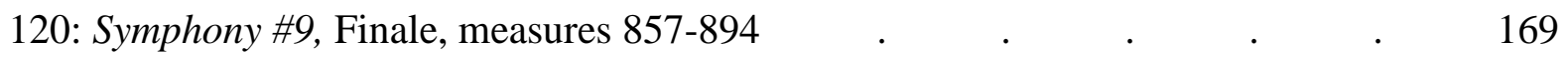

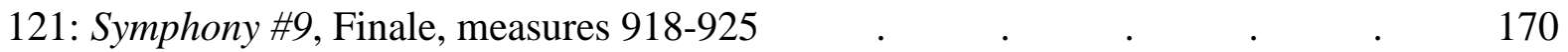

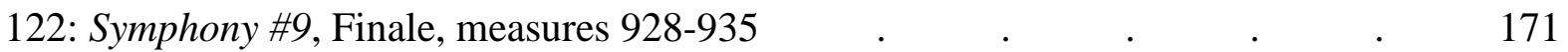




\section{Chapter I}

\section{Introduction}

Ludwig Van Beethoven is considered one of the first composers to realize in his compositions the wide-ranging performance potential of the trombone. Although the trombone had already been scored in orchestral works by George Frideric Handel, Wolfgang Amadeus Mozart, Franz Joseph Haydn, Christoph Willibald Gluck, Johann Joseph Fux, and even Johann Sebastian Bach, each of these composers (with the possible exception of Haydn) orchestrated the instrument in a more limited fashion. They either restricted trombone parts to sacred (Bach) or operatic (Gluck) music, or relegated the instrument to a more-or-less cola voce function (Fux). Although Mozart wrote for the trombone in a more versatile manner than his predecessors - even giving the instrument a prominent solo part in the Tuba Mirum section of his Requiem — such techniques were not revolutionary, but actually represented the traditional Austrian style of scoring for trombones. It was Ludwig Van Beethoven who was the first to truly emancipate the trombone from its sacred and operatic boundaries and write for it in various secular and non-choral genres, including symphonic and even chamber settings. Furthermore, the legacy of Beethoven's orchestration of trombone is significant: in the same way that composers followed Beethoven's example in compositional techniques, they also followed his example in orchestration, including his method of scoring for trombones. His examples of symphonic orchestration of the trombone would be followed and built upon by the succeeding generations of composers, including Berlioz, Schubert, Schumann, and Brahms. However, Beethoven's orchestration of trombones in chamber music would not be repeated for another hundred years, in the chamber works of Igor 
Stravinsky. ${ }^{1}$ In either case, it was Beethoven's influence that spurred later composers to write for the trombone in diverse genres. Had Beethoven not scored for the trombone using the varied genres and techniques that he did, the instrument might have suffered restricted orchestration for an even longer period of time.

\section{Statement of Purpose}

The purpose of this paper is to explore all the works of Ludwig Van Beethoven that include trombones in the orchestration. Fortunately, due to the limited number of works Beethoven wrote which included trombone, this task is quite possible in the span of one paper. Beethoven included trombones in 15 compositions, which are all available in the collected editions of his works.

\section{Need for the Study}

As will be shown in the Review of Literature section, there is somewhat of a paucity of in-depth research discussing Beethoven's orchestration of the trombone. This is interesting—even baffling—given the level of influence Beethoven had on all subsequent composers. Seemingly, there should be a significant amount of material elucidating the details of Beethoven's trombone writing, especially owing to the fact that he is often considered the composer who introduced the trombone into the symphony orchestra. With other instruments — even those that were still in the development stage in Beethoven’s timesuch is the case. However, there is little or no literature covering Beethoven's orchestration

\footnotetext{
${ }^{1}$ Stravinsky included trombones in several of his chamber works, including Octet, L'Histoire du Soldat, Circus Polka, and especially In Memoriam Dylan Thomas, written for solo tenor, string quartet, and four trombones. However, no composer of Beethoven's stature and orchestral reputation has written a work specifically for four unaccompanied trombones. Other works that approach the standing of Beethoven's Three Equali might be the Sonata for four trombones by Daniel Speer, Fili mi Absalom by Heinrich Schütz, written for four trombones and Baritone solo, and perhaps Two Equali for three trombones by Anton Bruckner, or his Motets scored for SATB chorus and three trombones.
} 
of the trombone, which for the most part had reached a plateau of physical development by the time of Leopold Mozart. Therefore, such a study is needed.

\section{Limitations of the Study}

Given the relative dearth of previous literature discussing the subject, there is a certain way in which this paper is breaking new ground. Therefore, to keep the subject of the study focused, the limitations are clarified herein. First, those composers who influenced Beethoven's writing for trombone-specifically Handel, Mozart, Gluck, Haydn, and Cherubini-will not be discussed in detail, but only to the extent necessary to demonstrate either sources of influence for Beethoven or to contrast styles of orchestration. Second, those composers following (and therefore influenced by) Beethoven also will not be discussed in any detail, but again only to illustrate the extent of his influence. The foundational character of this paper should serve as just that: a foundation. Ideally others will, in a response to this paper, "pick up the baton” and devote their energy to detailing just how and to what extent Beethoven influenced the trombone writing of the composers who followed him.

\section{Definitions}

There are some words used throughout this paper which require clarification:

1) Genre. This term is defined by the American Heritage Dictionary (Second College Edition) as "a category of artistic composition marked by a distinctive style, form, or content.” ${ }^{2}$ Therefore, the various genres discussed in this paper would include (but are not limited to): Instrumental genres: Symphony, Overture, Miscellaneous Orchestral Work, Chamber Quartet, and Military March. Vocal genres: Opera, Mass, and Oratorio.

\footnotetext{
${ }^{2}$ The American Heritage Dictionary Second College Edition (Boston: Houghton Mifflin Company, 1982), 553.
} 
2) Use. During research for this paper, in many of the sources examined, the term "use" was often encountered as a word describing how a composer orchestrates for a particular instrument, e.g., "Beethoven's use of trombones in Symphony \#5..." To avoid confusion, this paper will not employ the term "use the trombone" to describe the inclusion of trombones in a particular musical score. However, many works cited or quoted throughout this paper do employ the term "use" to describe "inclusion of a particular instrument in a musical score." Therefore, when quoted material includes the term "use," such as “Beethoven uses trombones in Symphony \#5," it should be assumed that the term "use” is defined as "inclusion of a particular instrument in a musical score," unless the context clearly requires a different meaning. If a different meaning is required, the context will be clarified so as to eliminate any possible confusion or alternative meaning of the term "use."

3) Musical Notation. The nomenclature for pitch recognition is as follows:

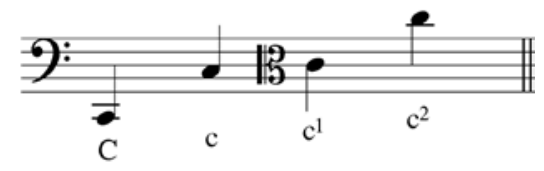

\section{Procedures}

Since this paper will explore Beethoven’s orchestrational application of the trombone, each work composed by Beethoven that includes trombone parts-symphonic, band, orchestral, choral, operatic, or chamber-will be examined. The principal goal will be to derive an understanding of Beethoven's orchestration in the several works in which he chose to include trombones by 1) outlining the historical background of the particular work under examination, insofar as is needed to understand (a) generally where the particular work was placed in Beethoven's life, and (b) specifically how the historical background may contribute 
to more fully understanding the nature of the trombone parts in the particular work under consideration, 2) elucidating the methods Beethoven used to score the instrument in the particular work under discussion by presentation of musical examples, and 3) emphasizing how Beethoven varied his orchestrational techniques among the works including trombones, to accomplish various musical purposes.

\section{Works Studied}

The works of Beethoven that include trombones are, in chronological order: Christ on the Mount of Olives, Opus 85; Leonore, Opus 72 (including Leonore Overtures 2 and 3, Opus 72a and 72b); Symphony \#5, Opus 67; Symphony \#6 (Pastorale), Opus 68; Incidental Music to the Ruins of Athens, Opus 113; Incidental Music to King Stephen, Opus 117; Three Equali, WoO. (Without Opus) 30; Wellington’s Victory (or The Battle of Vittoria), Opus 91; Fidelio, Opus 72 (including Fidelio Overture, Opus 72c); The Glorious Moment, Opus 136; It Is Accomplished, WoO. 97; Military March in D, WoO. $24 ;^{3}$ Consecration of the House Overture, Opus 124; March and Chorus from Ruins of Athens, Opus 114; Missa Solemnis, Opus 123; and Symphony \#9, Opus $125 .^{4}$

Three caveats regarding the grouping of works in this study follow. First, although the Opera Leonore is essentially the same work as Fidelio (notice the Opus number is the same), they are listed separately for the sake of the chronological order and to emphasize the difference in orchestration (Leonore is scored for three trombones whereas Fidelio employs only two). However, when Opus 72 is studied, the two versions-Leonore and Fidelio-will be discussed together, chronologically placed with Leonore, to help gain a more thorough

\footnotetext{
${ }^{3}$ David Guion erroneously lists this March for Military band as WoO 18 (see Guion, The Trombone: Its History and Music, 1697-1811 [New York: Gordon and Breach, 1988], 136).

${ }^{4}$ For the duration of this paper, English titles of works will be used, unless another author is being quoted.
} 
understanding of how the two scorings diverge, and how they are similar. There tend to be some differences in the orchestrational techniques Beethoven employed when he wrote for three trombones versus when he wrote for two. By including an examination of both versions of Opus 72 together, it will not only be possible to "compare and contrast" more readily, but it will also be possible to bring to light some of the differences in orchestrational techniques, as well as signs of Beethoven's musical evolution over time. Second, the two works Incidental Music to the Ruins of Athens (Opus 113) and Incidental Music to King Stephen (Opus 117)—although written prior to Three Equali-will be included in the "Patriotic Works" chapter, along with Wellington's Victory, The Glorious Moment, and It Is Accomplished - all of which were written after Three Equali. Because of the intended purpose of Opus 113 and 117 and the nature of their commission, it seems logical to include them with similar works, despite the slight disruption of the chronological order. Third, while Military March in D was composed chronologically at a time immediately after all the works examined in the "Patriotic Works" chapter, it fits neither into the subject matter nor the genres found in the "Patriotic Works" chapter. Therefore, Military March in D will be examined in conjunction with Three Equali under the "Non-Orchestral Works" chapter, as it is the only work other than Three Equali that fits under a genre that is non-orchestral. Finally, despite the fact that March and Chorus from Ruins of Athens (Opus 114) was premiered at the same time as Consecration of the House Overture (Opus 124)—and near the time of other compositions studied in the "Late Works" chapter-March and Chorus from Ruins of Athens is simply an excerpt from the complete work Ruins of Athens and includes no new music. Therefore it will be studied in detail as part of the complete Ruins of Athens, in the "Patriotic Works" chapter. 
A table, listing in chronological order all the works of Beethoven that include trombones, including date of composition, Opus (or "Without Opus") number, and instrumentation, is included below:

\begin{tabular}{|l|l|l|l|}
\hline \multicolumn{4}{|c|}{ Table 1: Works of Beethoven That Include Trombones } \\
\hline Date & Opus & & Title \\
\hline 1803 & 85 & Christ on the Mount of Olives & Alto, Tenor, Bass \\
\hline $1805-06$ & 72 & Leonore (\& Leonore Overtures 2 \& 3) & Alto, Tenor, Bass \\
\hline 1807 & 67 & Symphony \# 5 & Alto, Tenor, Bass \\
\hline 1807 & 68 & Symphony \# 6 & Alto, Tenor \\
\hline $1811-12$ & 113 & Ruins of Athens & Alto, Tenor, Bass \\
\hline $1811-12$ & 117 & King Stephen & Alto, Tenor, Bass \\
\hline 1812 & WoO 30 & Three Equali & Four Trombones \\
\hline 1813 & 91 & Wellington’s Victory & Alto, Tenor, Bass \\
\hline 1814 & 72 & Fidelio (and Fidelio Overture) & Tenor, Bass \\
\hline 1814 & 136 & The Glorious Moment & Alto, Tenor, Bass \\
\hline 1815 & WoO 97 & It is Accomplished & Alto, Tenor, Bass \\
\hline 1816 & WoO 24 & March in D for Military Band & Tenor, Bass (\& Serpent) \\
\hline 1822 & 124 & Consecration of the House & Alto, Tenor, Bass \\
\hline 1822 & 114 & March and Chorus from Ruins of Athens & Alto, Tenor, Bass \\
\hline $1822-23$ & 123 & Missa Solemnis & Alto, Tenor, Bass \\
\hline 1824 & 125 & Symphony \#9 & Alto, Tenor, Bass \\
\hline
\end{tabular}

\footnotetext{
${ }^{5}$ In the autograph of Three Equali, Beethoven does not specify which types of trombones were to be played, only that the instruments were to be trombones. Most likely the reason for this lack of distinction was to reflect the "equal instrumentation" attribute of the genre (see Andre Fiedler, "The Equale," Journal of the International Trombone Association 19 [January 1991], 40).
} 


\section{Chapter II}

\section{Review of Literature}

\section{Orchestration Texts by Composers}

Since Beethoven is considered the first major composer to free the trombone from its strictly ecclesiastical and dramatic moorings, one would expect to find a wealth of information regarding Beethoven's “revolutionary” scoring of the instrument. However, even the best texts on orchestration devote precious few pages (if even more than one page) to Beethoven and his revolutionary new orchestral instrument. One would logically assume that given the foundational role Beethoven played in the history of symphonic music, that his foundational orchestration practices would be discussed in detail. Such seems to be the case with the texts (and sections of texts) devoted to other instruments. Even the trumpet and horn-which during the time of Beethoven were not yet treated as chromatic instrumentsreceived significant attention by authors of orchestration volumes. Not so the trombone. For example, among the "classic" texts on orchestration by composers-including Nikolai Rimsky-Korsakoff $^{6}$ and Walter Piston ${ }^{7}$ - neither mention nor give any examples of Beethoven's orchestration of trombones. Hector Berlioz' is the only one of the classic treatises $^{8}$ to make mention of Beethoven's orchestrational techniques regarding trombones:

Beethoven sometimes used them in pairs, like trumpets, but the established practice of writing for them in threes seems preferable to me. ${ }^{9}$

\footnotetext{
${ }^{6}$ Nikoli Rimsky-Korsakoff, Principles of Orchestration, trans. Edward Agate (New York: Dover Publications, 1964).

${ }^{7}$ Walter Piston, Orchestration (New York: W.W. Norton and Company, 1955).

${ }^{8}$ Hugh Macdonald, Berlioz's Orchestrational Treatise: A Translation and Commentary (New York: Cambridge University Press, 2002).

${ }^{9}$ Macdonald, Ibid., 220. The Macdonald translation was chosen over other more well-known translations of the Berlioz treatise because Macdonald is the most accurate and modern in usage. The Strauss version is actually a translation of a translation-since Strauss originally used a German translation published by Peters for his version. The only other direct French-to-English translation is Mary Cowden Clarke's 1856 translation, translated in Victorian English. Furthermore, while the Strauss (translated by Front) and the Clarke are written
} 
Later, Berlioz praises the ingenuity of Beethoven in his orchestration of the trombone section when he writes that Beethoven...

“...ha[s] fully understood the importance of the trombone. [Beethoven] ha[s] shown exceptional intelligence in using this noble instrument to paint human passion or reproduce the sounds of nature. [He] ha[s] thus preserved its dignity and its poetry. ${ }^{10}$

But that is all Berlioz said about Beethoven's writing for trombones. Instead, he chose to focus more on Gluck for examples of trombone orchestration. ${ }^{11}$

\section{Orchestration Texts by Musicologists}

The orchestrational texts by musicologists and music historians fare slightly better than those written by composers. While Donald Rauscher ${ }^{12}$ and Alfred Blatter ${ }^{13}$ make no mention of Beethoven's contributions to the trombone literature, Blatter does at least include an excerpt of the Mozart Requiem, ${ }^{14}$ which most likely had some influence on Beethoven's orchestration of trombones in Missa Solemnis, Opus 123. Samuel Adler presents an excerpt of Symphony $\# 5^{15}$ and describes the effects of the introduction of the trombones to the Finale:

At the height of the Classical period, trombones were not included in most symphonies, although they were still standard in the opera and church orchestra. Beethoven waits until the final movement of the Fifth Symphony to introduce the trombones, which contributes to a tremendously climactic feeling...Notice how much more versatile the trombones are than the horns and trumpets, which get stuck on the tonic and dominant notes once the initial fanfare chord is over. ${ }^{16}$

more as orchestrational how-to texts, the Macdonald is translated from the viewpoint of a music historian, which, considering the evolution of many instruments since the time of Berlioz, makes more sense for this paper. Finally, the Strauss edition contributes no additions or editorial remarks to Berlioz' discussion of Beethoven's orchestration of the trombone, and therefore there is no content-related advantage in using the Strauss edition.

${ }^{10}$ Macdonald, Ibid., 225.

${ }^{11}$ Macdonald, Ibid., 221-222.

12 Donald Rauscher, Orchestration: Scores and Scoring (New York: The Free Press of Glencoe, 1963).

13 Blatter, Alfred, Instrumentation and Orchestration, (New York: Schirmer Books, 1997).

${ }^{14}$ Blatter, Ibid., 175.

${ }^{15}$ Samuel Adler, The Study of Orchestration (New York: W.W. Norton and Company, 1989), 332.

${ }^{16}$ Adler, Ibid., 330. 
Adler also provides an excerpt from Symphony \#9, Opus 125, as an example of one trombone playing alone without the rest of the trombone section (in a cola voce passage). ${ }^{17}$ Joseph Wagner presents a brief section more useful to this project. His orchestrational text contains an excellent chapter (“The Trombones as a Unit”) which includes a paragraph discussing Beethoven’s scoring for two trombones in Symphony \#6, Opus 68:

At this point the student orchestrator may acquire an expanded perspective through a study of the parts for two trombones in Beethoven's Sixth Symphony, the Pastorale. A comparison with that [sic] of the Chopin concertos reveals the extent of differences in approach and understanding between the two composers. The Beethoven score clearly indicates the advantages to be derived from using trombones as "group instruments" for harmony playing. Part writing for three trombones is similarly exploited by Beethoven in his Fifth and Ninth Symphonies. ${ }^{18}$

Wagner distinguishes Beethoven's scoring of two trombones as a far superior alternative to scoring for a single instrument—as Chopin did in his concertos—a practice Wagner earlier derides as sounding "inappropriate, weak, and slightly amateurish." ${ }^{19}$ He also includes an excerpt of Symphony \#5 as an example of tutti trombone writing. ${ }^{20}$ Although Cecil Forsyth ${ }^{21}$ has some interesting and provocative discussion regarding the orchestral trombone section, he lacks any information about Beethoven specifically. In addition, Forsyth's critique of Mozart's orchestration of the trombone is flawed and betrays a lack of knowledge of the Austrian church tradition of trombone writing. He claims, with no supporting evidence, that Mozart had no understanding of the trombone when he composed the Tuba Mirum solo in the Requiem, stating that the solo "...might better be described as Tuba dirum spargens sonum." 22

\footnotetext{
${ }^{17}$ Adler, Ibid., 316.

${ }^{18}$ Joseph Wagner, Orchestration: a Practical Handbook (New York: McGraw-Hill, 1959), 229.

${ }^{19}$ Ibid., 228.

${ }^{20}$ Ibid., 230.

${ }^{21}$ Cecil Forsyth, Orchestration (New York: The Macmillan Company, 1939).

${ }^{22}$ Forsyth, Ibid., 149. To define Forsyth’s clever-by-half play on words, "dirum" in this case means "shattered to pieces" or "broken," as opposed to the original "mirum," which means "wonderful." Unfortunately, the Forsyth text and its trombone inaccuracies influenced many orchestration treatises published in Great Britain.
} 


\section{Biographies and Online Resources}

The more well-known biographies of Beethoven, such as those by Thayer, ${ }^{23}$ Solomon, ${ }^{24}$ and Kinderman ${ }^{25}$ not only have helpful information regarding the historical context of the works that include trombones, but also specifically regarding Beethoven's orchestration of the trombone parts. These will be cited and quoted throughout the paper as the context warrants. There is also some information available from the various Internet sources dedicated to Beethoven that could potentially contribute to the subject at hand. The Beethoven Haus-Bonn (http://www.beethoven-haus-bonn.de) library catalog contains references to at least four articles that use the word "trombone" in them, but none are available in English. Another disappointing online source-at least disappointing as it relates to the search for literature discussing Beethoven's orchestration of trombones-titled Ludwig Van Beethoven's Website, (http://www.lvbeethoven.com/index_En.html) contains two somewhat interesting but mostly irrelevant articles which mention Beethoven and his scoring for trombones. The first, by Anthony Parsons—originally published by the British Trombone Society—discusses Beethoven Symphony \#5, Opus 67, (ostensibly supporting the claim that the presence of trombones in Symphony \#5 was the first instance of them in a symphony). ${ }^{26}$ The article does not devote very much space to actually discussing how the trombones are scored in Symphony \#5, Opus 67, or Symphony \#6, Opus 68. Instead, Parsons describes the famous concert where the aforementioned works were premiered in an anecdotal and humorous fashion, conveying various embarrassing happenings in the performance, rather than focusing on any trombone-related content. Another article

\footnotetext{
${ }^{23}$ Alexander Wheelock Thayer, Life of Beethoven, ed. Elliot Forbes (Princeton: Princeton Univ. Press, 1964).

${ }^{24}$ Maynard Solomon, Beethoven (New York: Schirmer, 2001).

${ }^{25}$ William Kinderman, Beethoven (New York: Oxford University Press, 2009).

${ }^{26}$ Anthony Parsons, "Symphonic Birth Pangs of the Trombone," Ludwig Van Beethoven Website, $<$ http://www.lvbeethoven.com/VotreLVB/English_TromboneSociety.html>, accessed 2 February 2008.
} 
contained within the same website, “Joachim Eggert: Trombone Pioneer,” by Avishai Kallai, discusses Swedish composer Joachim Eggert, who, according to the article, orchestrated for trombones in his Symphony \#3 in $E^{b}$ some eighteen months before Beethoven did. ${ }^{27}$ The article, while containing some excellent research on Eggert and the concert in which his Symphony \#3 was premiered, is again not particularly helpful for the subject matter at hand. The Online Trombone Journal (http://www.trombone.org) includes an article by David Guion, titled “A Short History of the Trombone.” Guion further complicates the issue of who was the first person to write for trombones in a symphony by introducing two new names as symphonic trombone pioneers: Joseph Krottendorfer and Ignaz Pleyel. Guion claims each of these composers wrote for trombones in symphonies some forty and sixteen years (respectively) before Beethoven. Guion, in the course of his discussion, dedicates a sentence or two to Beethoven’s orchestration of trombone in Symphony \#5, although his date of the premiere is inaccurate:

Beethoven's Fifth Symphony (1809) is the earliest use of the trombone in any symphonic work that is ever performed anymore, although the Third Symphony of the little-known Swedish composer Joachim Eggert (1807) appears to be worth reviving. Just as trombones have been permanent members of the operatic orchestra since Gluck, they have been fixtures in the symphonic orchestra since Beethoven. ${ }^{28}$

The British Trombone Society Website (http://www.trombone-society.org.uk) contains an excellent article by Kenneth Shifrin, discussing the history of the alto trombone, including an entire page dedicated to Beethoven's orchestration of the trombone section. There are several paragraphs in which Shifrin discusses material that will be elucidated in greater detail in this paper. He compares the trombone parts of Symphony \#5 to those of the other sections:

\footnotetext{
${ }^{27}$ Avishai Kallai, “Joachim Eggert, Trombone Pioneer,” Ludwig Van Beethoven Website (2008), <http://www.lvbeethoven.com/VotreLVB/English_TromboneAvishai.html>, accessed 18 February 2008.

${ }^{28}$ David Guion, “A Short History of the Trombone,” Online Trombone Journal, <http://www.trombone.org/articles/library/viewarticles.asp?ArtID=254> (2008), accessed 20 February 2008.
} 
Rhythmically, throughout the Finale of the Fifth Symphony, the trombones generally do not play the up-beats that are otherwise played by the full orchestra. They function mainly as harmonic reinforcement and are limited to simple rhythms. In only one tutti passage - the third bar of the opening theme with a rare up-beat—are they given anything shorter than crotchets to play. ${ }^{29}$

Shifrin continues his comparison of the trombone section to other sections of the orchestra:

Often the trombone parts have more in common with those of the woodwinds than with those of the trumpets and horns. [T] he passage from bars 7 to 15 in the last movement of Beethoven's Fifth Symphony, is interesting, for although the trombones, bassoons and clarinets function together, Beethoven curiously assigns the trombones different note-values from the woodwinds. In bar 7, for example, the first trombone and bass trombone double the first clarinet and contrabassoon respectively, but the trombones play dotted crotchets versus the woodwind's minims. It appears that Beethoven was taking into account the tendency of trombones to lag behind due to the distance of their position at the back of the orchestra. This would also seem to account for the dotted crotchet rest in bar 8-clearing the trombones a quaver early so they would not intrude upon the three-quaver pick-ups played by the upper woodwinds, horns and first violins. But in bar 9, which is identical to bar 7, Beethoven this time gives the trombones the same note-values as the clarinet and contra-bassoon; in bar 11 we are back to dotted crotchets against minims. Bar 10 is also perplexing. This is the same material as that of bar 8 , but now the bass trombone plays a dotted crotchet $\mathrm{E}$ against the alto and tenor's minim tied to a quaver. In bar 12, ironically, Beethoven demands a staccato fourth crotchet from the clarinets and bassoons but not from the trombones, who with their heavy voice would have a tendency to sound longer than the lighter woodwinds. In bar 13, while the bass trombone doubles the contra exactly in minims, the first two trombones double the clarinets and bassoons but with shorter notes. This means they are also playing shorter notes than the third trombone of the section. The same occurs in bar 15. Inevitably, bars 10, 13 and 15 can feel wrong to the trombone section. While some of these inconsistencies may be attributed to a copyist's error-certainly this could be the case for bar 12, for the staccato marking does not appear in the recapitulation - one wonders whether the scoring of the trombones came as an afterthought to Beethoven, who perhaps sketched their parts in rather hastily. ${ }^{30}$

The British Trombone Society Website also includes another article by the aforementioned

Avishi Kallai, examining an article written by trombonist Sarah Gordon, who has claimed

\footnotetext{
${ }^{29}$ Kenneth Shifrin, "The Alto Trombone in the Orchestra 1800-2000, British Trombone Society, http://www.britishtrombonesociety.org/resources/shifrin/the-alto-trombone-in-the-orchestra-1800-2000.html (2009), accessed 24 May, 2009.

${ }^{30}$ Shifrin, Ibid.
} 
another composer (this time Franz Ignatz Beck) wrote for trombones in a symphony before Beethoven did. ${ }^{31}$ Kallai continues this debate in his more recent article titled "Revert to Eggert." However, in each of these two Website examples, although Beethoven is mentioned, no new information is revealed. The most helpful website information clearly comes from the Shifrin article, which will no doubt prove invaluable in the section devoted to Beethoven Symphony \#5.

\section{Other Trombone-Related Resources}

Obviously, the texts dedicated to the history of the trombone offer the most extensive information. However, even those sources tend to be scant in their offerings. Trevor Herbert has a short, interesting reference to Beethoven's scoring of trombones, where Beethoven evidently wanted to find out the highest notes possible on the instrument:

Clearly Beethoven was interested in the trombone, and seems to have been aware that he was experimenting with it in the orchestra. A writer in The Harmonicon who had spent a day with Beethoven in 1824 reported that the composer "was desirous of ascertaining for a particular composition...the highest possible note on a trombone...but did not seem satisfied [with the answer he was given]." We do not know what work Beethoven had in mind, but it may well have been the Ninth Symphony, on which he was working during that year. ${ }^{32}$

Herbert also includes a one-page excerpt of Three Equali (WoO 30), where he interestingly gives suggestions as to which types of trombones were to play the Equali parts—something

Beethoven did not do in the original manuscripts. ${ }^{33}$ Philip Bate has a brief reference to Beethoven's scoring of trombones in the symphony:

Even as late as 1824-25, when Beethoven personally revised an autograph score of the Choral Symphony for the Philharmonic Society of London, he

\footnotetext{
${ }^{31}$ Avishai Kallai, "The Sackbut Rebut," The British Trombone Society Website, $<$ http://www.trombone-society.org.uk/resources/articles/kallai02.php>, (2008), accessed 20 February 2008.

${ }^{32}$ Trevor Herbert, The Trombone (New Haven: Yale University Press, 2006), 174-175.

${ }^{33}$ Herbert, Ibid., 164. See also the section discussing Three Equali, as well as fn. 5 supra.
} 
relegated the trombone parts to an appendix in the old manner, so powerful was the influence of custom. Yet Beethoven, years before this, had written trombone parts that were structurally essential in a number of his works. ${ }^{34}$

The last sentence from Bate seems to contradict one from Guion (see more details on his volume below) which reads, “...the hardest [trombone] parts can simply be left out with little or no harm to the total impact of the work." ${ }^{35}$ Most likely Guion makes this point in reference to the ad-hoc atmosphere present in orchestral trombone playing throughout late Eighteenth- and early Nineteenth-Century Austria; trombonists were not always available for performances, and as a result the parts were sometimes simply omitted ${ }^{36}$ David Gregory makes one brief comment on Beethoven's trombone orchestration in Symphony \#5:

Thrilling though their entry is, Beethoven's use of the trombones, here and elsewhere, showed little advance on the older style of writing. He used them harmonically, often with the rest of the brass and occasionally when the valveless trumpets and horns were unable to match their versatility, independently, with the alto trombone being given the melody. ${ }^{37}$

Gregory also mentions composer Franz Beck’s symphonic trombone orchestration preceding that of Beethoven’s. In addition, he includes a trombone excerpt from Symphony \#9 without comment. ${ }^{38}$ Finally, David Guion, in his excellent volume The Trombone: Its History and Music, 1697-1811, dedicates entire sections to discussions of Symphony \#5, Symphony \#6, ${ }^{39}$ and Christ on the Mount of Olives, Opus $85 .{ }^{40}$ Guion's considerations and insights into how Beethoven scored trombones are informative and helpful to this project:

\footnotetext{
${ }^{34}$ Philip Bate, The Trumpet and Trombone: An Outline of their History, Development, and Construction (London: Earnest Benn, Ltd., 1978), 232.

${ }^{35}$ David Guion, The Trombone: Its History and Music, 1697-1811 (New York: Gordon and Breach Publishers, 1988), 282.

${ }^{36}$ In addition, the specific trombones played (alto, tenor, bass) were not as clearly delineated as has been previously thought. For more on this see Howard Weiner: "When is an Alto Trombone an Alto Trombone? When is a Bass Trombone a Bass Trombone?-The Makeup of the Trombone Section in Eighteenth- and Early Nineteenth-Century Orchestras: Historic Brass Society Journal XVII (2005), 37-79.

${ }^{37}$ David Gregory, Trombone, (London: Faber and Faber, 1973), 127.

${ }^{38}$ Gregory, Ibid., 132.

${ }^{39}$ Guion, Ibid., 277-283.

${ }^{40}$ Ibid., 222-228.
} 
In Beethoven's handling of the trombone, he represents the tradition that can be traced through Haydn back to Handel rather than the Austrian tradition exemplified by Fux and Mozart. Beethoven's trombone parts are largely independent. They never slavishly double the chorus as in traditional Austrian church music, but they never take on a soloistic role, either. ${ }^{41}$

More particulars from Guion’s book will be examined in detail under the sections covering the specific works that he discusses, namely those composed before 1811.

There is also scant historically-oriented discussion of Beethoven's orchestration of trombone within the Dissertation and Thesis literature. One Master's Thesis that devotes a few pages to the essentials of Beethoven's trombone orchestration is “A Comparative Study of the Symphonic Trombone Scoring of Beethoven, Brahms, and Berlioz” by James D Lee. ${ }^{42}$ Lee’s insights into Beethoven Symphony \#5 and \#6 are similar to those of Shifrin:

Beethoven's trombone scoring in the Fifth Symphony, is fairly conservative in technical complexity. The rhythmic movement at half note equals 84 , is limited to simple quarter note patterns, isolated quarter notes (to strengthen and accent other parts), and broader sustained notes (to supply a harmonic background and strengthen the tutti sections), moving almost entirely in similar rhythm. Beethoven uses at most one octave and a major sixth of the two octaves and a minor seventh given by Berlioz as the full range of the various trombones. The alto and tenor trombone parts are most often scored in the upper two thirds of their range and written in intervals less than an octave apart, while the bass trombone part is usually written in the lower twothirds of its range. This is normally more than an octave below the alto trombone part. Because each trombone part is most often on a different note of the chord, the trombone section is harmonically independent much of the time. ${ }^{43}$

Again, such points serve to contribute to the subject matter at hand, but merely in a superficial manner, and only (in this case) pertaining to the writing in Symphony \#5. Among the Doctoral Dissertations that mention Beethoven's writing for trombones, the topic of discourse is exclusively from a performance practice viewpoint. Timothy Howe includes

\footnotetext{
${ }^{41}$ Ibid., 223.

${ }^{42}$ James D. Lee, "A Comparative Study of the Symphonic Trombone Scoring of Beethoven, Brahms, and Berlioz,” Master’s Thesis, Kent State University, 1974, 18-20.

${ }^{43}$ Ibid., 18-19.
} 
some general historical discussion of Beethoven's orchestration of the trombone, but mainly for the purpose of establishing performance practice. ${ }^{44}$ Howe- - though quite beneficial for the study of performance pedagogy—gives little detailed historical information (beyond his brief comments) that specifically addresses the issue of how Beethoven orchestrated the trombone section. In similar vein to Howe, Cassandra Fulmer discusses Beethoven Symphony \#9, but from the standpoint of performance practice. ${ }^{45}$ Her aim is to improve bass trombonists' performances at orchestral auditions. Although the approach taken by Howe and Fulmer is certainly not flawed — and is even extremely helpful for pedagogical and performance practice-the absence of any significant historically-centered discussion of Beethoven's works that include trombones further elucidates the need for such research.

The music history and trombone-related journals have a little more to offer than the trombone texts. There are some short contributions in the International Trombone Association Journal. Wallace Tucker mentions Beethoven in passing:

"Beethoven's use of trombones as an autonomous group is surpassed by his introduction of the trombones into his Fifth Symphony. From the symphony orchestra came greater trombonistic developments. ${ }^{46}$

John Drew devotes only slightly more space to Beethoven:

The trombone was first introduced into symphonic literature in the fourth movement of Beethoven's Fifth Symphony where three trombones were used: alto, tenor, and bass. It is evident, however, that the trombone was included primarily to reinforce the other lines and to add volume, rather than to serve a programmatic function. Three trombones became, for the most part, the standard number in symphonic compositions. ${ }^{47}$

\footnotetext{
${ }^{44}$ Timothy E. Howe, "Developing a Historical Model for Trombone Performance Practice in German and Austrian Orchestral Works from the Period 1785-1830,” D.M.A. Dissertation, University of Nebraska, 2002.

${ }^{45}$ Cassandra R. Fulmer, “The Role of the Bass Trombone in Haydn's 'Die Schöpfung', Beethoven's 'Ninth Symphony', and Brahms' 'Fourth Symphony': A Tutorial Focusing on Historical Background and Preparation Suggestions,” D.M.A. Dissertation, Louisiana State University, 1998.

${ }^{46}$ Wallace Tucker, "The Trombone Quartet: Its Appearance and Development Throughout History,” Journal of the International Trombone Association VII (January 1979), 4-5.

${ }^{47}$ John Drew, "The Emancipation of the Trombone in Orchestra Literature," Journal of the International Trombone Association IX (March 1981), 2.
} 
Both of these quick references do not contribute anything more to the current subject matter, and are not particularly helpful. Jim Montgomery has an informative discussion of George Frideric Handel's orchestration of the trombone, ${ }^{48}$ which although not specifically mentioning Beethoven, will no doubt be helpful in researching composers who influenced Beethoven in his orchestration of trombones. Handel certainly falls into this category. In fact, in the Consecration of the House Overture, Opus 124, Beethoven pays homage to Handel, at one point freely quoting several passages from King Saul. The other International Trombone Association Journal source germane to Beethoven's orchestration of trombone is an article by Andre Fiedler discussing Beethoven's Three Equali, as well as Two Equali written by Anton Bruckner. ${ }^{49}$ There are some excellent articles found in the Historic Brass Society Journal. The first is by David Guion, titled "What Handel Taught the Viennese about the Trombone.” Guion goes beyond Montgomery and discusses the strong influence Handel's orchestration of trombone had on later Viennese composers, including (via Gluck) Beethoven..$^{50}$ Probably the two most helpful articles from the Historic Brass Society Journal were written by Howard Weiner. The first, titled "When is an Alto Trombone an Alto Trombone? When is a Bass Trombone a Bass Trombone?-The Makeup of the Trombone Section in Eighteenth- and Early Nineteenth-Century Orchestras,"51 discusses the makeup of Austrian trombone sections within the timeframe of the title, focusing on the fact that the nomenclatures “alto," tenor," and "bass" trombone may not have been as clearly defined as was originally thought. The other article by Weiner is dedicated entirely to Beethoven's

\footnotetext{
${ }^{48}$ Jim Montgomery, “The Use of the Trombone by G.F. Handel,” Journal of the International Trombone Association XIII, N. 3 (July 1985), 32-34.

${ }^{49}$ Andre Fiedler, “The Equale,” Journal of the International Trombone Association IXX (January 1991), 40-41.

${ }^{50}$ David Guion, "What Handel Taught the Viennese About Trombone," Historic Brass Society Journal XV (2003), 291-321.

${ }^{51}$ Howard Weiner, "When is an Alto Trombone an Alto Trombone? When is a Bass Trombone a Bass Trombone?-The Makeup of the Trombone Section in Eighteenth- and Early Nineteenth-Century Orchestras, Historic Brass Society Journal XVII (2005), 37-79.
} 
Three Equali. $^{52}$ This article, extensive and well-written, offers a wealth of historical information regarding the history of the composition of Three Equali, as well as an examination of the original manuscripts, which were made available to Weiner during his research. His excellent article is extremely beneficial in the chapter discussing that work.

In conclusion, a review of the available literature shows that there is a significant amount of writing concerning Beethoven that sheds little or no light on the subject at hand. This is especially true of “older” research—that done earlier than the 1980's—and also of literature that has been considered "standard," even by those authors who are writing today. More recent research offers a somewhat more sizeable amount of help, but for the most part these sources still give only a thumbnail sketch. Exceptions to this are Howard Weiner's informative articles—one of which is devoted to Beethoven's work Three Equali. One other exception might be the volume by Guion, which has larger sections—sometimes as many as seven pages-dedicated to Beethoven. But comparatively, with the exception of Weiner (and possibly of Guion), for the most part there is a paucity of information specifically addressing Beethoven's orchestration techniques regarding the trombone (as compared to literature discussing other aspects of Beethoven's compositional practices). Such a discovery (or perhaps more accurately, such a lack of any significant discovery) continues to be intriguing, given the magnitude of Beethoven's influence on the world of classical music in general, and the subject of the trombone in particular. In view of this, a detailed study of Beethoven's orchestration of the trombone, including an investigation of all his compositions that include trombones, seems not only warranted, but long overdue.

\footnotetext{
${ }^{52}$ Howard Weiner, “Beethoven’s Equali (WoO 30): A New Perspective,” Historic Brass Society Journal 14 (2002), 215-277.
} 


\section{Chapter III}

\section{Early Works}

\section{Christ on the Mount of Olives, Opus 85}

The first surviving ${ }^{53}$ work by Beethoven which included trombones is Christ on the Mount of Olives, Opus 85, ${ }^{54}$ completed in early 1803 . At this time Beethoven lived in Vienna, having recently been engaged as resident composer for the Theater-an-der-Wein. ${ }^{55}$ His first duty in the new position was to write an opera, which turned out to be a long time coming and quite different from the original commission. In fact, not until 1805 would Leonore be completed. In the meantime, in order to take advantage of the excitement created by his new appointment, Beethoven seized the opportunity and quickly completed Christ on the Mount of Olives, which, according to Kinderman, he had begun in late $1802 .{ }^{56}$ However, Beethoven's friend Anton Felix Schindler places the first sketches of Christ on the Mount of Olives as early as $1801 .^{57}$ The libretto was written by poet Franz Xaver Huber, personal friend of Beethoven and editor of the Wiener Zeitung, one of the oldest newspapers still in publication. Beethoven and Huber completed Christ on the Mount of Olives over a period of some 14 days. $^{58}$ The work received its premiere at the Theater-an-der-Wein on April 5, 1803, performed alongside the Symphonies \#1 and \#2, and the Piano Concerto \#3. The

\footnotetext{
${ }^{53}$ Early in his career Beethoven sometimes destroyed works of which he did not approve. Schindler mentions this twice. (See Anton Schindler, Beethoven as I Knew Him, ed. Donald W. MacArdle, trans. Constance S. Jolly [London: Faber and Faber, 1966], 42, 130.)

${ }^{54}$ In his volume The Trombone: Its History and Music, 1697-1811, Guion erroneously lists Christ on the Mount of Olives as Opus 86 instead of 85.86 is the Opus number for Mass in C, which contains no trombone parts. ${ }^{55}$ Alexander Wheelock Thayer, Life of Beethoven (Princeton: Princeton University Press, 1964), 327.

${ }^{56}$ William Kinderman, Beethoven (London: Oxford University Press, 2009), 94.

57 "Even so, this cantata had been sketched as early as 1801 in the nearby town of Hetzendorf where Beethoven had spent the summer. He himself showed me in 1823 the secluded spot in the garden of the Schönbruss palace where he had done this preliminary work. It was an oak tree which branched into two strong trunks about two feet above the ground, forming a comfortable place to sit.” (See Anton Schindler, Beethoven as I Knew Him, ed. Donald W. MacArdle, trans. Constance S. Jolly [London: Faber and Faber, 1966], 99.)

${ }^{58}$ Thayer, Ibid., 328.
} 
concert began at 6:00 PM, but was so long that other pieces originally scheduled had to be omitted. Thayer says the new oratorio was "coldly received." He quotes a local reviewer, probably Viennese playwright August von Kotzebue:

Even our doughty Beethoven, whose oratorio Christus am Olberg was performed for the first time at suburban Theater-an-der-Wein, was not altogether fortunate, and despite the efforts of his many admirers was unable to achieve really marked approbation. True, the two symphonies and single passages in the oratorio were voted very beautiful, but the work in its entirety was too long, too artificial in structure and lacking expressiveness, especially in the vocal parts. The text, by F.X. Huber, seemed to have been as superficially written as the music. ${ }^{59}$

Beethoven himself seemed to be unhappy with the work, stating that "it had been a mistake" to write the part of Christ in the modern vocal style. ${ }^{60}$ The work did undergo revision and was not published until 1811. Christ on the Mount of Olives was one of several important works to be composed in 1803, including Symphony \#3, Opus 55 (“Eroica”).

Christ on the Mount of Olives has three trombone parts: alto, tenor, and bass. The parts were added quite late during the composition of the work. Ferdinand Reis, Beethoven's young student at the time, describes how the parts were written:

I found him [Beethoven] in bed, writing on separate sheets of paper. To my question what it was he answered, "Trombones." The trombones also played from these sheets at the performance. Had someone forgotten to copy these parts? Were they an afterthought? I was too young at the time to note the artistic interest of the incident; but probably the trombones were an afterthought, as Beethoven might as easily have had the uncopied parts as the copied ones. ${ }^{61}$

Apparently, due to the infrequent presence of trombones in an orchestra at the time of Christ on the Mount of Olives, the parts were not included in the score. Beethoven was following the common practice of his time by writing the trombone parts separate from the score. He

\footnotetext{
59 Thayer, Ibid., 330.

${ }^{60}$ Ibid., 330-331. See Guion, The Trombone: Its History and Music, 1697-1811, 223. Thayer probably meant that the solo part was too operatic and unlike a traditional oratorio part (see Solomon, Beethoven, 247).

61 Thayer, Ibid., 328-329.
} 
continued this practice in later works. John Marsh, in his 1807 Hints to Young Composers of Instrumental Music, says, "The trombones being therefore not in general use, composers seldom insert parts for them in their scores, but leave them to be added afterwards..."62 The trombones only play in four of six numbers in the work, and within those numbers they usually do not play throughout, but instead are reserved for the role of producing dramatic effect in certain sections of each number. Guion believes that the role trombones play in this case is a symbolic one:

In common with most German-speaking composers, Beethoven uses trombones to represent the voice of God. They appear in the introduction, Jesus's [sic] opening Recitative (his prayer for deliverance), an angel chorus, and the Seraph's announcement of God's will. ${ }^{63}$

Guion's view has much to commend it. It was the view of composers a generation before and even a generation after Beethoven (to a much lesser extent) that trombones filled a mostly sacred or ecclesiastical role in music. The Austrian tradition of trombone writing was that they play a supportive ${ }^{64}$ role in church music. Most works that included trombones from the generations of composers preceding Beethoven were of the sacred genres: masses, motets, and oratorios. Examples would be Handel's King Saul, The Creation by Haydn, and the Coronation Mass, the Great Mass in C Minor, and Requiem by Mozart. Even many of the works which employed trombones in a more dramatic (thus non-sacred) role tended toward the "underworldy" or "otherworldly" milieu, such as Mozart's Don Giovanni, Alceste by Gluck, and perhaps even the earlier Orfeo by Monteverdi. Felix Mendelssohn, of the generation following Beethoven, said that "the trombones are too sacred for frequent use.”65

\footnotetext{
${ }^{62}$ See Timothy Howe, "Developing a Historical Model for Trombone Performance Practice in German and Austrian Orchestra Works from the period 1785-1830,” D.M.A. Dissertation, University of Nebraska, 2002, 26.

${ }^{63}$ David Guion, The Trombone: Its History and Music, 1697-1811, 223

${ }^{64}$ Guion would call it "slavish."

${ }^{65}$ Nat Shapiro, An Encyclopedia of Quotations about Music (New York: Doubleday \& Co., 1978), 89.
} 
Maynard Solomon sheds some light onto another possibly related reason for the inclusion of trombones in Christ on the Mount of Olives. It is probably not coincidental that Christ on the Mount of Olives was the first work Beethoven composed immediately after his writing of the Heiligenstadt Testament. Briefly described, the Testament—dated October 6 and October 10, 1802—could be considered Beethoven's “confession” to his deteriorating hearing as the reason for his bouts of depression and his misanthropic behavior. It is also a resignation to his increasing deafness and a submission to Fate and to God. ${ }^{66}$ The oratorio has been described as a "depiction of Christ's struggle within himself.” ${ }^{67}$ Solomon describes it "as an unorthodox exploration of the psychological presence of Christ." ${ }^{\text {68 }}$ The subject that is causing Christ's internal struggle, his deeply disturbing psychological condition, is deatha subject not lightly mentioned in the Heiligenstadt Testament. In fact, there are parts of the Christ on the Mount of Olives libretto that have much in common with the subject matter of the Heiligenstadt Testament. ${ }^{69}$ It seems that at this time in his life, because of the deep psychological and physical difficulties he was experiencing, Beethoven briefly turned his mind to God—specifically in this case to the sufferings of Christ—and his religious impulses. That Beethoven was always a "religious" man-that he strongly believed in the "Fatherhood of God and the Brotherhood of Man"-seems clear, based on his music and writing. But Christ on the Mount of Olives had a more personal flavor to it, as if Beethoven himself were identifying - through his recent crises and through the Heiligenstadt Testament—with Christ's death. Trombones, traditionally the instruments of the underworld and of death, were the logical choice to accompany the subject of Christ's death.

\footnotetext{
${ }^{66}$ Solomon, Ibid., 247-249. It could also have been a suicide note, and Beethoven simply did not go through with the suicide (see Solomon, Ibid., 154, 283).

${ }^{67}$ David Guion, The Trombone: Its History and Music, 1697-1811, 223

${ }^{68}$ Solomon, Ibid., 249.

${ }^{69}$ Barry Cooper, Beethoven and the Creative Process (Oxford: Clarendon, 1990), 48.
} 
The style of the trombone parts in Christ on the Mount of Olives has been described by Guion as decidedly non-Austrian:

In Beethoven's handling of the trombones, he represents the tradition that can be traced through Haydn back to Handel rather than the Austrian tradition exemplified by Fux and Mozart. Beethoven's trombone parts are largely independent. They never slavishly double the chorus as in traditional Austrian church music, but they never take on a soloistic role, either. ${ }^{70}$

The Austrian tradition elucidated by Guion is probably best exemplified by Mozart's “Great” Mass in C Minor. In it, the trombones—alto, tenor, and bass-while possessing a few simple passages with the rest of the orchestra, for the most part "slavishly" double the alto, tenor, and bass vocal parts throughout the work. In other words, they serve a cola voce role, and do little else except for a few supportive chords in tutti sections. The same could be said for the Mozart Requiem-especially the Bärenreiter and the newer Levin editions. Even the solo tenor trombone in the Tuba Mirum section of the Dies Ire follows the Austrian church music tradition exemplified by Fux. Handel, on the other hand (with Haydn and Gluck following his example), wrote for the trombones as a more versatile group, with the section doubling instrumental parts in one section and vocal parts in another, and not necessarily the same part through the entire musical number. Beethoven, in Christ on the Mount of Olives, followed the example of Handel, Haydn, and Gluck (and Salieri as well) instead of the example of fellow Austrians Fux and Mozart. ${ }^{71}$ However, there is some disagreement on this point. William Drabkin, in his discussion of Missa Solemnis, discusses the influence of Mozartespecially his sacred music—on Beethoven:

But the sacred work which [Beethoven] seems to have cherished above all was Mozart's Requiem; he staunchly defended it when rumors of its doubtful authenticity reached Vienna in the mid-1820’s. Recently, a Beethoven sketchleaf came to light on which the Kyrie of the Requiem is written out in short

\footnotetext{
${ }^{70}$ Guion, Ibid.

${ }^{71}$ Guion, "What Handel taught the Viennese about the Trombone," 291.
} 
score, with extensive annotations of its themes and formal sections. It is the only such "analysis" by Beethoven, and probably dates from the period of work on the "et vitam venture" fugue of the Missa Solemnis. ${ }^{72}$

The compelling and historically-based argument made by Drabkin cannot be quickly dismissed. However, neither can the analysis of the actual trombone parts by Guion. A synthesis of these two viewpoints is the most plausible way to describe how Beethoven could be influenced by both Mozart and Handel. Beethoven was influenced by Mozart in his writing of sacred music in the Austrian church music style (which he did on occasion), while at the same time he was also influenced by Handel in his writing for trombones.

As was stated above, in Christ on the Mount of Olives, trombones only play in four of six numbers in the work: Number 1, the Introduction and Recitative; Number 2, the Chorus; Number 3, Recitative; and Number 6, Final Chorus. In each case, the trombones play when a message is being delivered either to God (Number 1 Recitative), or from God (the other three instances). The ranges of the parts are $\mathrm{g}$ to $\mathrm{d}^{2}$ for the alto, $\mathrm{c}$ to $\mathrm{a}^{1}$ for the tenor, and $\mathrm{F}$ to $\mathrm{c}^{1}$ for the bass. The Introduction, in $\mathrm{e}^{b}$ minor, begins with the tenor and bass trombones doubling the horns and bassoons. The alto trombone remains silent until the chorus in Number 2:

Example 1: Christ on the Mount of Olives, Number 1, measures 1-2

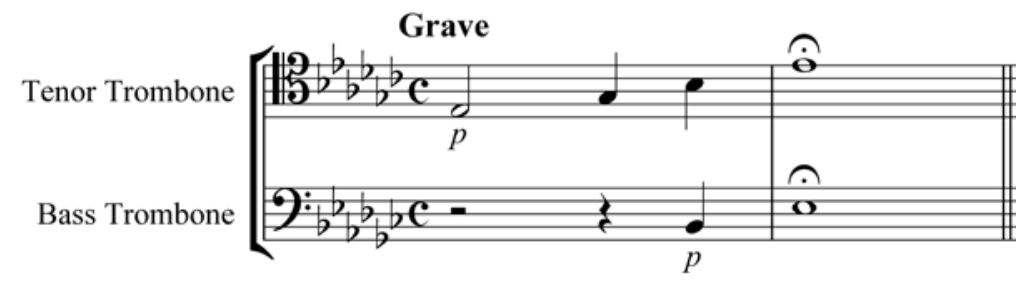

Guion writes regarding the Introduction, "although the score is marked "Trombone Basso" for the lowest part, Beethoven clearly expected it to be played on a trombone in $\mathrm{B}^{\mathrm{b}}$ : he avoids the low $\mathrm{E}^{b}$, which he surely would have used without hesitation if it had been available."73

\footnotetext{
${ }^{72}$ William Drabkin, Missa Solemnis (Cambridge: Cambridge University Press, 1991), 21.

${ }^{73}$ Guion, The Trombone: Its History and Music, 1697-1811, 223.
} 
Guion may have a point, but it does not explain the absence of the low $\mathrm{G}^{b}$ immediately following the absent low $\mathrm{E}^{b}$. This note is playable on a tenor trombone, yet it is not present. Beethoven may have left out the $G^{b}$ for balance reasons: instead of making the lowest trombone come in on the minor third and risk that particular note standing out, the note is omitted, thereby preserving balance. A similar reason was echoed by Forsyth:

...the piano octaves of two trombones always need caution in treatment. The sound of the instrument is naturally so full of a certain threatening purpose that the slightest variation from the serious, the majestic and the pompous becomes vulgarized almost to the level of a personal insult. ${ }^{74}$

Since Forsyth cautioned writing for trombones in soft octaves, there was probably an established precedent for such a technique. If this were the case, it is doubtful that Beethoven would have been completely ignorant of it. Therefore, assuming Beethoven did indeed mean to write for bass trombone, he may have omitted the low $\mathrm{E}^{b}$ and low $\mathrm{G}^{b}$ to avoid the problem elucidated by Forsyth. Another reason for omitting the $\mathrm{G}^{b}$ is harmonic: instead of entering with the $\mathrm{G}^{b}$ minor third, the lower part enters with a $\mathrm{B}^{b}$ - the fifth of the chordon the final beat of the measure, intensifying the dominant-to-tonic motion.

The rest of the Introduction has the trombones switching back and forth between supporting the winds and horns to supporting the strings:

Example 2: Christ on the Mount of Olives, Number 1, measures 23-24

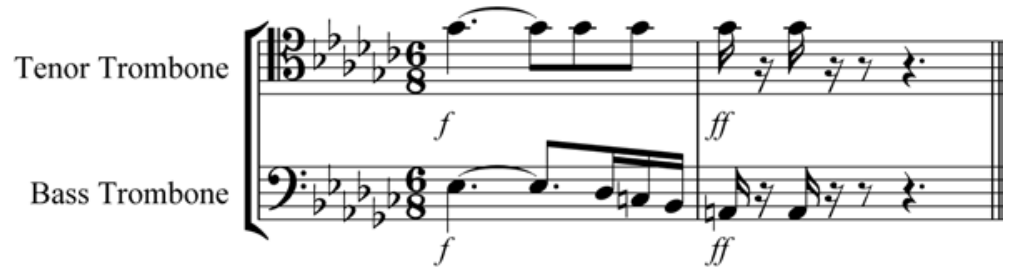

In this case, the tenor trombone continues supporting the woodwinds by doubling the first clarinet in the first measure of the example, while the bass trombone, at the sixteenth notes in

\footnotetext{
${ }^{74}$ Cecil Forsyth, Orchestration (London: Macmillan, 1926), 149.
} 
the first measure, switches from doubling the second horn to doubling the celli and basses. In the second measure of the example both parts support the strings, with the tenor trombone doubling the first violins and the bass trombone again doubling the celli and basses. While the first sixteenth note of the second measure is tutti, the second sixteenth is played by the strings and the trombones alone. The result is a momentary prominence on the part of the trombones. This prominence is repeated and even expanded in the next example:

Example 3: Christ on the Mount of Olives, Number 1, measures 29 and 30

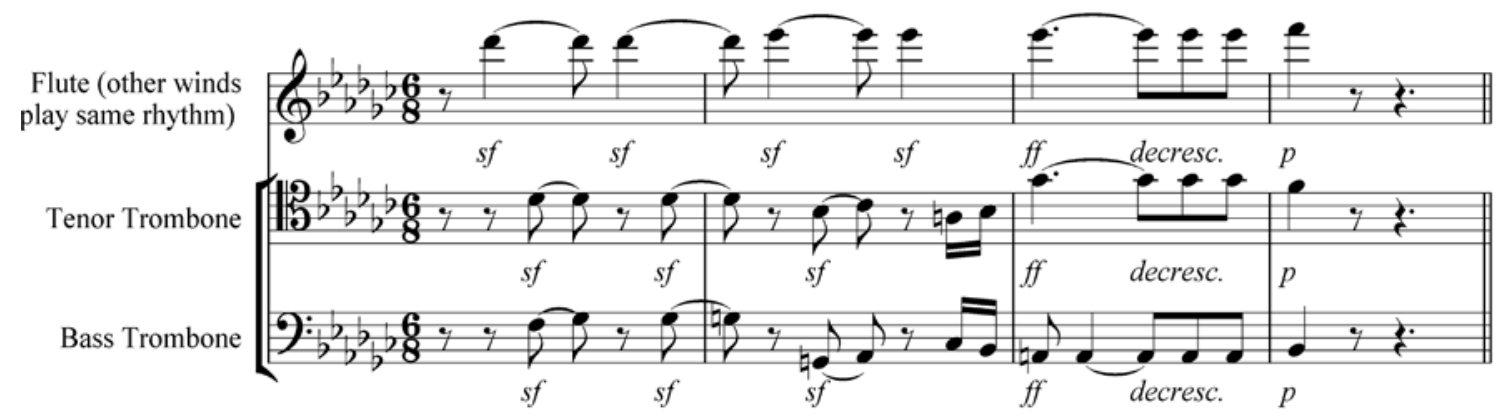

The trombones play their sforzandos on beats independent of those played by the winds, horns and strings. Again, the result is a brief prominence of the trombones within the texture of the entire orchestra. This is a technique that Beethoven will regularly return to in other works that include trombones, as will be seen below.

The final example from the first number in the oratorio shows another type of "brief prominence.” In measures 14 through 16 of the Recitative, the trombones, while sharing sforzandos with other sections (bassoons and violins), hold their note values longer than the strings (half notes versus quarter notes) and also hold through a rhythmic pattern (doubledotted eighths played by the winds). The result-another example of the scoring of trombones influenced by Handel and Haydn—is a briefly prominent part. The Austrian tradition of church music would in this particular case not include trombones; they would 
remain silent, or at best play downbeats that were equal in value to the other sections. This approach is markedly different from that of other Austrian composers before Beethoven:

Example 4: Christ on the Mount of Olives, Number 1, measures 68-71

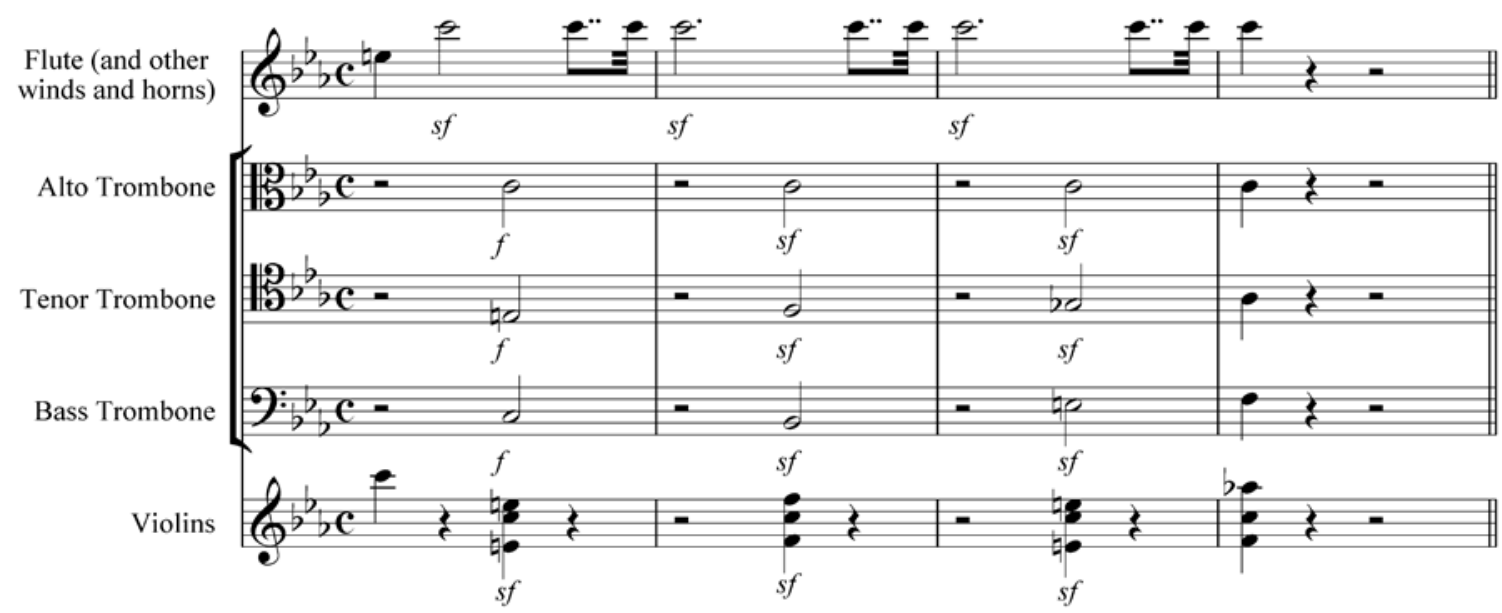

The musical result is also quite different from other Austrian composers before Beethoven.

The two choruses in Christ on the Mount of Olives which include trombones-the second half of the chorus in Number 2 and the final chorus of the work-are similar in their treatment of the instrument. The trombones flow freely from doubling important chorus entrances and endings, to doubling various other instruments and sections (especially the bass trombone loosely doubling the celli and basses), to having parts that could be described as somewhat independent. The doubling of important choral entrances looks like this:

Example 5: Christ on the Mount of Olives, Number 2, measures 205-210

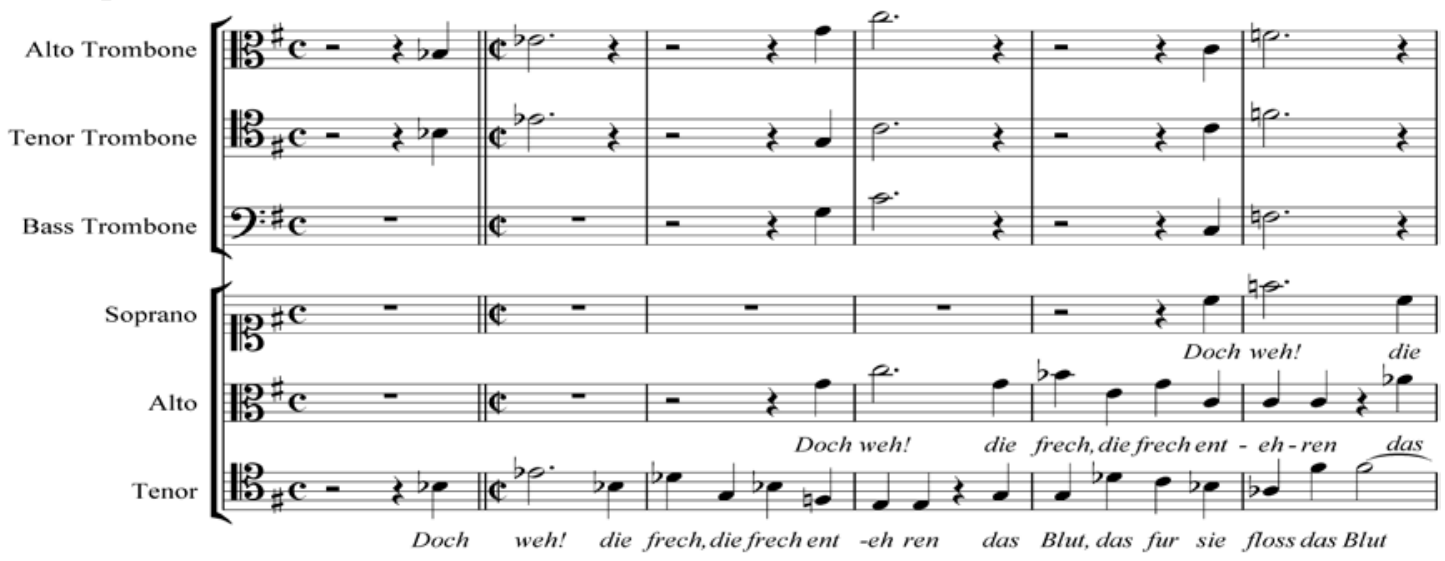


The bass trombone doubles the cello and bass parts. In some measures of this example, it doubles the parts outright; in other measures, the doubling is much looser:

Example 6: Christ on the Mount of Olives, Number 2, measures 236-242

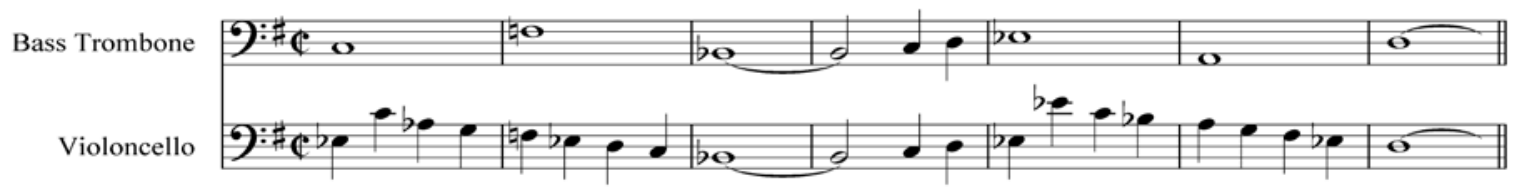

When the bass trombone doubles more loosely, it holds one chord member-usually the root-while the celli and basses outline the scale behind the chord. There are also instances where the trombones work with the other brass to form brass section parts, which then actwith the timpani—-to support the strings and winds:

Example 7: Christ on the Mount of Olives, Number 6, measures 259-263

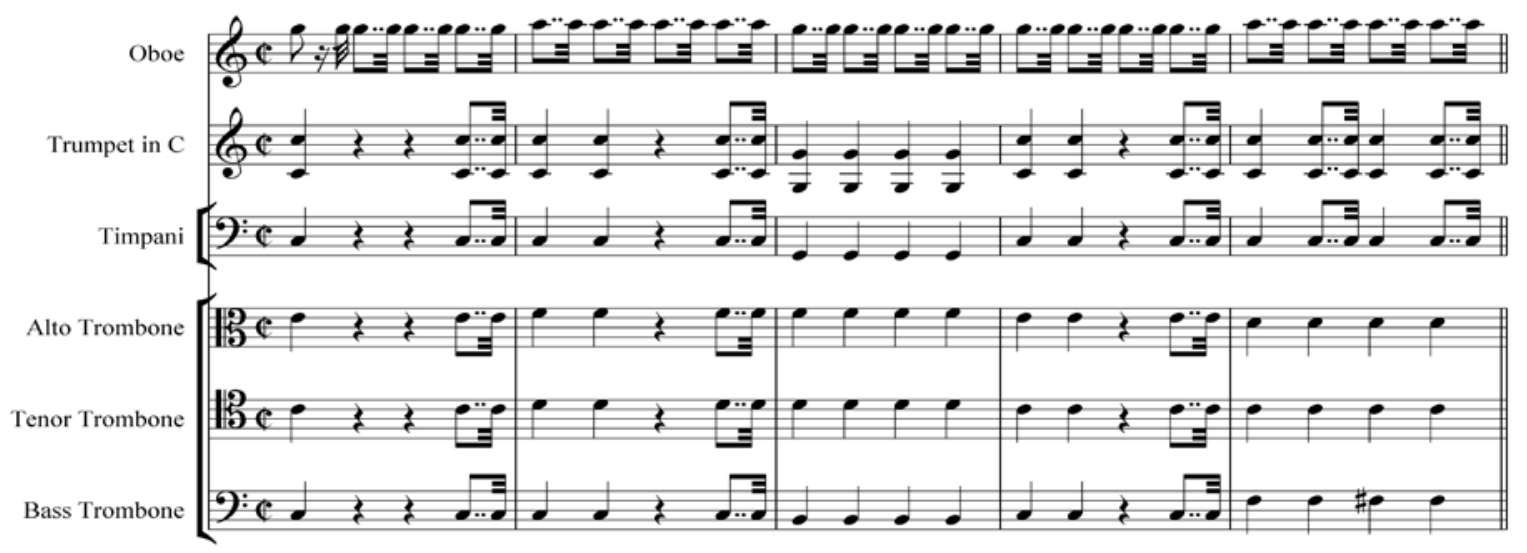

Finally, there are instances where the trombones are independent of any other section:

Example 8: Christ on the Mount of Olives, Number 6, measures 393-397

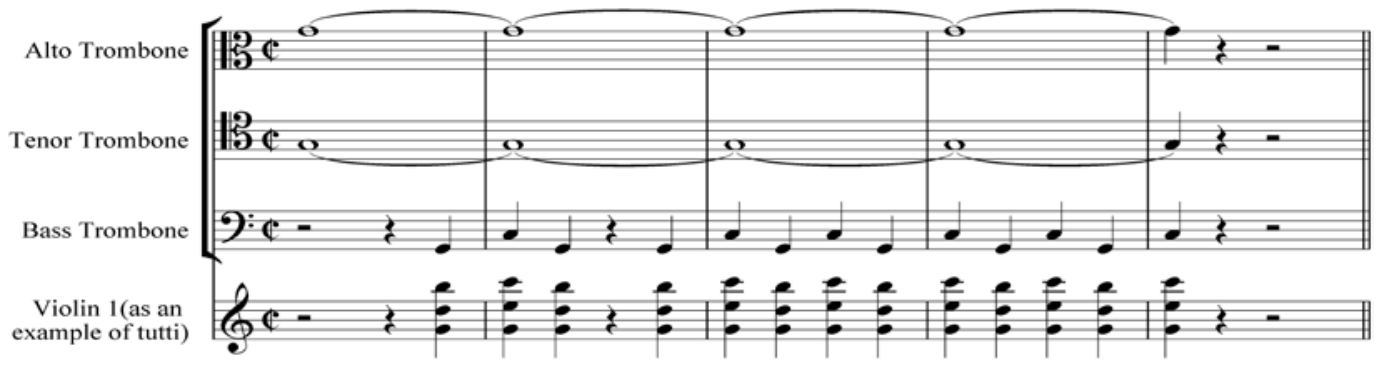

In the above example, the alto and tenor trombones hold out a $G$ in octaves when no other member of the orchestra is doing so, while the bass trombone doubles the basses with the 
tutti rhythm. The result is quite effective in making the trombone section (or most of it) prominent while at the same time keeping them under some level of control and balance.

There are two other trombone section passages in Christ on the Mount of Olives worth mentioning. The first are the soft half notes near the end of Number 2:

Example 9: Christ on the Mount of Olives, Number 2, measures 266-271

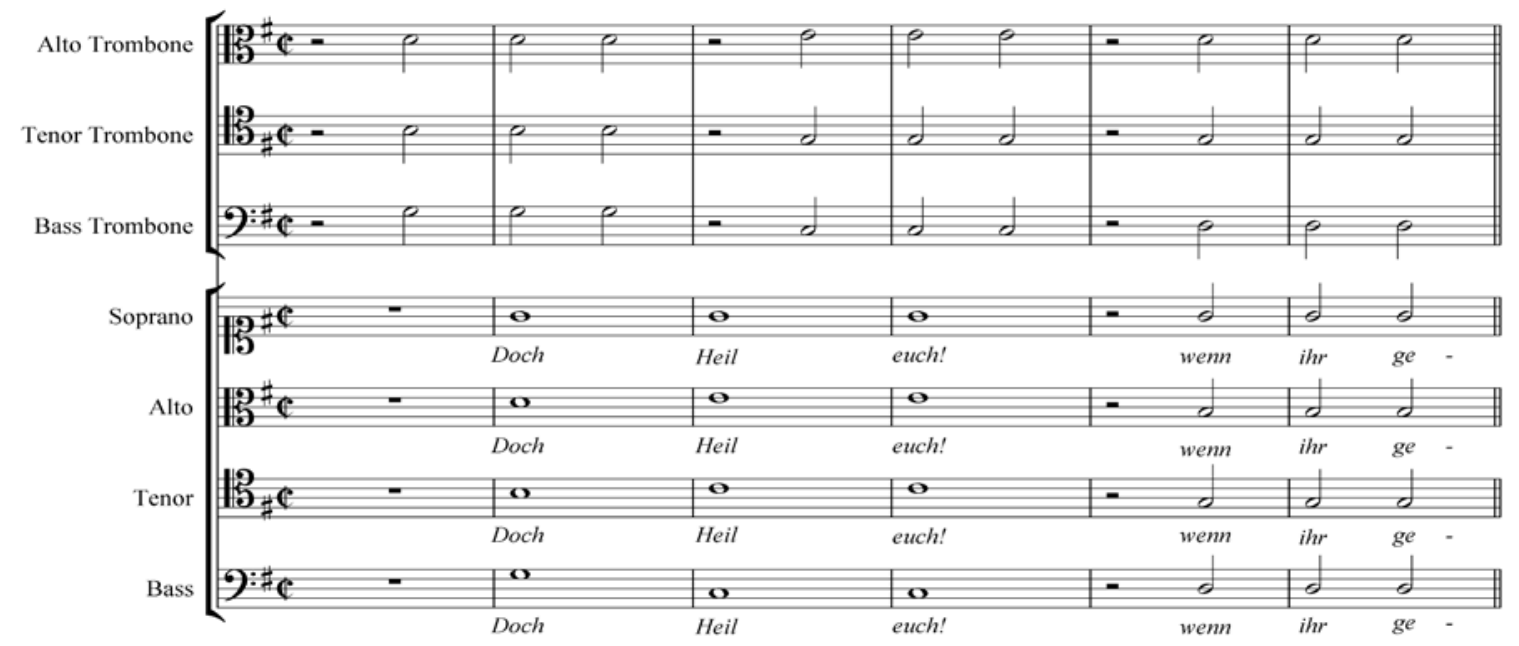

The gentle play between the trombone section (backed by pizzicato strings on the beginning of each half note) and the chorus is a new development in trombone writing. Guion says:

More common eighteenth-century practice was for the trombones to drop out during soft passages. [Here] Beethoven uses them as the only sustaining instruments, giving them a more prominent and important role than they have had in most non-solositic movements. ${ }^{75}$

Notice too, in the last two measures of the example, that instead of continuing to simply double the alto voice, Beethoven wrote the alto trombone to fill out the octaves and double the bass voice one octave higher. This is another example of Beethoven's departure from the traditional Austrian church music style of writing, where the trombones blindly follow their corresponding vocal parts. In the above examples, the trombone parts are significantly more flexible and serve to fill in where needed.

\footnotetext{
${ }^{75}$ Guion, Ibid., 225.
} 
The final passage bearing mention is in the Recitative from Number 3:

Example 10: Christ on the Mount of Olives, Number 3, measure 7-9

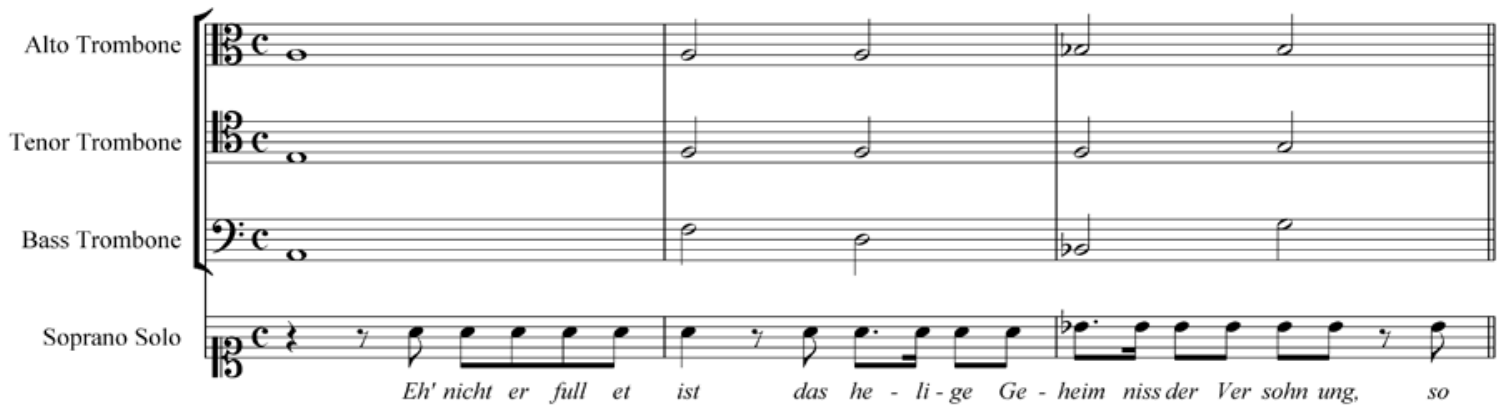

The trombones in this passage were actually mentioned by the reviewer of Zeitung für dei Elegante Welt, who said, “There are a few admirable passages: an air of the Seraph with trombone accompaniment in particular makes an excellent effect.”76 Guion indicates that these particular trombone parts were the ones Beethoven added at the last minute. ${ }^{77}$

In conclusion, Beethoven's first attempt at writing trombone parts points not only to a willingness to break with the Austrian church music tradition of the time-namely that the trombone should be written only to double the chorus or to play in tutti sections-but also to an understanding of, even a sensitivity to, how the instrument could be orchestrated more effectively. The trombone parts in Christ on the Mount of Olives do more than evidence the “English” or independent orchestral style used by Handel and Haydn. The parts, though certainly not complex, show both sophistication and flexibility. However, the work is not without its faults. The omission of the alto trombone in the introduction is curious. Guion offers the idea that Beethoven left out the "brighter" alto in the dark e $\mathrm{e}^{b}$ minor passage. ${ }^{78}$ However, to say that the alto trombone is "bright" is to misunderstand the instrument. The alto trombone may play higher, but actually, the instrument possesses a tonal quality that is

\footnotetext{
${ }^{76}$ Alan Tyson, “The 1803 Version of Beethoven’s Christus am Oelberge,” The Musical Quarterly, 56 (1970), 551.

${ }^{77}$ Guion, The Trombone: Its History and Music, 1697-1811, 225.

${ }^{78}$ Ibid., 223.
} 
best described as "melancholy," especially when played soft. The opening of the oratorio would have been an ideal place for the alto, at least in terms of the dark foreboding opening of which Guion speaks. It is more likely that Beethoven omitted the alto for balance reasons. There were six players, in three pairs, in the opening, and the addition of the alto would have made the three pairs unbalanced. ${ }^{79}$ Overall—trivial balance issues aside—Christ on the Mount of Olives represents a significant step forward—especially in Austria—in trombone writing. The trombones fill several different roles in the work. They sometimes support the choir; they sometimes support the other brass or even the winds. Other times they act independently of all other sections. And in many cases the section switches from one of these roles to another within a musical number, sometimes even within a measure. The seamlessness of such a role change in the score is impressive and musically satisfying. This level of sophistication was not evident in Mozart, despite the fact that his Requiem includes one of the most famous trombone solos in the repertoire.

\begin{tabular}{|c|l|c|l|l|c|c|c|}
\hline \multicolumn{6}{|c|}{ Table 2: Trombone Statistics for Christ on the Mount of Olives, Opus 85 } \\
\hline \multicolumn{2}{|c|}{ Movements } & \multicolumn{3}{|c|}{ Measures } & \multicolumn{3}{c|}{ Ranges } \\
\hline Total & \#Played & Total & \#Played & \%Played & Alto & Tenor & Bass \\
\hline 6 & 4 & 1312 & 200 & 15 & $\mathrm{~g} \mathrm{to} \mathrm{d}^{2}$ & $\mathrm{c} \mathrm{to}^{1}$ & $\mathrm{~F} \mathrm{to} \mathrm{c}^{1}$ \\
\hline
\end{tabular}

\section{Leonore and Fidelio, Opus 72}

The first work in which Beethoven included trombones in the score was his only oratorio. The second work in which he included trombones was his only opera. The roots of Leonore/Fidelio can be traced to 1803, the same year as the premiere of Christ on the Mount of Olives. Although composition of Symphony \#3 (Eroica) was most on his mind, Beethoven

\footnotetext{
${ }^{79}$ However, having said that, it does seem that Beethoven never really settled into orchestrating the alto trombone with any consistency. As will be shown below, the alto trombone parts in Beethoven's works range from practically non-existent to erratic to spectacularly difficult.
} 
had during that time also sketched music that Elizabeth Forbes describes as "a trio for soprano, tenor, and bass, the finale to an opera on the subject of Alexander the Great in India." ${ }^{80}$ In addition, for most of 1803 he had been collaborating with Magic Flute librettist Emanuel Schikaneder on a possible opera titled The Fire of Vesta. ${ }^{81}$ The plot not being to Beethoven's liking, ${ }^{82}$ he searched elsewhere, eventually discovering in early 1804 Leonore, a popular French libretto by Jean-Nicolas Bouilly, which was at the time being translated into German by Joseph Sonnleithner of the Vienna Court Theatres. ${ }^{83}$ Beethoven hoped to be finished with the new opera by June 1804, but due to problems-many outside of his control — the premiere of the opera did not occur until over a year later. During this time there was a change in management of the Theater an-der-Wein resulting, according to Solomon, in “...suspension or even annulment of [Beethoven's] contract, which was not reinstated until late 1804.”84 Furthermore, Beethoven was at this time revising and completing Eroica, and this may have distracted him from earnest composition of Leonore. ${ }^{85}$ Finally, according to Thayer, Leonore was a work that Beethoven agonized over, most likely due to his lack of experience in composing for the operatic genre. ${ }^{86}$ Thayer says, quoting

\footnotetext{
${ }^{80}$ Elizabeth Forbes, “Introduction to Fidelio," in Fidelio, ed. Nicholas John (London: John Calder Publishers, 1980), 7.

${ }^{81}$ Forbes, Ibid. As was noted in the historical background discussion of Christ on the Mount of Olives, as resident composer at the Theater an-der-Wein, one of Beethoven's duties was to compose an opera.

${ }^{82}$ Kinderman relates this paragraph about what Beethoven thought of the plot and libretto of Emanuel Schikaneder's The Fire of Vesta:

In a letter of 4 January 1804 to the writer and editor Johann Friedrich Rochlitz, Beethoven explains that he lingered for half a year over Schikaneder's libretto and had composed several numbers, although the overall plan and sense of its heroic Roman subject remained obscure to him, and the language and verses of its characters sounded like "present-day Viennese apple vendors." Decrying the use of magic as a theatrical effect, Beethoven explained to Rochlitz that "Schikaneder's realm has been totally eclipsed by the light of the clever and practical French operas."

(see William Kinderman, Beethoven [New York: Oxford University Press, 2009], 115).

${ }^{83}$ Thayer, Life of Beethoven, 346.

${ }^{84}$ Solomon, Beethoven, 170.

${ }^{85}$ On the other hand, Solomon sees it differently, saying, "Beethoven’s preoccupation with Fidelio from late 1804 until the spring of 1806 had dammed up work on other projects" (See Maynard Solomon, Beethoven, 259).

${ }^{86}$ Thayer, Ibid., 381.
} 
Von Breuning: “...nothing, perhaps, has caused Beethoven so much vexation as this work, the value of which will be appreciated only in the future..." ${ }^{87}$

The opera, including an overture that would come to be known as Leonore Overture \#2, was finally premiered—under the new title Fidelio ${ }^{88}$-on November 20, 1805 . The timing of the premiere could not have been worse. The French army, led by Bonaparte, had occupied the city the same week as the premiere, and most of the financiers and nobility — the social strata that upheld Beethoven's popularity—had already fled the city. Fidelio premiered to a practically empty house. One correspondent described the scene this way:

A new Beethoven opera "Fidelio or Die ehelich Liebe" has not pleased. It was performed only a few times and after the first performance [the theatre] remained completely empty. Also the music was really way below the expectations of amateur and professional alike. The melodies as well as the general character, much of which is affected, lack that happy, clear, magical impression of emotion which grips us so irresistibly in the works of Mozart and Cherubini. The music has some beautiful passages, but it is very far from being a perfect, yes, even successful work. The text, translated by Sonnleithner concerns a story of rescue which has become in fashion ever since Cherubini’s “Deux Journées." 89

After only three dismal performances, Beethoven withdrew the opera. Forbes continues:

Realizing that the opera had failed chiefly because of the deficiencies of the libretto, and feeling strongly that so much wonderful music should not be allowed to disappear, Beethoven's friends urged him to revise his score. ${ }^{90}$

After another year of revisions and distractions, the opera received another performance, this time with Leonore Overture \#3, at the Theater an-der-Wein on March 29, and again on April 10, 1806. This production, again according to Thayer's recounting (of a letter by tenor Röckel—who sang the part of Florestan in the 1806 production of the opera), “...was

\footnotetext{
${ }^{87}$ Thayer, Ibid., 393.

${ }^{88}$ Part of the reason for the new title was to avoid problems not only with the occupying French, but with others of nobility as well. Leonore was a story based on true happenings, and not unlike The Marriage of Figaro, brought with it certain political ideals of freedom and liberty that were opposed by the ruling classes.

${ }^{89}$ Thayer, Ibid., 387.

${ }^{90}$ Elizabeth Forbes, “Introduction to Fidelio,” in Fidelio, ed. Nicholas John (London: John Calder Publishers, 1980), 9.
} 
exceedingly well received by a select public, which became more numerous and enthusiastic with each new representation..."11 Unfortunately, Beethoven, being unlearned in the logistics of opera productions, overestimated the profits, and when he was paid an amount less than he was expecting, felt himself cheated, flew into a rage, and again withdrew the opera. If not for Beethoven's own fiery and debilitating temper, and perhaps lingering personal angst surrounding the opera, the success of Fidelio probably would have continued at that time, spreading outward from Vienna. It was not until 1814, with Beethoven's popularity at a peak following the enormous success of Wellington's Victory, Opus 91, a completely revised version of Fidelio was produced at the Kärntnertor Theater on May 23, 1814. A repeat performance-including the newly-composed Fidelio Overture-was presented on May 26. This new overture, according to Thayer, “...was received with tumultuous applause and the composer again called out twice at this repetition [sic]." ${ }^{92}$ More resounding successes came during subsequent performances on June 2, 4, and 7. Productions of the belatedly successful opera spread like wildfire throughout Europe, including cities such as Leipzig, Dresden, Berlin, St. Petersburg, and Amsterdam.

Fidelio is unique and interesting to study among Beethoven's works which include trombones because there are essentially two versions of the opera: the 1805-06 version (which for the sake of clarity will be called Leonore); and the 1814 version, titled Fidelio. What makes it even more interesting is that at first glance, while Leonore was scored for three trombones—alto, tenor, and bass—Fidelio is scored for just two- tenor and bass. (It is the 1814 version [Fidelio] that is usually performed today.) ${ }^{93}$ Such a difference in scoring

\footnotetext{
${ }^{91}$ Thayer, Ibid., 397.

${ }^{92}$ Thayer, Ibid., 583. Forbes says the repeat performance was on May $25^{\text {th }}$ (see Forbes, Ibid., 11).

${ }^{93}$ Berlioz noted three trombones in an 1841 performance of the opera, likely making it the 1805-1806 version. (See Hector Berlioz, The Memoirs of Hector Berlioz, trans. David Cairns [New York: Alfred Knopf, 2002], 268.)
} 
presents interesting comparisons between the two styles of orchestration. Therefore, it is beneficial to depart from the chronologically-based study of Beethoven's works and insert Fidelio at this point in the timeline—especially because it is essentially the same work—and construct comparisons between the two versions that could be revealing of diverse scoring techniques. Unfortunately, the two different versions of the opera have no exactly corresponding musical examples allowing for the direct comparison of the scoring techniques used for three trombones versus those techniques used for two trombones. While Leonore is in designation scored for three trombones, in reality just a handful of measures of the opera proper (as opposed to the overtures) are actually scored for three. Most of the 1805-06 version of the opera is scored for the same pair as is Fidelio: tenor and bass. And while it is true that both Leonore Overture \#2 and \#3 are scored for three trombones-with the alto part being mostly as substantial as the other two-the thematic material of the 1814 Fidelio Overture (scored for two trombones) differs significantly enough from that of Leonore Overture \#2 and \#3 that there are again no directly corresponding passages to compare.

However, one comparison that can be made is in the actual presence of any trombone parts at all in the various movements of Leonore (1805-06) versus the same corresponding movements in Fidelio (1814). The two versions of the opera do not have trombones in the same corresponding musical numbers. For example, Leonore Number 8 (Arie mit Choir) has two trombone parts (tenor and bass), while the corresponding number in Fidelio (Number 7: Arie mit Choir) has none. It is the same case with Leonore Number 13 (Introduction and Arie) and the corresponding Fidelio Number 11. The Finale of Leonore Act III has alto, tenor, and bass trombones, while the Finale of Fidelio Act II has no trombones at all. ${ }^{94}$ The scoring differences between the Finales of Act I are less drastic: instead of three trombones

\footnotetext{
${ }^{94}$ While the music in these two Finales is similar, the Finale of Fidelio is condensed. (See also fn. 107 infra.)
} 
versus none, Leonore includes alto, tenor, and bass trombones, while Fidelio has only tenor and bass. It is always Leonore that has more trombones in more numbers. In other words, there are no numbers from Fidelio that include trombones while their counterparts in Leonore do not. Below is a chart comparing the two versions:

\begin{tabular}{|c|c|c|c|c|c|}
\hline \multicolumn{6}{|c|}{$\begin{array}{c}\text { Table 3: Contrasting Trombone Scoring in Opus } 72 \\
\end{array}$} \\
\hline \multicolumn{3}{|c|}{ Leonore: 1805 and 1806} & \multicolumn{3}{|c|}{ Fidelio: 1814} \\
\hline No. & Title & Trombones & No. & Title & Trombones \\
\hline Ov. & Leonore. $2 \& 3^{95 a}$ & $\mathrm{~A}, \mathrm{~T}, \mathrm{~B}$. & Ov. & $\overline{\text { Fidelio }}$ & T, B. \\
\hline 1 & Arie & Tacet & \multicolumn{3}{|c|}{ Left blank to line up musical material } \\
\hline 2 & Duett & Tacet & 1 & Duett & Tacet \\
\hline 3 & Terzett & Tacet & 2 & Arie $^{b}$ & Tacet \\
\hline 4 & Quartett & Tacet & 3 & Quartett & Tacet \\
\hline 5 & Arie & Tacet & 4 & Arie & Tacet \\
\hline 6 & Terzett & Tacet & 5 & Terzett & Tacet \\
\hline 7 & Marsch & Tacet & 6 & Marsch & Tacet \\
\hline 8 & Arie mit Choir & T, B. & 7 & Arie mit Choir & Tacet \\
\hline 9 & Duett & T, B. & 8 & Duett & T, B. \\
\hline 10 & Duett & Tacet & \multicolumn{3}{|c|}{ Left blank to line up musical material } \\
\hline 11 & Recitative \& Arie & Tacet & 9 & Recitative \& Arie & Tacet \\
\hline 12 & Finale & $\mathrm{A}, \mathrm{T}, \mathrm{B}^{\mathrm{C}}$ & 10 & Finale & T,B. \\
\hline 13 & Introduction \& Arie & $\mathrm{T}, \mathrm{B} .{ }^{d}$ & 11 & Introduction \& Arie & Tacet \\
\hline 14 & Melodrama \& Duet & $\mathrm{T}, \mathrm{B}{ }^{e}$ & 12 & Melodrama \& Duet & T, B. \\
\hline 15 & Terzett & Tacet & 13 & Terzett & Tacet \\
\hline 16 & Quartett & $\mathrm{T}, \mathrm{B} .{ }^{\prime}$ & 14 & Quartett & $\mathrm{T}, \mathrm{B} .^{\prime}$ \\
\hline 17 & Recitative \& Duett & Tacet & 15 & Duett & Tacet \\
\hline 18 & Finale & A, T, B. ${ }^{g}$ & 16 & Finale & Tacet \\
\hline
\end{tabular}

\footnotetext{
${ }^{95}$ Notes corresponding to table: $a$ ) the 1805 version used Leonore Overture \#2, the 1806 version used Leonore Overture \#3. b) The material for this number is the same as Number 1 in Leonore. c) Early in the number there are seven measures only for tenor and bass. Later, the entire section plays another six measures. $d$ ) Trombones only play in the Intro. $e$ ) The trombones only play in the Duett. $f$ ) The trombones only play six measures (and the last five in the Leonore version). $g$ ) Trombones only play the opening and measures 260-262.
} 
As can be seen, there are trombones in Leonore Numbers 8, 13, and 18, while there are no trombones in the corresponding numbers from Fidelio. Was this a deliberate act on Beethoven's part (and those helping him), when he revised the opera for its 1814 production, to omit trombone parts where they once had been? Or was it an oversight, and if so, why? There are some clues to the answers to these questions in the available biographies of Beethoven. First, Beethoven had already shown he followed the established practice of adding trombone parts as an afterthought-not to the score, but on actual extra sheets of music and in the individual parts. In the above discussion of Christ on the Mount of Olives, Ferdinand Reis found Beethoven in bed early one morning, writing out trombone parts ${ }^{96}$ most likely to the Recitative beginning Number $3 .{ }^{97}$ Reis noted that in the subsequent performances the trombones played from the actual sheets on which Beethoven had been working. Thayer cites another example of Beethoven adding trombone parts on separate sheets as an afterthought, specifically with the instructions to add them later to the score:

To show Beethoven did have such afterthoughts, Krehbeil cites the example of trombone parts for the Trio in the Scherzo of the Ninth Symphony which he found among Thayer's papers. These parts contained also Beethoven's instructions to the copyist as to where to introduce them in the score, thus proving that they were afterthoughts. ${ }^{98}$

Most likely, Leonore is another example of a work in which Beethoven added trombone parts either on separate sheets of music or in the existing trombone parts, apart from the score. ${ }^{99}$ In 1806, several weeks after Beethoven in a fit of rage had withdrawn the score of the opera, he sent word to Baron Peter von Braun-then manager of the Theater an-der-Wein-that he wished to borrow a few of the individual parts, the set of which had evidently remained in the

\footnotetext{
96 Thayer, Life of Beethoven, 328.

97 Alan Tyson, “The 1803 Version of Christus am Oelberge,” The Musical Quarterly 56 (1970), 551.

98 Thayer, Ibid., 328, note 5.

${ }^{99}$ Schindler also mentions later additions of parts for other instruments in an aria. In that case it was horn parts that were added. (See Schindler, Beethoven as I Knew Him [London: Faber and Faber, 1966], 126.)
} 
possession of the theater. Among them were the three trombone parts. Thayer writes:

[Beethoven] asked...to borrow the following: “...the three trombone [parts]...I need them, but only for a day, in order to have a few trifles copied for myself, which could not be written into the score for want of room. ${ }^{100}$

Whether or not the parts were lent to Beethoven is not mentioned, but the note does show that there were separate trombone parts which included music that was not in Beethoven's personal score. The question of whether these specific parts were eventually included in Beethoven's personal score is mostly irrelevant: apparently he misplaced his score, and in 1814 he had to borrow one from Count Moritz Lichnowsky for the revival of the opera. ${ }^{101}$ Probably what had happened is that some of the trombone music from the earlier Leonore, written on the parts from the Theater an-der-Wein, was not in the score Beethoven borrowed to revise for the 1814 production of Fidelio. So they were omitted from the 1814 version of the opera. Most likely these included the few instances in Leonore where the alto trombone played, since the 1814 version of the opera is scored for only tenor and bass trombone. This is further borne out by Fidelio Overture, newly composed in 1814, which also only calls for tenor and bass trombone. Beethoven would have used the borrowed score-which was apparently absent any alto trombone parts—as a basis for Fidelio Overture.

A question brought up by these points is this: when Beethoven was re-writing Fidelio in 1814, why did he not simply re-score the opera to include three fully-active trombones instead of two? The Kärntnertor Theater-where the 1814 production of Fidelio took place-certainly had the capacity to support a three-trombone section, with its spacious, elegantly-decorated facilities and enviable payroll. ${ }^{102}$ In fact, during the same time period as the 1814 production of Fidelio, the Theater was also presenting Mozart's Don Giovanni,

\footnotetext{
${ }^{100}$ Thayer, Life of Beethoven, 398 (emphasis in original).

${ }^{101}$ Elizabeth Forbes, "Introduction to Fidelio," 9.

102 Thomas Forrest Kelly, First Nights: Five Musical Premieres (New Haven: Yale University Press, 2000), 124.
} 
which includes three trombones in the orchestral score. ${ }^{103}$ So, not only were three trombones available to Beethoven, but the chosen venue could support them. Several reasons contribute to the fact that Beethoven did not re-score Fidelio to include three trombones. First, in early 1814 Beethoven was busy with many performances of his works, including the premiere of his Symphony \#8. Thayer speaks of several important performances and social gatherings which contributed to delays in the revision of Fidelio during early $1814 .{ }^{104}$ In fact, the new Fidelio Overture was not ready for the first performance of the opera on May 23, and another overture was substituted; ${ }^{105}$ it was not until the May 26 performance that the new Fidelio Overture was ready. These delays support the idea that the 1814 revision of Fidelio was more rushed than Beethoven would have preferred. Therefore, it is quite feasible that, given the time constraints, Beethoven simply left the trombone parts as is. One final reason he could have preserved the two-trombone orchestration was to contribute to the overall lighter scoring of the 1814 revision of the opera. The earlier version was considered too heavy, ${ }^{106}$ and one way to lighten the orchestration was to write for two trombones instead of three.

The trombone writing in Fidelio is sparse: in sixteen musical numbers, trombones only play in four of them, plus the Overture. The published Fidelio trombone parts consist of two printed sides of one sheet. To give an illustration of the overall sparseness of the trombone parts in Fidelio, the first entrance of the trombones (seen in Example \#22, and probably best described as a section solo as opposed to a momentary prominence) is played after 229 measures of rest, including one 183-bar rest, (with no cues for help with the

\footnotetext{
${ }^{103}$ Johann Wenzel Tomaschek and Abram Loft, “Excerpts from the Memoirs of J. W. Tomaschek,” The Musical Quarterly, Vol. 32, No. 2 (April 1946), 250.

${ }^{104}$ See Thayer, Life of Beethoven, Ibid., 574, 576, 579, 580, 581.

${ }^{105}$ There is debate as to which overture was substituted. Schindler says it was Leonore Overture \#1, Treitschke wrote in his memoirs that it was Creatures of Prometheus, tradition says it was Ruins of Athens. (See Forbes, "Introduction to Fidelio," 11.)

${ }^{106}$ Wenzel in his memoirs mentions the heaviness of the two-trombone section (see Wenzel, Ibid., 251). Imagine his reaction to a section of three trombones.
} 
entrance). The section fares only a little better in Leonore, where it plays in seven of eighteen numbers, plus the Overture. The Leonore range is $g$ to $c^{2}$ for the alto, the tenor is $c$ to $\mathrm{a}^{1}$, and the bass is $\mathrm{F}$ to $\mathrm{d}^{1}$. The Fidelio range is $\mathrm{d}$ to $\mathrm{b}^{1}$ for the tenor, and $\mathrm{F}$ to $\mathrm{b}$ for the bass. The first trombone entrance in Fidelio (the opera proper) is in Number 8 (Duet), and both parts play exactly three notes, two of which (shown below) are members of a diminished chord: the first time with the bassoons and strings, the second with the horns and the winds:

Example 11: Fidelio, Number 8, measures 115 and 123

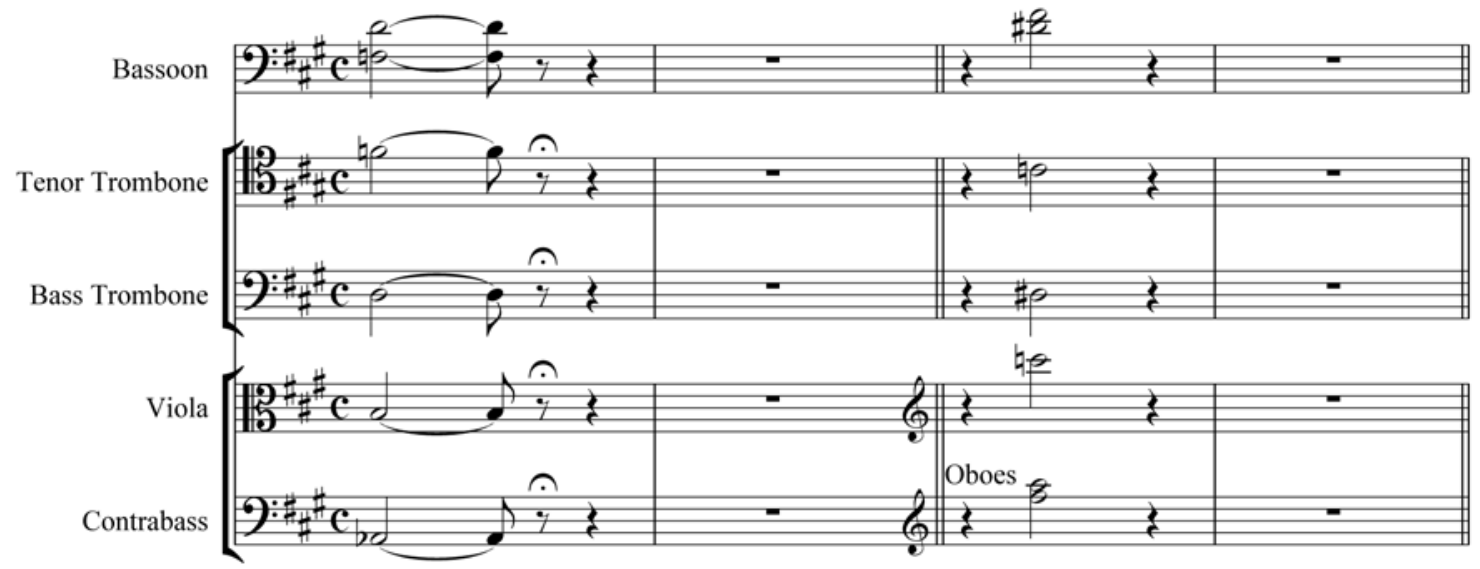

The style of scoring in most of Fidelio differs somewhat from the style Beethoven utilized in Christ on the Mount of Olives, where the trombone parts were more varied. At times the trombone parts served to double and support choir entrances and endings. Other times they supported the rest of the brass, woodwinds, or even the strings-either in tutti segments or as support of specific sections. Other times the trombone parts were written independently of any other section. In Fidelio, the trombones never double the chorus and rarely act independently, with the exception of the dungeon scene, which will be discussed below. The trombones almost exclusively are simply two more voices in large tutti sections, especially when diminished chords are involved. In Leonore, however, the trombone parts are closer to the style of orchestration found in Christ on the Mount of Olives than that found in Fidelio. 
Although Leonore contains no examples of the trombones doubling the chorus (with one possible exception in Example 18), there is more complexity and sophistication to the parts and less rhythmic abbreviation. In addition, there are more "momentary prominences" as was described in Christ on the Mount of Olives. Here is one example from Leonore:

Example 12: Leonore, Number 8, measures 115-120

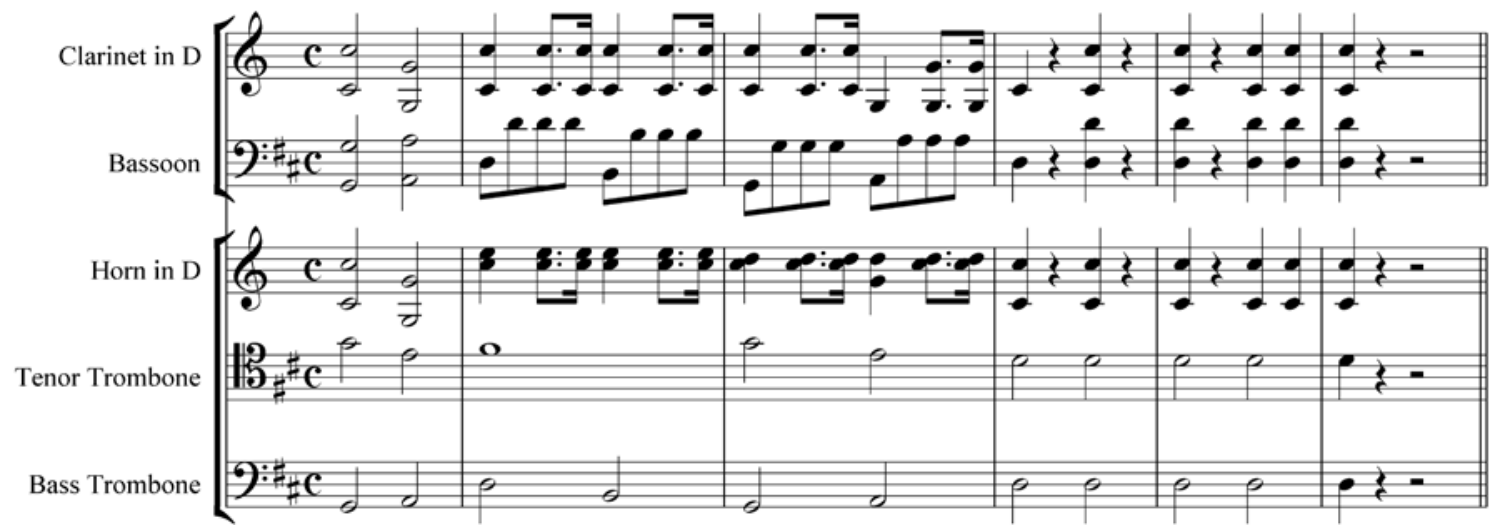

The trombones have their "momentary prominence" in measures 118 and 119, where they alone hold half notes, while the rest of the orchestra plays quarter notes with rests (as the other parts included indicate), or eighth notes with rests (in the strings). In the entire number the trombone parts are comparatively extensive, with the section having music to play in half of the 122 measures. The quantity of bars played is significant, especially considering that some numbers have only a handful of notes for the trombones to play (not to mention the overall abundance of trombone tacets throughout the opera). The parts are written in such a way that the trombones are simply two more members of the brass section in tutti measures, with the rhythms identical to those of other sections playing the tutti. The other instruments the trombones double tend to be either bassoons (down an octave when written in the bass trombone part) or horns, but this is hardly a pattern. There are many other instances where the trombones are found doubling oboe parts in lower octaves, clarinets, or even the flutes. In all of the tutti doubling the two trombone parts tend to be written far from one another; 
usually at an interval of a tenth, sometimes even wider. There are a few measures where the two trombone parts converge to intervals as small as a third, but mostly they are wider than an octave. However, in all the cases of the "momentary prominence," the two trombone parts are invariably in octaves. See Example 12 on the previous page for illustrations of both the wide tutti intervals (first measure) and the momentary prominence octaves (fourth measure). More of the prominent octaves will be seen in the dungeon scene discussed below. In the following example, it is probable that the trombone parts were written as an afterthought and therefore were not in the score Beethoven conducted from during the 1806 production. Apart from the trombones, the voicings of Leonore and the voicings of Fidelio are identical. Excerpts of the opening passages from each version are below for comparison:

Example 13: Fidelio, Number 7, measures 2-5

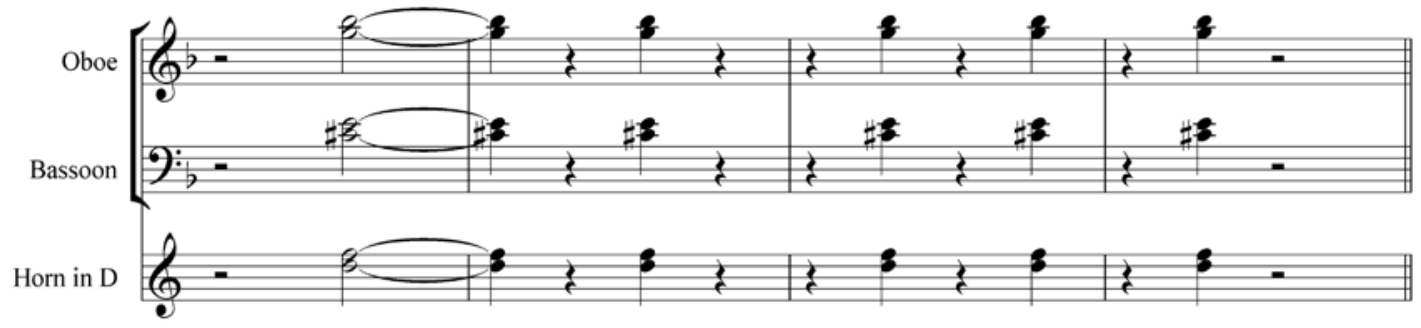

Example 14: Leonore, Number 8, measures 2-6

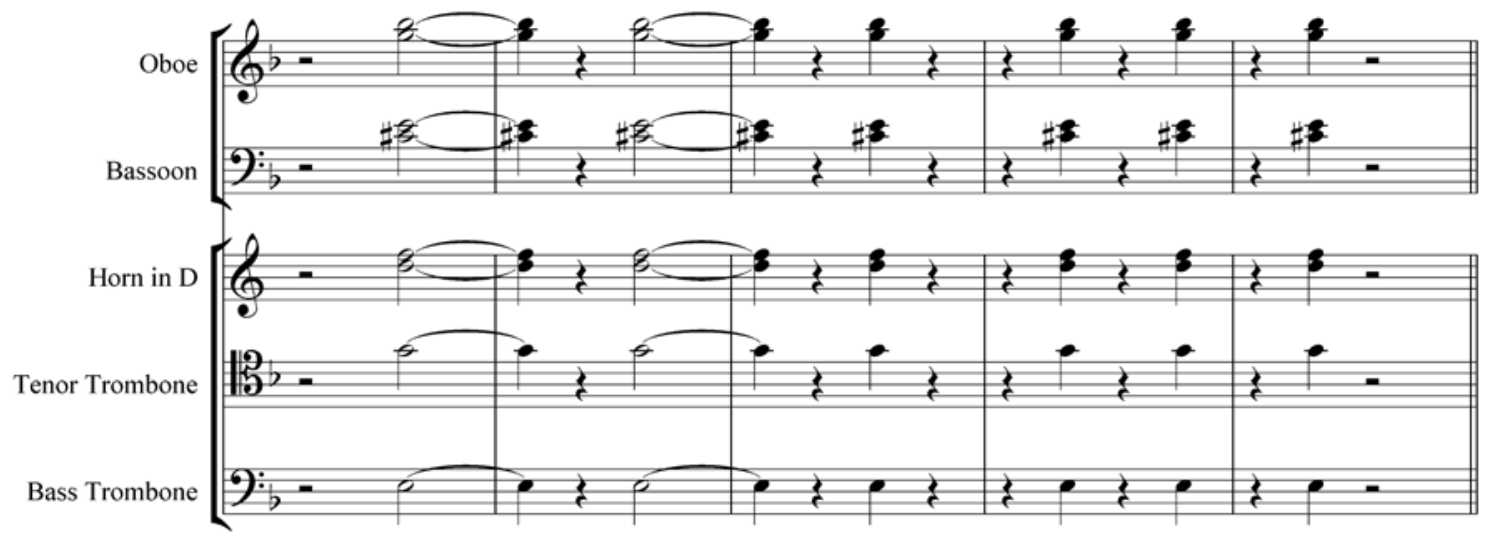

Although the Leonore version has an extra measure, the chord members assigned to the individual parts are exactly the same in both versions. Most likely, sometime during the 
rehearsals—or even between performances—of the 1806 production of Fidelio, more music was added to the trombone parts at the Theatre an-der-Wein, but not to the score. Beethoven probably borrowed the trombone parts from the theatre and added the notes to his score. But, since he subsequently misplaced his personal score and had to borrow one from Count Lichnowsky for the 1814 production —and the added trombone parts evidently were not in Lichnowsky's score- the Fidelio version contains no trombone parts in Number 7. Another small example of this same incidence bears mention. In the Finale of Act II, ${ }^{107}$ the trombones in Leonore have a momentary prominence (on the downbeat) not found in Fidelio:

Example 15: Leonore, Number 12, measures 282-283

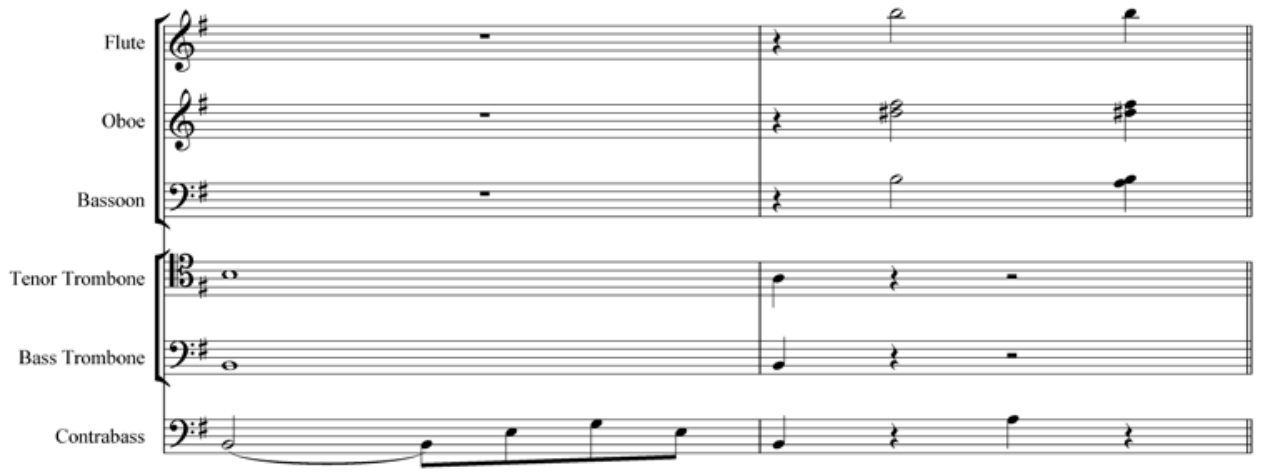

Example 16: Fidelio, Number 10, measures 228-229

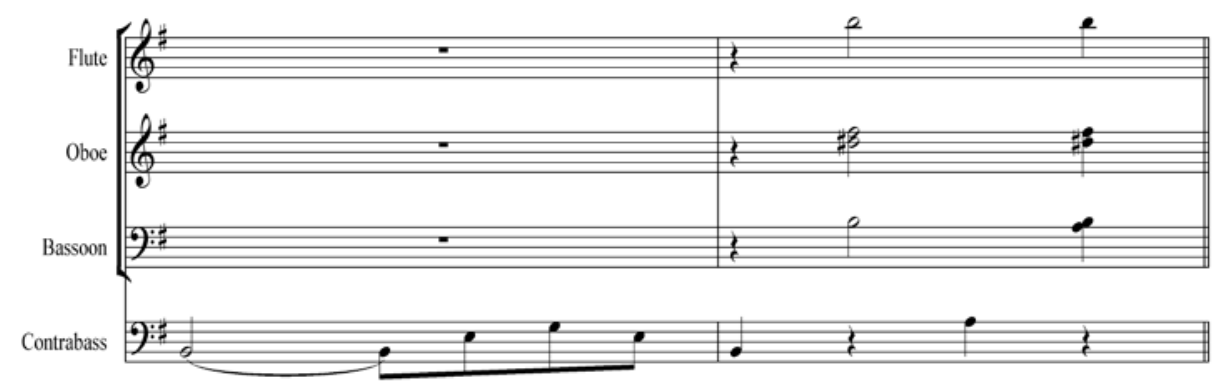

Again, the trombones are in octaves. It also seems that the momentary prominences were for the most part afterthoughts on the part of Beethoven, since they appear more frequently in Leonore, and the corresponding music in Fidelio does not have trombone parts at all.

\footnotetext{
${ }^{107}$ While Leonore was in three acts, Fidelio was pared down to two.
} 
The two instances in Leonore where the alto trombone plays were likely written as later additions—and therefore probably do not appear in the original score—although that is difficult to determine with certainty in this particular case. Both alto passages in Leonore do not have exactly corresponding sections in Fidelio for comparison. Each of these cases is demonstrable of a specific style of orchestration. The first is an example of tutti scoring:

Example 17: Leonore, Number 12 (Finale Act II), measures 459-463

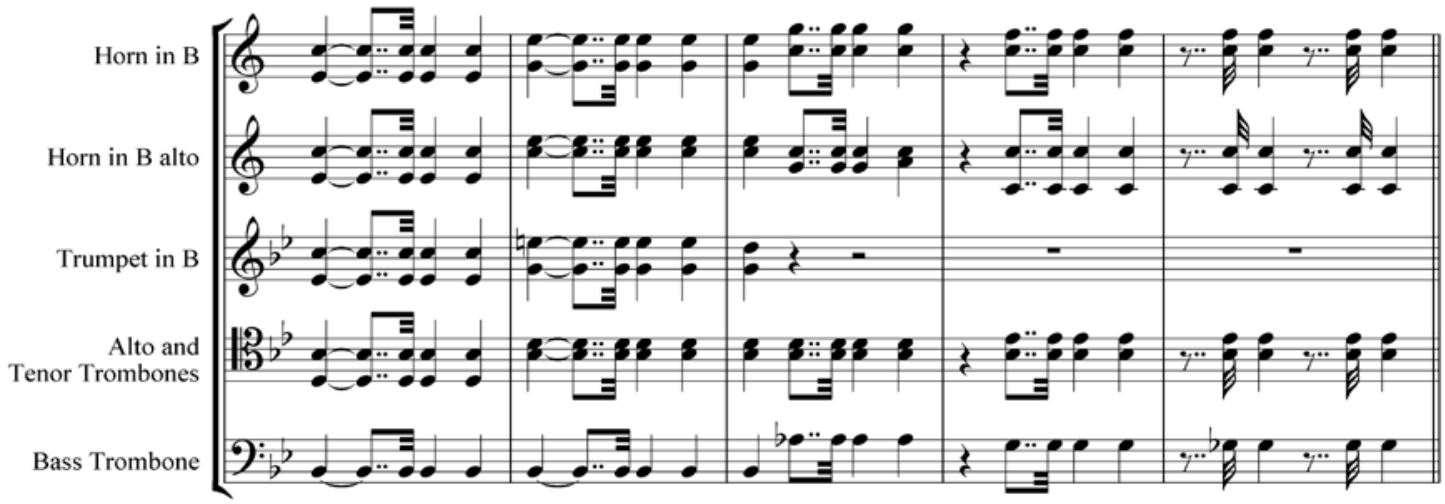

Rhythmically, the trombones here are written equally to the rhythm of the other brass, as well as all the woodwinds (not shown). This type of rhythmical complexity in trombone parts of Beethoven's time tends to be rare. In fact Guion says:

Oddly enough, Beethoven's trombone parts have less in common with the traditional Viennese manner of writing for trombones than with the new style from France...French trombone parts...consist exclusively of the least interesting of the instruments' capabilities: doubling, rhythmic punctuation, harmonic filler, and making loud sounds. ${ }^{108}$

Guion's point may be borne out in other of Beethoven's works which include trombonesespecially Symphony \#5 and the Pastorale Symphony, but the rhythmic complexity of this particular passage seems to be an exception to Guion's rule.

The other passage from Leonore which includes alto trombone is from the Finale of Act III. Here is the only example in the opera where the trombones come close to

\footnotetext{
${ }^{108}$ David Guion, The Trombone: Its History and Music, 1697-1811 (New York: Gordon and Breach, 1988),
} 135. 
performing the traditional Austrian practice of doubling the choir. Notice how the alto trombone doubles the soprano voice part and the tenor trombone doubles some of the alto voice notes, completing chords as needed. This technique will be seen in later works where the trombones have less of a role supporting the choir and more of an orchestral tutti role:

Example 18: Leonore, Number 18 (Finale Act III), measures 9-14

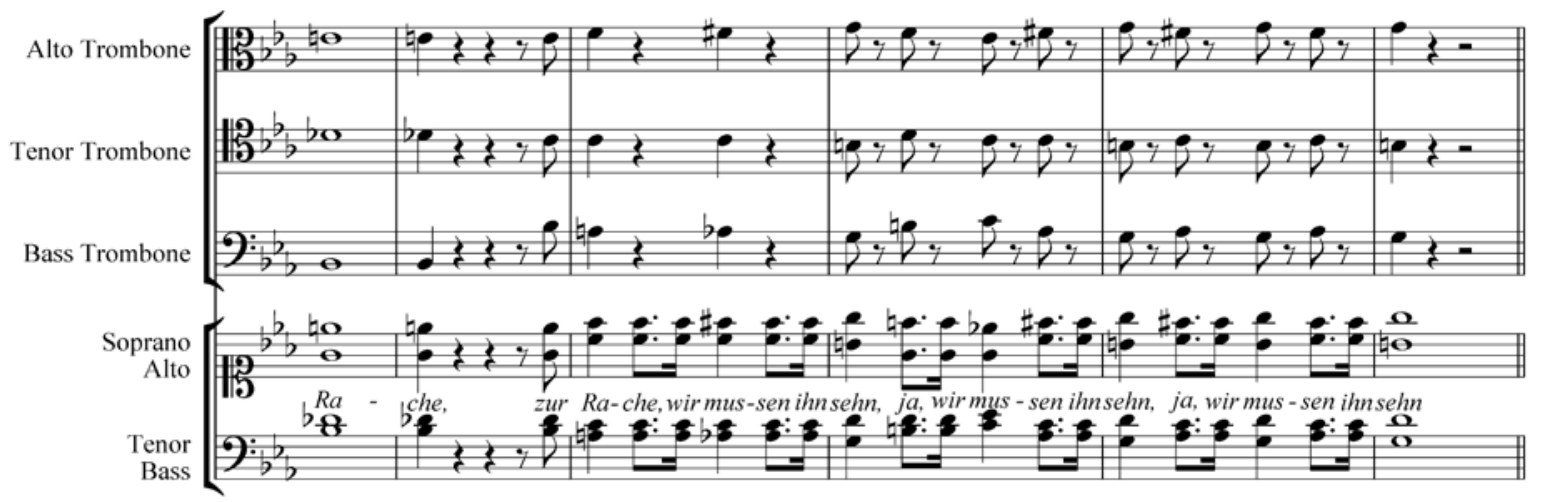

The trombones support the choir by accentuating every other beat in measure eleven, then every beat in measures twelve and thirteen, creating strength and force in the choir, making it sound louder while at the same time preserving the clarity and balance of the voices.

It is necessary to show one more Leonore example-from a fragment of an alternate version of Number 18 - where the trombones have the same rhythms as the rest of the brass:

Example 19: Leonore, supplemental fragment of Number 18, measures 336-340

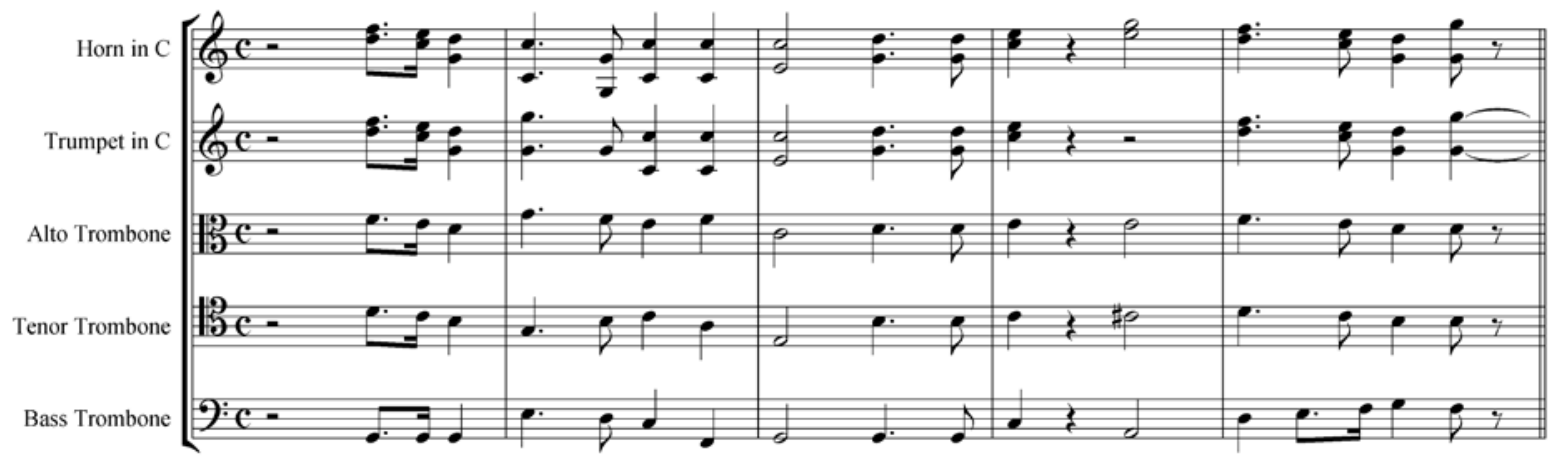

Not only do the trombones have the same rhythm as the other brass, but the bass trombone actually has the most complex rhythm of all the brass, in measure 5 of the example. 
Assuming that this fragment was composed at a time chronologically later than the corresponding music in the actual score of Leonore, it is also more proof that the trombone parts in Leonore were more complex and still evolving, and that over time more extensive trombone parts - especially for the alto trombone-had been added to the opera.

Probably the most interesting parts for the trombones in Fidelio are contained in Number 12, the dungeon scene. Here the instruments are thematically on familiar ground. As stated before, by Beethoven's time trombones had already long been associated not only with ecclesiastical topics, but also with the broader topics of spiritualism, death, and the underworld. The Austrian tradition of including trombones in church music only served to further reinforce this thematic role of the instrument. In the dungeon scene of Fidelio, Number 12, Melodram and Duet, the trombones play almost exclusively in octaves. One exception is whenever the bass trombone's lower octave part requires a note lower than an F. Then the part is raised an octave to play in unison with the tenor trombone. One example of this technique-which occurs throughout the number-is below:

Example 20: Fidelio, Number 12, measures 227-232

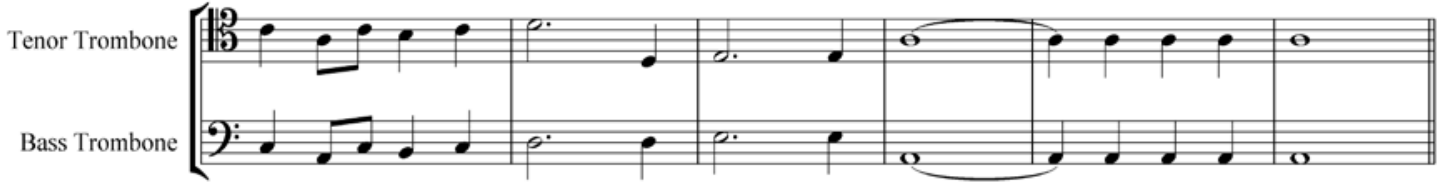

The low notes that were taken up the octave in the bass trombone part are playable on the instrument. Weiner would probably state the reason for the octave leap is that most likely, even though the part says "bass trombone," it was played on a tenor trombone. ${ }^{109}$ Although the instrumentation seems strictly designated, composers were often required to write for the instruments available at the time, especially an instrument as new to the "secular" orchestra

\footnotetext{
${ }^{109}$ See Howard Weiner, “When is an Alto Trombone an Alto Trombone?”, 66.
} 
as the trombone. In this case, with the tenor trombone, any note below a low E would be off the instrument's range. Furthermore, Forsyth's contention ${ }^{110}$ that the lowest notes on the instrument — especially in soft dynamics—are difficult to play clearly is probably the reason why the low E is also brought up the octave in measure 229. The other exception to the octave rule in the Fidelio dungeon scene is this:

Example 21: Fidelio, Number 12, measures 78-83

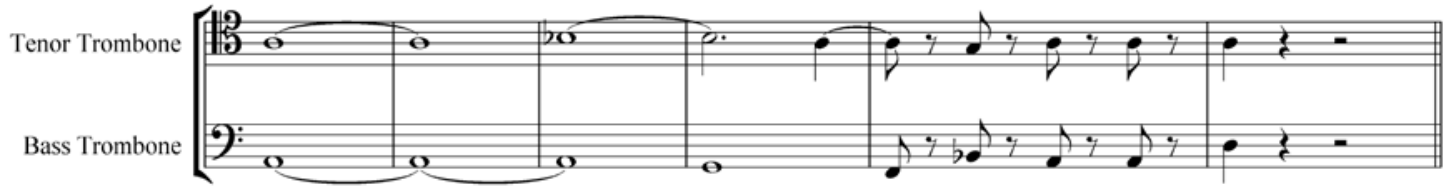

The passage begins in octaves, then opens to the minor ninth, then to the tenth (one of the common intervals found in the Fidelio (and Leonore) trombone parts. The passing minor ninth, especially because it is tied over the bar, is another example of a momentary prominence found in the trombone parts.

Before leaving Fidelio (and Leonore) completely, it is necessary to touch on the three overtures which call for trombones. (Leonore Overture \#1, Opus 138, written for an 1807 production in Prague that evidently never happened, contains no trombone parts.) The Fidelio Overture, being composed in conjunction with the later 1814 production, requires the same pair of trombones as does the 1814 version of the opera. In this overture, the trombone parts are written more often than not as sparsely as in the rest of the opera. Predominantly, when they do have parts, the two trombones play at wider intervals-usually of a tenth or greater-unless there is a momentary prominence or a section solo, in which case the two parts are invariably in octaves. The octaves serve to heighten the prominence effect, allowing the instruments to be clearly heard through the full orchestra:

${ }^{110}$ Cecil Forsyth, Orchestration, 149. 
Example 22: Fidelio Overture, measures 230-233

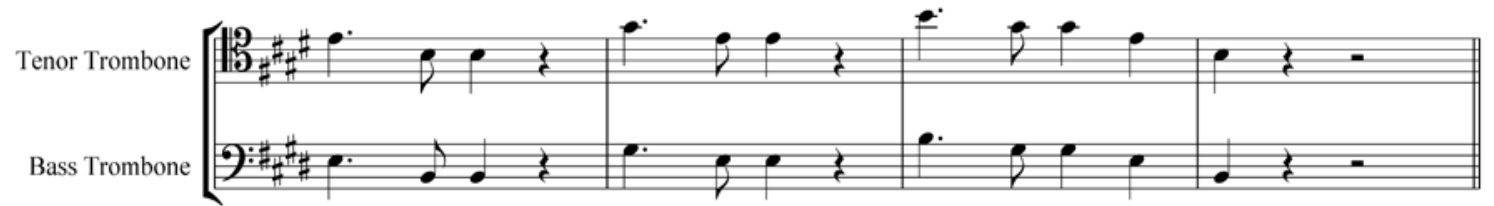

This passage is probably best described as a section solo instead of a momentary prominence.

The other two overtures, Leonore Overture \#2 and Leonore Overture \#3, also offer insights into Beethoven's trombone scoring methods. Since these overtures were performed at the 1805 and 1806 Theatre an-der-Wein productions, they were composed for three trombones. There are passages where the trombones have different parts in exactly the same corresponding section of music in the two different overtures. The trombone entrance in the first allegro section of Leonore Overture \#2, like the first entrance of the trombones in Fidelio Overture, consists of the melody, albeit a different melody in Fidelio Overture than in Leonore Overture \#2 (for the Fidelio melody, see example 22, directly above):

Example 23: Leonore Overture \#2, measures 89-95

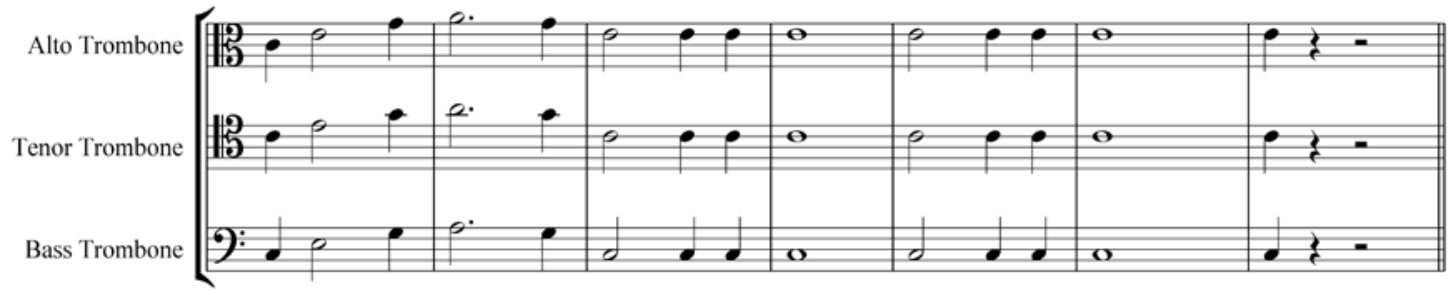

But the same passage from Leonore Overture \#3 has the trombones playing chords, while the woodwinds play the melody (which they also do in Leonore Overture \#2):

Example 24: Leonore Overture \#3, measures 70-76

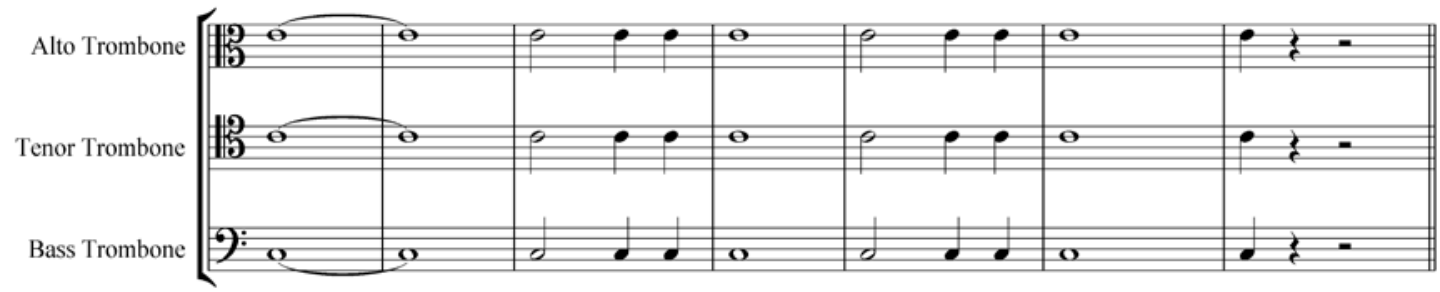


Finally, the tenor and bass trombones play without the alto twice in Leonore Overture \#2, following Beethoven's preference for that pair throughout Leonore:

Example 25: Leonore Overture \#2, measures 236-244

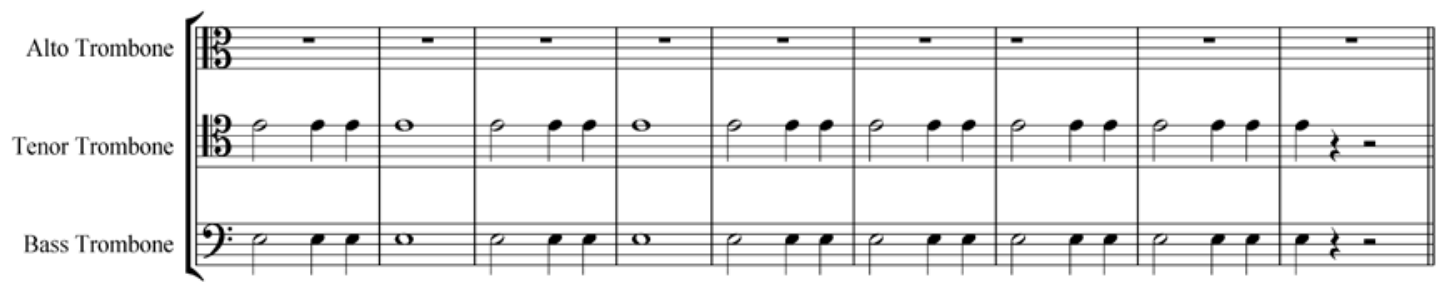

However, it is just the opposite case in Leonore Overture \#3, where the alto and tenor trombones play without the bass trombone two times. Indeed, the alto trombone part is generally more complicated in Leonore Overture \#3 than it is in Leonore Overture \#2. This trend of an increasingly complex alto trombone part continues in the next work with trombones—Symphony \#5—-which certainly includes an alto trombone part on a much higher level of sophistication (and difficulty) than that of Leonore Overture \#3.

Example 26: Leonore Overture \#3, measures 104-112

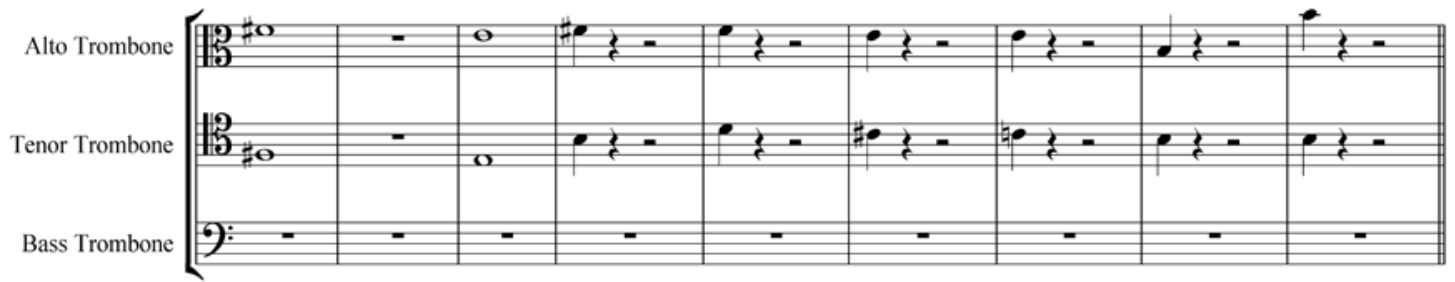

One possible explanation for this case could be that the alto was needed for the higher tessitura of the passage. However, putting aside Weiner's assertion that most likely Beethoven was writing all his parts for tenor trombones, a quick look at Example \#22 shows that Beethoven had no problem writing the tenor trombone part up to the $\mathrm{b}^{1}$ shown in Example \#26. A more probable explanation was that over the two years spanning the 1805 and 1806 productions of Leonore, the alto trombone part had evolved from a handful of notes (found in the 1805 Leonore score) to something much more interesting, of which the Leonore 
Overture \#3 part was but a small example. It is quite possible that the original trombone parts at the Theatre an-der-Wein had a much more complete alto trombone part—one equal in stature to the tenor and bass parts - which never made it to the score. Leonore Overture \#3 seems to demonstrate this possibility.

In conclusion, the trombone parts in Fidelio (and Leonore) show a style of trombone orchestration similar to that of Christ on the Mount of Olives, absent the role of supporting the choir-with one possible exception in the 1805-1806 scores of the opera (what is now called Leonore). The trombones were orchestrated to double other sections in tutti passages, to act as a section independently during brief moments of prominence, or (in one 1805-1806 case) to support (but not be enslaved to) the chorus. Furthermore, Leonore quite possibly symbolizes "the trombone section that could have been." The evolution of the trombone parts over the first years of the opera, with Leonore Overture \#3 being the most sophisticated example, demonstrates what vibrant trombone parts Beethoven had the ability to write. The fragment from the Finale of Leonore shown in Example \#19 above is an even better illustration. In it, the trombone parts have shown a clear evolution from a simplistic duet of doublers in earlier editions, to a fully functional three-instrument section, able to interact with the rest of the orchestra with complete proficiency. The latest trombone parts (of which the Leonore fragment is an example) indicate the direction Beethoven's orchestration of trombones would have continued had Leonore not been subject to political circumstances beyond his control, as well as his own personal struggles in composing an opera.

\begin{tabular}{|c|l|c|l|l|c|c|c|}
\hline \multicolumn{3}{|c|}{ Table 4: Trombone Statistics for Leonore (1805), Opus 72, with Overture \#2 } \\
\hline \multicolumn{2}{|c|}{ Movements } & \multicolumn{3}{|c|}{ Measures } & \multicolumn{3}{c|}{ Ranges } \\
\hline Total & \#Played & Total & \#Played & \%Played & Alto & Tenor & Bass \\
\hline $18+$ Ov. & $7+$ Ov. & 4057 & 348 & 9 & g to c $^{2}$ & c to a $^{1}$ & F to d $^{1}$ \\
\hline
\end{tabular}




\begin{tabular}{|c|c|c|l|l|c|c|c|}
\hline \multicolumn{3}{|c|}{ Table 5: Trombone Statistics for Leonore (1806), Opus 72, with Overture \#3 } \\
\hline \multicolumn{3}{|c|}{ Movements } & \multicolumn{3}{c|}{ Measures } & \multicolumn{4}{c|}{ Ranges } \\
\hline Total & \#Played & Total & \#Played & \%Played & Alto & Tenor & Bass \\
\hline $18+$ Ov. & $7+$ Ov. & 4155 & 393 & 11 & g to b $^{1}$ & c to a $^{1}$ & F to d $^{1}$ \\
\hline
\end{tabular}

\begin{tabular}{|c|c|c|l|l|c|c|c|}
\hline \multicolumn{2}{|c|}{ Table 6: Trombone Statistics for Fidelio (1814), Opus 72, with Fidelio Overture } \\
\hline \multicolumn{2}{|c|}{ Movements } & \multicolumn{3}{|c|}{ Measures } & \multicolumn{3}{c|}{ Ranges } \\
\hline Total & \#Played & Total & \#Played & \%Played & Alto & Tenor & Bass \\
\hline $16+$ Ov. & $4+$ Ov. & 3108 & 121 & 4 & N/A & $\mathrm{d} \mathrm{to} \mathrm{b}^{1}$ & F to b \\
\hline
\end{tabular}

\section{Symphony \#5, Opus 67}

The roots of Beethoven's most well-known work can be traced back to 1804, where ideas turned up in the Eroica sketchbook. ${ }^{111}$ Composition of the work did not begin in earnest until after the 1806 production of Leonore. Solomon writes:

The termination in March 1806 of Beethoven's long operatic labors seems to have unleashed a flood of important instrumental compositions, which were now written out simultaneously or in rapid succession... ${ }^{112}$

The bulk of work on Symphony \#5 probably happened during later 1807 and early 1808. The premiere of Symphony \#5-and Symphony \#6, as well as excerpts from the Mass in C Major, Opus 86, the Choral Fantasia, Opus 80, and the Piano Concerto in G, Opus 79-took place on December 22, 1808, at the Theater-an-der-Wein. ${ }^{113}$ The descriptions of the premiere were mixed. Fellow composer Johann Friedrich Reichardt describes the performance:

I accepted the kind offer of Prince Lobkowitz to let me sit in his box with hearty thanks. There we continued, in the bitterest cold, too, from half past six to half past ten, and experienced the truth that one can easily have too much of a good thing - and still more of a loud. Nevertheless, I could no more leave the box before the end than could the exceedingly good-natured

\footnotetext{
${ }^{111}$ Maynard Solomon, Beethoven, 188.

112 Ibid.

113 Apparently, the reason so many of Beethoven's premiere performances were just before Easter and Christmas was that these were the only days the Viennese theatres were open for public concerts. (See Schindler, Beethoven as I Knew Him, [London: Faber and Faber, 1966], 141.)
} 
and delicate Prince, for the box was in the first balcony near the stage, so that the orchestra with Beethoven in the middle conducting it vexed our patience in the highest degree. Poor Beethoven, who from this, his own concert, had found in the rehearsals and performance had lot of opposition and almost no support. Singers and orchestra were composed of heterogeneous elements, and it had been found impossible to get a single full rehearsal for all the pieces to be performed, all filled with the greatest difficulties. ${ }^{114}$

The opposition of which Reichardt spoke was most likely due to Beethoven's angry outbursts. According to Spohr in his autobiography, no one in the orchestra except the leaders would have anything to do with Beethoven during the rehearsals. In fact, none of the musicians would even agree to rehearse unless Beethoven left the room. ${ }^{115}$ Other personal accounts of the premiere mention instances of Beethoven forgetting his instructions to the orchestra regarding entrances and repeats. Ignaz von Seyfried said:

When the master brought out his orchestral Fantasia with chorus, he arranged with me at the somewhat hurried rehearsal, with the wet voice-parts as usual, that the second variation should be played without repeat. In the evening [of the concert], however, absorbed in his creation, he forgot all about the instructions which he had given, repeated the first part while the orchestra accompanied the second, which sounded not altogether edifying. A trifle too late, the Concertmaster, Unrath, noticed the mistake, looked in surprise at his lost companions, stopped playing and called out drily [sic]: "Again!” A little displeased, the violinist Anton Wranitsky asked "With repeats?" "Yes," came the answer, and now the thing went straight as a string. ${ }^{116}$

Trombone historian Anthony Parsons has this account of the Piano Concerto from Seyfried:

Forgetting that he was soloist, he jumped up and down and began to conduct in his own peculiar fashion. At the first sforzando, he threw his arms so wide that he knocked over both lamps from the music stand of piano [sic] ${ }^{117}$

Two choirboys were dispatched to hold the lamps, but things fared no better the next time:

When the fatal sforzando burst forth, one poor boy received from Beethoven's right hand such a sharp slap on the face that, terrified, he dropped the lamp to

\footnotetext{
114 Thayer, Life of Beethoven, 448.

115 Thayer, Ibid., 447.

116 Thayer, Ibid., 449.

117 Anthony Parsons, "First Night Nerves: The Symphonic Birthpangs of the Trombone,” British Trombone Society Website, http://www.britishtrombonesociety.org, accessed 9 June, 2009.
} 
the floor. The other boy succeeded in avoiding the blow by ducking in time. If the audience laughed the first time, they now indulged in a truly bacchanalian riot. Beethoven broke out in such a fury that when he struck the first chord of the solo, he broke six strings. ${ }^{118}$

While Parsons alleges this episode happened during the concert, Thayer, asserting that it took place at a rehearsal, says, "It is absolutely certain, however, that nothing of the kind occurred at the concert itself." ${ }^{119}$ Thayer's viewpoint is most likely the correct one.

The trombone parts in Symphony \#5 have been described as "mere filler with no real interest of their own." ${ }^{120}$ While this may be true on the surface, the presence of the instrument in a work by such a well-known composer is a significant landmark. Even Beethoven himself felt the inclusion of trombones in the new work worth mentioning specifically in a letter to his patron Count Oppersdorf. ${ }^{121}$ As mentioned above, some writers-Parsons for one-claim that Beethoven's Symphony \#5 was the first instance of trombones in a symphony. This was the conventional wisdom until recent scholarship has revealed at least three other minor composers who included trombones in symphonies predating Beethoven's Symphony \#5. The composers offered as those orchestrating for trombone in a symphony prior to Beethoven are Joachin Eggert, ${ }^{122}$ Franz Ignatz Beck, ${ }^{123}$ and Joseph Krottendorfer. ${ }^{124}$ Most likely all these did in fact orchestrate for trombones in a symphony before Beethoven. But what makes Beethoven Symphony \#5 significant and distinct is that it was the first written by an individual considered a "major" composer, and that the work immediately became part of the standard orchestral repertoire.

\footnotetext{
118 Parsons, Ibid.

${ }^{119}$ Alexander Thayer, Life of Beethoven, 447.

${ }^{120}$ David Guion, The Trombone: Its History and Music, 1697-1811, 279.

121 Thayer, Ibid., 433.

${ }^{122}$ Avishai Kallai, “Joachin Eggert: Trombone Pioneer.” Ludwig van Beethoven Website, $<$ http://lvbeethoven.com> (2008), accessed 18 February, 2008.

${ }^{123}$ Sarah Gordon, "Das sinfonische Werk von Franz Beck," British Trombone Society Website, <http://www.britishtrombonesociety.org> (2009), accessed 9 June, 2009.

${ }^{124}$ Guion, Ibid., 135.
} 
Symphony \#5 has in the score parts for three trombones: alto, tenor and bass. In this case, due to tessitura issues in the alto trombone part, there is a question of whether or not the part was written for the true alto instrument, or for a tenor trombone with a smaller bore and mouthpiece. As will be discussed below, there is historical evidence indicating that late Eighteenth- and early Nineteenth-century Viennese orchestral trombone sections performing works that specified alto trombone or bass trombone did not necessarily play those particular instruments, but instead played all the parts on tenor trombones. ${ }^{125}$

The trombones remain silent throughout the first three movements, until they join the orchestral tutti forces in the heroic and triumphal opening chords of the Finale. The flute and trumpet are shown as examples of the rhythmic activity of the rest of the winds and brass:

Example 27: Symphony \#5, Finale, measures 1-6

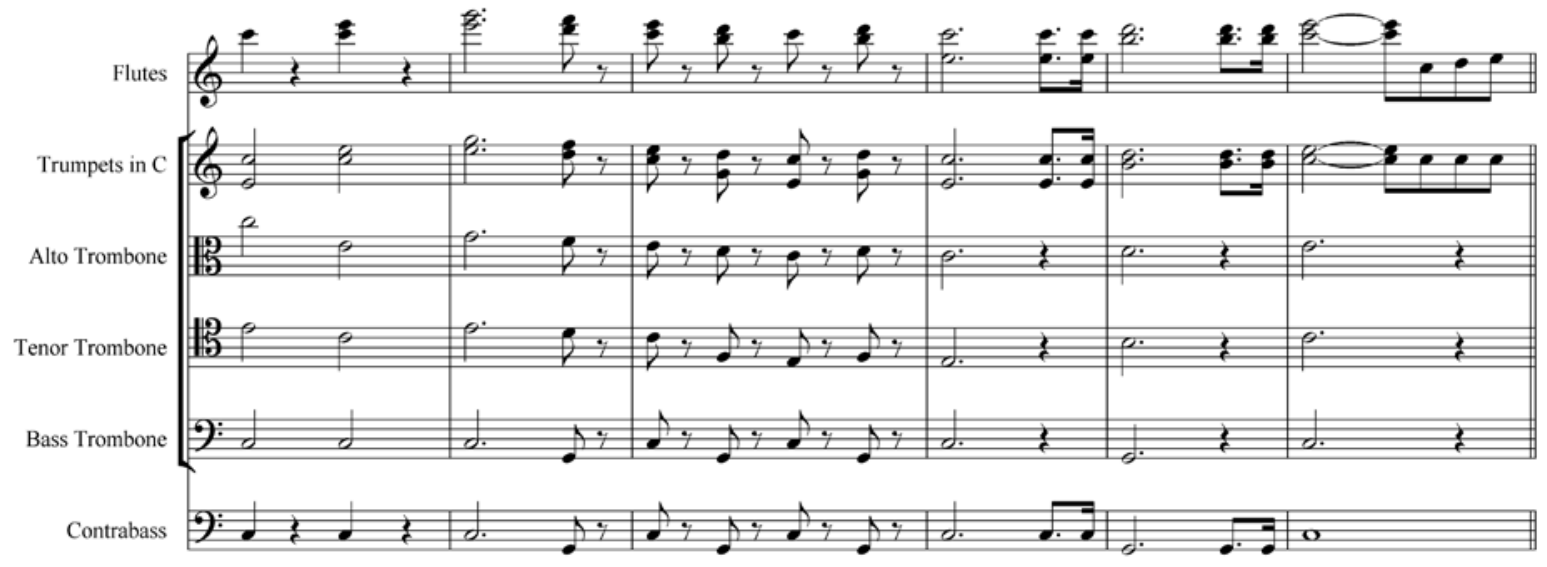

This example is indicative of a number of techniques. First, the bass trombone tends to double the bass and cello lines throughout the movement. The method of doubling is similar to that of Christ on the Mount of Olives, where the bass trombone part is less complicated rhythmically than the string basses or celli. In more technical passages, the bass trombone doubles the outline or the downbeats of the string passage:

\footnotetext{
${ }^{125}$ Howard Weiner, "When is an Alto Trombone an Alto Trombone? When is a Bass Trombone a Bass Trombone?-The Makeup of the Trombone Section in Eighteenth- and Early Nineteenth-Century Orchestras,” Historic Brass Society Journal 17 (2005), 37-79.
} 
Example 28, Symphony \#5, Finale, measures 32-37

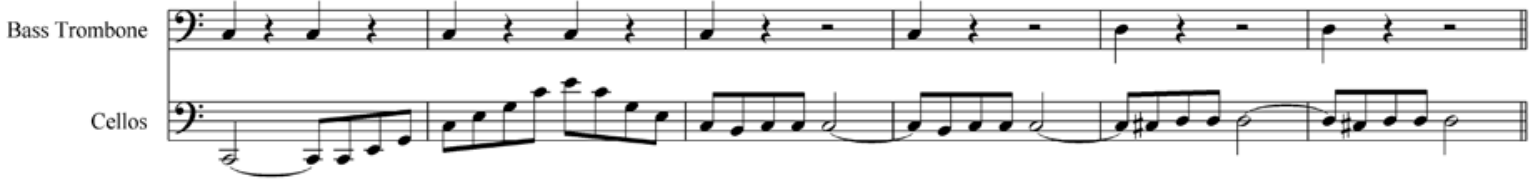

Referring back to example 27, the alto and tenor trombones are scored in close position more often than they were in either Christ on the Mount of Olives or (especially) Fidelio/Leonore. In fact, with the exception of three measures, the widest interval between the alto and tenor parts is an octave. The most common interval the two instruments play is a third, with the sixth behind that. The entire Example 27 shows the prevalence of thirds and sixths between the two parts. The alto part acts independently in its doubling: it is not tied to a particular instrument as the bass tends to be. The instruments the alto doubles most often include first clarinet, first bassoon, and sometimes the violins. The tenor tends to double the second counterparts of the same instruments, as well as the second trumpet.

The tessitura of the alto trombone part is legendary. Written up to $\mathrm{f}^{2}$, the note still is the highest note for trombone in the standard orchestral repertoire:

Example 29: Symphony \#5, Finale, measures 74-82

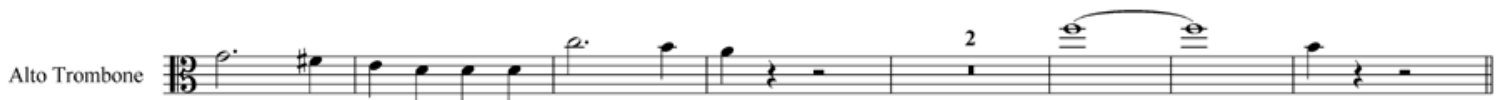

While conventional wisdom indicates that in this case Beethoven wrote this part specifically for alto trombone due to the unusually high range, recent scholarship indicates otherwise. According to Howard Weiner, Gluck — the composer whom Guion says had a significant influence on Beethoven in his orchestration of the trombone ${ }^{126}$-was writing the same note for the tenor trombone in his opera Alceste, 41 years before Beethoven wrote Symphony \#5. ${ }^{127}$ The passage is playable—with effort—on a modern tenor trombone, but the tone color

\footnotetext{
${ }^{126}$ David Guion, “What Handel Taught the Viennese about Trombone,” Historic Brass Society Journal 15, 292.

${ }^{127}$ Howard Weiner, Ibid., 64.
} 
of the instrument is inappropriate, due to its larger mouthpiece, bell and bore. The tenor instrument of Beethoven's time-again according to Weiner-would have required significantly less effort, and would have had the appropriate sound, owing to its narrower bore, bell, and smaller mouthpiece, as compared to its modern counterpart. ${ }^{128}$

Example 27 also shows the rhythmic simplicities of the trombone section parts as opposed to those of the other sections. In measures four and five, beat four, only the trombones do not have the dotted eighth and sixteenth note rhythm (second violins and violas have a tremolo). This same trend continues throughout the passage:

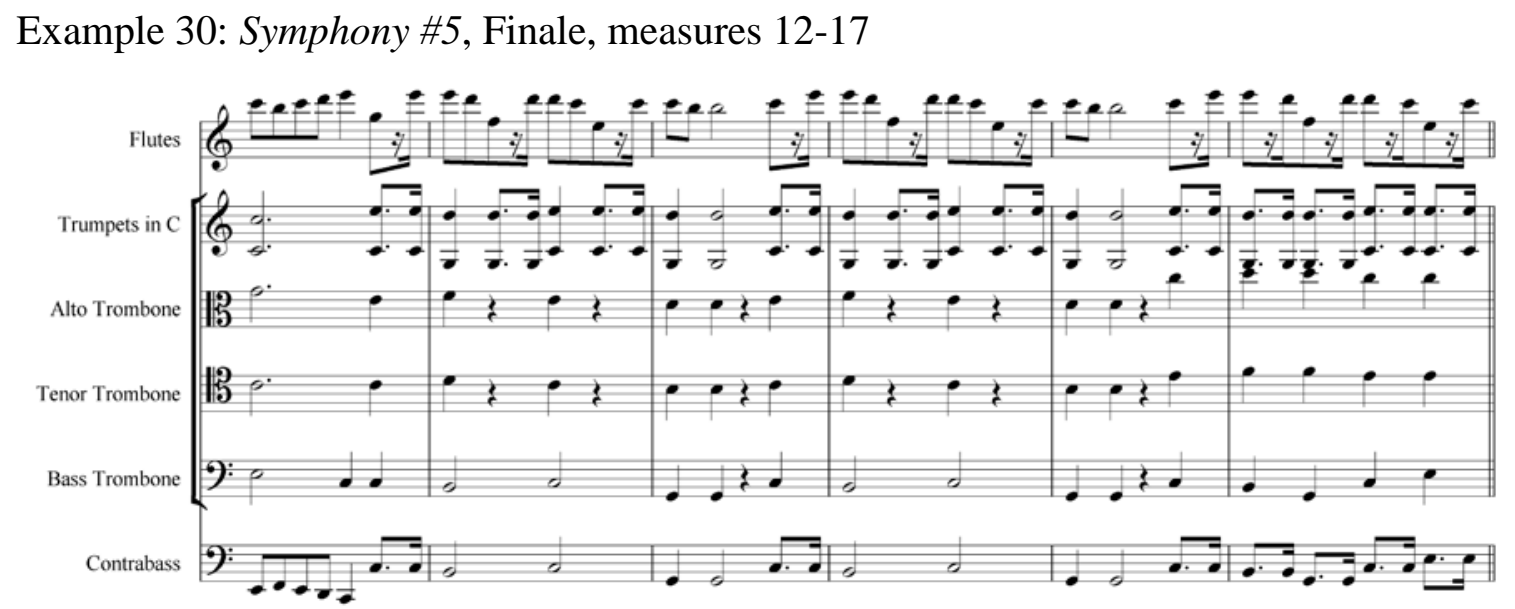

The rhythm of the trombones is always simplified and lengthened in comparison to the other sections - such as the flutes and trumpets-which again are shown as an example of the rhythm of the rest of the brass and woodwinds.

Guion believes that Beethoven was influenced by the French style of trombone writing in Symphony \#5 (and Symphony \#6):

Beethoven's trombone parts have less in common with the traditional Viennese manner of writing...than with the new style from France...French composers were severely limited in what they could expect of trombones because of the lack of expert players. French trombone parts therefore consist

\footnotetext{
${ }^{128}$ Weiner, Ibid.
} 
exclusively of the least interesting of the instrument's capabilities: doubling, rhythmic punctuation, harmonic filler, and making loud sounds. ${ }^{129}$

Guion's point is buttressed by comments from Maynard Solomon, who describes French Revolutionary music as having an influence on Beethoven. ${ }^{130}$ Some of the composers listed by Solomon include Cherubini, Méhul, Gossec, Kreutzer, and Berton. In fact, Solomon says that Beethoven’s “Heroic” style was “...a collaboration between Vienna and France.” 131 In addition, a common view of trombones at the time was that "Sustained notes can be expressed on this instrument as on no other in the world.” ${ }^{132}$ Therefore, a reduction of sustained pitches in the trombone parts - in an effort to reduce their dominance over the entire orchestra-would be considered good orchestration. On the other hand, referring to the Leonore fragment in Example 19, in the recent past-just two years prior to writing Symphony \#5-Beethoven did write trombone parts with the same level of rhythmic complexity as the other sections. In addition, notice in Example 30 that the trumpets-which match the rhythm of the horns_-also have simplified rhythms as compared to the woodwinds and violins. What other factors could explain the reason Beethoven trimmed not just the rhythm of the trombone parts, but also the rhythms of the other brass, in his Symphony \#5? A look at the end of his Eroica may shed some more light onto the issue:

Example 31: Symphony \#3, Finale, measures 452-455; 464-465

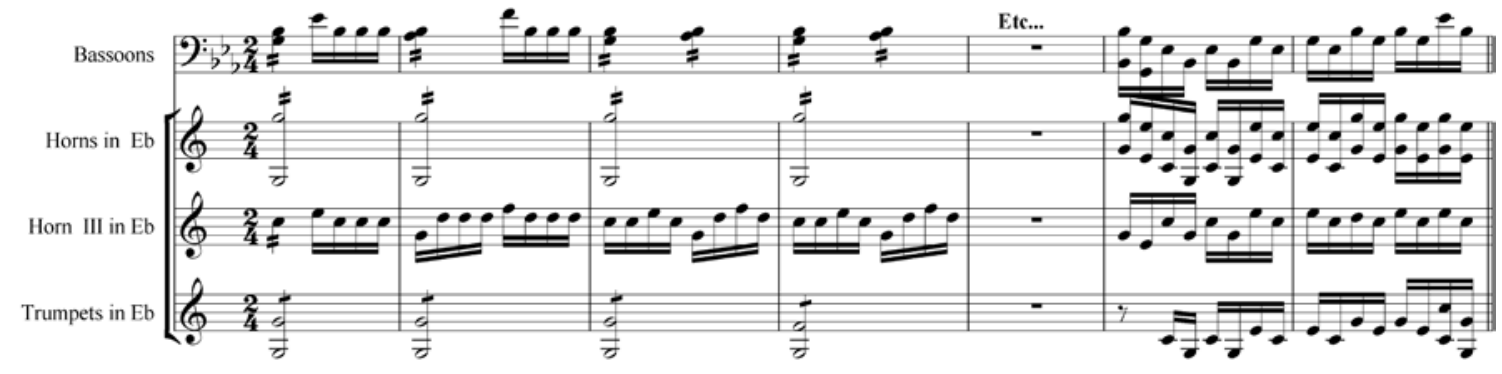

\footnotetext{
${ }^{129}$ David Guion, The Trombone: Its History and Music, 1697-1811 (New York: Gordon and Breach, 1988 ), 135.

130 Maynard Solomon, Beethoven, 179-180.

${ }^{131}$ Solomon, Ibid.

${ }^{132}$ Christian Schubart, Ideen zu einer Aesthetik der Tonkust, quoted in David Guion, The Trombone: Its History and Music, 1697-1811, 85. (Also quoted in Howe, 29.)
} 
This section, with its heavy, triumphal (heroic) ending, is orchestrated so thickly that almost the entire orchestra is playing sixteenth notes. In fact, only the timpani part does not have sixteenth notes. The idea is valid: a strong, rhythmic ending with forceful drive to the final bar. The actual result, however, is extremely difficult to achieve with so many instruments playing the exact same rhythm. Bombast is usually the result, unless the orchestra plays extremely lightly, which defeats the whole purpose of the ending. The Finale of Symphony \#5 has the same heavy rhythmic drive as the Finale of Eroica, but the effect is properly accomplished, exactly because not every instrument plays the same rhythm. Some sections play the complete rhythm (woodwinds and strings), some play part of the complete rhythm (trumpets and horns), and some play just the building blocks of the rhythm (trombones). The result is the creation of a heavy beat, balanced with the forward-moving drive; something not so easily accomplished with the scoring found in the ending of Erioca.

Symphony \#5 also includes what is probably best described as a trombone section solo, though it is shared with the bassoons:

Example 32: Symphony \#5, Finale, measures112-118

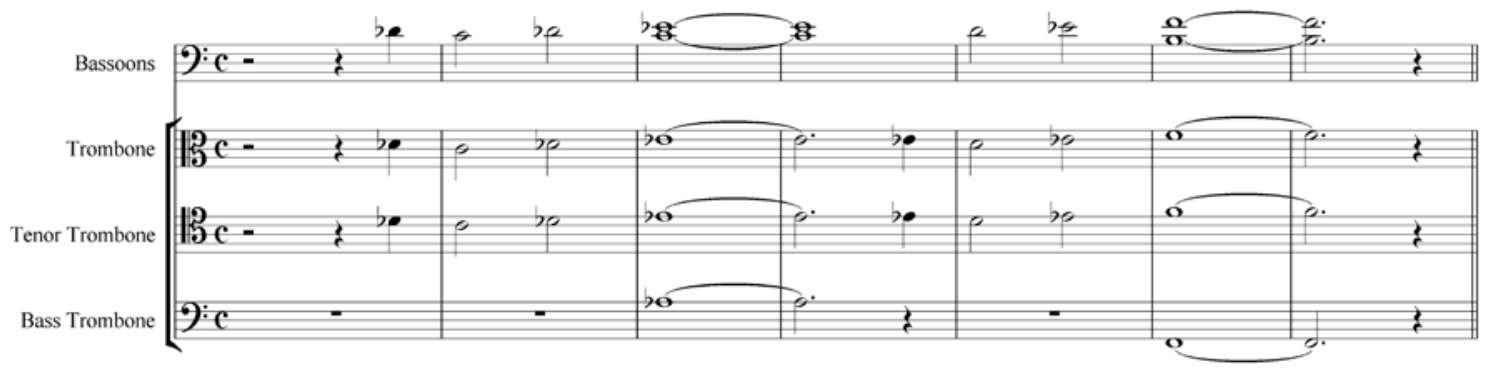

It is interesting that in this case Guion calls this passage a "moment of prominence." 133 But a momentary prominence is probably better described as just that: a note (or several notes) or a passing tone that can be heard peeking out of the fabric of the music for a brief moment. This particular passage in Example 32 is probably too important to be called a momentary

${ }^{133}$ Guion, The Trombone: Its History and Music, 1697-1811, 279. 
prominence. It is best described as a section solo, though obviously not a complete trombone section solo, since the bassoons play the same melody, and the horns-in measures 115116 - join in on the second phrase of the melody already established by the trombones (and bassoons). There is also another particular short but very effective momentary prominence in the alto trombone towards the end of the work:

Example 33: Symphony \#5, Finale, measures 289-294

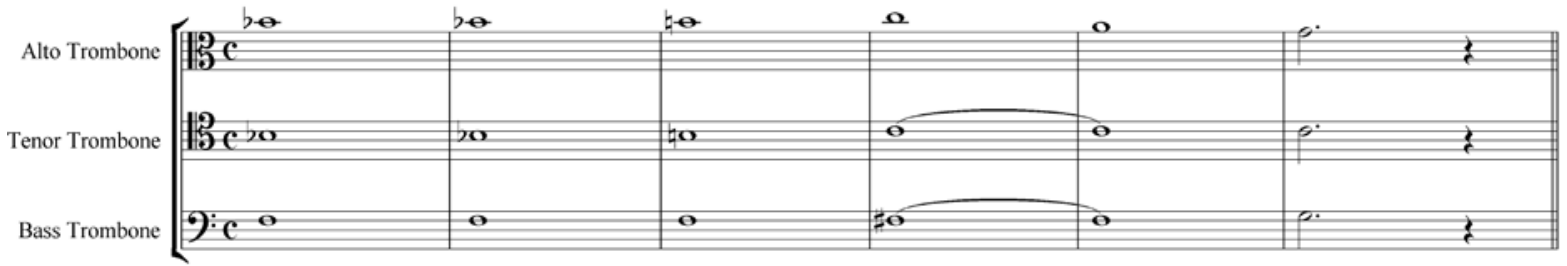

In the fifth measure of the example, the alto trombone moves to an $\mathrm{a}^{1}$ while all other instruments in the orchestra continue holding the note from the previous measures, as the tenor and bass trombones do. The alto is the only instrument changing notes in the measure. One other momentary prominence- -this time for the entire section—occurs in the coda:

Example 34: Symphony \#5, Finale, measures 386-390

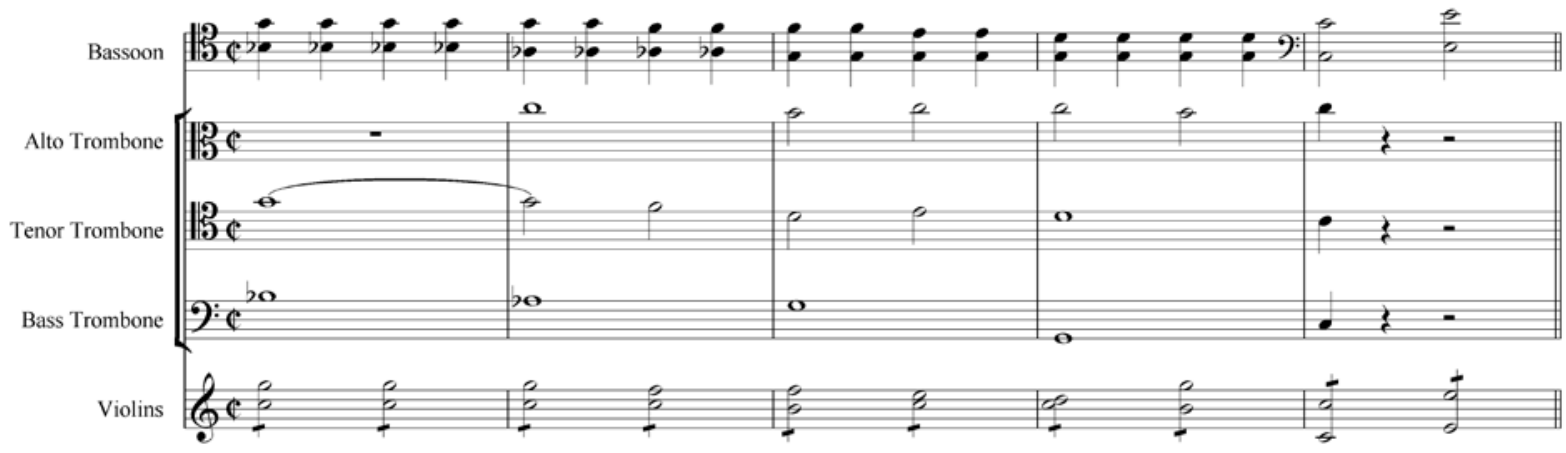

While the rest of the orchestra (with the exception of the flute, which follows the same idea as that of the trombones) has quarter notes, the trombone section enters with these chords, floating above the rhythmic activity in another moment of prominence.

In conclusion, while the trombone parts in Beethoven’s Symphony \#5 are not per se unique or particularly virtuosic, the fact that three trombones were included in the score of a 
symphony by a prominent composer of international fame is noteworthy and influential. The Beethoven imprimatur was crucial to the acceptance of the trombone section as a regular part of the orchestra from that time on. The particular style of the movement-one of jubilation - also contributed to the notion that the trombone section could be written to depict musical ideas other than death, the underworld, and ecclesiastical pomp. The rhythmic abbreviation of the trombone parts, while probably reflecting the French-influenced style of writing for trombones that was popular at the time, more importantly created a situation where the section contributed positively to the overall strong pulse of the movement, without any of the bombastic, overbearing rhythmic clutter found in earlier compositions.

\begin{tabular}{|c|l|c|l|l|c|c|c|}
\hline \multicolumn{7}{|c|}{ Table 7: Trombone Statistics for Symphony \#5, Opus 67 } \\
\hline \multicolumn{2}{|c|}{ Movements } & \multicolumn{5}{c|}{ Measures } & \multicolumn{3}{c|}{ Ranges } \\
\hline Total & \#Played & Total & \#Played & \%Played & Alto & Tenor & Bass \\
\hline 4 & 1 & 1566 & 214 & 14 & $\mathrm{a}^{\mathrm{b}^{1}}$ to $\mathrm{f}^{2}$ & c to $^{1}$ & $\mathrm{~F}_{\text {to c }}{ }^{1}$ \\
\hline
\end{tabular}

\section{Symphony \#6 (Pastorale), Opus 68}

Although the seeds of this work can be traced to a time even earlier than Symphony \#5-to 1803-the vast majority of it was composed in 1808. Symphony \#6 is one of a set of important works composed post-Leonore from 1806 to 1808, including Symphony \#4 and \#5, Opus 60 and 67, Concerto for Violin and Orchestra, Opus 61, Overture to Coriolan, Opus 62, and the Mass in C, Opus 86. Beethoven was composing Symphony \#5 and Symphony \#6 almost simultaneously in 1807-1808. This in itself is fascinating, for as Kinderman says:

The Fifth and Sixth Symphonies are not only sharply profiled individuals but are diametrically opposed to one another in conspicuous features of their structure and expression...the Fifth and Sixth Symphonies represent disparate musical worlds that ultimately complement one another. ${ }^{134}$

\footnotetext{
${ }^{134}$ William Kinderman, Beethoven (New York: Oxford University Press, 2009), 146.
} 
Both works were premiered at the Theater an-der-Wein on December 22, 1808. Other interesting historical events surrounding the premiere of Symphony \#6 can be found above, in the section discussing the premiere of Symphony \#5. The Pastorale Symphony, like Symphony \#5, seems to have been ill-received at first. Beethoven’s attempt at describingthrough music — the life of the Austrian country folk was met with epithets of "child's play, ${ }^{\circledR 35}$ especially in response to the second movement and its depictions of birds by a brook. It is commonly supposed that the Pastorale Symphony was an original attempt on Beethoven's part to portray nature in music. However, as Thayer has said, "It was never so much the ambition of Beethoven to invent new forms of musical works, as to surpass his contemporaries in the use of those already existing." ${ }^{136}$ Reis said that as far as music depicting nature is concerned, Haydn's The Creation and The Seasons were never far from Beethoven's mind as examples to surpass. In addition, Maynard Solomon has some more psychological insights into the work, which he calls “exceptional in Beethoven’s output:” 137

With the Pastorale Symphony, the working out of Beethoven's postHeiligenstadt projects seemed to be coming to a close. It was especially fitting that this cycle should terminate in idyllic repose, with an Arcadian conclusion to the heroic quest of the preceding half decade. Beethoven's struggles with fate-which is to say, with every embodiment of authority, domination, and mortality - were not yet at an end, but were temporarily set aside while he rejoiced in a...return to nature and childhood...” ${ }^{138}$

Symphony \#6-a five-movement work—only includes trombones in the fourth and fifth movements. Although this is twice the number of movements as the trombones play in Symphony \#5, the trombone parts in Symphony \#6 are significantly pared down and even less

\footnotetext{
135 Thayer, Life of Beethoven, 437.

${ }^{136}$ Ibid., 436. From the context of Thayer's remark, it is clear that in using the term "form" in this case, Thayer was not describing a musical form, such as Sonata Form, but instead he was using the term in a broader sense, such as to describe type or variety. This is borne out in the next paragraph on page 436, where the term "form" is used again in its broad sense, to describe type or variety.

${ }^{137}$ Solomon, Beethoven, 267.

${ }^{138}$ Solomon, Ibid., 266.
} 
interesting musically. In fact, the trombones play about one-third as much over two movements in Symphony \#6 as they do over one movement in Symphony \#5. Guion points out that the trombones were listed last—out of score order—on the original title page of Symphony \#6, suggesting that they were added as an afterthought, as was the case in earlier works already studied. ${ }^{139}$ This was common practice in the early Nineteenth Century. ${ }^{140}$ Another possible reason could have been one of practicality: for performances where trombones were unavailable, they could simply be omitted at minimal artistic cost. ${ }^{141}$

The score calls for only two trombones; but unlike Fidelio, where tenor and bass are required, in Pastorale the parts are for alto and tenor. Because scoring for alto and tenor was actually common in Viennese church music at the time, ${ }^{142}$ this pair was not so unusual. In fact, it was the tenor-bass pair found frequently in Christ on the Mount of Olives and in Leonore that was less common, but again not unknown. That the Symphony \#6 trombone parts were for alto and tenor could have been an indication of Beethoven's growing interest in the alto trombone, which had begun in the later productions of Leonore and increased significantly in Symphony \#5. As was the case in Symphony \#5, the trombones in Symphony \#6 remain silent for three movements, making their first entrance at the peak of the fourth movement's storm scene, ${ }^{143}$ where—in the words of Berlioz—-"the trombones burst forth": ${ }^{144}$

\footnotetext{
${ }^{139}$ Guion, The Trombone: Its History and Music, 1697-1811, 280.

${ }^{140}$ John Marsh, in his 1807 Hints to Young Composers of Instrumental Music, says, "The trombones being therefore not in general use, composers seldom insert parts for them in their scores, but leave them to be added afterwards...” (See Timothy Howe, "Developing a Historical Model for Trombone Performance Practice in German and Austrian Orchestra Works from the period 1785-1830,” D.M.A. Dissertation, University of Nebraska, 2002, 26.)

${ }^{141}$ Guion, on page 282, contends that instead of omissions of the entire parts, less accomplished trombonists could simply omit difficult notes or passages. Considering Guion's point, one is left to wonder about the abilities of such musicians who would be required to omit notes or passages from parts that are already quite simple even for nominally accomplished trombonists.

${ }^{142}$ Guion, The Trombone: Its History and Music, 1697-1811, 137. See also Weiner, "When is an Alto Trombone an Alto Trombone?...”, 61.

${ }^{143}$ Which is replete with the tone-painting piccolo, depicting lightning (see Kinderman, Beethoven, 148).

${ }^{144}$ Hector Berlioz, Beethoven (Boston: Crescendo Books, 1975), 33.
} 
Example 35: Symphony \#6, Fourth movement (“Storm”), measures 106-111

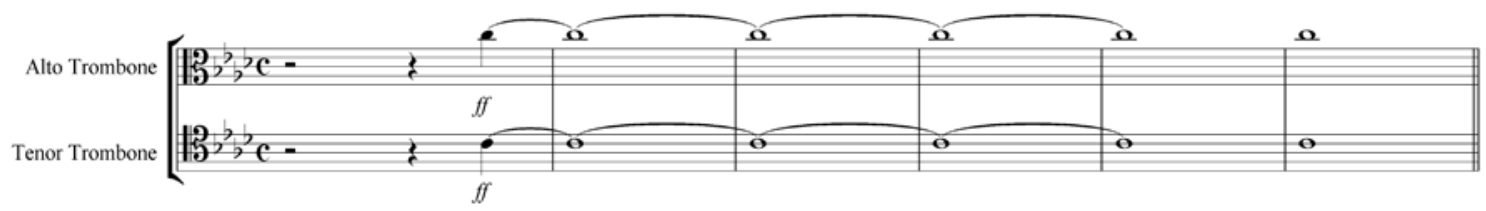

The trombones here, and throughout the movement, are written in octaves. They double the flutes, oboes, timpani, and first violins on the $\mathrm{C}$, with other instruments filling in the rest of the diminished chord. A similar style of scoring — trombones playing diminished chords with full orchestra-was found in Fidelio/Leonore, shown above in Example 11. The difference is that in Fidelio, the trombones are in tenths; in Symphony \#6, the trombones are in octaves.

The Finale includes some other techniques which have now become familiar. First, the "rhythmic abbreviation” technique from Symphony \#5 returns, where the trombones do not play as complex a rhythmic pattern as the other instruments. In this case the trumpets and horns are shown as well, to compare the more complex rhythm they play with that of the trombones. The final bar of the example has longer note values in the trombones:

Example 36: Symphony \#6, Finale, measures 28-32

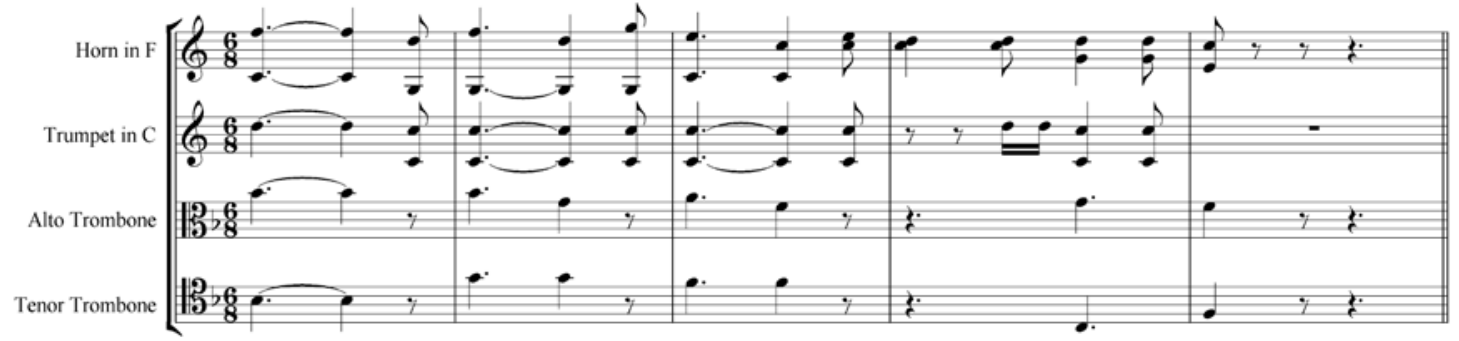

This longer note value is interesting, for by writing the longer value, Beethoven in effect was giving instructions to the trombone section to release their note after the rest of the orchestra. Given Beethoven's likely awareness of the description of trombone sostenuto by Schubart (quoted in both Howe and Guion ${ }^{145}$ ), Beethoven must have wanted the notes played by the trombones in this instance to be clearly heard. Notice too in this example the prevalence of

145 “Sustained notes can be expressed on this instrument as on no other in the world.” (See supra fn. 132.) 
thirds between the two trombones. The fifth movement of Symphony \#6 has the trombones playing in thirds more than any other interval.

The next example has both a momentary prominence and rhythmic abbreviation. The rhythmic play between the trumpets and trombones creates the prominence:

Example 37: Symphony \#6, Finale, measures 46-49

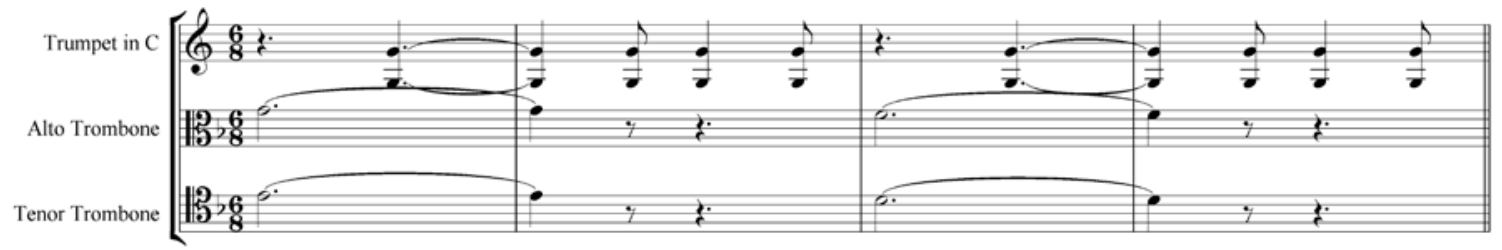

The final example from the symphony may represent a new technique. The trombones begin a melody on the downbeat of each measure- - using the abbreviated rhythm technique already seen in this work and Symphony \#5-and the horns complete the melody using more complex rhythms. The trumpet parts are added to show the rhythmic differences in this passage. Notice also the final note of the example. The trombones have a longer note value than any other instruments in the orchestra, except for the string bass (not shown):

Example 38: Symphony \#6, Finale, measures 132-139

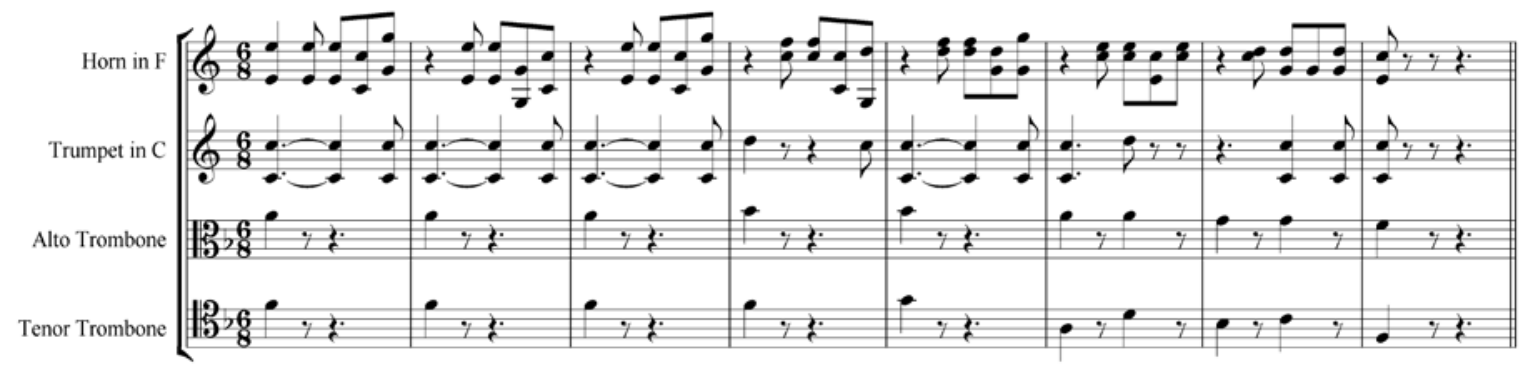

Since the (non-chromatic) horns at this point in the music have the ability to play the note played by the trombones, Beethoven did not insert the trombones on the downbeats to provide a note the horns could not play. It is clear that he wanted the unique color of the trombones at this point to provide the downbeat of each measure of the horn melody. On the 
other hand, this could simply be another example of the trombone section providing tutti downbeats—a common technique already encountered.

In conclusion, the trombone writing in Symphony \#6 is the least complex of any of the works yet examined. While the parts in Symphony \#6 include examples of what is beginning to be considered customary Beethovenian orchestrational techniques for trombonesrhythmic abbreviation, doubling the woodwinds, octave playing, use of thirds and sixths, and longer note values - the complexity of the trombone parts is significantly below that of any of the previous works studied. It is as if the trombones in Symphony \#6 were even less than an afterthought, and could be considered "optional." If this was indeed the case, some composers—Chopin, for one—followed Beethoven's example and included a single optional bass trombone part in many of their works, especially their concertos. Finally, the possible addition of a new orchestrational technique, labeled melodic completion, is noted in Example 38, near the end of the work. Actually, this technique might more accurately be called "melodic commencement," since it is the trombones that begin the melody, with the completion of the melody in the horns. However, this could also be another example of the trombones providing tutti downbeats. Whether or not this is a new melodic completion technique or standard tutti downbeats will probably be more easily determined if other examples occur in works not yet studied.

\begin{tabular}{|c|l|c|l|l|c|c|c|}
\hline \multicolumn{7}{|c|}{ Table 8: Trombone Statistics for Symphony \#6, Opus 68 } \\
\hline \multicolumn{3}{|c|}{ Movements } & \multicolumn{3}{|c|}{ Measures } & \multicolumn{3}{c|}{ Ranges } \\
\hline Total & \#Played & Total & \#Played & \%Played & Alto & Tenor & Bass \\
\hline 5 & 2 & 1334 & 73 & 5 & f to $^{2}$ & c to g $^{1}$ & N/A \\
\hline
\end{tabular}




\section{Chapter IV}

\section{Non-Orchestral Works}

\section{Three Equali, WoO 30}

Before discussing the fascinating history of the creation of Three Equali, it is necessary to describe what an "equale" is or what "equali" are. The Oxford Companion to Music defines equale as:

A work in which instruments or voices of the same type play each part. In Austria during the 18th century and the early 19th the term denoted a type of short piece played, usually by four trombones, at a funeral service. ${ }^{146}$

As the definition indicates, equali were well-known in Austria, especially in Linz. In fact, Linz Cathedral Kapellmeister Franz Xaver Glöggl, in his book Church Music Regulations, describes the highest class of funerals this way:

In the first class, the arrival of the clergy is announced by a short funeral piece (equale) with trombones or other wind instruments as a sign of the sacred funeral act for those present. After its completion, the funeral procession begins to move. ${ }^{147}$

According to the Grove's Dictionary of Music, the only well-known example of this genre is the Beethoven Three Equali, ${ }^{148}$ and possibly Two Equali by Linz native Anton Bruckner. ${ }^{149}$

Beethoven composed Three Equali while visiting his brother Johann in Linz during the Autumn of 1812. The past several months had been particularly difficult for Beethoven, both physically and emotionally. He had been busy traveling that summer and had been away from Vienna for several months. The summer of 1812 was also the emotionally-

\footnotetext{
${ }^{146}$ Bellingham, Jane, “Equale,” The Oxford Companion to Music. Ed. Alison Latham. Oxford Music Online, <http://www.oxfordmusiconline.com/subscriber/article/opr/t114/e2296> (2009), accessed 12 June, 2009.

${ }^{147}$ Howard Weiner, “Beethoven’s Equali (WoO 30): a New Perspective,” Historic Brass Journal 14 (2002), 227.

${ }^{148}$ Maurice J.E. Brown, “Equale,” Grove Music Online, Oxford Music Online, $<$ http://www.oxfordmusiconline.com/subscriber/article/grove/music/08899> (2009), accessed 12 June 2009.

${ }^{149}$ Bellingham, Ibid.
} 
draining culmination of Beethoven’s love affair with the "Immortal Beloved"-most likely Antonie Brentano-a Viennese of aristocratic birth who almost abandoned her marriage to Frankfurt merchant Franz Brentano to become Beethoven’s lover. ${ }^{150}$ Before returning to Vienna, Beethoven, after the harrowing summer, visited Linz. In fact, Solomon opines that the reason Beethoven tarried in Linz was to avoid witnessing the departure of the "Immortal Beloved" from Vienna. ${ }^{151}$ Kapellmeister Glöggl announced in the Linzer Musik-Zeitung that Beethoven had arrived in Linz sometime before October 5:

Now we have had the long wished for pleasure of having within our metropolis for several days the Orpheus and great musical poet of our time, Herr L. van Beethoven; and if Apollo is favorable to us we shall also have an opportunity to admire his art and report upon it to the readers of this journal. ${ }^{152}$

While some of the events surrounding Beethoven's visit are vague, Thayer contends that one of the main reasons for his visit to Linz was most likely to attempt to stop his brother from marrying. There were rumors in Vienna of his brother Johann's impending marriage to Therese Obermeyer, ${ }^{153}$ a woman Johann had been living with, and who was the niece of a couple to whom he was renting part of his house. Thayer suggests that Beethoven, fearing difficulties similar to those he had with his other brother's wife, sought to intervene. ${ }^{154}$ However, Solomon implies Beethoven’s recent “Immortal Beloved” experience was one of the reasons he so vehemently objected to his brother's marriage: "If the eldest brother was unable to have his own woman, why should this be permitted to the youngest?” 155 Johann refused to heed his older brother's advice to break off the affair, which enraged Beethoven. Solomon fills in some more details of the disturbing domestic affair:

\footnotetext{
${ }^{150}$ For a fascinating discussion on the history and identity of the "Immortal Beloved," see Solomon, Beethoven, 207-246.

${ }^{151}$ Solomon, Beethoven, 239.

${ }^{152}$ Thayer, Life of Beethoven, 540.

${ }^{153}$ Ibid.

${ }^{154}$ Ibid, 541.

${ }^{155}$ Solomon, Ibid., 282.
} 
His brother refused, whereupon Beethoven, enraged, visited the bishop and the civil authorities, finally obtaining a police order compelling Therese to leave Linz should the illicit relation continue. Nikolaus Johann's response was to marry Therese on November $8 .{ }^{156}$

Apparently, this was when Beethoven turned to Glöggl for help in this difficult situation, and asked him to serve as a mediator of sorts. ${ }^{157}$ Glöggl—being on staff at the Linz Cathedral— no doubt had influence with the religious authorities, and in any event was thoroughly acquainted with Beethoven's brother, referring to him as a "wretched human being." 158 It was Glöggl for whom Three Equali was written. Glöggl’s son Franz elaborated:

Beethoven was on intimate terms of friendship with my father, Kapellmeister of the cathedral in Linz, and when he was there in 1812, he was at our house every day and several times took meals with us. My father asked him for an Aequale for 6 trombones, as in his collection of old instruments he had a soprano and a quart ${ }^{159}$ trombone, whereas only alto, tenor, and bass trombones were commonly used. Beethoven wanted to hear an Aequale such as was played at funerals in Linz, and one afternoon when Beethoven was expected to dine with us, my father appointed three trombone players and had them play an Aequale as desired, after which Beethoven sat down and composed one for 6 trombones, which my father had his trombonists play, etc. ${ }^{160}$

The mention of " 6 trombones" is likely a mistake on the part of Franz Glöggl, who recounted the event to Thayer almost sixty years later. ${ }^{161}$ Since both Glöggl men could play trombone, one of them probably completed the visiting trombone trio to make a quartet, ${ }^{162}$ thereby providing Beethoven with an example of an equale, immediately after which he proceeded to write his own Three Equali, perhaps as repayment for the Kapellmeister's help during his

\footnotetext{
${ }^{156}$ Solomon, Beethoven, 282.

${ }^{157}$ Howard Weiner, “Beethoven’s Equali: A New Perspective,” Historic Brass Society Journal 14 (2002), 217.

${ }^{158}$ Weiner, Ibid.

${ }^{159}$ A "quart" trombone was another name for a bass trombone, usually pitched a fourth lower than the tenor trombone. (See Trevor Herbert, The Trombone [New Haven: Yale University Press, 2006], 36.)

${ }^{160}$ Thayer, Life of Beethoven, 541.

${ }^{161}$ However, the Critical Edition of the Three Equali states that Beethoven had composed "more than the three surviving Equali.” It also quotes a letter of Glöggl to Robert Schumann mentioning another Equale, which "must be regarded as lost." (See introduction to Three Equali, Beethoven Werke VI; 1, trans. Richard Scruggs, [Munich: Henle, 2008], 365.) Weiner opines this might be the Equale for 6 trombones that the Gloggl son mentioned to Thayer. Weiner has other interesting and provocative observations regarding the "lost Equale." (See Weiner, "Beethoven’s Equali: A New Perspective,” Historic Brass Society Journal 14 [2002], 233-234.)

${ }^{162}$ Weiner, Ibid., 216
} 
embarrassing family fiasco. The first of the Three Equali appears in its entirety below:

\section{Example 39: Equale 1 from Three Equali ${ }^{163}$}
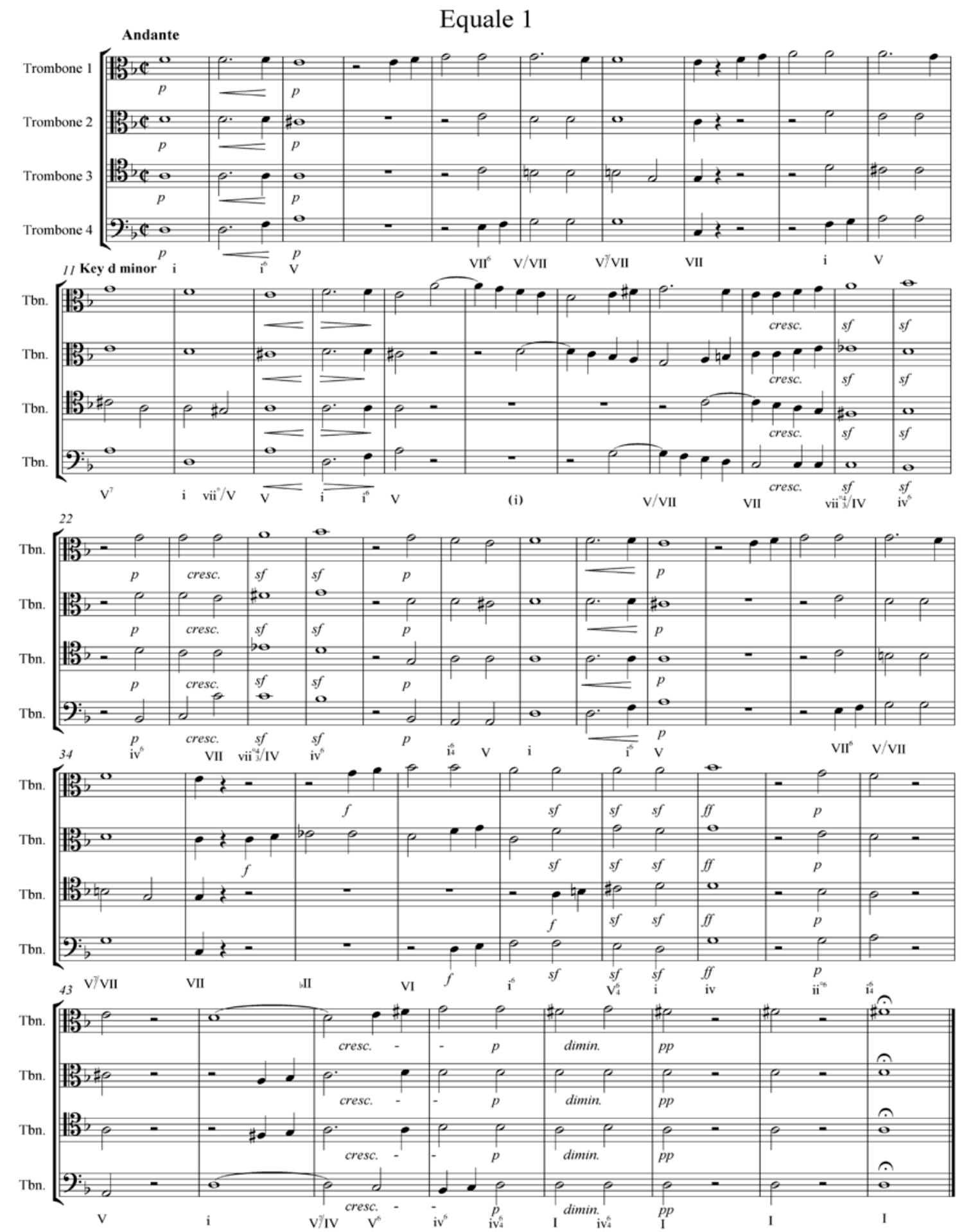

${ }^{163}$ The Three Equali shown in this chapter are engraved from Beethoven's original handwritten manuscripts. (See Beethoven Haus-Bonn Website <http://www.beethoven-haus-bonn.de> (2009), accessed 15 July 2009.) 
The total range in Equale 1 is from A in the fourth part to $b^{b^{1}}$ in the first part. The span of the four parts tends to stay within a tenth, and never exceeds two octaves (seen in measure 21). The piece is in the key of $d$ minor throughout, except at the end, where it ends in D Major. However, there could be an argument made for a brief tonicization of the subtonic C major in measures 6-8, and in the recapitulation, measures 33-35. In this piece, the parts either work together as a quartet, as in the first three measures, or they interact individually, as in measures 15-18. (Not until Equale 3 is there an example of the parts working in pairs.) The piece contains examples of counterpoint "reminiscent of Renaissance harmonies," ${ }^{164}$ which Beethoven studied under both Haydn and Albrechtsberger. ${ }^{165}$ The parts tend toward close position in measures 1-3 (and again in measures 12-14), then expand to the full intervallic breadth of the piece — two octaves—in measures 19-21 (and again in measures 22-25). While all three of the Equali are mainly chordal in structure (most melodic lines that can be heard are the product of the four-part chord progressions-another allusion to a Renaissance compositional technique), Equale 1 has the most number of passages that could be considered homophonic. Such melodic fragments can be heard in measures 4-5, beginning in the first trombone part. They are then passed among the various parts in measures 8 and 9, with the upward motion in the first and fourth trombones. The resolving downward motion, with the melodic fragments embellished and lengthened, is then found in all four parts in measures 15-19. The opening is repeated starting in measure 28, but the upward motion that begins again in measure 31 is never really resolved to downward motion. The piece ends in D Major, but it is slightly unstable due to the unresolved forward motion and the minor iv chords in measures 46 and 47 , instead of a $\mathrm{V}^{7}$ chord creating a more

\footnotetext{
${ }^{164}$ Thomas Scherman, "Three Equali," in Beethoven Companion, ed. Thomas Scherman and Louis Biancolli (Garden City: Doubleday and Co., 1972), 747.

${ }^{165}$ Solomon, Beethoven, 91, 97, 391.
} 
definitive dominant-tonic cadence. The final plagal cadence again hearkens back to the Renaissance. The next Equale Beethoven wrote is below:

Example 40: Equale 2 from Three Equali ${ }^{166}$

\section{Equale 2}
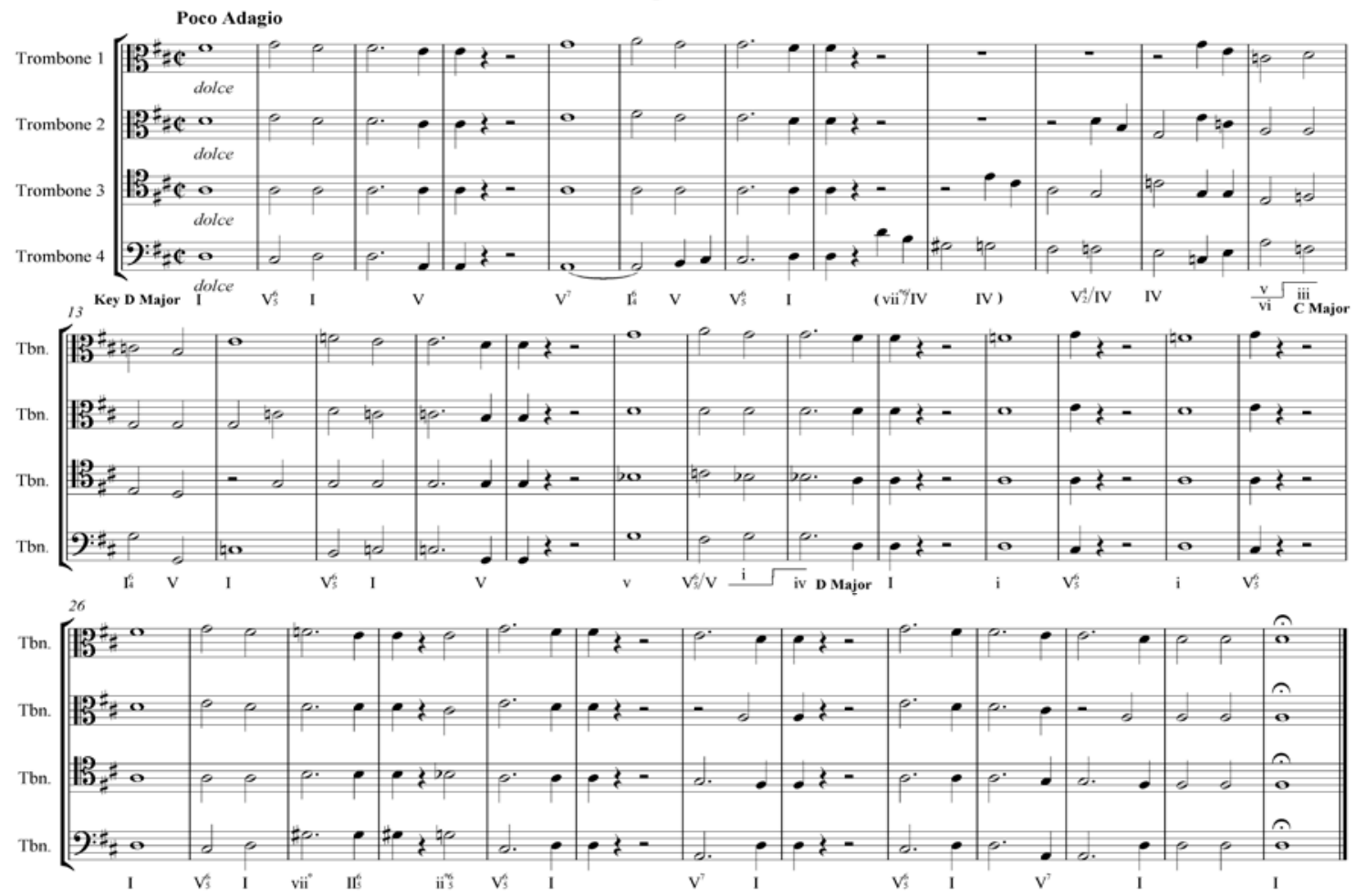

The range of Equale 2 is similar to that of Equale 1: from $\mathrm{G}$ in the fourth trombone to $\mathrm{a}^{1}$ in the first part. The overall span of the four parts, while tending to again hover around a tenth, tends to open to intervals wider than the tenth more often than does Equale 1. The style is softer and gentler ${ }^{167}$ than Equale 1. The thematic material of Equale 2 is clearly derived from Equale 1. For example, the basis of the first four measures of Equale 2 can be seen in the first three measures of Equale 1, while measures 8-11 of Equale 2 can be seen in measures 15-18 in Equale 1. One significant difference between Equale 2 and the others is that there is a true modulation to a different key—in this case C Major-in measure 14. This

\footnotetext{
${ }^{166}$ The autographs have a mistake in measure 13 of the first trombone part. Apparently in this measure, Beethoven "slipped into tenor clef.” (See Weiner, Equali, Ibid., 234.) The above rendering has been corrected. ${ }^{167}$ Scherman, Ibid.
} 
is probably another example of the derivative nature of Equale 2: whereas Equale 1 has a simple tonicization of C Major, Equale 2 fully modulates to C Major, ${ }^{168}$ modulating back to the home key of D Major in measures 19-20. The other two Equali stay in their respective home keys throughout, with the exception of Equale 1's aforementioned brief tonicization of the subtonic. Another difference in Equale 2 can be seen in measures 32 and 36 . The second trombone has its own momentary prominence, entering on the second beat alone, where the other three parts had already entered on beat one. In addition, of the three pieces, Equale 2 is the only one where parts cross in registers, found in measures 10-12. Finally, the only instance of a passing tone—again reminiscent of Renaissance compositional techniques—can be seen in Equale 2, measure 6, in trombone four. Equale 2 seems to have the most satisfying final cadence of the three pieces, due to the clear $\mathrm{V}^{7} \rightarrow \mathrm{I}$ perfect authentic cadence at the end, and the close position of the final chord. The third and final Equale is below:

Example 41: Equale 3 from Three Equali

Equale 3
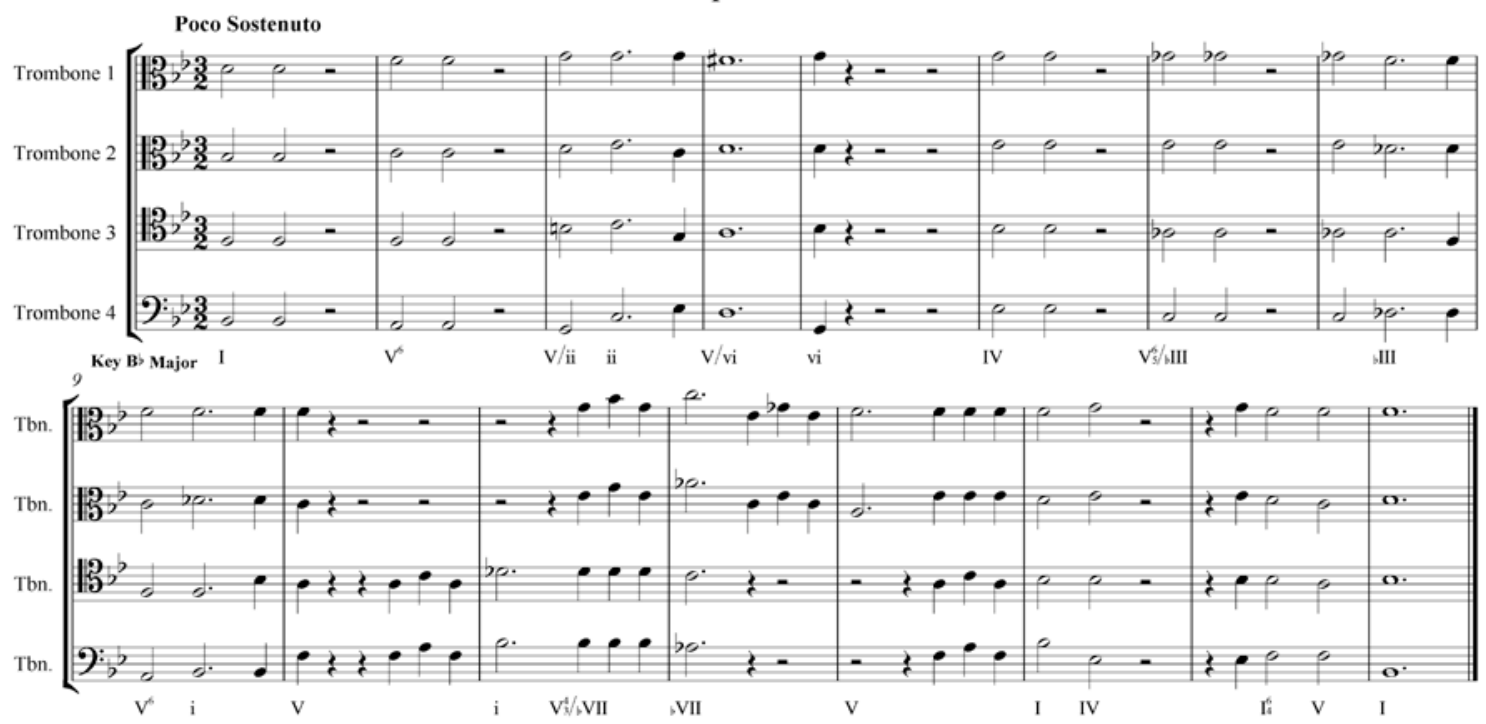

${ }^{168}$ The justification for Equale 2 possessing a modulation and Equale 1 only having a tonicization is threefold: 1) The accidentals indicating a new key remain in Equale 2 for several measures, not just one or two measures an in Equale 1;2) There is a clear cadence in the new key (Equale 2, measure 14); and 3) the new key remains long enough for the ear to become accustomed to it (which is the case in Equale 2 but not Equale 1). 
Equale 3 has the widest tessitura of the three, with the lowest note, G, in the fourth trombone, and the highest note, $\mathrm{c}^{2}$, in the first part. However, the tessiturae of the other two Equali are only smaller by a whole step (Equale 1) and a minor third (Equale 2). Equale 3 is in the key of $\mathrm{B}^{b}$ Major throughout, and absent any modulations or tonicizations. In fact, this piece is the simplest of the three, both harmonically and melodically. Still, it does have qualities the others do not possess. First, only in Equale 3-in measures 10-13 - do the trombones play in pairs. Trombones three and four pair off in measures 10-11, trombones one and two in measures 12-13. Second, it is the only Equale in triple meter-in this case $3 / 2$ time. The other two are in 2/2 time. The overall pulse of Equale 3 is probably best executed with a heavier and more distinct feeling than the other two Equali. The tempo marking, Poco Sostenuto, is not as much a tempo marking as an indication of how long to play the opening notes. Although the piece is short—almost perfunctory—it fits as the closing epilogue following the other more substantial Equali 1 and 2. "It is the most solemn and moving of the three." ${ }^{169}$ The final cadence is similar to that of Equale 2, but not as strong, despite the familiar $\mathrm{I}^{6} / 4 \rightarrow \mathrm{V} \rightarrow \mathrm{I}$ cadence, probably because of the suddenness of the cadence following movement from the tonic to the subdominant in measure 14, and because the first trombone ends on the fifth of the chord, making the cadence imperfect authentic.

Neither Beethoven's manuscript nor any of the early editions ${ }^{170}$ of the Equali specify alto, tenor, or bass trombone. Perhaps to encourage the idea of equal voices, the instruments were not specified. The style of the pieces is choral, with no particular part having prominence over the others. In fact, although a melody can be distinguished at timesespecially in Equale 1-for the most part the melody is created by the harmonic motion. In

\footnotetext{
${ }^{169}$ Scherman, Ibid.

${ }^{170}$ One edition of Equali 1 and 3 was published in 1827.
} 
other words, these pieces do not rely on a texture of melody and accompaniment. Each of the three pieces - especially Equali 2 and 3-employs silences where the entire quartet rests. This technique allowed the chords played to echo freely without clashing with the following chords. While the sound would be effective in an outdoor setting - which these pieces were probably written for ${ }^{171}$ — the effect would be multiplied even more in a cathedral setting.

Each of the Three Equali has their distinctive traits and interesting details, as was discussed above. However, one other particularly interesting point seen in the original manuscripts still needs further discussion. Equale 1 has by far the largest amount of musical expression markings — such as dynamics and accents—of the three. In fact, Equale 2 only has dolce written in as a performance instruction, and Equale 3 has no instructions apart from the tempo marking, which, as mentioned above, is not really a tempo marking at all. ${ }^{172}$ Guion notes this peculiarity as well:

In his "Drei Equali für vier Posaunen” (WoO 30, 1812), each movement is shorter, less carefully marked in terms of dynamics and articulations than the one before, almost as if Beethoven were in a hurry to finish a commission he did not much care about. ${ }^{173}$

In fact, with the exception of dolce in the beginning of Equale 2, there are no musical expression markings in the second and third Equali whatsoever. Weiner puts it this way:

Beethoven's handwriting becomes larger and clearly more hurried in the course of the manuscript. The first page contains forty-one measures, with seven to nine measures on a line; the second page has twenty-one measures with six on each full line; the third page, twenty-six measures with five to six on each full line; and the fourth page, sixteen measures with three to four on each full line. Comparing the last page to the first, one can almost sense Beethoven's growing impatience, his desire to be done with this task. ${ }^{174}$

\footnotetext{
${ }^{171}$ Weiner asserts that "Glöggl’s Church Music Regulations make it clear that equali were intended to be played in the open air," and he includes a reproduction of a Stöber watercolor of Beethoven's funeral procession, showing trombones outside in the open air playing the Three Equali (see Weiner, "Equali,” Ibid., 228, 241).

${ }^{172}$ All markings in the Public Domain autographs - which are in the State Library in Berlin - are reflected in the scores reproduced in this paper.

${ }^{173}$ Guion, The Trombone: Its History and Music, 1697-1811, 282-283.

${ }^{174}$ Weiner, “Equali,” Ibid., 234.
} 
Both Guion and Weiner suggest that the reason for fewer marks as the manuscript progresses was due to a desire to finish the project. However, Weiner also suggests a possibility that the “...change in handwriting [was] caused by growing excitement on Beethoven’s part.”175 There could be an explanation for the reduction in the attention to the details during composition that reconciles both these assertions. According to Glöggl's son, Beethoven was invited that day to the Glöggl home to share a meal and to listen to a group of trombones play some equali. If Glöggl's son was at least partially accurate in his description of the events of the visit, then after Beethoven listened to the trombones, he immediately composed a piece for them (presumably Equale 1) — with more attention to detail since it was the first piece he wrote- which the trombones then immediately performed. ${ }^{176}$ If that were the case, then obviously Equale 2 would be more hurried than Equale 1, since Beethoven would be writing Equale 2 to be played immediately after its completion. The same goes for the writing of Equale 3, but probably on an even more rapid scale than Equale 2. This would explain why there are no dynamic markings in either Equale 2 or Equale 3, and also why Equale 3 appears to be even more hurried in the autographs ${ }^{177}$ —and shorter—-than Equale 2.

It is well-known that two of the Equali-Numbers 1 and 3-were set to words and performed at Beethoven's funeral on March 29, 1827. ${ }^{178}$ These two Equali were alternatively sung by four-part male chorus and played by trombones during the funeral procession. Weiner describes this arrangement of two of the Three Equali as:

...transposed down a tone, with the Latin and German texts "Miserere mei/Ach erbarme Schöpfer" (Equale 1) and "Amplius lava me/Reinige Vater mich” (Equale 2) set for four men's voices and optional accompaniment by

\footnotetext{
${ }^{175}$ Weiner, Ibid.

176 Thayer, Life of Beethoven, 541.

${ }^{177}$ Referring to the original autographs of Three Equali, Weiner says "Beethoven's handwriting becomes larger and clearly more hurried in the course of the manuscript” (Weiner, “Equale,” Ibid., 234).

178 Ibid., 1054.
} 
four trombones or piano...It is surely not necessary to point out that the choice of text and its performance in alternation with an ensemble of trombones correspond exactly to Glöggl's description of a "funeral of the first class." ${ }^{179}$

The first Equale and accompanying "Miserere" text were again performed at requiem services honoring Beethoven on April 3 and April 26, 1827. The "Miserere" also turned up in Nuremberg at a memorial concert held on the first anniversary of Beethoven's death. ${ }^{180}$ Equale 2, set to a text by Franz Grillparzer, was performed in early November 1827, at the dedication of Beethoven's gravestone. In addition, Equale 2 with the Grillparzer text was performed in Vienna at the one-year and the two-year anniversaries of Beethoven's death. All three Equali with vocal parts were eventually published by Tobias Haslinger: Equali 1 and 3 in 1827 and Equale 2 in 1829. The Equali became very popular pieces following Beethoven's death, with publications in other European countries following in 1828-1830.

To conclude, Three Equali is an improbable, almost contradictory work. Composed during an excursion likely filled with strife and anger, the three pieces evoke peace and tranquility. Written hurriedly and probably all but forgotten by Beethoven, they were resurrected fifteen years later to become indispensable in the solemnities surrounding his death. Composed on the fly at a dinner with friends, they became one of the pillars of nineteenth-century trombone chamber music. Three Equali represents another example of Beethoven looking back to earlier time periods, in this case the Renaissance. (In a later chapter, it will be the Baroque and Handel in Consecration of the House.) The Equali are written in the Renaissance style, with block chords, counterpoint, and passing tones; however, the harmonic activity is classic-romantic, with unambiguous cadences, chromatic movement, and modal borrowing. The parts are simple—almost pedestrian—yet the musical

\footnotetext{
${ }^{179}$ Weiner, “Equale,” Ibid., 239.

${ }^{180}$ Ibid., 241.
} 
effect when performed is elegant and touching. The individual trombone parts contain no technical challenges, but nevertheless each part has a particular passage, chord member, or note that makes it interesting to execute and rewarding to hear. Sequentially, each of the Three Equali is less complicated; yet it is Equale 3 that is the most musically sublime. These three short, simple chorale-style works represent the genius of Beethoven, who in a postluncheon respite could create from a few simple ideas music of such enduring beauty.

\begin{tabular}{|l|l|c|l|l|c|c|c|c|}
\hline \multicolumn{7}{|c|}{ Table 9: Trombone Statistics for Three Equali, WoO. 30 } \\
\hline \multicolumn{3}{|c|}{ Movements } & \multicolumn{5}{c|}{ Ranges } \\
\hline Total & \#Played & Total & \#Played & \%Played & $\mathbf{1}$ & $\mathbf{2}$ & $\mathbf{3}$ & $\mathbf{4}$ \\
\hline 3 & 3 & 104 & 104 & 100 & b to c $^{2}$ & g to a $^{1}$ & d to e $^{1}$ & G to d $^{1}$ \\
\hline
\end{tabular}

March in D for Military Band, WoO. 24

The Military March in D was composed in late Spring, 1816 for the Civil Artillery Corps Band in Vienna, at the request of Lieutenant Commander Franz Xaver Embel. He had written to Beethoven, saying, “The Artillery Corps begs for the honor of a March for Turkish Music from the pen of the distinguished Herr Louis van Beethoven.”181 At the time, the Viennese were fascinated with Turkish, or as it was called, "Janissary” music, with its prominent orchestration for triangle, bass drum, cymbals, and other percussion instruments. ${ }^{182}$ The march was premiered under the title "March No. 4 for Grand Military Parade,” at a military parade in Vienna on June 3, 1816. ${ }^{183}$ The first three marches of the four were shorter military tattoos written around 1809-1810, and do not include trombones in the

\footnotetext{
${ }^{181}$ Thomas Scherman, “March in D for Band,” in Beethoven Companion, ed. Scherman and Biancolli, 622.

182 Bruce Gleason, “A Guide to Teaching Beethoven’s Marches,” Music Educators Journal, Vol. 82, No. 4 (Jan., 1996), 19.

${ }^{183}$ Gleason, Ibid.
} 
score. ${ }^{184}$ Beethoven offered the suite of four marches (with newly-composed trios for the three shorter tattoos) for publication by Peters in $1823,{ }^{185}$ at a time when he was in some financial difficulty. Peters rejected the suite, along with some other miscellaneous songs Beethoven had offered as well. ${ }^{186}$ The March was not published until after Beethoven's death, and then only in an arrangement by Czerny for Piano four hands. It was not until 1864 that the March was published in its original orchestration by Breitkopf and Härtel. ${ }^{187}$

The Military March in D is the longest, most thickly scored, and most sophisticated and ambitious of all the various military music Beethoven wrote (which was about eight pieces). ${ }^{188}$ He even wrote out the recapitulation of the march in full, indicating that he wanted all repeats played during the Da Capo of the march (which was contrary to tradition). March in $D$ is also the only wind band piece that includes trombones, and as far as can be determined, it is the only composition in which Beethoven included an instrument called a Serpent (the forerunner of the tuba): a large instrument with finger holes and a tuba-like mouthpiece, coiled in a snake-like shape. The March calls for tenor and bass trombones, which share a line on the full score. The alto trombone, "rarely represented in military music," ${ }^{189}$ is not scored in this piece. Military music was probably considered too heavy in style and orchestration for the alto trombone, with its small size and melancholy tone. It is also possible that of the three most common trombones, the alto trombone at the time still maintained the strongest ecclesiastical ties, and therefore it might have been considered inappropriate to include alto trombone in military-style music. However, since Beethoven

\footnotetext{
${ }^{184}$ Willy Hess, "Marches for Band,” in Beethoven Companion, ed. Scherman and Biancolli, 621.

${ }^{185}$ Willy, Ibid.

${ }^{186}$ Thayer, Life of Beethoven, 793.

${ }^{187}$ Gleason, Ibid.

${ }^{188}$ Scherman, Ibid.

${ }^{189}$ Will Kimball, “Alto Trombone History Timeline,” http://www.kimballtrombone.com/alto-trombone/altotrombone-history-timeline (2009), accessed 23 October, 2009.
} 
included the Serpent, the regular complement of three in the low brass was preserved. The tessiturae of the trombone parts is slightly extended, more like the ranges Beethoven called for in his later works. The bass trombone ranges from $\mathrm{F}$ to $\mathrm{f}^{1}$; the tenor ranges from $\mathrm{A}$ to $\mathrm{a}^{1}$.

The trombone parts are diversely scored, sometimes in octaves and unison, but often in harmony, depending on the need. The widest interval between the two trombones is a tenth, which only happens once. The bass trombone and Serpent play almost completely in octaves or in unison, and the tenor trombone either fills in with another octave or supplies a different chord member, such as the third. The first entrance of the trombones is in the pickup to the fourth measure. There are many dotted rhythms typical of Turkish marches:

Example 42: Military March in D, measures 4-8

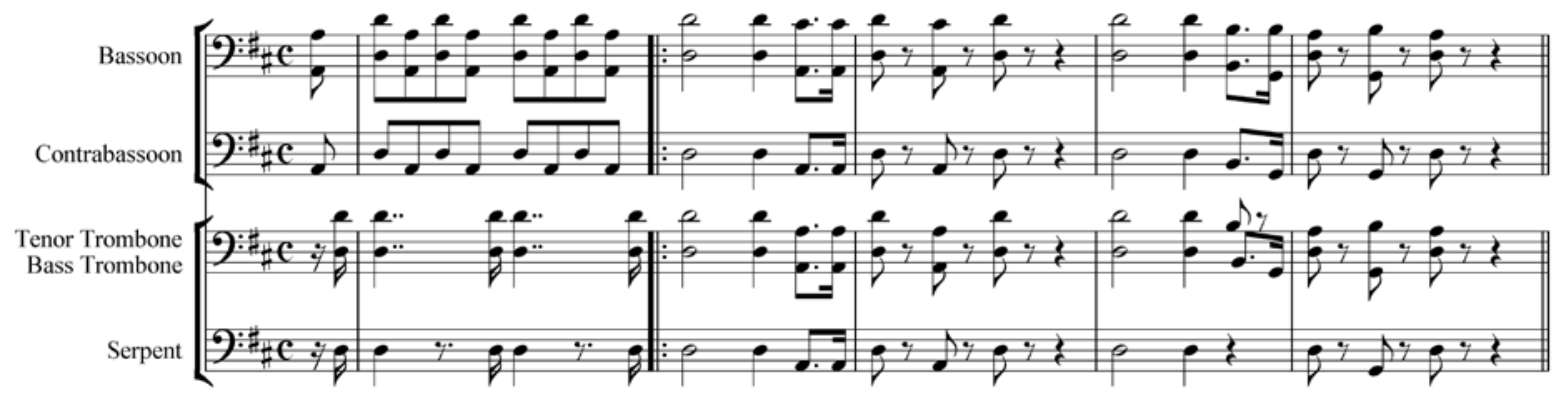

Here the trombones are mostly in octaves. In the last measure of the example, they are in tenths. The following measures include a low brass section solo, joined by the bassoons:

Example 43: Military March in D, measures 9-14.

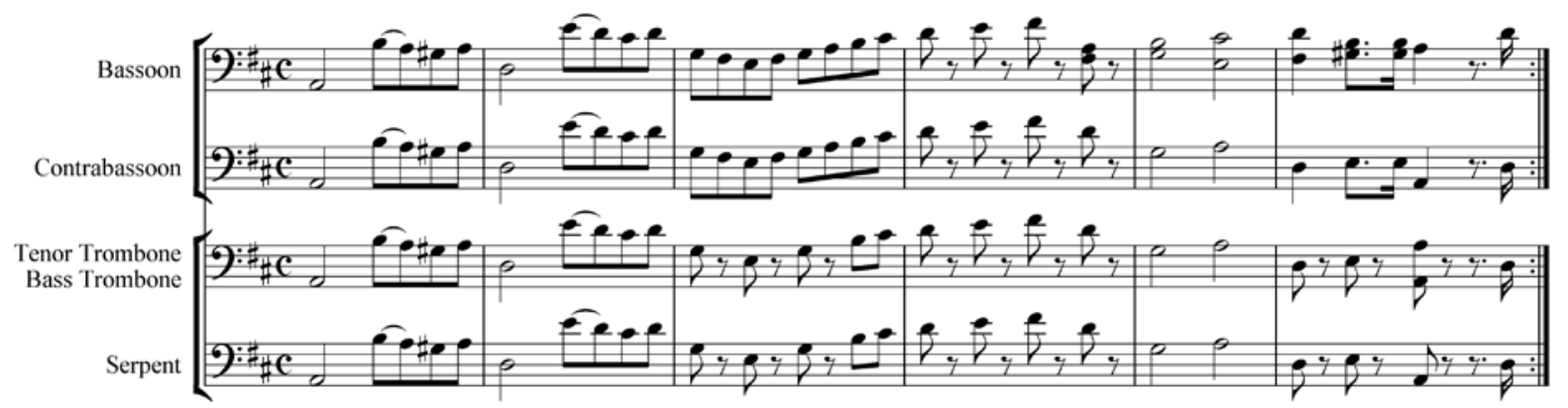

The lower voices are in unison in the section solo. Also, the above example shows rhythmic abbreviation in the trombones (and Serpent) in the third and last measures of the example. 
This technique has been seen regularly in earlier works studied. In the next example, the trombones—joined by the Serpent—play in simple harmonies of fifths and partial chords:

Example 44: Military March in D, measures 28-33

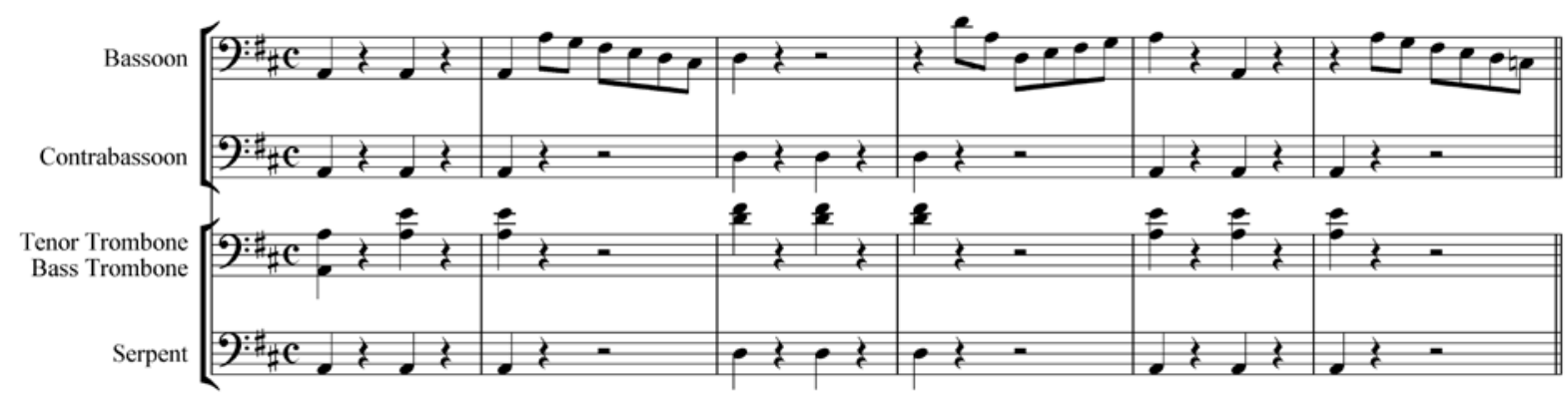

The simple harmonies above become more complex in the next section:

Example 45: Military March in D, measures 35-41

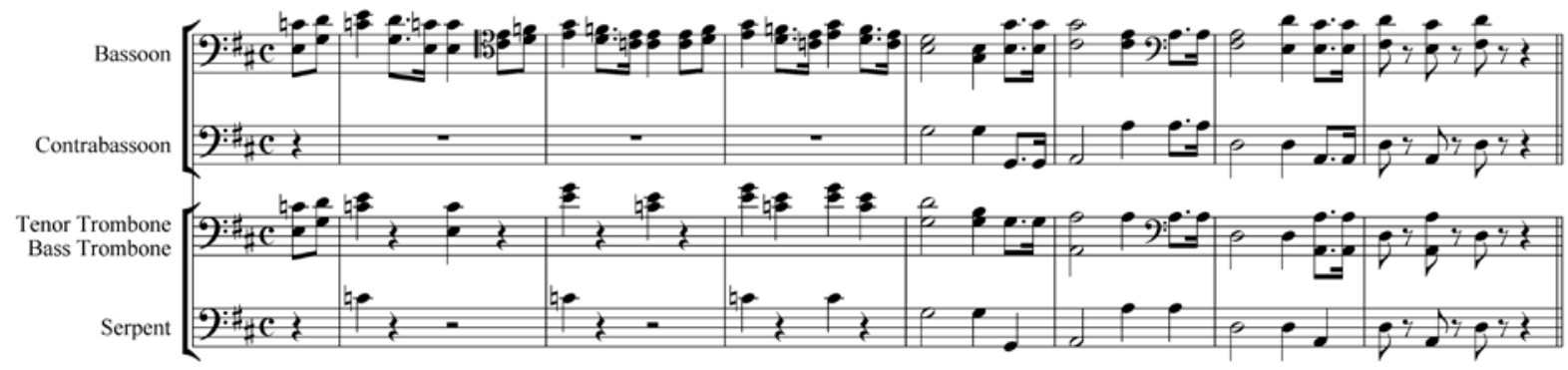

In the second and third full measures of the example, the trombones and Serpent form close position triads, thus creating a "low brass trio" despite having only two trombones. Also there is more rhythmic abbreviation between the trombones and bassoon in the first three measures, as well as more abbreviation between the trombones and the Serpent in the fifth and sixth measures. The final example is another low brass and low woodwind section solo:

Example 46: Military March in D, measures 49-55

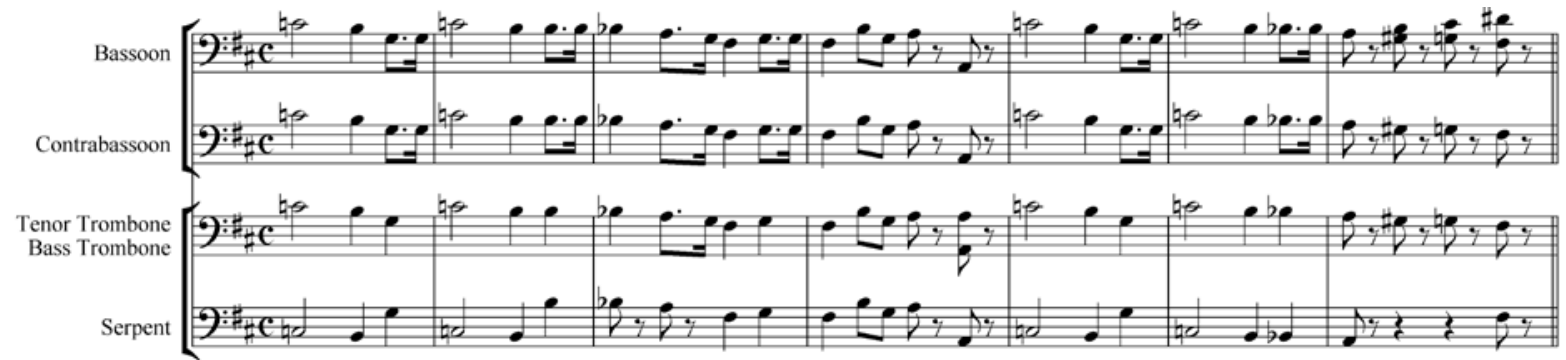


The third measure of the example shows two levels of rhythmic abbreviation. First, the trombones have abbreviated rhythms as compared to the bassoons. Second, the Serpent has further abbreviated rhythms-more so than the trombones. Also, the Serpent part includes some unique octave shifts in the first and fifth measures. These are not compensatory measures, since the range of the Serpent extends down almost another octave below the $G$ in question. It is difficult to determine why Beethoven wrote the wide shifts, but perhaps he wanted more support in the middle octave, leaving the lower octave to be handled by the contrabassoon. The march continues past the above examples to a short Trio section and then is recapitulated in its entirety, including all repeats.

To conclude the Military March in D, the trombone parts are exclusively tutti and provide a supportive role for the more prominent low woodwinds. The parts are straightforward and unambiguous in their military flavor, and the section has few resting measures. The two trombone parts are mostly in octaves or unison, with occasional harmonies. While there are many places in the score where the trombones play the same rhythm as the rest of the band, there are other sections where their parts are rhythmically simpler than their low woodwind counterparts. While there are several section soli, the melodies are always shared with the bassoons. Finally, as far as can be determined, the Military March in D is the only work by Beethoven that includes a part for Serpent.

\begin{tabular}{|c|l|c|l|l|c|c|l|}
\hline \multicolumn{6}{|c|}{ Table 10: Trombone Statistics for Military March in D, WoO 24.} \\
\hline \multicolumn{2}{|c|}{ Movements } & \multicolumn{3}{c|}{ Measures } & \multicolumn{3}{c|}{ Ranges } \\
\hline Total & \#Played & Total & \#Played & \%Played & Tenor & Bass & Serpent \\
\hline 1 & 1 & 143 & 137 & 96 & A to a & F to f $\#^{1}$ & F to f\# ${ }^{1}$ \\
\hline
\end{tabular}




\section{Chapter V}

\section{Patriotic Works}

\section{Incidental Music from the Ruins of Athens, Opus 113}

The first two works examined in this section were actually written before Three Equali, but due to the subject matter and the function of the works, they are best placed in this chapter. The Ruins of Athens, Opus 113, and King Stephen, Opus 117, were both originally written as commissions to commemorate the opening of a new municipal theatre in Pest, Hungary. The Kaiser Franz had authorized the building project in 1808, but due to financial issues and war, completion of the building was delayed, and finally projected for the Emperor's name day, October 4, 1811. ${ }^{190}$ As the project progressed through 1810, the lyricist August von Kotzebue was secured to write the text for the works to be performed at the grand opening. Two librettos (among others) which Kotzebue quickly wrote for the event were The Ruins of Athens and King Stephen. These two were then sent to Beethoven in late July, 1811. Thayer continues:

In a letter to [music publishers] Breitkopf and Härtel on October 11, 1811, Beethoven reported that the package was delivered during [his] journey to Teplitz, that he started work three weeks later-about August 20 —and that he sent the music off to Pest on September 13. Beethoven's correspondence, then, implies that all this incidental music was completed in less than a month.

During this time-as Thayer indicates—Beethoven was traveling, first to Teplitz for a vacation, then to Prague. ${ }^{191}$ During his time in Teplitz, not only did Beethoven compose the music to both Ruins of Athens and King Stephen, but also completed revisions to Christ on

\footnotetext{
190 Thayer, 509.

${ }^{191}$ Schindler describes this sequence of events as happening in July, 1812. However, he could not have been correct, since the premiere of both Ruins of Athens and King Stephen-according to the local newspapers-was in February 1812. There is no way Beethoven could have been composing the same works in July 1812, five months later! (See Schindler, Beethoven as I Knew Him, [London: Faber and Faber, 1966], 163.)
} 
the Mount of Olives, preparing it for publication by Breitkopf and Härtel. ${ }^{192}$ Most likely the revised and ready to be published score of Christ on the Mount of Olives accompanied the letter to the music publishers quoted above. While in Prague, Beethoven visited his friend Count Lichnowsky and attended a performance of his Mass in $C$ at the Count's estate. ${ }^{193}$ The premieres of both Ruins of Athens and King Stephen did not actually happen until February 9, 1812, which served the dual purpose of honoring the Kaiser's birthday celebration (February 12) and the opening of the theatre. Both works were warmly received, and repeat performances on February 10 and 11 were delivered “...to crowded audiences which received Beethoven's music to König Stephan and Die Ruinen von Athen (reported to be 'very original, excellent and worthy of its master’) with clamorous applause.” ${ }^{194}$ However, Solomon's comments shed quite a different light on the two works, when he says both Ruins of Athens and King Stephen:

...were written rapidly in the short space of three weeks at Teplitz in late summer 1811. Opuses 113 and 117 were intended to celebrate...a patriotic occasion that called for expressions of flattery and adulation. In The Ruins of Athens, Minerva awakens from a two-thousand year sleep to find Athens occupied, the Parthenon in ruins, and culture and reason banished from the Mediterranean, but, happily, still alive in Pest under the enlightened rule of Emperor Franz. Similarly, King Stephen, which is subtitled Úngarns erster Wohltäter ("Hungary's First Benefactor")...is a transparent homage to the Austro-Hungarian Kaiser. It contains several women's choruses patently derived from Haydn’s Seasons. ${ }^{195}$

Solomon continues along the same lines when he says "Beethoven did not have his heart in these compositions, which clearly were done as hackwork to gratify a royal patron.”196 Kinderman goes on to say that both The Ruins of Athens and King Stephen are "far beneath

\footnotetext{
192 Solomon, 237.

193 Ibid.

194 Thayer, 524.

195 Solomon, 273.

196 Solomon, Ibid. Kinderman says the exact same thing, even using the same word "hackwork" (see Kinderman, Beethoven, 172).
} 
the level of his other compositions." ${ }^{197}$ Both of these assertions fly in the face of Beethoven's own feelings for the two works. According to London Times Chief Music Critic William S. Mann, "Beethoven was fond ${ }^{198}$ of his Kotzebue music, and referred to King Stephen and The Ruins as 'my little operas.'”199 Mann less cynically describes the plot of Ruins of Athens:

"The Ruins" was an extremely tactful piece describing how Minerva wakes from two thousand years of sleep. Her first thought is to return to Athens, her old cultural stamping ground, but she is appalled to see the Parthenon in ruins, and the home of Socrates under the dominion of the Ottomans...Only in Pest, Mercury tells her, are culture and reason cultivated, under the enlightened patronage of Emperor Franz, to whom choruses of thanksgiving are sung. ${ }^{200}$

Ruins of Athens includes in the score parts for three trombones: alto, tenor, and bass. Probably one of the main reasons both Ruins of Athens and King Stephen included trombones-besides the instruments' efficacy as aural bridges between the chorus and orchestra—is because at the same time of their composition, Beethoven was working on the published version of Christ on the Mount of Olives, which also included trombones. The trombone parts in Christ on the Mount of Olives (which he would have been editing) probably served to encourage Beethoven to include trombone parts in the compositions he was working on at the same time. While the tessitura is typical for the tenor trombone ( $\mathrm{d} \#$ to $\mathrm{b}^{1}$ ), the alto range is somewhat lower than what is usual for Beethoven: e to $\mathrm{c}^{2}$. However, the bass trombone part is the most interesting. It ranges from $\mathrm{B}^{b^{0}}$ to $\mathrm{e}^{1}$, by far the lowest range of any work by Beethoven. While Ruins of Athens is an eight-movement work, the trombones play in Numbers 3, 6, 7 (with a Recitative preceding Number 7), and 8. Number 3 includes parts for only alto and bass, and the Recitative preceding Number 7 is written only

\footnotetext{
${ }^{197}$ Kinderman, Ibid., 172.

${ }^{198}$ And Beethoven was not above disparaging his own works, which he did with Christ on the Mount of Olives. (See Eduard Hanslick, "Missa Solemnis" in Beethoven Companion, ed. Thomas Sherman and Louis Biancolli [Garden City: Doubleday, 1972], 957.)

${ }^{199}$ William R. Mann, "Incidental Music to King Stephen," in Beethoven Companion, ed. Thomas Sherman and Louis Biancolli (Garden City: Doubleday, 1972), 679.

${ }^{200}$ William R. Mann, Ibid., 676.
} 
for alto and tenor trombone. The first entrance of the trombones, in Number 3, "Chorus of the Dervishes," consists exclusively of octaves between the bass trombone and the alto trombone, with just the strings and brass playing:

Example 47: Ruins of Athens, Number 3, measures 15-18

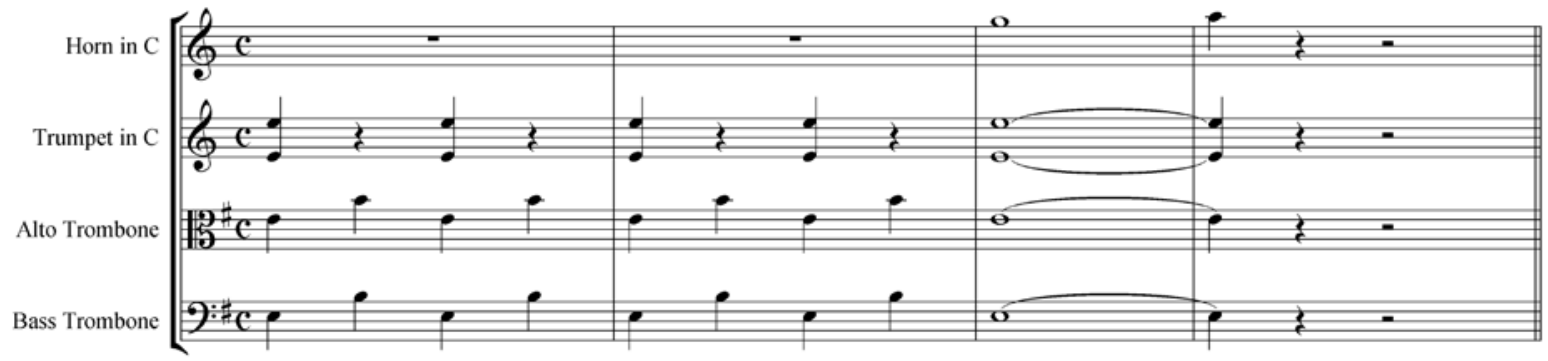

The choir enters on the held chords, and continues with the body of the chorus, while the trombones double the melody:

Example 48: Ruins of Athens, Number 3, measures 21-29

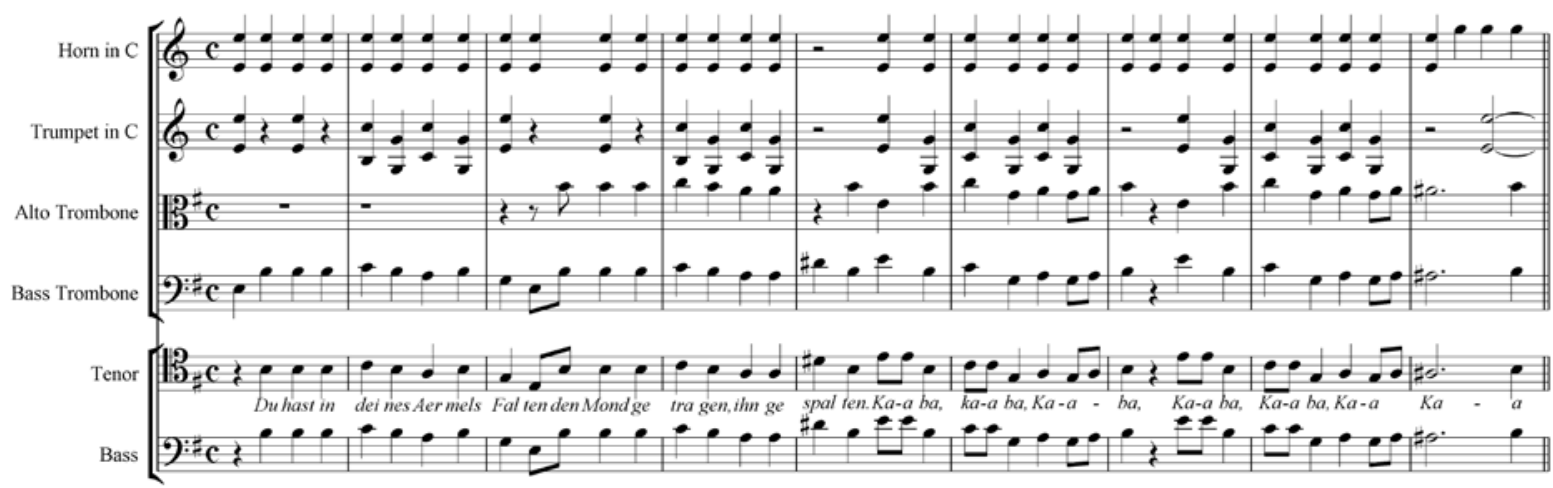

Duhast in dei nesAermels Fal tenden Mondge tra gen, ihn ge spal ten.Ka-a ba, ka-a ba,Ka-a - ba, Ka-a ba, Ka-a ba,Ka-a Ka - a

The bass trombone doubles the entire melody, except the eighth notes where the chorus sings "Kaaba," but the alto trombone does not enter until the third bar of the chorus, and at the upper octave where no voice is written. In this case, the alto part was probably written not as much to double the chorus (and therefore help the vocalists find their pitch) but more to add drama and color to the entire number. While this particular movement features only octaves between the trombones-typical when Beethoven scores for only two-in other numbers where all three trombones play, the intervals are usually thirds, sixths, or tenths, which again 
is typical for Beethoven. Usually the tenor and alto are in closer intervals such as thirds, and the bass is often a sixth or more below the tenor. Rarely, and always at the end of a number, all three trombones play chords in close position—usually spanning the interval of a fifth—to bring out the chord more clearly. This close position technique also appears in Wellington's Victory and the Finale of Symphony \#9.

Number 6, March and Chorus, ${ }^{201}$ has the most interesting trombone parts of the entire work. They enter in measure 120 with the tutti orchestra:

Example 49: Ruins of Athens, Number 6, measures 120-123

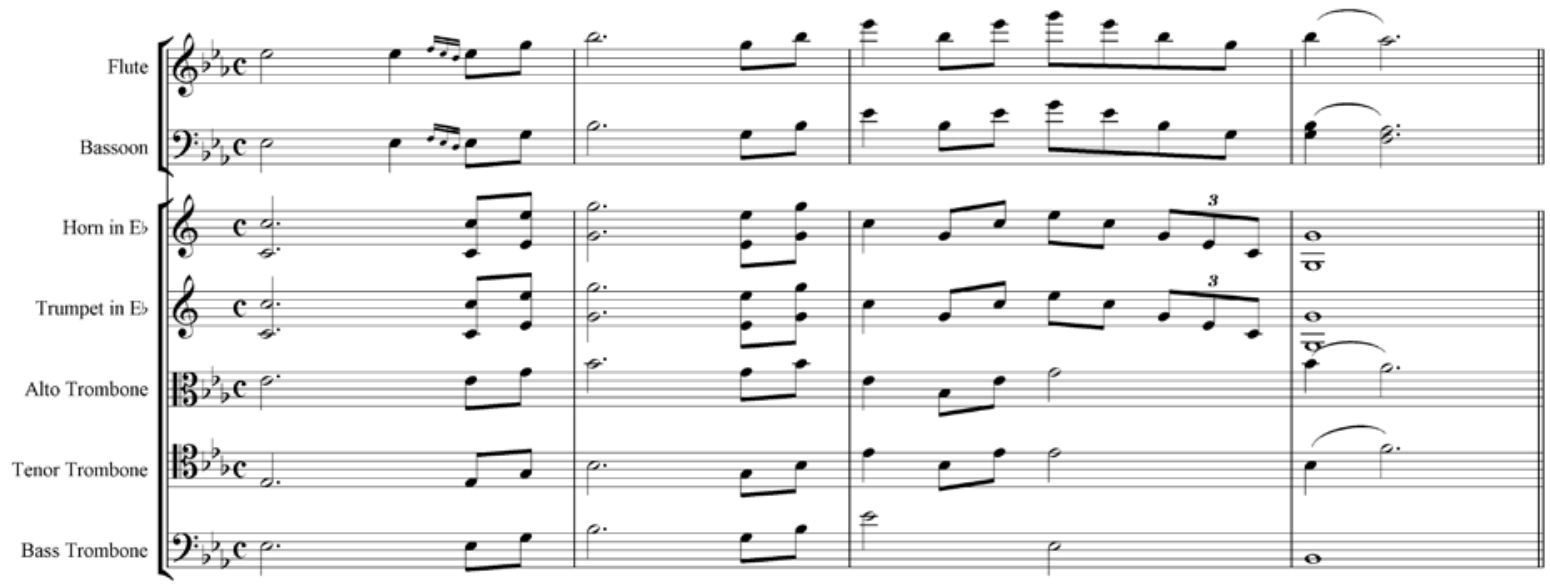

The trombones have what could be called a hybrid style, as some of it is tutti (the second measure of the example), and other parts are rhythmic abbreviation (the third measure of the example). The next example has the lowest notes Beethoven ever wrote for the trombone:

Example 50: Ruins of Athens, Number 6, measures 129-134

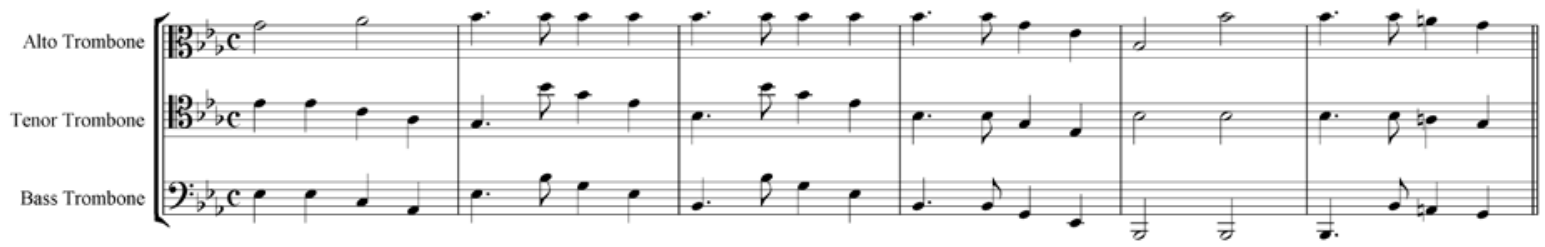

\footnotetext{
${ }^{201}$ This number was also separated out (and assigned its own Opus, 114) by Beethoven in 1822 to accompany Consecration of the House Overture for the opening of the Josephstadt Theatre. For more information on the March and Chorus from Ruins of Athens, as well as more historical background on the opening concert, see the section in the next chapter below.
} 
The low $\mathrm{B}^{b^{0}}$ in the bass trombone part is a major third lower than any other of Beethoven's trombone parts, and it brings up some questions. Howard Weiner ${ }^{202}$ has asserted that there were none—or very few—bass (or "quart," as they were called) trombones in Vienna at the time of Beethoven. He bases this assertion on a quote by Fux from some 80 years earlier:

Johann Georg Sturmb, master of the waits at Klosterneuburg, humbly requests to be accepted into imperial services as a quart trombonist. However, because this instrument would contribute nothing to the improvement of the imperial musical establishment, but, on the contrary, would be detrimental on account of its unpleasant sound, I cannot recommend this supplicant's request. ${ }^{203}$

Weiner's point is that because the instrument sounded bad, it eventually faded away into obsolescence. However, if the Viennese trombonists alive at the time of Beethoven played all of their trombone parts—regardless of the title "alto" or "bass"-on tenor trombones pitched in $\mathrm{B}^{b}$ or $\mathrm{A}$, as Howard Weiner has asserted, then this particular passage presents a quandary. The low $\mathrm{E}^{b}$ is not playable on a tenor trombone pitched in $\mathrm{B}^{b}$, but could be played on a bass or "quart" trombone; and the low $\mathrm{B}^{\mathrm{b}}$ is not playable on a bass trombone pitched in $\mathrm{E}$ or $\mathrm{F}$, but it is playable on a tenor trombone, or a bass trombone pitched in $\mathrm{E}^{b}$ or $\mathrm{D}$. Weiner suggests the solution was the use of "false" tones, where the trombonist produced notes normally not on the instrument by "lipping down" the note, producing a sound that approximated the pitch and tone color of the note desired. ${ }^{204}$ While the "false" tone technique was most likely present in early Nineteenth-Century Vienna, it seems doubtful that this technique-if it were known to him-would be encouraged by the perfectionist Beethoven, especially if an instrument capable of playing the "real" notes were available. (The sound quality of "false" tones is questionable at best.) Furthermore, in other cases in

\footnotetext{
${ }^{202}$ Howard Weiner, "When is an Alto Trombone an Alto Trombone? When is a Bass Trombone a Bass Trombone: the Makeup of the Trombone Section in Eighteenth- and Early Nineteenth-Century Orchestras," Historic Brass Society Journal 17 (2005), 37-79.

${ }^{203}$ Weiner, Ibid., 67.

${ }^{204}$ Weiner, Ibid.
} 
earlier works, Beethoven specifically avoids the notes in question; ${ }^{205}$ in Ruins of Athens he does not. Therefore, he most likely wrote the part specifically to be played on a bass trombone. Finally, Ruins of Athens was premiered in Pest. It is not known for certain that there were examples of bass trombones in Pest during the time period in question, but Hungary had a vital musical culture, strongly influenced and supported by the Austrian and Bavarian aristocracy ${ }^{206}$ — who did have a long legacy of employing trombonists and therefore had access to bass trombones. ${ }^{207}$ In addition, there are examples in Pest of other trombones during that time. ${ }^{208}$ Beethoven, perhaps aware that the instrument was used in Pest, wrote it in its proper range.

Another interesting example of momentary prominence occurs in Number 6 as well.

Example 51: Ruins of Athens, Number 6, measures 135-141

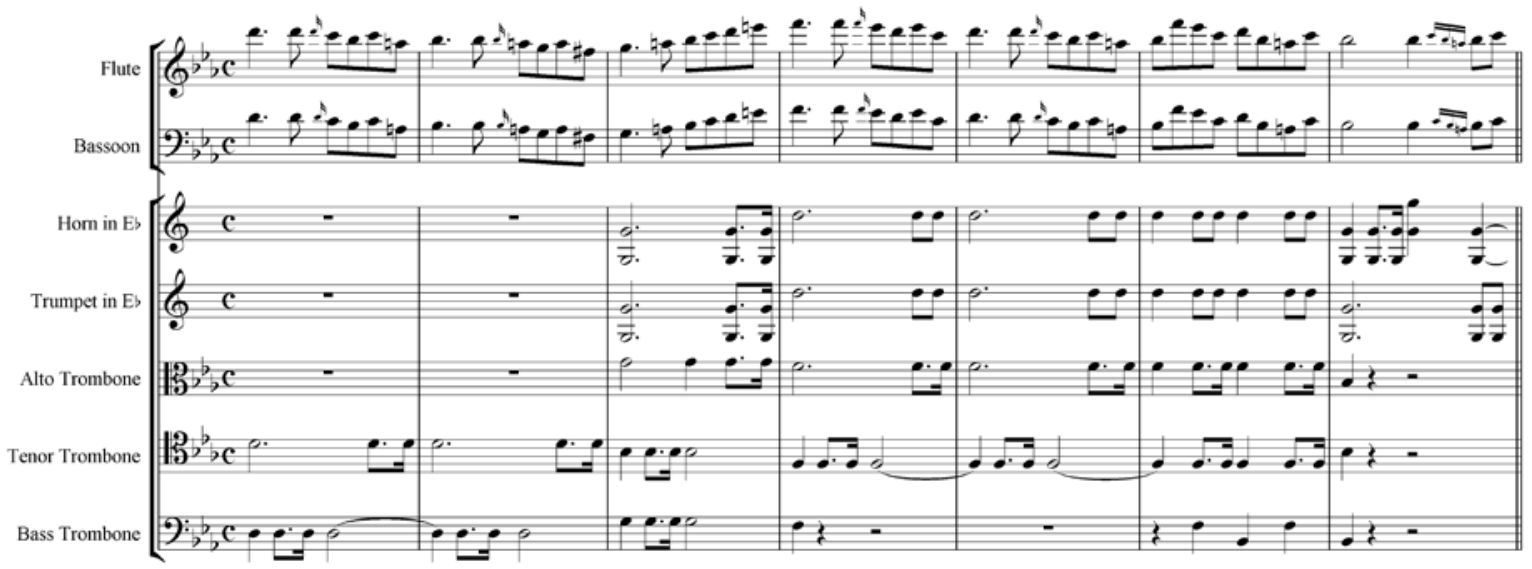

The trombones begin as the only instruments with the dotted rhythm. In the next phrase, the trumpets and horns displace the dotted rhythm while the trombones continue with their original rhythm. The rhythmic interplay creates the trombone prominence. The last example

\footnotetext{
${ }^{205}$ Especially see Fidelio for examples of avoidance of bass trombone notes by Beethoven.

${ }^{206}$ David Wyn Jones, The Symphony in Beethoven's Vienna, (Cambridge: Cambridge Univ. Press, 2006), 57.

${ }^{207}$ See Trevor Herbert, The Trombone (New Haven: Yale University Press, 2006), 113-117. See also Howard Weiner, "When is an Alto Trombone an Alto Trombone? When is a Bass Trombone a Bass Trombone? -The Makeup of the Trombone Section in Eighteenth- and Early Nineteenth-Century Orchestras, Historic Brass Society Journal 17 (2005), 66-67. Logically, if an individual were applying for a quart (or bass) trombone position at a court orchestra, the instrument was available to them.

${ }^{208}$ Trevor Herbert, Ibid., 315.
} 
from Number 6 is toward the end of the March, where each section is playing one of the rhythmic motifs already introduced. In this case, the woodwinds have eighth notes, the horns have triplets, the trumpets have dotted eighths and sixteenths, and the trombones have a more drawn out rhythm, which most of the others join in the final measures of the example:

Example 52: Ruins of Athens, Number 6, measures 157-161

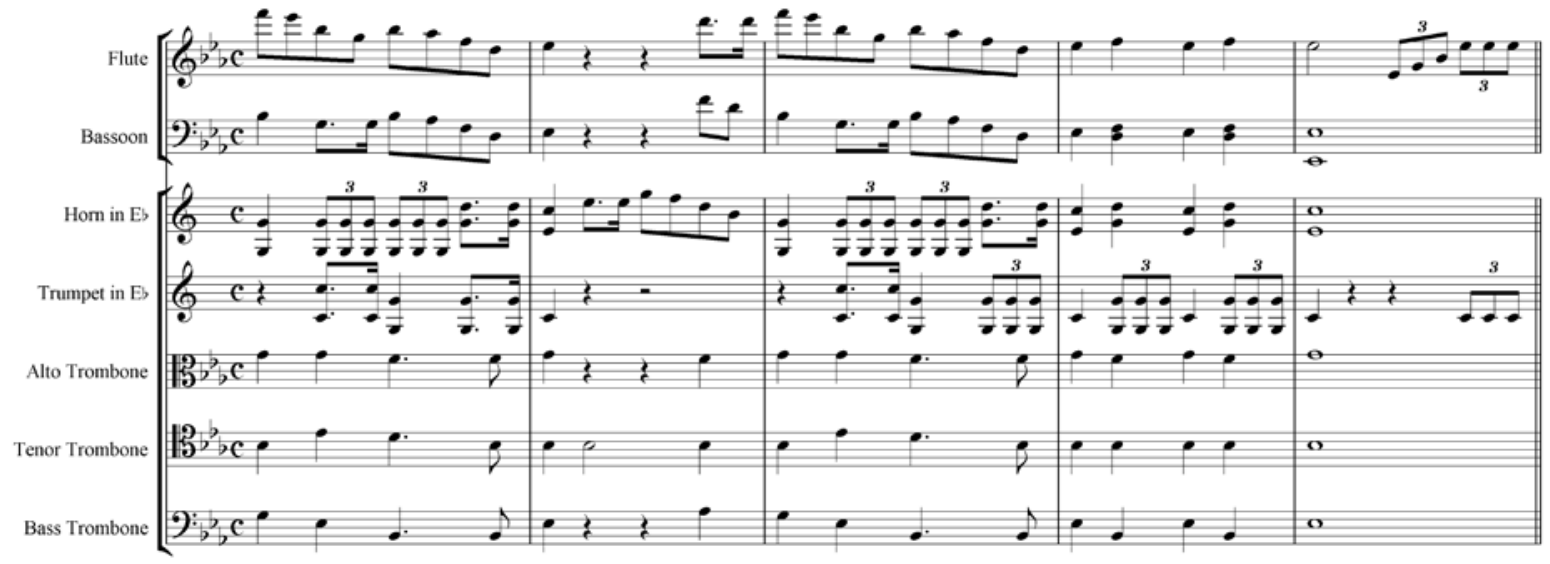

Number 7 begins with a Recitative where the trombones play with the rest of the winds and brass in held chords. The trombone parts in this section loosely double the chorus:

Example 53: Ruins of Athens, Number 7, measures 151-157

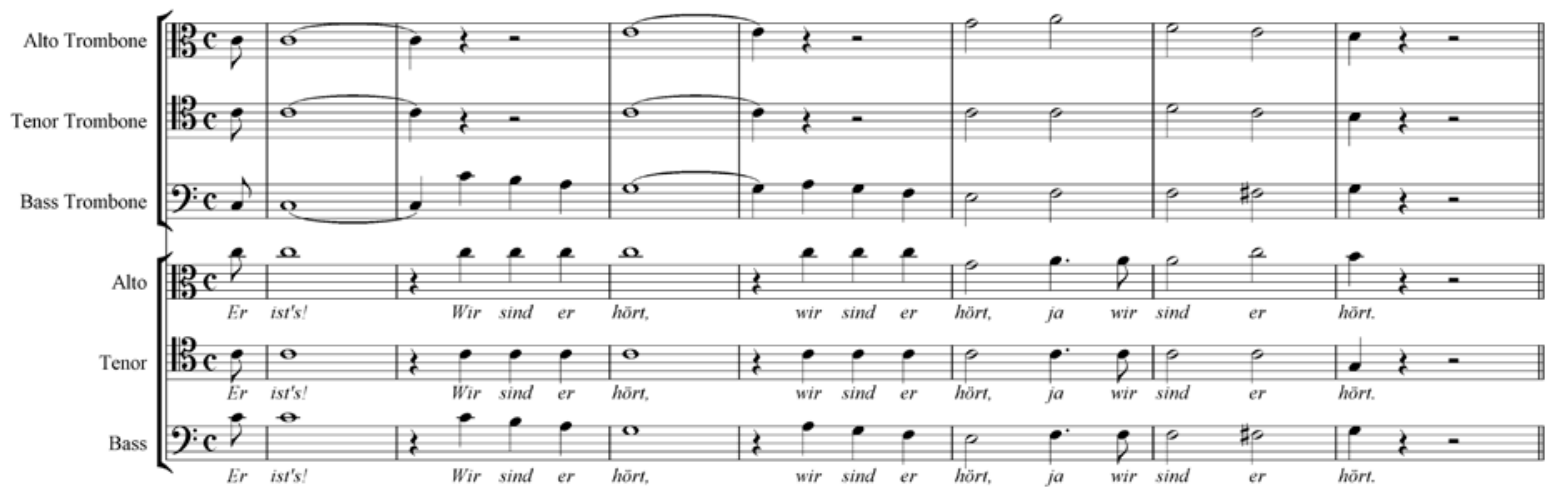

In the above example, the trombones support their usual choral parts, except for the second and fourth measures, where the alto and tenor parts are omitted and only the bass trombone doubles the bass voice. Beethoven probably left off the alto and tenor trombones in these 
two measures because there were already enough woodwinds doubling the tenor and alto voices, and to add more instruments at this point would only serve to overbalance the choir.

The last eleven measures of Number 7 represent an example of combined roles for the trombone section. At first they mostly double the chorus along with the rest of the winds and brass. Then they switch over to tutti notes and rhythms to conclude the number:

Example 54: Ruins of Athens, Number 7, measures 186-193

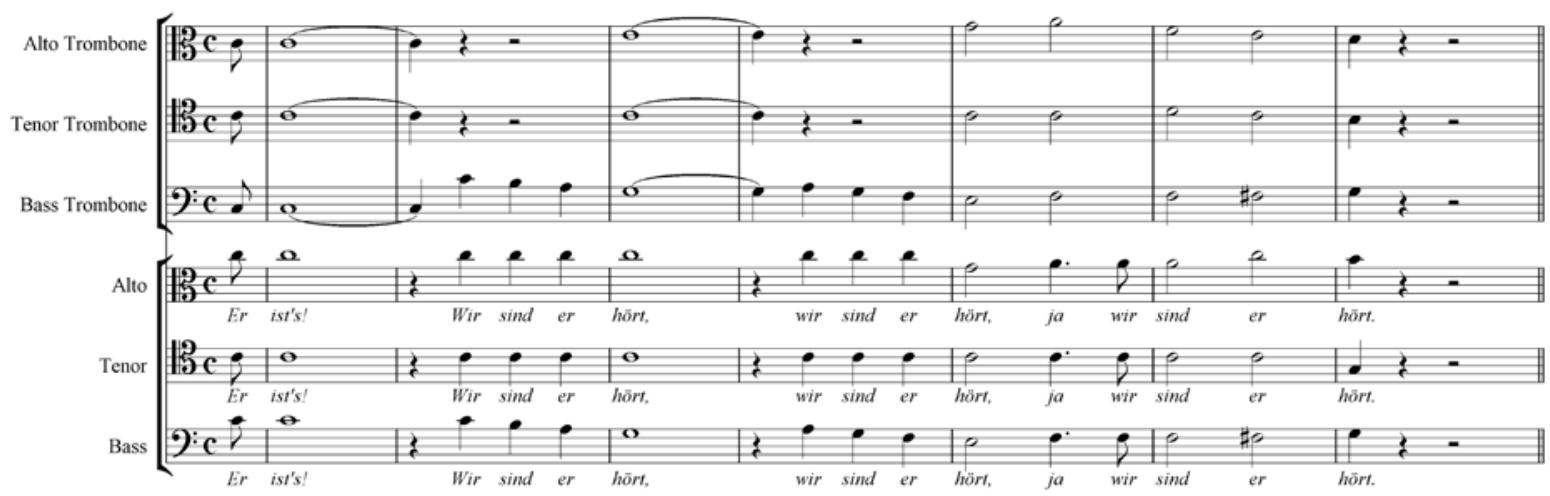

In Number 8, which is the Final Chorus, the trombones are in a purely orchestral tutti mode.

The section does not double the chorus in any way, but instead remains with the orchestra:

Example 55: Ruins of Athens, Number 8, measures 76-83

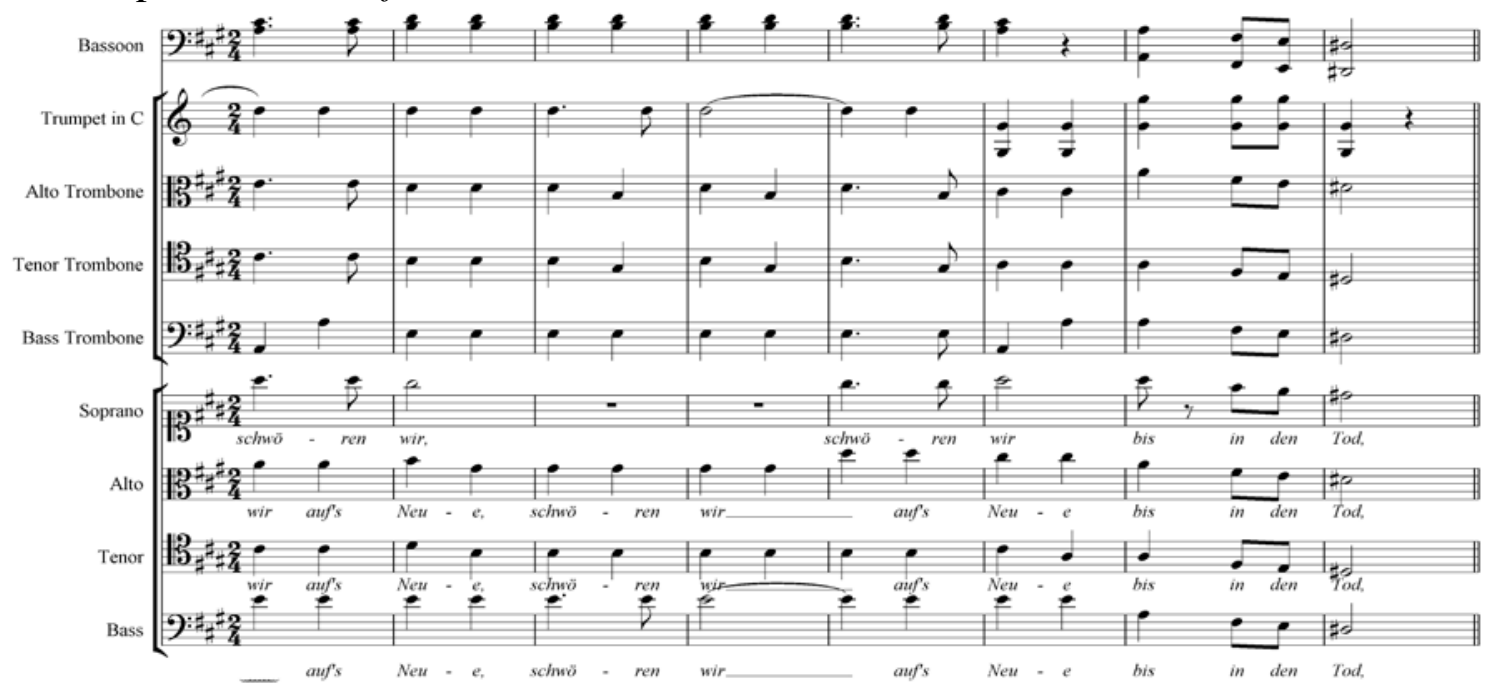

This technique of including trombones while the chorus is singing, but not giving them the chorus parts to double, is a new technique on the part of Beethoven. In earlier works 
involving chorus, when the trombones play at the same time the chorus sings, they are usually doubling the chorus. It could be argued that they are doing so in this example as well, since all the notes in the choir parts are also in the trombone parts. However, the nature and style of the trombone parts clearly indicates they are acting as part of the wind and brass section-as in earlier symphonic works—and that any trombone notes in the example that double the choir are simply tutti chord tones and not specific choral doubling. There is even one phrase that resembles passages from Symphony \#5. Compare Example 56 below with Example 34, on page 60:

Example 56: Ruins of Athens, Number 8, measures 143-150

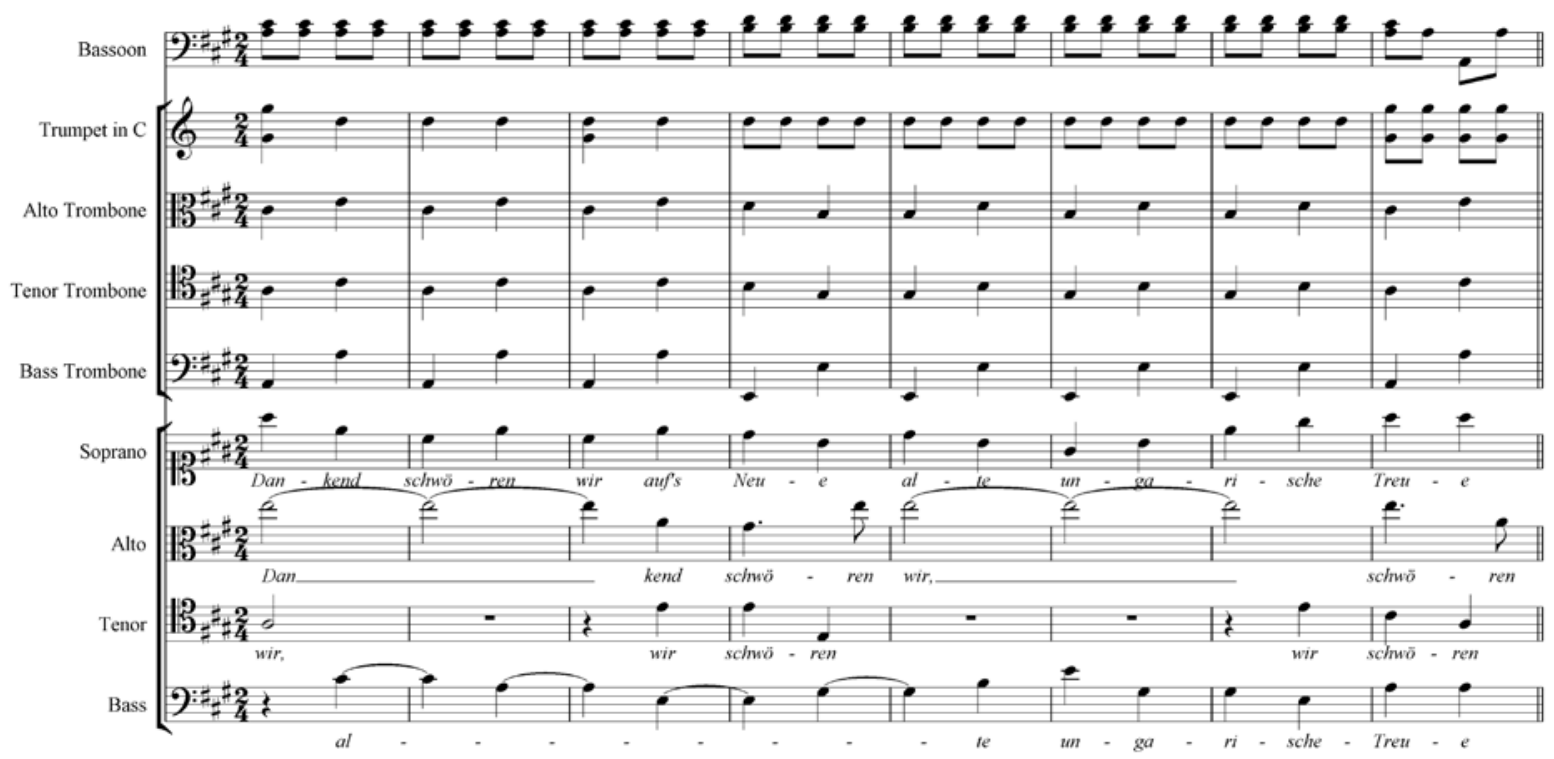

The trombones are the only instruments playing quarter notes, except for a few measures in the trumpets and horns. They solidify the downbeat and forward-moving pulse while the other instruments provide the running eighths (winds and other brass) and sixteenths (upper strings, not shown). As was seen in Symphony \#3, had Beethoven given the trombones running eighths as well, there would have been insufficient forces to provide the downbeat, resulting in a bombastic jumble, difficult to play cleanly and keep moving ahead. 
In conclusion, the trombone parts in Ruins of Athens have most of the techniques that have been shown as typical in Beethoven's compositions: doubling the chorus, brass section and tutti playing with or without rhythmic abbreviation, and momentary prominence. But there does seem to be a higher level of creativity in handling the trombone parts. Beethoven has taken advantage of the color differences between the various members of the trombone section by, for example, writing the alto part to enter several bars after the other parts, thus adding different brighter sounds on top of the already existing sounds. He also extended the low range of the bass trombone considerably in Ruins of Athens, thereby creating yet another set of darker, lower sounds. One possible reason for Beethoven's desire for more "colors” of sounds in Ruins of Athens was to produce the "exotic" Turkish style of music, depicting the occupation of Athens by the Ottomans. ${ }^{209}$ Beethoven, probably in an effort to find new variations in sounds, adjusted the trombone part assignments—writing for just two of the three trombones in Number 3 and the Recitative preceding Number 7. The scoring for only alto and bass in Number 3 is especially interesting. He had previously written for tenor and bass (Fidelio) as well as alto and tenor (Symphony \#6), but alto and bass is a new combination. Coupled with these new techniques is an overall increase in flexibility in the trombone parts: they change more quickly between the various roles than in previous works. All these new ideas contribute to a more creative approach to writing for trombones. Some aspects of this approach continue in the other work written at the same time, King Stephen.

\begin{tabular}{|}
$\mid$\begin{tabular}{|c|l|c|l|l|c|c|c|}
\hline \multicolumn{7}{|c|}{ Table 11: Trombone Statistics for Ruins of Athens, Opus 113 } \\
\hline \multicolumn{2}{|c|}{ Movements } & \multicolumn{5}{|c|}{ Measures } & \multicolumn{3}{c|}{ Ranges } \\
\hline Total & \#Played & Total & \#Played & \%Played & Alto & Tenor & Bass \\
\hline 8 & 4 & 1129 & 256 & 23 & e to c & d\# to $b^{b^{1}}$ & $\mathrm{~B}^{b^{0}}$ to e \\
\hline
\end{tabular}
\end{tabular}

${ }^{209}$ Solomon, Beethoven, 273. 


\section{Incidental Music from King Stephen, Opus 117}

The historical background surrounding the composition of King Stephen is the same as that of Ruins of Athens, described above. Both texts were written by August von Kotzebue. The premiere of both King Stephen and Ruins of Athens took place on February 9, 1812 with repeat performances on February 10 and 11. ${ }^{210}$ Maynard Solomon claims that Beethoven "did not have his heart in these compositions," 211 but others say that not only was Beethoven greatly impressed with the lyricist Kotzebue (to the extent that he asked him for an opera text $)^{212}$ but-as mentioned above-he also was quite fond of both Ruins of Athens and King Stephen, referring to them as "my little operas." ${ }^{213}$ The plot, though similarly patriotic, differs from Ruins of Athens in that instead of the subject matter hearkening back to antiquity, the plot surrounds the life of Hungarian King Stephen and his founding of the Hungarian Empire in 1000 AD.

The score of King Stephen, like its twin Ruins of Athens, includes what has become the traditional complement of three trombones: alto, tenor, and bass. The tessiturae of the three are more conservative than Ruins of Athens: the alto is from $\mathrm{f} \#$ to $\mathrm{b}^{1}$, the tenor is from e to $\mathrm{f} \#^{1}$, and the bass is from $\mathrm{G}$ to $\mathrm{c}^{1}$. There are only one or two passages in octaves: the rest are chordal, usually in close position—rarely spanning more than a sixth. A few chords in tenths can be found, but they are the exception. While the trombones play in more movements than they did in Ruins of Athens (Numbers 1, 2, 3, 7, 8), they play in fewer actual measures than in Ruins of Athens. In addition, overall the trombone writing is much less adventurous in King Stephen than in Ruins of Athens. However, one new scoring

\footnotetext{
210 Thayer, Life of Beethoven, 524.

211 Solomon, Beethoven, 273.

212 Thayer, Ibid.

${ }^{213}$ William Mann, “Incidental Music to King Stephen,” in Beethoven Companion, ed. Thomas Scherman and Louis Biancolli (Garden City: Doubleday, 1972), 678-679.
} 
development can be seen in Number 3, the Victory March. Here Beethoven for the first time scored for one (bass) trombone: it alone acts as the trombone section.

The first entrance of the trombones-in Number 1-has them playing the downbeats with the strings while the winds play the moving passages:

Example 57: King Stephen, Number 1, measures 13-20

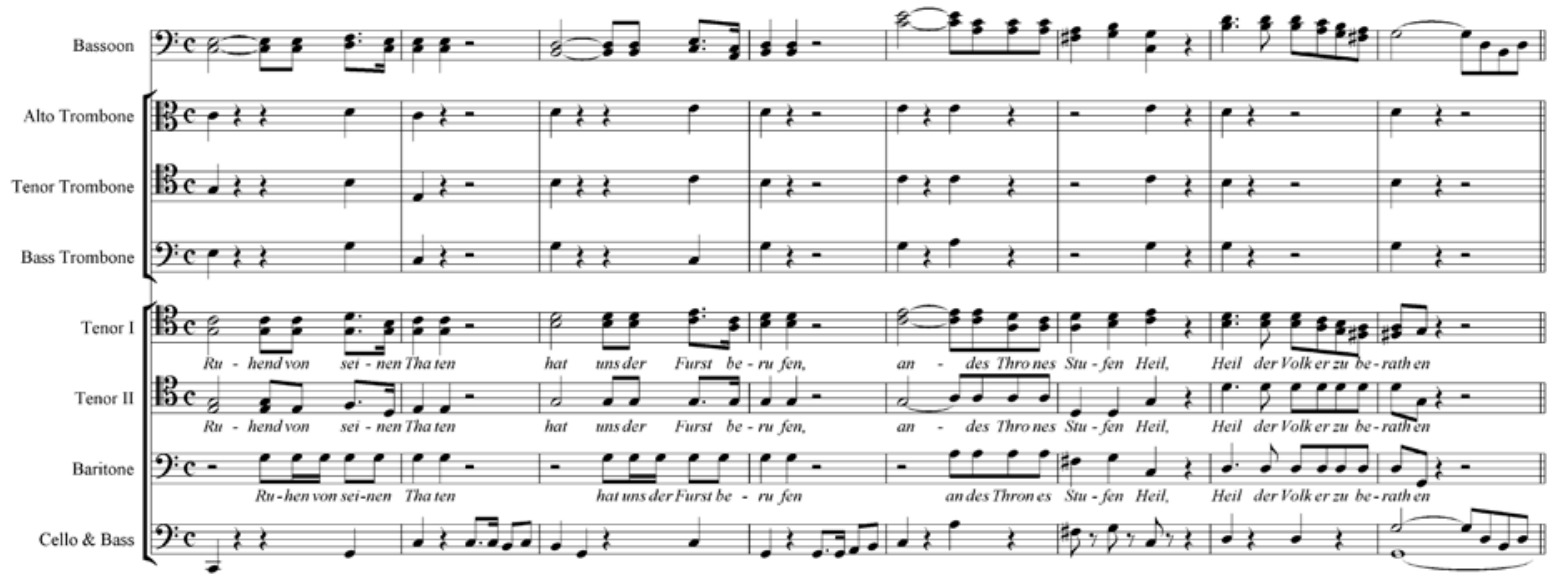

Here the trombones do not double the chorus, and rarely do throughout the work. The bass trombone mostly doubles the basses and celli with a significantly simplified rhythm (but notice the first note is not doubled), while the alto and tenor trombones tend to double the violins (not shown). One of the rare instances of the trombones doubling the chorus occurs near the beginning of Number 2:

Example 58: King Stephen, Number 2, measures 20-27

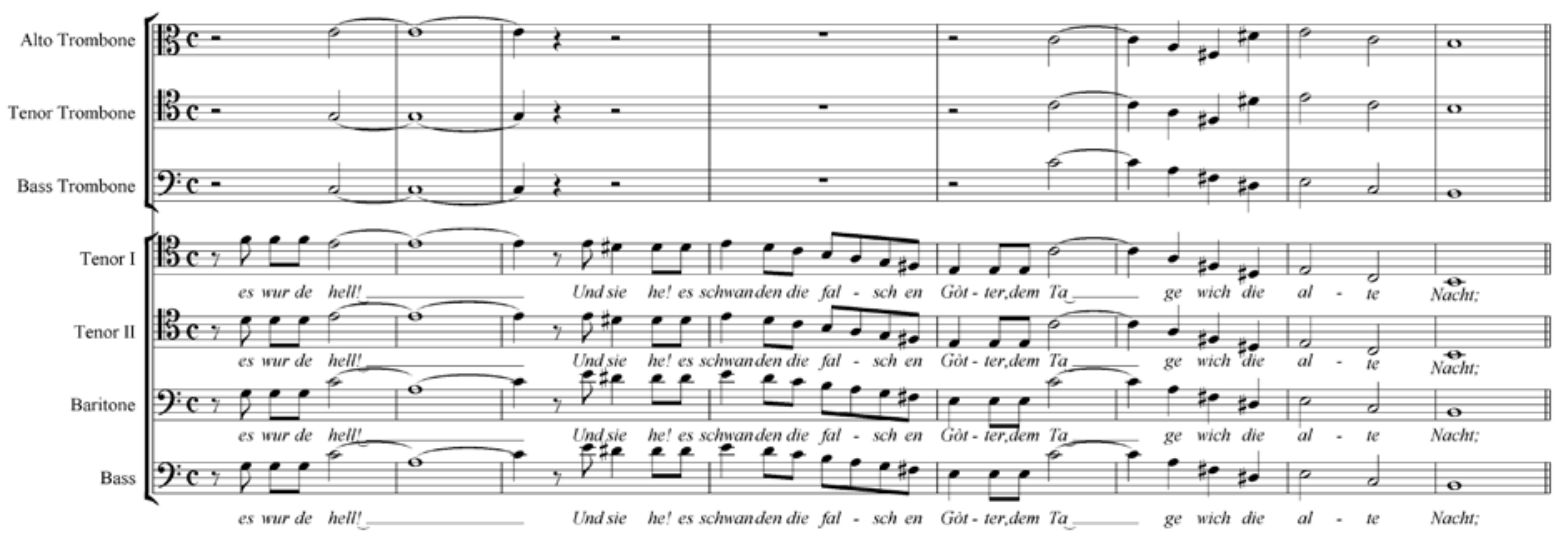


The trombones only double the longer note values; all eighth notes are omitted in the trombones and are instead played in the woodwinds. The trombone chord in the first measure is one of the few open position chords found in the work's trombone parts. Also, note how the alto trombone doubles the tenor vocal part, while the tenor trombone fills out the chord by playing a $G$, which is a note with no corresponding voice part. In the next measures the trombones switch from doubling the chorus to acting as tutti instruments:

Example 59: King Stephen, Number 2, measures 28-32

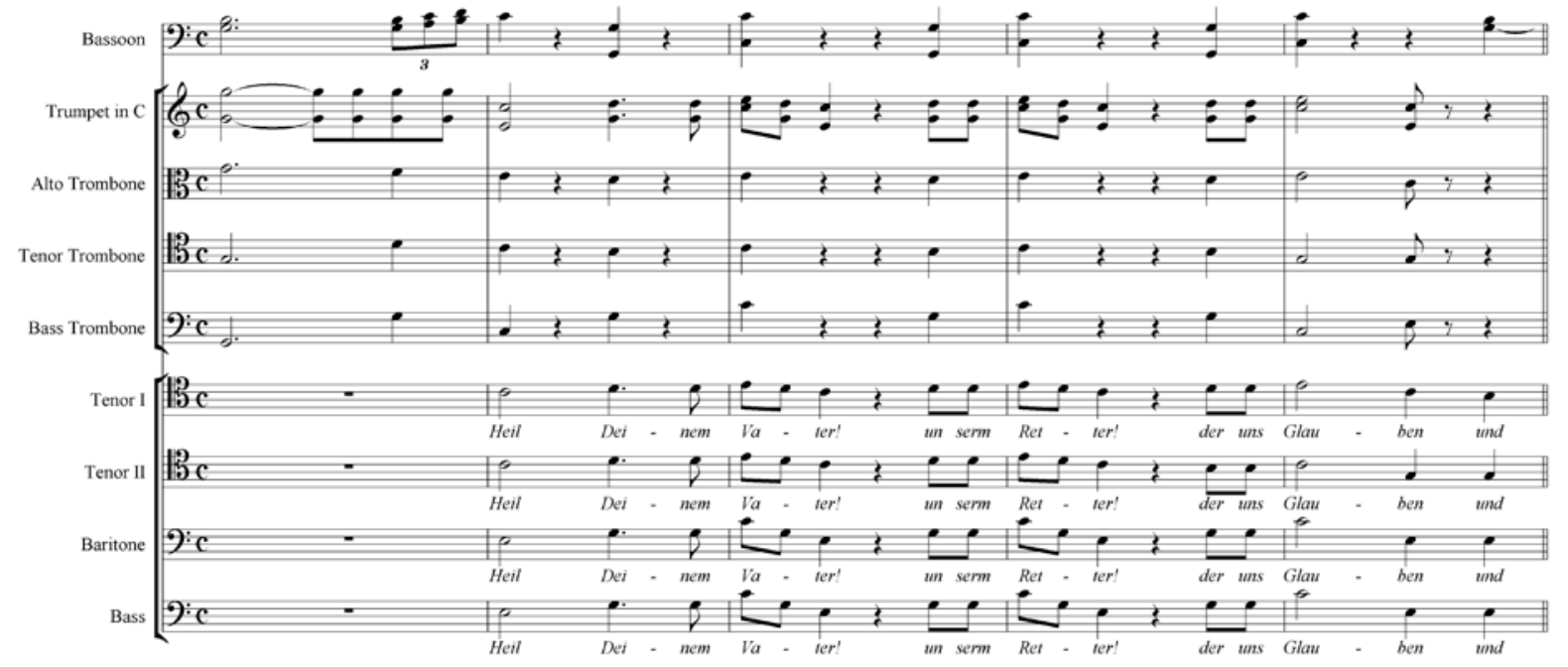

In these measures the instruments doubling the choir switch from the trombones and woodwinds (seen in the previous example) to the trumpets and horns. The example also shows a short rhythmic abbreviation in the trombones in the first measure. In the rest of the example the trombones exactly double the rhythm of the entire orchestra (except horns and trumpets, which are doubling the rhythm of the chorus).

The next selection comes from Number 3, the Victory March, with its aforementioned orchestration for only one trombone--in this case the bass trombone. While scoring for bass trombone alone was a known practice at the time, ${ }^{214}$ Beethoven's action of scoring in this method served to influence composers of the next generation. This style of writing for one

${ }^{214}$ Timothy Howe, Ibid., 26. 
trombone would be carried on by Chopin, Paganini, and others, especially in the orchestral accompaniment parts to their various solo concertos: ${ }^{215}$

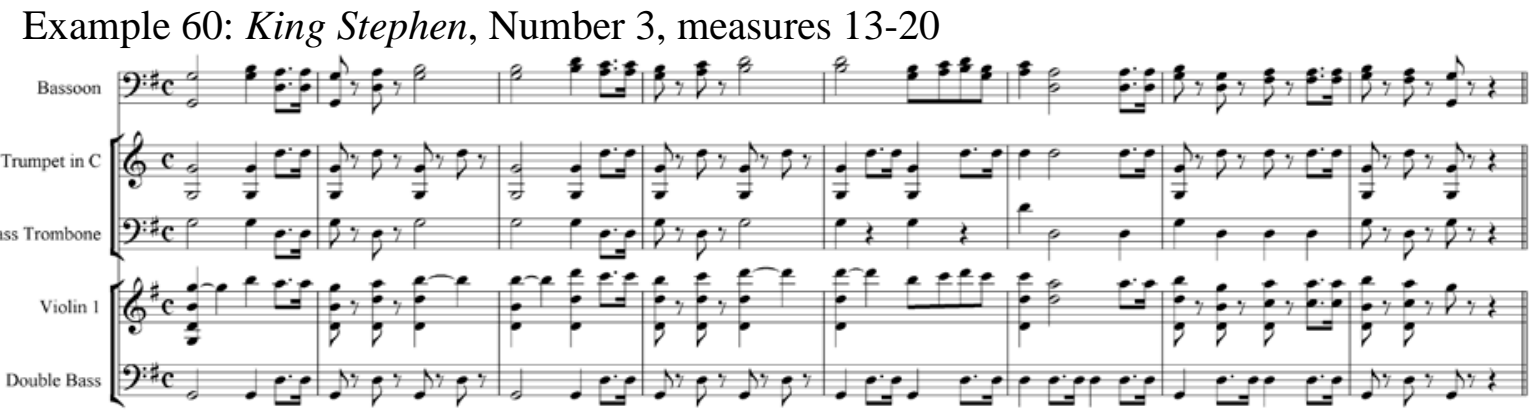

The bass trombone loosely doubles the basses and celli, with some notes in the bass trombone longer in value than those of the basses. The following example shows the classic rhythmic abbreviation found in most of the works that are scored for just one trombone:

Example 61: King Stephen, Number 3, measures 38-46

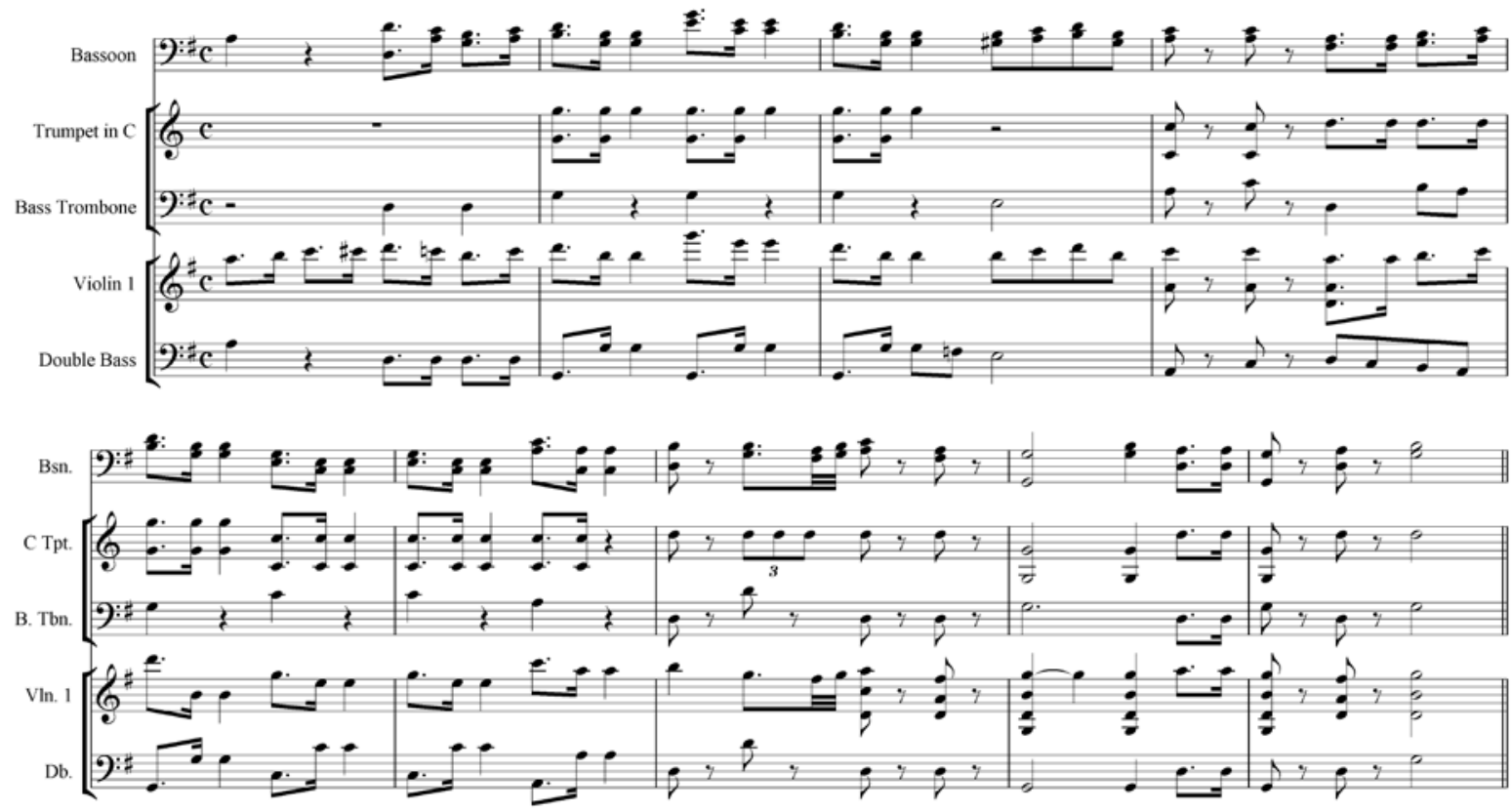

${ }^{215}$ Interestingly, Joseph Wagner in his book Orchestration: A Practical Handbook, describes one trombone (bass or otherwise) alone in an orchestra as sounding "inappropriate, weak, and slightly amateurish. (See Joseph Wagner, Orchestration: A Practical Handbook [New York: McGraw-Hill, 1959], 228.) While there may be some validity to Wagner's claim with older works-such as those mentioned above (concertos by Paganini or Chopin) - there are plenty of examples of works with only one trombone that do not sound inappropriate, weak, or amateurish. La Bourgeois Gentilhomme by Richard Strauss, La Creation du Monde by Darius Milhaud, Pulchinella by Igor Stravinsky, and the two sets of Old American Songs by Aaron Copland are all excellent examples, as are the many waltzes and polkas by other members of the Strauss family, most of which included only one bass trombone in the orchestral score. 
Although the bass trombone could play the full rhythmic passages, it was more important to achieve ensemble clarity by abbreviating the rhythm in the part. The next example shows that the trombones can be written with the same complex rhythms in appropriate sections:

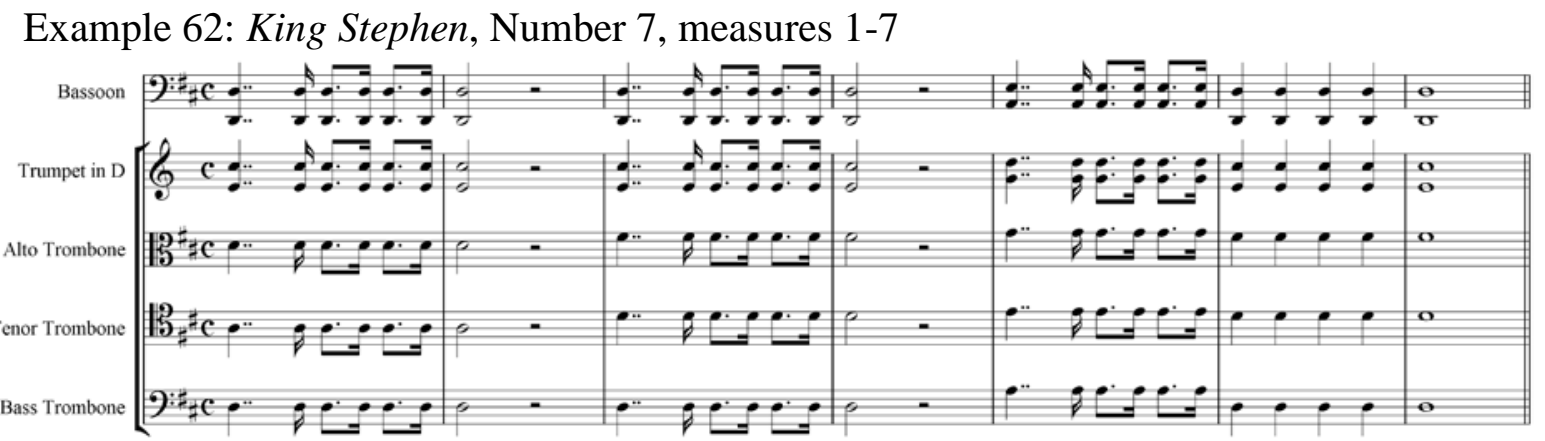

The rhythm is the same in the trombones as the other winds and brass, but the alto and tenor trombones change chord members-along with the flutes and oboes (not shown)—in the third and fourth measures of the example. All other instruments play the same chord members in the first four measures. It is similar to Example \#17 from Leonore. The final example, from Number 8, indicates a Haydn-influenced technique, where the trombones support the tutti orchestra, at the same time doubling certain measures in the chorus:

Example 63: King Stephen, Number 8, measures 28-34

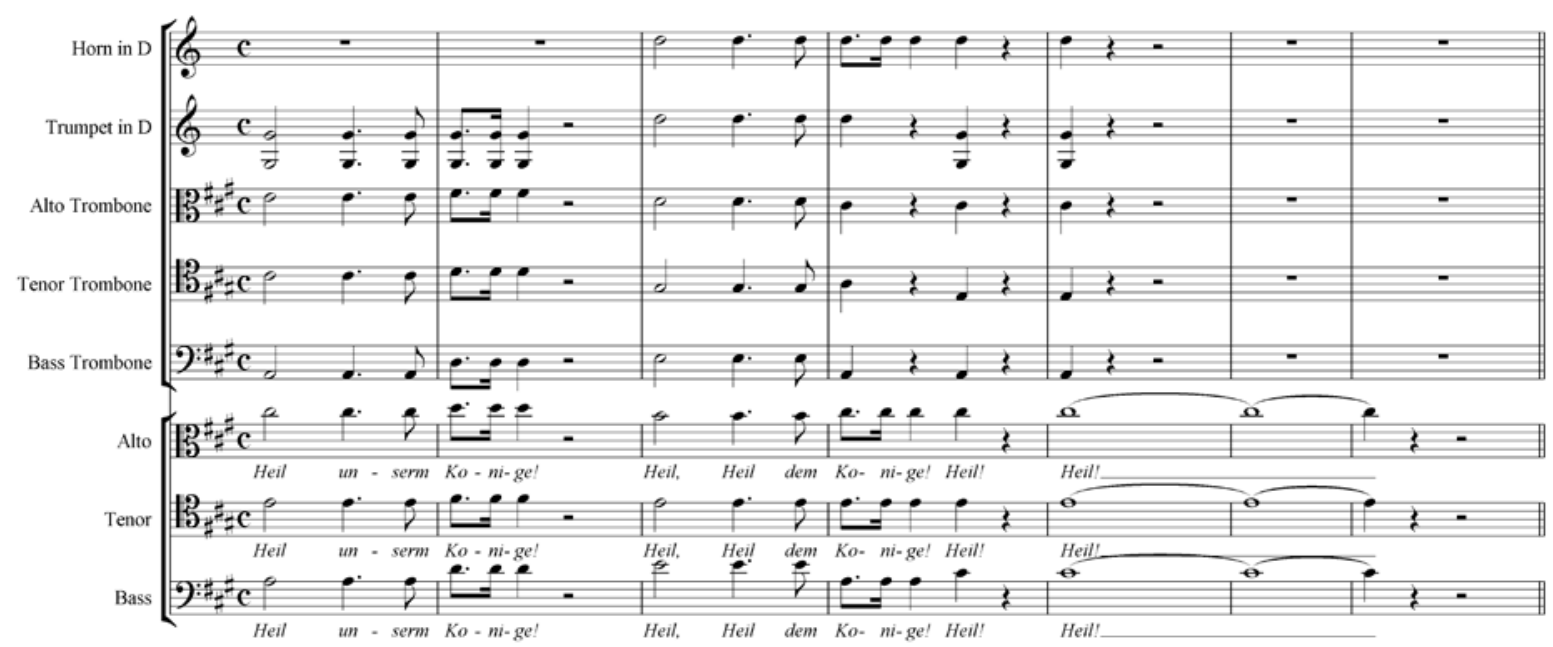

The alto trombone doubles the tenor voice, and the tenor trombone doubles the alto voice down one octave, while the bass trombone does the same with the bass voice. This example 
could perhaps be better labeled a tutti orchestra passage, since the trombones seem to be filling in a particular chord member that fits their respective tessiturae, rather than doubling a specific voice. Furthermore, the horns take over doubling the chorus in the third measure of the example-along with the woodwinds-but only for half a measure. Therefore, it is probably better to describe this section as tutti orchestra, with independent chorus.

To conclude, King Stephen, a rarely performed work, is mostly conservatively orchestrated as far as the trombones are concerned. The ranges of the three instruments are more limited than in other works, including the concurrently composed Ruins of Athens. The three trombones are scored in techniques now shown to be typical of Beethoven. However, the trombones do little actual doubling of the chorus, but instead are used mostly as tutti instruments. There are no section soli or even momentary prominences. The tutti sections employ the usual techniques already seen, including rhythmic abbreviation. Nevertheless, King Stephen does incorporate one noteworthy trombone scoring technique: in the Victory March, only one (bass) trombone is included in the score. This technique influenced the next generation of composers, including Chopin and Paganini, who wrote for one bass trombone in their orchestral accompaniment for concertos; as well as Johann Strauss, Jr., who scored many of his waltzes for orchestra with one bass trombone. Examples of later works employing only one trombone include La Bourgeois Gentilhomme by Richard Strauss and Pulchinella by Igor Stravinsky.

\begin{tabular}{|c|l|c|l|l|c|c|c|}
\hline \multicolumn{6}{|c|}{ Table 12: Trombone Statistics for King Stephen, Opus 117 } \\
\hline \multicolumn{2}{|c|}{ Movements } & \multicolumn{3}{c|}{ Measures } & \multicolumn{4}{c|}{ Ranges } \\
\hline Total & \#Played & Total & \#Played & \% Played & Alto & Tenor & Bass \\
\hline 9 & 5 & $1101^{216}$ & 105 & 10 & F\# to b & e to f\# ${ }^{1}$ & G to c $^{1}$ \\
\hline
\end{tabular}

${ }^{216}$ Almost 50\% of this figure represents the Overture, which does not have any trombone parts. 


\section{Wellington's Victory, Opus 91}

If there was a single work of Beethoven's that served to finally thrust him into his long sought-after position of world-renown composer, it was Wellington's Victory, also called The Battle of Vittoria. Schindler said regarding this particular time in Beethoven’s life:

We now stand at the threshold of one of the most important times in the master's life when, with the exception of a few professional musicians, all the voices that up to this moment had been at odds finally united in unanimous acclaim. ${ }^{217}$

The first half of 1813 had been an artistically dry time in Beethoven’s life, with just a handful of works composed. He was personally in a state of disarray, both physically ${ }^{218}$ (due to fighting illness all year) and financially (due to the economic downturn in Austria from the war with France). ${ }^{219}$ Despondency bore down hard on him in the wake of the 1812 "Immortal Beloved" incident, and he had all but withdrawn from society. ${ }^{220}$ Solomon suggests that he may have begun to contemplate suicide in the Spring of $1813 .{ }^{221}$

However, when Vienna received news of the defeat of Napoleon in Spain on June 21, Beethoven was approached by inventor and opportunist Johann Nepomuk Mäzel to collaborate on a work commemorating the victory. Mäzel had the idea-with sketches to accompany it—-to write a piece to be played by his recently-designed elaborate mechanical instrument called the Panharmonicon. ${ }^{222}$ Beethoven expanded the sketches and re-wrote the piece for full orchestra, complete with two antiphonal bands. ${ }^{223}$ There is some disagreement among scholars as to how much of the music of Wellington's Victory was written by Beethoven and how much was written by Mäzel. Some maintain that the majority was from

${ }^{217}$ Anton Schindler, Beethoven as I Knew Him (Chapel Hill: University of North Carolina Press, 1966), 167.

${ }^{218}$ Solomon, Beethoven, 285

${ }^{219}$ Schindler, Ibid., 165.

${ }^{220}$ Kinderman, Beethoven, 190.

${ }^{221}$ Solomon, Ibid., 283.

${ }^{222}$ The Panharmonicon was a large instrument that mimicked the sounds of all the orchestral instruments.

${ }^{223}$ Kinderman, Ibid., 192-193. 
Mäzel while others say that he only contributed the fanfares and battle signals. ${ }^{224}$ The work was performed, along with Symphony \#7—considered at the time to be a piece composed to accompany Wellington's Victory—at a combination Academie and benefit concert (to raise money for wounded Austrian and Bavarian veterans) on December 8 and 12, 1813. Several composers performed in the orchestra, including Hummel, Salieri, Spohr, and Meyerbeer. ${ }^{225}$ The concerts were by far the most successful Beethoven had ever performed. He was so elated with the results that he wrote a letter of thanks to be printed in the Wiener Zeitung:

I esteem it to be my duty to thank all the honored participants in the Akademie given on December 8, and 12, for the benefit of the sick and wounded Austrian and Bavarian soldiers who fought in the battle at Hanau, for their demonstrated zeal on behalf of such a noble end.

It was an unusual congregation of admirable artists wherein every individual was inspired by the single thought of contributing something by his art for the benefit of the Fatherland, and who without consideration of their rank cooperated in subordinate places in the excellent execution of the whole.

While Hr. Schuppanzigh at the head of the violins carried the orchestra by his fiery and expressive playing...Hr. Salieri did not scruple to beat time for the drummers and salvos. Hr. Spohr and Hr. Mayseder [sic], each worthy of leadership because of his art, collaborated in the second and third places and Hr. Siboni and Hiuliani also occupied subordinate positions.

To me the direction of the whole was assigned only because the music was of my composition; had it been by another, I should have been as willing as Hr. Hummel to take my place at the big drum, as we were all filled with nothing but the pure love of country and of joyful sacrifice of our powers for those who sacrificed so much for us.

But our greatest thanks are due to $\mathrm{H}$. Mäzel, since it was he who first conceived the idea of this concert and there fell to him afterwards the management, care and arrangement - the most arduous labors of all. I must also thank him in particular, because by the projection of this concert, he gave me the opportunity, long and ardently desired, by means of the composition especially written for this philanthropic purpose and delivered to him without pay, to lay a work of magnitude upon the altar of the Fatherland under the existing conditions.

Since, however, a notice will soon be published of all those who collaborated on this occasion and the part that they played, the public can then see for themselves with what noble self-denial a number of the finest artists

\footnotetext{
${ }^{224}$ Kinderman, Ibid.

${ }^{225}$ Thayer, 567. Apparently the fellow composers were rather jocular during the performances, for he describes the affair as a "stupendous musical joke (Thayer, Ibid.)."
} 
worked together for one fine objective. It was through my encouragement that the leading masters were assembled. ${ }^{226}$

Beethoven capitalized on the achievement and repeated the program—with the addition of selections from The Ruins of Athens-in January 1814. The January concert, attended by some 5000 people, was even more successful. Schindler says regarding this performance, which was held at a large and elaborate hall called the Great Redoutensaal:

This hall afforded an opportunity to put into execution for the first time the many subtleties written into the Battle symphony. From the long corridors and opposed rooms one could hear the enemy armies advance towards each other, creating a stunning illusion of the battle. The author of this book was present and can testify that the enthusiasm of the audience, heightened by patriotic emotions because of the victory just won, reached overwhelming proportions. ${ }^{227}$

The addition of the selections from Ruins of Athens at the January concert necessitated some deletions, and Beethoven chose to delete the works written by Mäzel. This elicited legal action between Mäzel and Beethoven, for Mäzel felt sidelined, despite his ceaseless labor planning, organizing, and executing the December 8 and 12 concerts. Thayer says:

Mäzel saw, therefore, that the objects for which he had sacrificed the "Battle," for which he had lost so many precious weeks and had spent so much labor and pains, were accomplished insofar as Beethoven's new works were now the subjects of general interest and curiosity, and their repeated performance to large and profitable audiences was secured. To his courage and sagacity this was wholly due. It is thoroughly unjust to deny or ignore the value of his services. What his feelings were now, to find himself deprived of all share in the benefit resulting from them, and therefore left without compensation, may readily be conceived. ${ }^{228}$

Legal battles notwithstanding, the timing of the entire event could not have been better for Beethoven. With Austrian patriotic emotions running high at the December concerts, the Viennese finally and irrevocably established Beethoven's reputation as a composer of

\footnotetext{
${ }^{226}$ Schindler, Beethoven as I Knew Him, 168-169.

${ }^{227}$ Ibid, 169.

${ }^{228}$ Thayer, Ibid., 569.
} 
significant and remarkable music. Personally for Beethoven, who was fully aware of Wellington's low level of musical sophistication ${ }^{229}$-Kinderman calls Wellington's Victory kitsch $^{230}$ - the true victory was the enthusiastic reception of his Symphony \#7 and Symphony \#8 (premiered at another Redoutensaal concert on February 27, 1814). Maynard Solomon says, "Overnight, Beethoven attained a level of national popularity that he had never previously experienced." ${ }^{231}$ One of the main reasons for the enormous success of Fidelio in Spring 1814 was that Beethoven’s standing as a great composer had already been confirmed during the Wellington's Victory (and Symphonies \#7 and \#8) concerts the prior winter.

Wellington's Victory has in the score three trombones: alto, tenor, and bass. The range of the parts spans from $\mathrm{G}$ in the bass trombone to $\mathrm{c} \#^{2}$ in the alto and tenor. Although the $\mathrm{c \#}^{2}$ is typical for an alto trombone part written by Beethoven, the same note for the tenor trombone is unusual. However, this particular high note for the tenor seems to be an anomaly, because the rest of the work encompasses a range more typical for that of a tenor trombone. The chords played by the trombone section tend towards close position more often than has been seen in previously studied works. While there are examples of intervals as wide as two octaves between the three parts, these are restricted to where the section plays in octaves. When the section plays in chords, the three parts tend to stay within the interval of a fifth or a sixth. Again, there are exceptions - where the span between the top and bottom parts is as wide as a tenth. But more often when the section plays in chords, the span stays inside an octave. The aural result of these closer-voiced chords is a brighter, more

\footnotetext{
${ }^{229}$ On the other hand, it seemed as if Beethoven still took pride in works that even he considered to be of a lower level of sophistication. In response to a reviewer who had criticized Wellington's Victory, he wrote, "Ah, pitiful scoundrel, my s**t is better than [anything] you have ever thought." (See Kinderman, Beethoven [New York: Oxford University Press, 2009], 201.) (Expletive not redacted in the original.)

${ }^{230}$ Kinderman, Beethoven, 191-198. He also says, "Whereas the true work of art shows qualities of openness, originality, and irrationality, kitsch displays a closed and rational system of imitation.” (Kinderman, Ibid., 191.) ${ }^{231}$ Solomon, Beethoven, 286.
} 
compact sound, which projects more readily than a chord of wider span. In a "noisemaker" work—as Solomon calls $i^{232}$ — such as Wellington's Victory, this is an advantageous quality. In a more serious work such as Symphony \#5, the darker, open position chords, which have more blending capabilities, are more desirable.

The alto trombone part primarily doubles a high horn or first clarinet, while the tenor trombone doubles a low horn, second clarinet, or sometimes a bassoon part-unless the trombones are in octaves, at which point they usually double the celli, basses, or bassoon. The bass trombone doubles the celli and basses exclusively, in the typical "loose doubling" technique seen in earlier works. The orchestrational methods applied to the trombone section in Wellington's Victory follow the typical Beethoven styles previously encountered. There are sections where the trombone parts have rhythmic abbreviation, meaning that while the general rhythm of the phrase is followed by the trombone section, the parts are less complicated rhythmically than the other instruments scored in the same passage:

Example 64: Wellington's Victory, Victory Symphony, measures 44-52

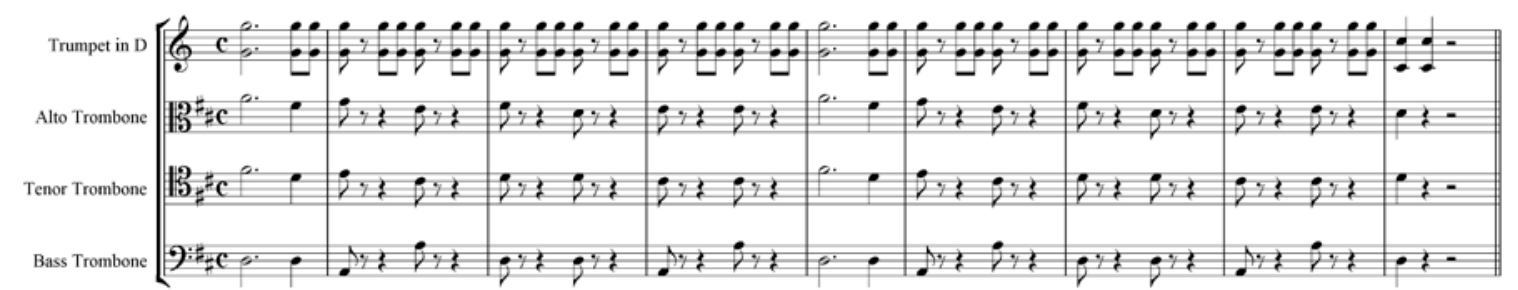

In this case, the trombones are the only instruments playing the abbreviated rhythm. All other instruments are playing the rhythm seen in the trumpet parts, with the exception of the triangle and bass drum, which are resting. Even the two eighth notes in the first and fifth measures of the example are abbreviated to a quarter note in the trombone parts. Oftentimes in other works Beethoven wrote the note values of the trombone parts longer than the rest of

${ }^{232}$ Solomon, Ibid., 287. 
the orchestra, thereby creating a built-in "hangover" note. However, the first entrance of the trombones in Wellington's Victory shows just the opposite technique:

Example 65: Wellington's Victory, Battle, measures 1-8

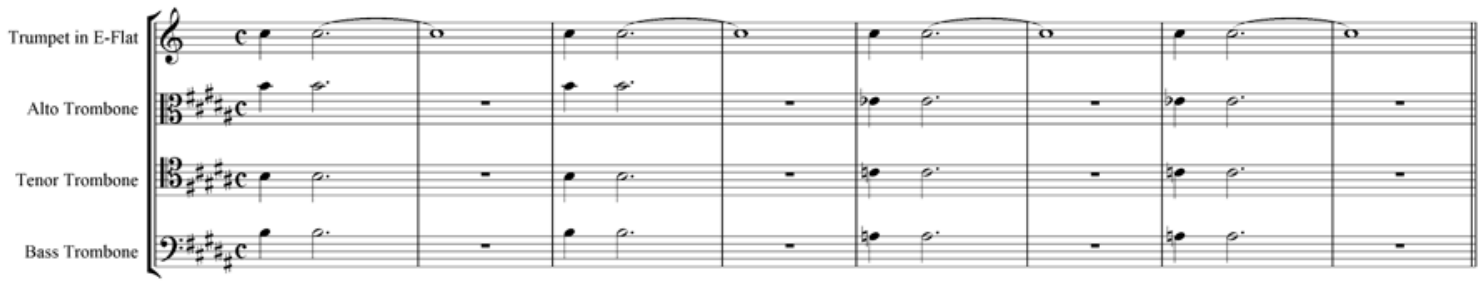

The trombones are again the only section to drop out on the second measure of the sustained notes. The other winds and brass have the rhythms shown in the trumpet part. Beethoven probably omitted the more powerful trombones in this instance so as not to bury the first violins, which at this point in the music are written down to the lowest notes of the instrument. There are, however, some passages where the trombone section does have notes of a value longer than the other winds and brass-in the technique that has been more commonly found-creating in this case both the written-in hangover and a momentary prominence. The bassoons represent the rhythm played by the rest of the woodwinds:

Example 66: Wellington's Victory, Battle, measures 47-55

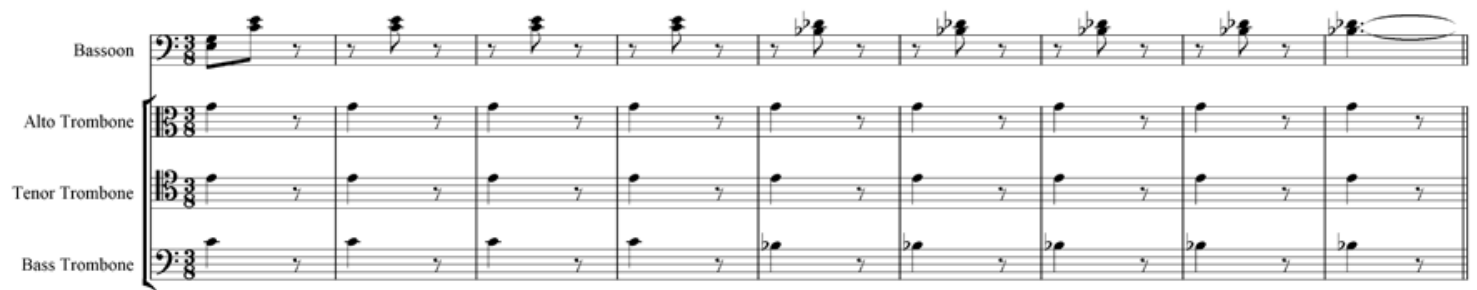

Not only is this an example of the longer note values and prominence of the trombones, but at the last measure, where the winds continue for four measures, the trombones only play the first part of the first measure, providing a strengthening of the downbeat while maintaining clarity through the passage. Examples of this were seen in Symphony \#5. A more vivid 
example of the clarity attained by omitting certain notes within a passage is shown below. The horn parts are shown as examples of the rhythm of the rest of the brass and woodwinds:

Example 67: Wellington's Victory, Victory Symphony, measures 225-233

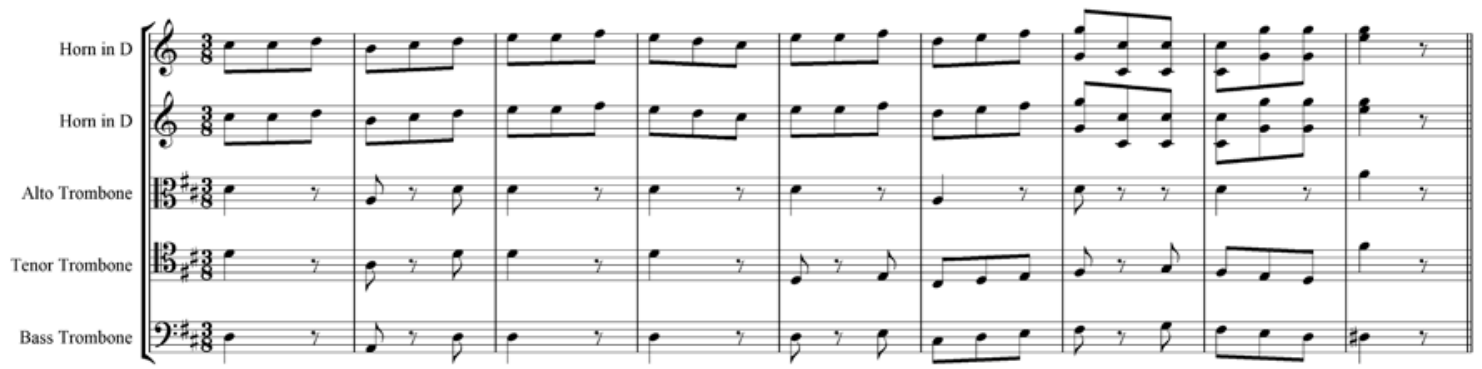

In the first measures, the trombones play the downbeat only, as has been seen in other examples. Then, starting with the fifth measure, the tenor and bass trombones play an abbreviated version of the melody, leaving out every repeated note, as the horn parts — with the complete melody — reveal. This could very well be an example of the "French distrust" of fast trombone notes Guion referred to in describing Beethoven's scoring for trombones. ${ }^{233}$ It does seem that in this case Beethoven simplified the trombone parts to prevent the section from lagging behind the rest of the winds and brass in the technically complex passage.

Wellington's Victory also includes a few passages where the trombone section has the same note values as the rest of the orchestra. The note values tend to be long in those cases:

Example 68: Wellington's Victory, Charge, measures 17-21

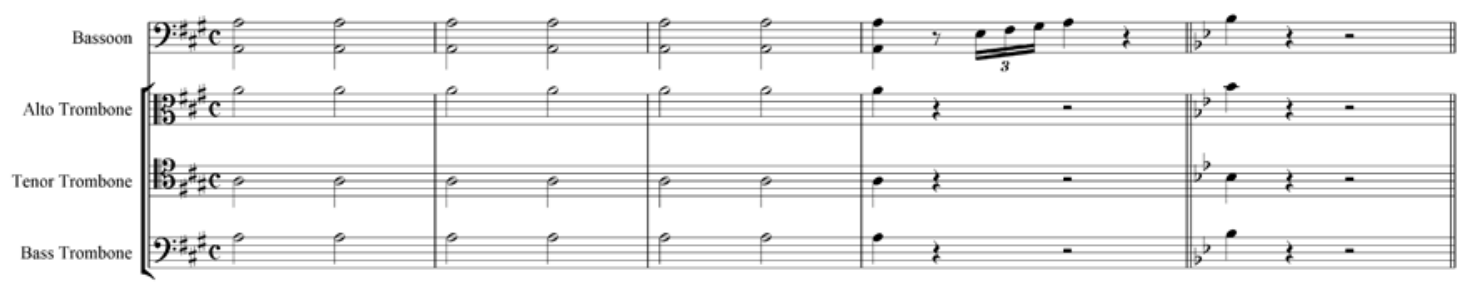

This same basic passage is played four times, each time one half-step higher, building in intensity. The trombones play the second and third times. Later, in the same "Charge"

\footnotetext{
${ }^{233}$ Guion, The Trombone: Its History and Music, 1697-1811, 277. By the term “French Distrust," Guion is referring to the poor quality of French trombonists at the time, and their inability to play notes of any rapidity.
} 
movement, there is a passage where the bass trombone plays higher than the tenor trombone:

Example 69: Wellington's Victory, March, measures 91-98

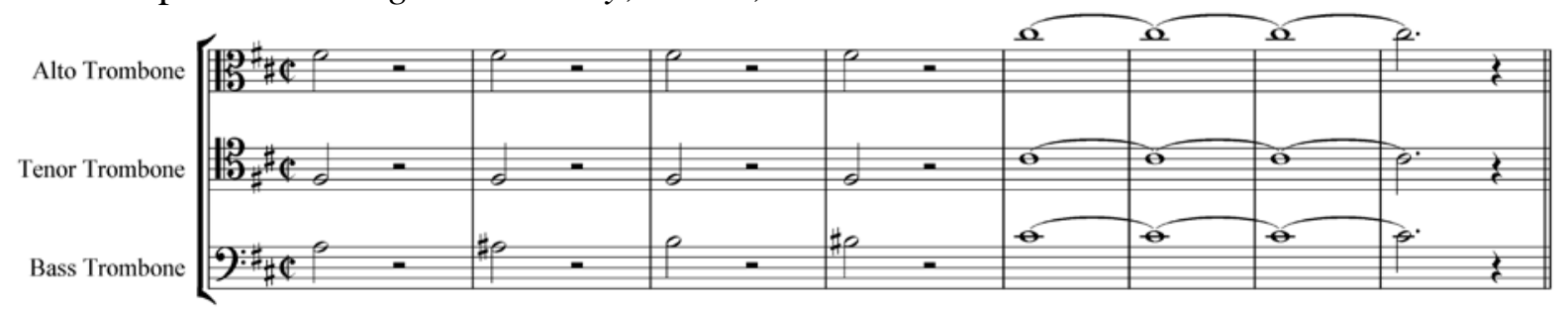

In other works that include trombones, even when they were doubling voices in a fugue, Beethoven-likely in an effort to preserve the specific tone color of the three different trombones - tended to avoid writing the bass trombone higher than the tenor, or the tenor higher than the alto. But in this particular passage, which is repeated in the next eight measures, the bass trombone for four measures (two times) is higher than the tenor, until they join together on the unison $\mathrm{c \#}^{1}$. The reason for this exception is that in this passage, the bass trombone doubles the bass part, and Beethoven probably chose to continue the doubling through the passage, rather than transfer the bass line to a higher instrument like the tenor trombone. By keeping the part in the bass trombone, Beethoven was able to preserve a consistent tone color.

There is also one example of what could be called a section solo, though it is not on the same level of sophistication as compared to section soli from other works already studied:

Example 70: Wellington’s Victory, Victory Symphony, measures 288-292

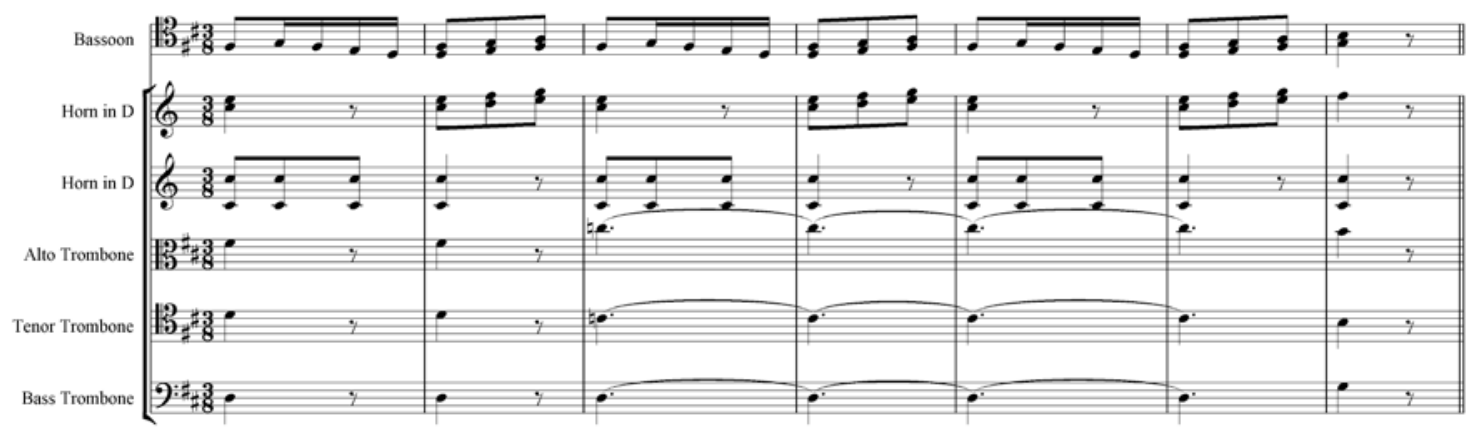


The trombones are the only instruments to sustain the Dominant $7^{\text {th }} \mathrm{C}$, although the violas and second violins have the same note on a tremolo. The musical outcome is very effective: the burden to resolve the dominant seventh builds through the four measures of the chord, and the silent bar (not shown in the example) immediately following the resolved chord makes the resolution even more provocative. The trombones, with their powerful projective capabilities, are the perfect instruments to create and resolve this level of musical tension.

In conclusion, Wellington's Victory employs, for the most part, techniques for orchestrating the trombones that have been encountered before. The section is scored almost exclusively as doublers in tutti passages. The rhythms of the doubling parts are usually simplified so as to avoid "fast" notes. Sometimes the trombone notes are longer than the rest of the orchestra, and sometimes they are shorter. Usually the longer note values create a phenomenon where the trombones "hang over" longer than the rest of the orchestra. The overall tessitura of the trombone section tends to stay within a tenth-somewhat narrower than in other works. In addition, another technique that was not seen in earlier works is the use of close harmony in the trombone parts. There are many instances where the three trombone parts stay within a fifth. This happens more often in Wellington's Victory than in any work yet encountered. The closer harmony tends to make the trombone section stand out more than wider harmonies (such as those of a tenth or above). There are several momentary prominences where the trombones have an important chord or moving passage. There is also one unusual section solo—on one note.

\begin{tabular}{|c|l|c|l|l|c|c|c|}
\hline \multicolumn{6}{|c|}{ Table 13: Trombone Statistics for Wellington's Victory, Opus 91 } \\
\hline \multicolumn{2}{|c|}{ Movements } & \multicolumn{3}{|c|}{ Measures } & \multicolumn{4}{c|}{ Ranges } \\
\hline Total & \#Played & Total & \#Played & \%Played & Alto & Tenor & Bass \\
\hline 2 & 2 & 698 & 290 & 42 & a to $\#^{2}$ & $\mathrm{e}^{b}$ to $\mathrm{c}^{2}$ & $\mathrm{G}$ to gb \\
\hline
\end{tabular}




\section{The Glorious Moment, Opus 136}

The enormous success of Wellington's Victory—and more importantly Symphony \#7 and Symphony \#8-set the stage for a European-wide explosion of Beethoven’s popularity. The Vienna Congress, convened in November 1814, brought to that city royalty and diplomats from virtually every country in Western Europe. Although the purpose of the Congress was clearly political—the drawing of peace treaties and new political boundaries following the end of the Napoleonic Wars and the dissolving of the Holy Roman Empirethe cultural activities surrounding the Congress were tremendous. Solomon says:

...a vast program of entertainment intended to divert the throngs of idle notables wholly occupied the foreground. Kaiser Franz appointed a festivals committee, whose members "were driven to distraction by the task of inventing new forms of amusement." There was a multitude of balls, banquets, and gala performances and an endless variety of tournaments, hunts, theatricals, sleighing expeditions, ballets operas, balloon ascents, and torchlight parades. ${ }^{234}$

As dignitaries poured into Vienna for the Congress and availed themselves of the many distractions, they were exposed to the music of Vienna's great composers, including Beethoven. He had been on vacation in Baden at the time, but cut it short to return to Vienna for the Congress. ${ }^{235}$ The Court Theatres, now under the direction of Ferdinand Plaffy, produced Fidelio on September 26, which was attended by many of the visiting dignitaries, ${ }^{236}$ including Alois Weissenbach, poet and Professor of Surgery at the St. John's Hospital in Salzburg. After the performance, he wrote in his memoirs, titled "Journey to the Congress:"

Completely filled with the gloriousness of the creative genius of this music, I went from the theatre home with the firm resolve not to leave Vienna without having made the personal acquaintance of so admirable a man; and strangely enough! when I reached my lodgings I found Beethoven's visiting card upon my table with a cordial invitation to breakfast with him in the morning. And I

\footnotetext{
${ }^{234}$ Solomon, Beethoven, 289.

${ }^{235}$ Thayer, Life of Beethoven, 593.

${ }^{236}$ Ibid., 594.
} 
drank coffee with him and received his handgrasp and kiss. Yes, mine is the proud privilege of proclaiming publicly, Beethoven honored me with the confidence of his heart. ${ }^{237}$

Thayer contends that it was at this meeting that Beethoven received a text which he then set to the music of The Glorious Moment, a work he had been composing over the last few months in anticipation of the Vienna Congress. After three postponements due to problems in producing accurate parts, ${ }^{238}$ Beethoven premiered his new cantata—despite it not being thoroughly proofread—on November 30, along with his already popular works Wellington's Victory and Symphony \# 7. The attending dignitaries exposed to Beethoven's music at the performances in November spread word of the genius of the Viennese composer. David Wyn Jones says, "For the first time in his career Beethoven was at the very centre of musical life in Vienna.”239 The level of popularity Beethoven achieved from the performances of his Symphony \#7, Wellington's Victory, and Fidelio in 1813 and 1814 was unprecedented. His compositions specifically written for the Congress of Vienna set the stage for even further augmentation of his elevated status. Schindler says:

At the end of [this time] we saw the composer at a height of fame never before achieved by a musician who was still in the midst of his artistic activity. Let us not forget, however, that this fame was the fruit of twenty years' unremitting toil. This moment of glory, coinciding as it did with a moment of profound historical significance, was one of the most brilliant events in the whole history of music. ${ }^{240}$

As with most of the Vienna Congress works, The Glorious Moment is virtually unknown today, but at its premiere, the work was very warmly received and considered to contain excellent music. However, Weissenbach's text was deemed far below the level of the music

\footnotetext{
${ }^{237}$ Thayer, Ibid., 595.

${ }^{238}$ Alan Tyson, "Steps to Publication-and Beyond," in Beethoven Companion, ed. Denis Arnold and Nigel Fortune (London: Faber and Faber, 1971), 471-472. This also explains the surprising differences between the trombone parts in the Breitkopf and Härtel edition of The Glorious Moment and the new Critical Edition (See Beethoven Werke X; 1, The Glorious Moment [Munich: Henle, 1996], 184-189, 221-225, 249-253).

${ }^{239}$ David Wyn Jones, The Symphony in Beethoven's Vienna (New York: Cambridge University Press, 2006), 169.

${ }^{240}$ Schindler, Ibid., 204-205.
} 
that accompanied it. In fact, while Mendelssohn said that musically the work contained “splendid things,” he dismissed the text as “wretchedly stupid words.” 241

The score of The Glorious Moment calls for alto, tenor, and bass trombone. The work consists of six movements, with the trombones present in all six. In most of the numbers they tend to support the full chorus. The range of the trombones in The Glorious Moment is unlike other works written during the same time period: the tessiturae are more along the lines of Symphony \#5, with the alto part ranging from $\mathrm{f}$ to the high $\mathrm{e}^{2}$. The tenor ranges from a surprisingly low $A$ to $\mathrm{g}^{1}$, and the bass is from $\mathrm{G}$ to $\mathrm{d}^{1}$. The section tends to play in chords, mostly in close position. In fact, there is only one instance of a chord spanning a tenth, one instance of an eleventh, and one of a thirteenth. The trombone section rarely plays in octaves, and when they do, it is usually a tutti section where the orchestra plays in unison. Another interesting aspect of The Glorious Moment is that, besides Consecration of the House, it is the only orchestral work where the trombone section plays the very first measure:

Example 71: The Glorious Moment, Number 1, measures 1-5

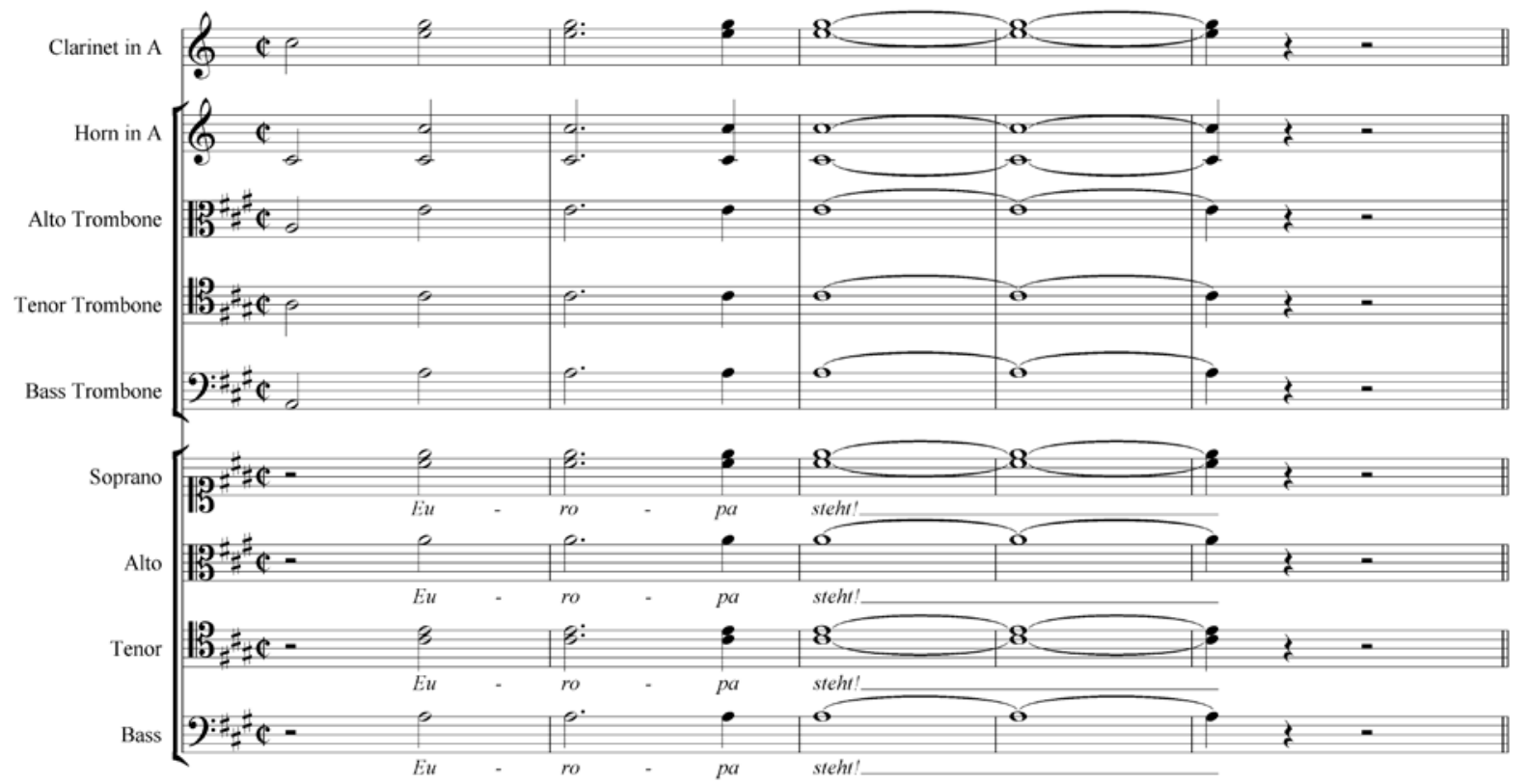

${ }^{241}$ Letter from Felix Mendelssohn, quoted in Beethoven Companion, ed. Thomas Scherman and Louis Biancolli (Garden City: Doubleday, 1972), 783. 
Throughout Number 1, the trombones join the various tutti sections, though not specifically doubling the choir:

Example 72: The Glorious Moment, Number 1, measures 98-103

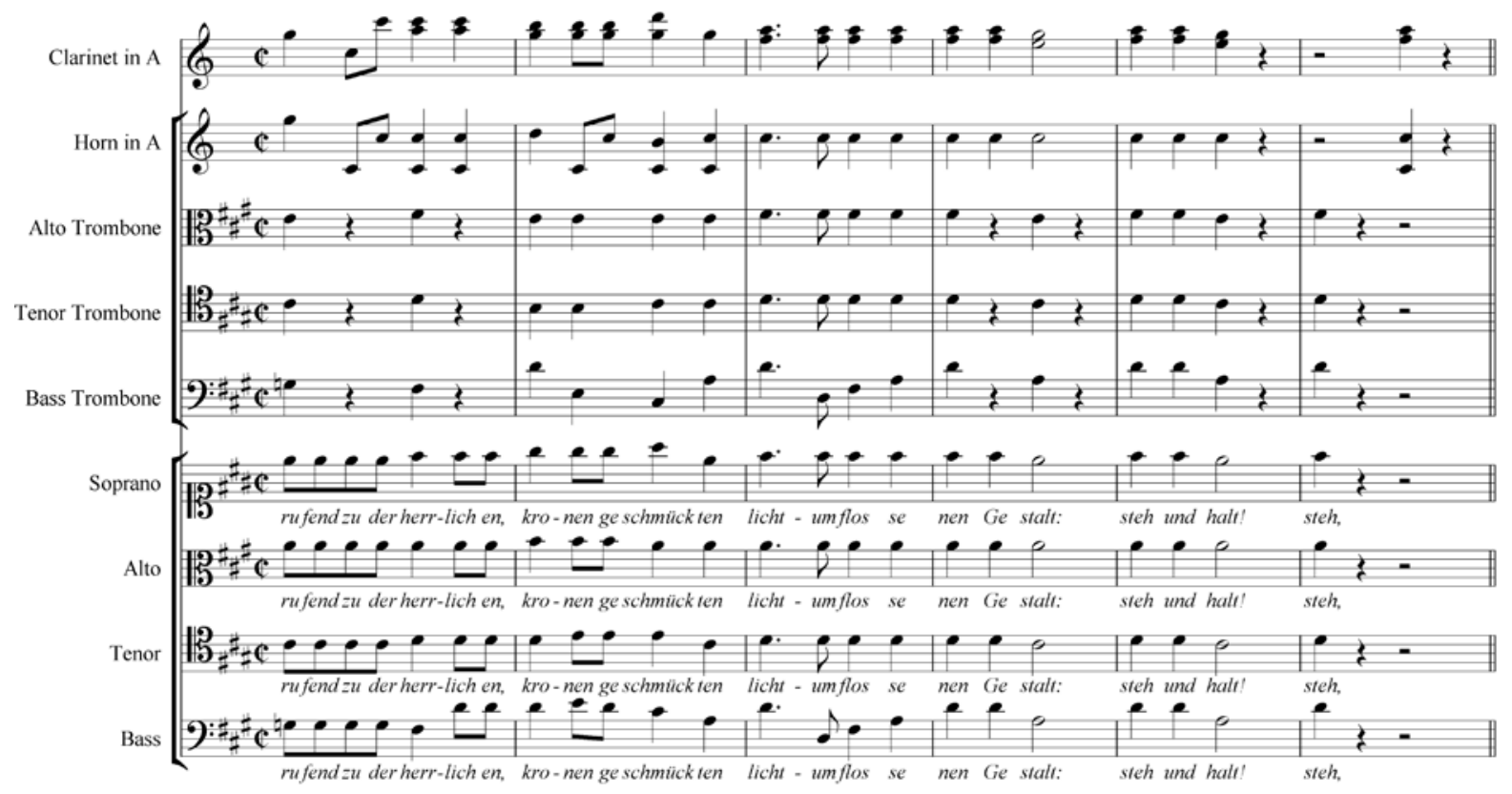

In the last measure of the example, the trombones (and strings, not shown) switch over to doubling the voices on the downbeat, but for just two measures. The rest of the number is tutti section playing. In the next number (2), the trombones enter in the opening Recitative. They are also the only brass instruments to play the rhythmic passage with the woodwinds:

Example 73: The Glorious Moment, Number 2, measures 10-18

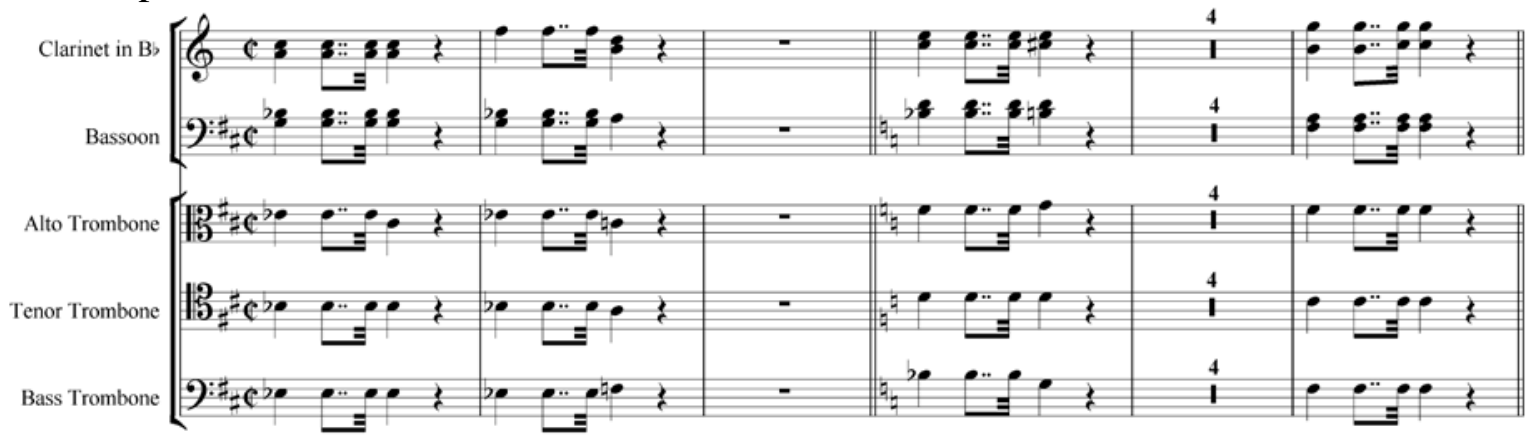

In this example, there is no rhythmic abbreviation: the trombones play the same rhythm as do the rest of the woodwinds. This example resembles Example \#17 from Leonore. It seems 
that in Recitatives, Beethoven tended to not rhythmically abbreviate the trombone parts.

Several of the following examples contain trombone parts not in the original Breitkopf and Härtel edition of The Glorious Moment. In fact, the new Critical Edition has the trombones playing in 85 more measures than the old edition. ${ }^{242}$ Most of these examples are indicative of different orchestrational techniques. The first one is tutti scoring:

Example 74: The Glorious Moment, Number 2, measures 46-65

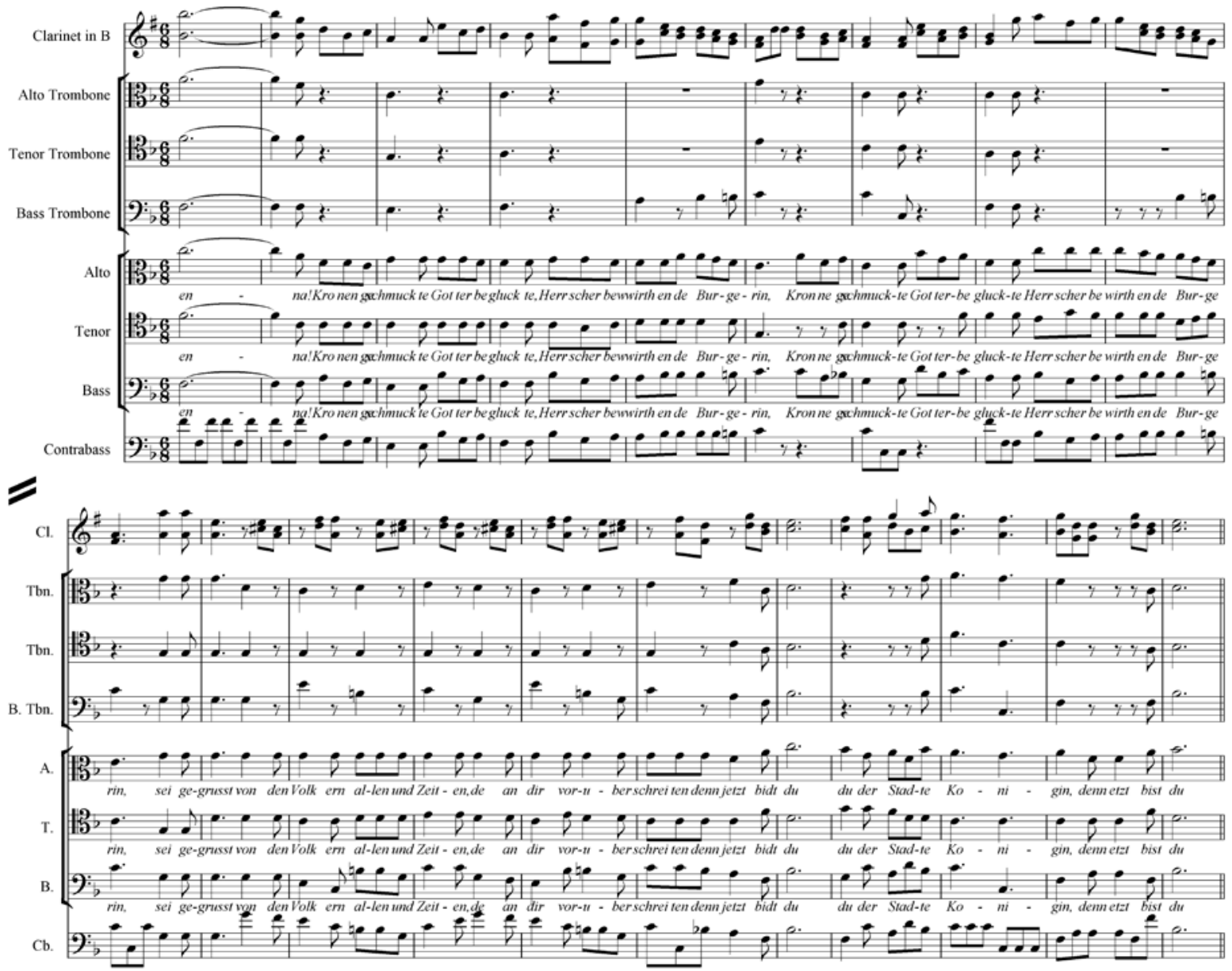

The trombone section plays mostly tutti downbeats throughout this passage, with only occasional notes (in the bass trombone) matching those of the choir (the fifth and ninth measures of the example). These same notes are doubling the string bass as well, so again this is most likely an indication of tutti playing on the part of the trombones, instead of

${ }^{242}$ See Beethoven Werke X; 1, The Glorious Moment (Munich: Henle, 1996). 
occasional doubling of the choir. The clarinet part is indicative of the activity of the rest of the woodwinds, and the high strings (not shown) play eighth notes and sixteenth notes throughout the passage.

The next section not in the Breitkopf and Härtel score is from the third movement. It is an excellent example of the Viennese church music style of trombone writing:

Example 75: The Glorious Moment, Number 3, measures 193-204

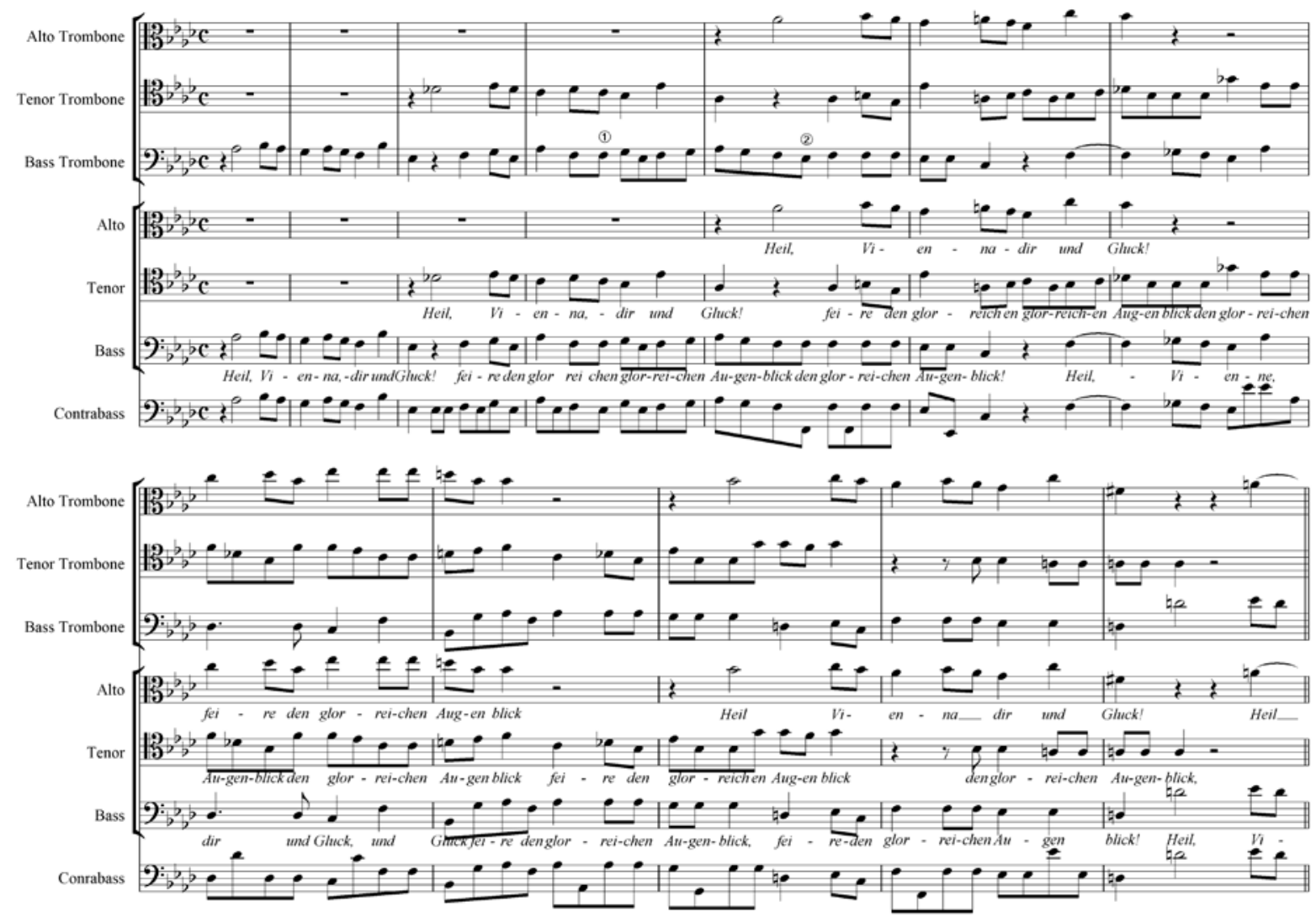

The trombones follow their corresponding vocal parts exactly: the alto trombone doubles the alto voice, the tenor trombone the tenor voice, and the bass trombone the bass voice. ${ }^{243}$ The woodwinds and strings (not shown) have eighth and sixteenth notes. Notice especially the alto trombone part. In this case, when the alto voice reaches into the extreme upper tessitura

${ }^{243}$ Notice the (1) and the (2) above the bass trombone part in measures four and five of this example. In these two cases, the note in the bass trombone creates a whole step between the string bass (measure four) and the bass voice (measure five). While it is difficult to determine whether these two notes are errors in this case, there is a similar case in Missa Solemnis that is easier to figure out. See discussion of Missa Solemnis below. 
of the alto trombone, Beethoven (or more likely a copyist) did not omit the alto trombone notes (as was done in Missa Solemnis and Symphony \#9), but instead had the instrument play up to the high $e^{b^{2}}$, a range that had not been used since Symphony \#5. ${ }^{244}$ This same form of Austrian style doubling continues in the following measures:

Example 76: The Glorious Moment, Number 3, measures 205-212

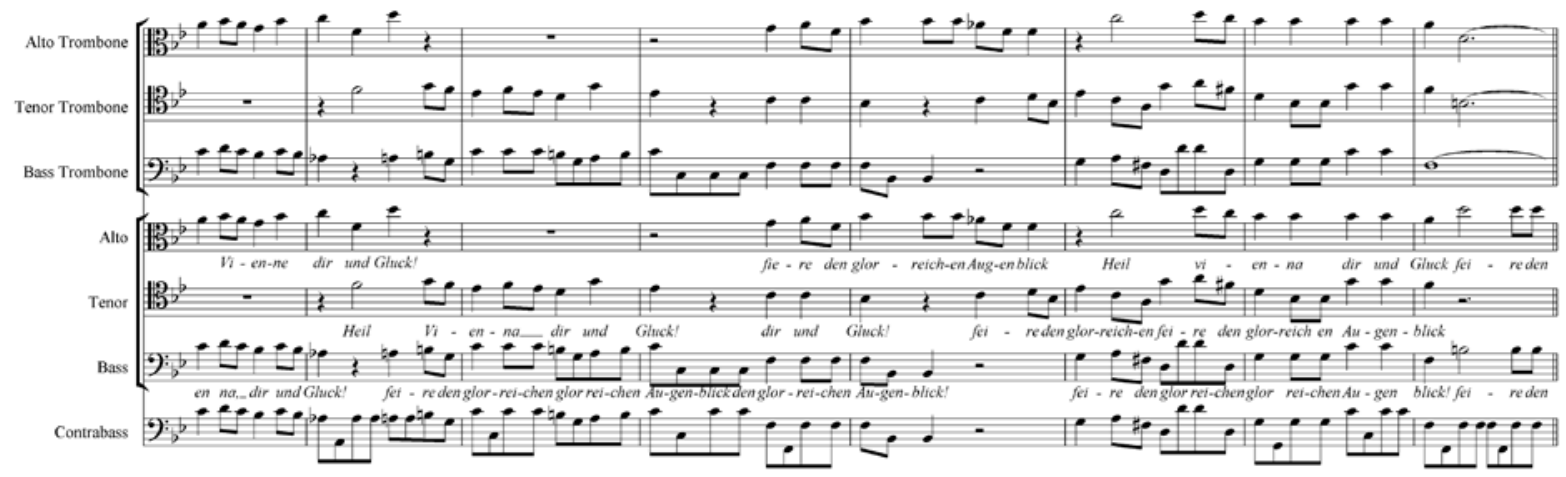

Notice the last measure of the example, where the trombone parts change from doubling the chorus to more of a tutti role. This continues through the end of the movement: ${ }^{245}$

Example 77: The Glorious Moment, Number 3, measures 216-223

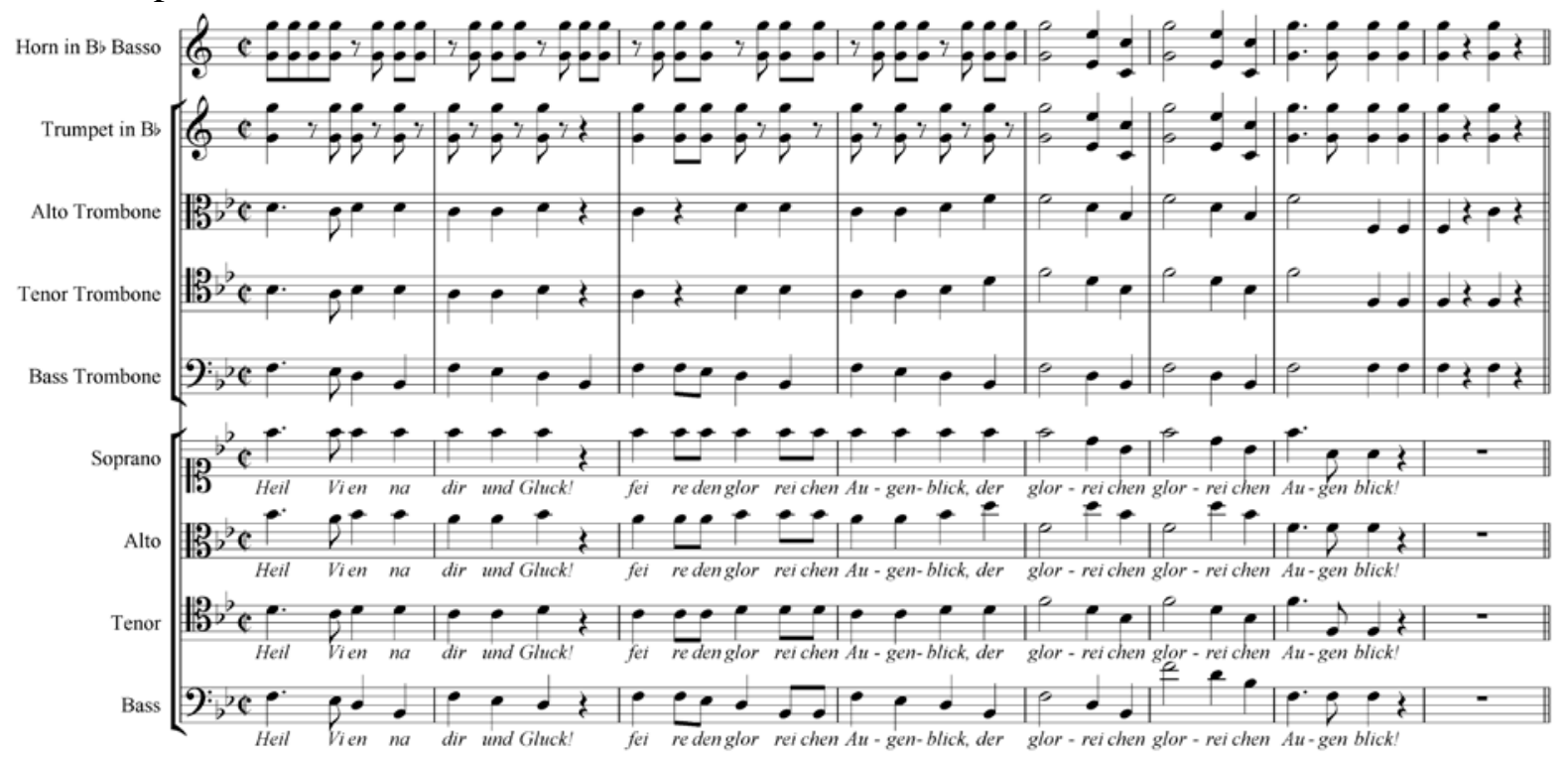

${ }^{244}$ Tyson, "Steps to Publication—and Beyond," in Beethoven Companion, Ibid., 471. However, had the copyists more time to carefully edit the parts, they might have removed the high alto trombone notes. (For more information on copyists, see the discussion of Missa Solemnis below. Also see Tyson, "Notes on Five of Beethoven's Copyists," Journal of the American Musicological Society 23 [1970], 439-471.)

${ }^{245}$ In this example (Number 77), the trombone parts are the same in both editions. 
Notice the change in doubling assignments in this example. First, the alto trombone doubles the tenor voice at pitch while the tenor trombone doubles the alto voice one octave lower. Second, only the bass trombone has moving eighth notes in the third measure of the example. Third, it is the trumpet—not the clarinet as in previous examples—-that doubles the soprano part. At this point, it is as if Beethoven were creating a hybrid of the Handel/Haydn style and the Viennese church music style, forming a trombone section that acts as a bridge between the choir and the orchestra—not completely doubling either entity, but filling in parts as needed to support either orchestra or chorus. This is also seen in Example 79 below.

The Recitative in Number 4 is similar in scoring as the previous Recitative studied (see Example 73 above), except that in this case the rhythm of the trombones is abbreviated. The reason may be because in this example the sixteenth notes are pickups, whereas in Example 73 (and Example 17, Leonore), the rhythmic passage begins on the beat. Perhaps Beethoven trusted the trombones to play complex rhythms insofar that there were no pickup notes involved. His concern could have been because the trombone section, placed in the back of the orchestra, might be behind the beat when playing pick-up notes:

Example 78: The Glorious Moment, Number 4, measures 7-9

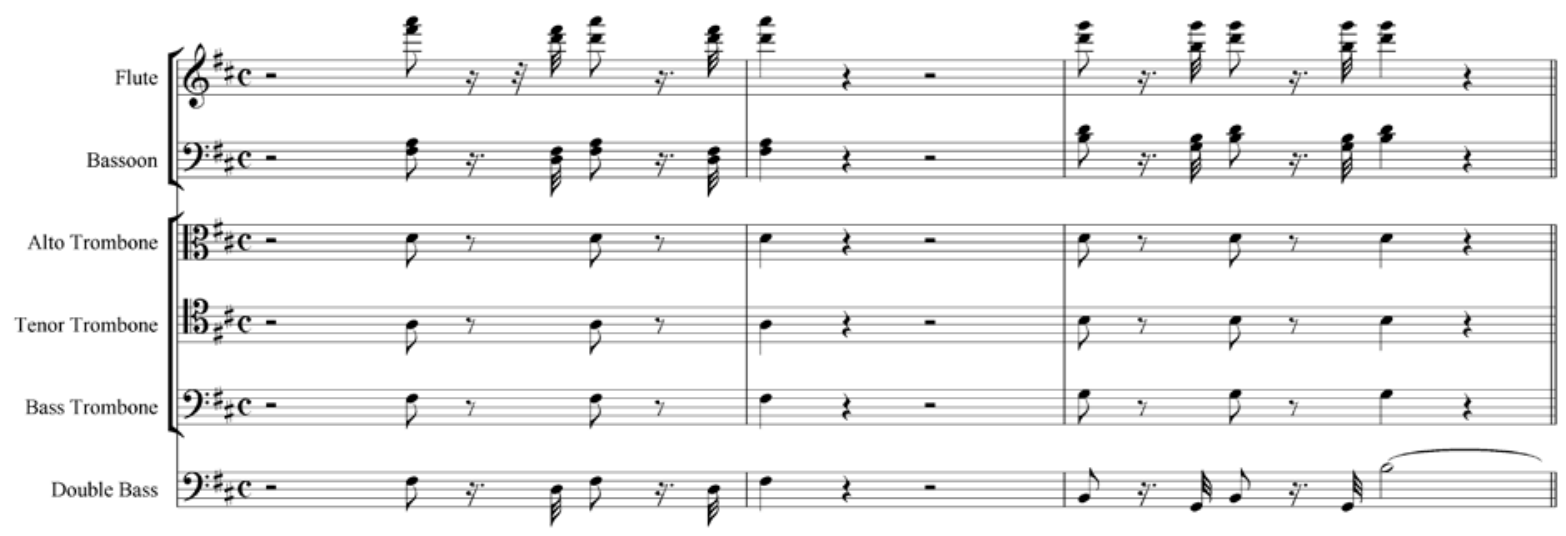

As was the case in the previous Recitative, the trombones are the only brass instruments playing. Doubling is typical in the bass trombone, which follows the celli and basses in the 
first two measures; however, it is atypical in the alto trombone, which doubles the second flute in the first measure of the example, joined by the first bassoon in the third measure.

The next example—-the final one from trombone parts not found in the earlier editions of The Glorious Moment—is closer to the Handel/Haydn style of trombone writing:

Example 79: The Glorious Moment, Number 4, measures 55-74

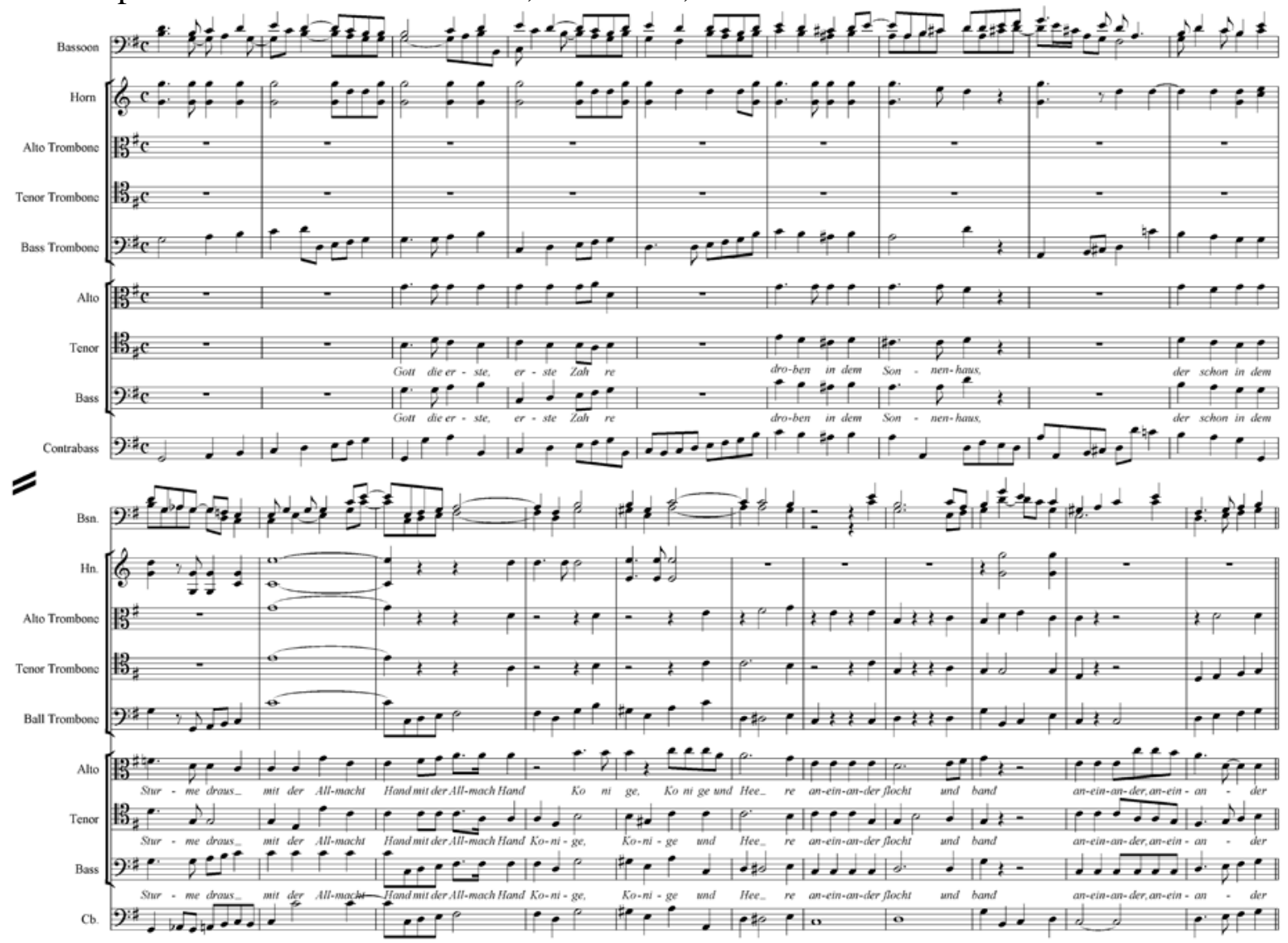

The bass trombone plays the entire passage more or less acting independently of the other two trombones. This is reminiscent of how the bass trombone was scored as a section of one in King Stephen. In the first two measures of the example the bass trombone doubles the string basses. Then, in the third and fourth measures of the example, the part switches to doubling the choir. This switching back and forth continues throughout the example. Sometimes the rhythm is abbreviated (eighth and tenth measures), but in the first measure of the example the bass trombone part is more complicated rhythmically than the string bass 
part. The bassoons provide an example of the activity of the other woodwinds. The high strings (not shown) have running eighth notes throughout the example. When the alto and tenor trombones finally enter (the eleventh measure of the example), they provide simple tutti downbeats, as well as some filling out of the chords. The bass trombone does not join the tenor and alto trombones in this, but continues to be independent of the rest of the trombone section, doubling the string bass and bass voices. The alto and tenor trombones in this example are acting in support of the horns and trumpets (not shown).

The final two movements of The Glorious Moment have the same trombone parts in both the earlier editions and the latest Critical Edition. The Recitative in the beginning of Number 5 is noteworthy, representing one of the only momentary prominences for the trombone section found in the work:

Example 80: The Glorious Moment, Number 5, measures 1-5

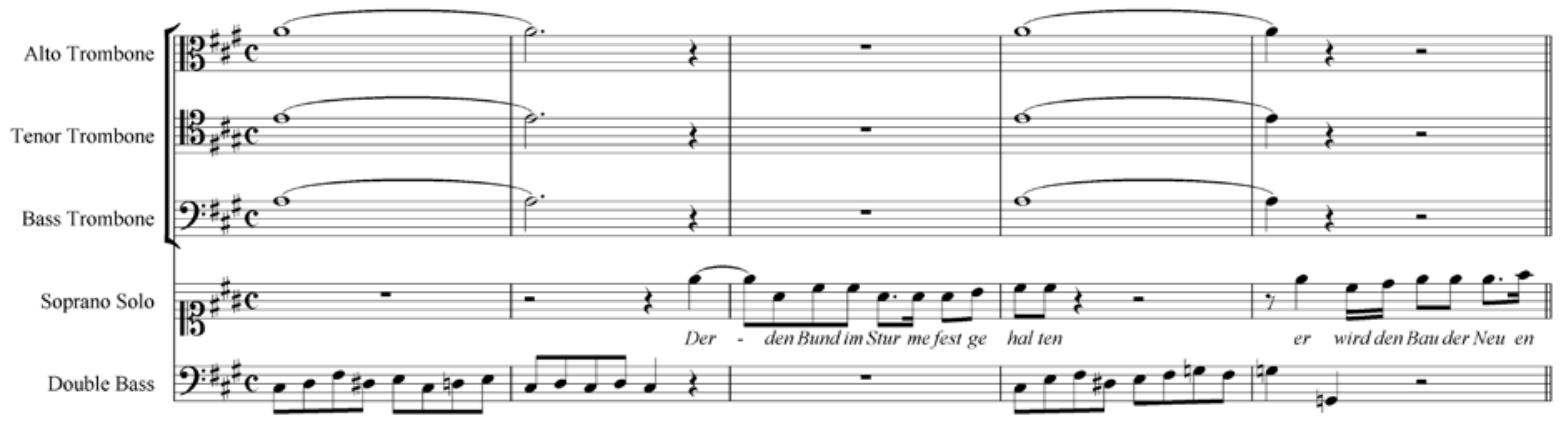

The double bass plays eighth notes while the rest of the strings (not shown) have sixteenth notes. The trombones play their chord alone, while the rest of the orchestra and chorus remain silent. The open fifth combined with the rest of the chord filled in by the fast-moving unison strings effectively depicts a storm scene, to which the vocal soloist is referring.

The final movement (Number 6) includes a fugue for the chorus, to which, in past works, Beethoven has shown a tendency to add trombones. In The Glorious Moment, the 
trombones double the chorus during the fugue, but the doubling is a patchwork and scant, as was often the case in Christ on the Mount of Olives:

Example 81: The Glorious Moment, Number 6, measures 120-139246

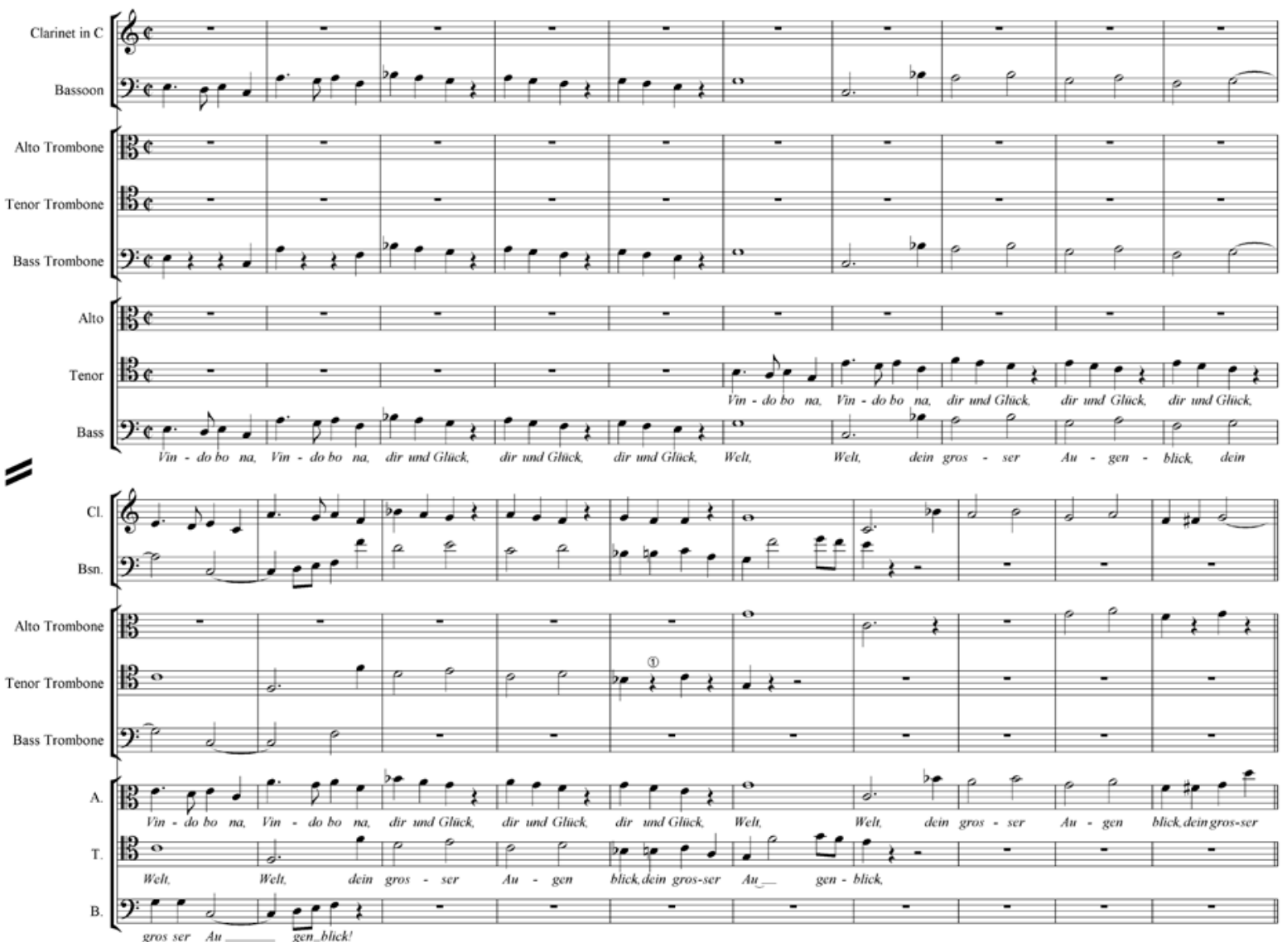

While the bassoon doubles the bass voice completely in the beginning of the example, the bass trombone fills in only half of the notes, and continues to do so through measure twelve of the example. When the tenor trombone enters in measure eleven, it is already six measures into the tenor voice's fugue subject; the beginning of the subject is omitted in the tenor trombone. The alto trombone's fugue subject is even more scant. Not only is the opening part of the subject omitted, but so are several other notes in the second half of the subject. The entire fugue subject of the alto voice is instead doubled by the clarinet. Later in

\footnotetext{
${ }^{246}$ In the measure with the (1) the tenor trombone plays a "b" in the Breitkopf and Härtel edition, the same as the Bassoon. The latest Critical Edition omits this note. (See Beethoven Werke X; 1, The Glorious Moment [Munich: Henle, 1996], 303.)
} 
the fugue, the trombones double the fugue fragment that is in half notes and quarter notes, while the woodwinds fill in the fragments that are twice as fast:

Example 82: The Glorious Moment, Number 6, measures 163-175

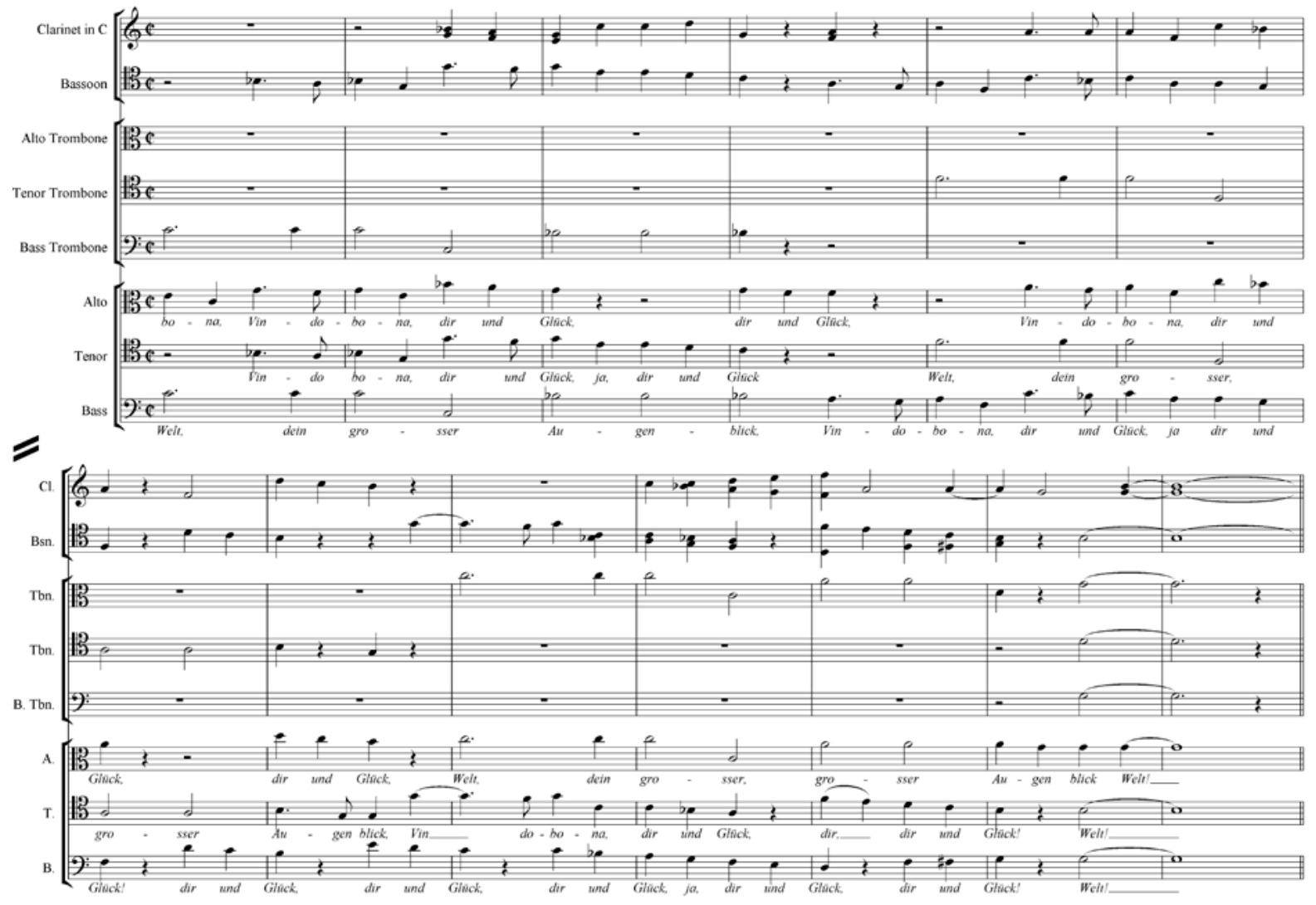

The longer subject, coupled with the words "Welt, dein grosser Augenblick" (meaning "world, your big moment”), is always played by the trombones, joined by the horns (not shown). The other more rhythmically complex fugue subject associated with the words "Vindobona, dir und Glück,” (meaning “Vindobona, you and good fortune”) is played by the woodwinds. The bassoons double excerpts of the tenor and bass voices, while the clarinets double the altos. The flutes and oboes (not shown) double the sopranos. As the work reaches its triumphant finale typical of Beethoven, the trombones join the tutti orchestra and chorus, the three parts doubling their respective voices: the bass trombone doubles the bass voice, the tenor trombone doubles the tenor voice, and the alto trombone doubles alto voice: 
Example 83: The Glorious Moment, Number 6, measures 215-224

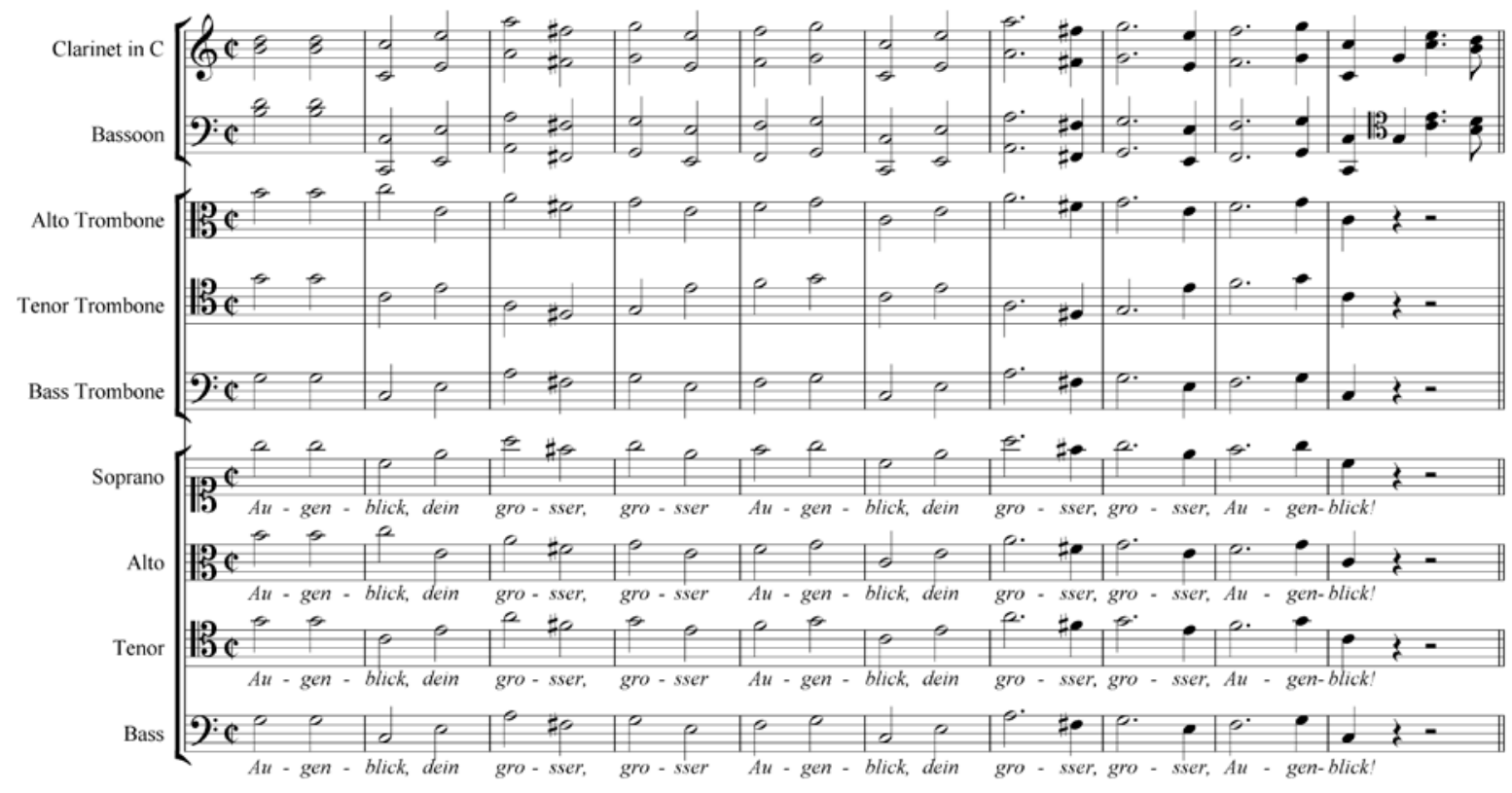

The work concludes with several measures like the final one in the above example, with trombones on the downbeat and the other brass and woodwinds with more complex rhythms. The Glorious Moment is Beethoven's only work which includes trombones, where the section plays both the beginning measures and the final measures as well. In fact, in Beethoven's choral works that include trombones, the percentage of measures the trombones play in The Glorious Moment is surpassed only by Missa Solemnis. The final measures of the work include a momentary prominence in the trombones and three downbeat chords:

Example 84: The Glorious Moment, Number 6, measures 228-234

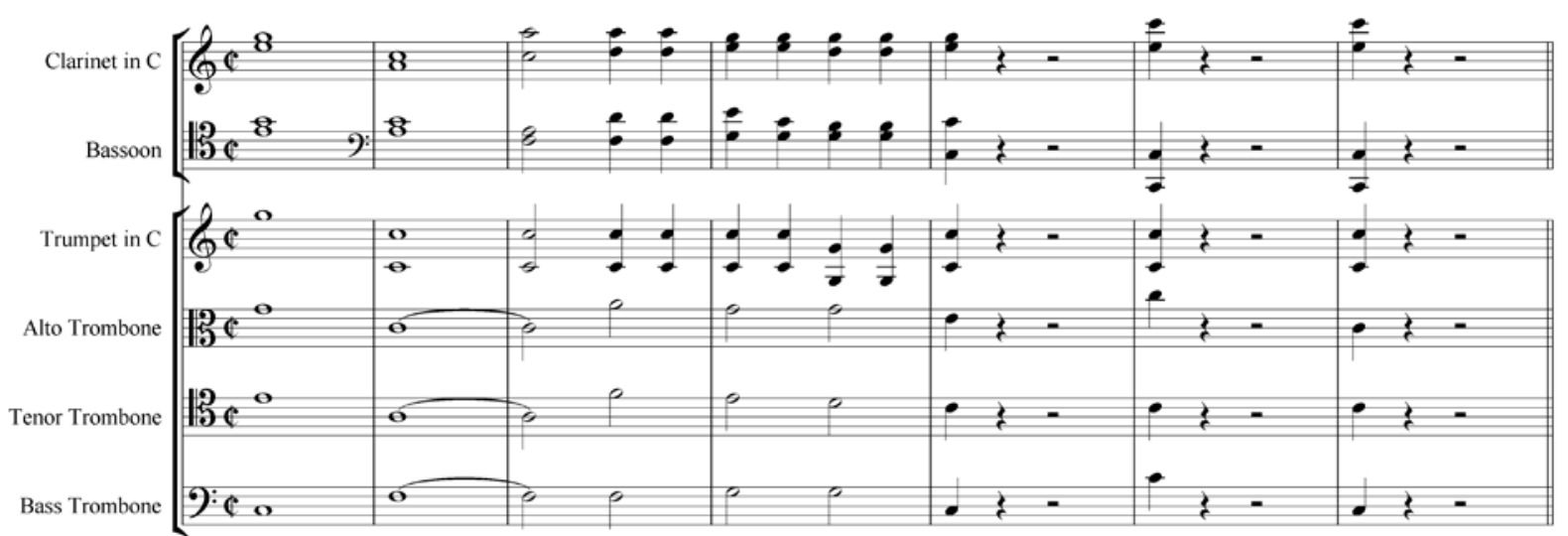


The trombones are scored in close harmony and root position, creating a clear, bright chord that stands out from the texture of the orchestra for a brilliant ending.

To conclude The Glorious Moment, this little-known work contains trombone scoring techniques that are not unusual for Beethoven. Some of the methods encountered include tutti orchestration with both typical and atypical doubling scenarios (typical would be bass trombone doubling string bass; atypical would be alto trombone doubling flute), rhythmic abbreviation, and momentary prominence. The presence of the trombones is limited to Recitatives and large choral sections, especially the choral fugues. For the most part, solo passages and arias do not include trombones in the orchestration. This is different than Christ on the Mount of Olives, for example, where the trombones-playing background chords softly—-were written as solo accompaniment. The range of the section-with the low $\mathrm{A}$ in the tenor and the high $\mathrm{e}^{b^{2}}$ in the alto — tends to be wider, along the lines of more daring works such as Symphony \#5. This is a departure from the conservative trend in the trombone range represented in most of Beethoven's other works written during this same time period. The trombone parts in The Glorious Moment are more extensive than in Beethoven's previous works that include trombones: the section plays in every number in the work, with more measures played overall. There are many trombone passages in The Glorious Moment that are brilliantly orchestrated, effective to hear, and interesting to perform.

While there are some examples of the Viennese church music style of doubling the chorus - found in the excerpts from the latest Critical Edition of the score-for the most part the choral doubling is influenced by the style of Handel and Haydn. Absent the Viennese church music examples, most of the choral doubling throughout the work is more abbreviated and a patchwork, as it was in other works such as Christ on the Mount of Olives. The 
Handel/Haydn technique successfully bolsters the choir in passages where the forces of the trombones are needed, but not so extensively as to over-orchestrate the trombones and bury the voices. The trombone scoring in the Recitatives begins to indicate a pattern of more rhythmically extensive trombone parts in specific applications. The replacing of the alto trombone-the instrument which traditionally doubled the alto voice-by the clarinet is a new idea developed throughout the vocal "patriotic works." This technique was further cultivated by the next generation of composers, especially Schubert. However, others such as Mendelssohn would continue to prefer the alto trombone over the clarinet as the instrument designated to double the alto voice.

\begin{tabular}{|c|l|c|l|l|c|c|c|}
\hline \multicolumn{6}{|c|}{ Table 14: Trombone Statistics for The Glorious Moment, Opus 136 } \\
\hline \multicolumn{2}{|c|}{ Movements } & \multicolumn{3}{c|}{ Measures } & \multicolumn{4}{c|}{ Ranges } \\
\hline Total & \#Played & Total & \#Played & \%Played & Alto & Tenor & Bass \\
\hline 6 & $6^{247}$ & 1056 & $297^{248}$ & 28 & f to e $b^{2}$ & A to g & G to d $^{1}$ \\
\hline
\end{tabular}

\section{It Is Accomplished, WoO 97}

The last of what have been called the Patriotic works is a short piece for orchestra, choir, and bass solo. The year It Is Accomplished was written-1815-was another artistically dry time for Beethoven. The only important works of the year were the Sonata for Piano, Opus $90,{ }^{249}$ and the Two Sonatas for Cello and Piano, Opus $102 .{ }^{250}$ He also had very few performances in 1815, one of them being a benefit for the Children’s Hospital Fund on December 25, where Christ on the Mount of Olives was performed. ${ }^{251}$ The other work that received attention was It Is Accomplished, which was performed in Vienna on July 15, 16,

\footnotetext{
247 The trombones play only the Recitative in Number 5.

248 The Old Beethoven Edition has trombones in 212 measures, making the percentage 20 instead of 28.

${ }^{249}$ Kinderman, Beethoven, 202.

${ }^{250}$ Ibid., 204.

${ }^{251}$ Solomon, Beethoven, 289-290.
} 
and 23. ${ }^{252}$ The short work was based on the final scene of an operetta titled "The Honored Gates.” Utilizing a text from Fidelio librettist and translator Georg Freidrich Treitschke (who wrote the 1814 version of the Fidelio libretto), It Is Accomplished was composed to commemorate the defeat of Napoleon at Waterloo. Solomon says It Is Accomplished was one of Beethoven's more successful attempts at “...rekindle[ing] the fading embers of his popularity by pursuing the musical formulas that had worked so well during the immediately preceding years.”253 The year 1815 brought to a close an era in Beethoven’s life. Over the past few years of 1812-1814 he had attained fame throughout Europe and had composed some of the most important works of his life. ${ }^{254}$ However, he would also emerge from this rich time to see some of his strongest supporters and closest benefactors die, including Lichnowsky and Lobkowitz. ${ }^{255}$ Kinderman sums up the period in Beethoven’s life:

His public popularity was now on the wane; the composer of the hour was Rossini. As complete deafness closed in on Beethoven, he approached his greatest artistic challenges. Slowly and deliberately he assembled the elements of an unprecedented stylistic synthesis, whereby nothing was lost and yet everything changed. ${ }^{256}$

While the performances of It Is Accomplished offered Beethoven a temporary respite from the difficulties associated with his physical ailments and waning artistic popularity, the years following the Vienna Congress would turn out to be his most difficult and challenging.

In It Is Accomplished-a relatively short work consisting of 165 measures-the trombones play only two short sections: the first one comprising seven measures, and the second section comprising the final sixteen measures of the work. The range is more limited

\footnotetext{
${ }^{252}$ Thayer, Ibid., 620.

${ }^{253}$ Solomon, Ibid., 291.

${ }^{254}$ However, Solomon also rather cynically says that the Vienna Congress works were "filled with bombastic rhetoric and 'patriotic' excesses, mark[ing] the nadir of Beethoven's artistic career. In them his heroic style is revived, but as parody and farce (Solomon, Ibid., 287).”

${ }^{255}$ Ibid, 294.

${ }^{256}$ Kinderman, Ibid., 209.
} 
than any other work in which Beethoven included trombones. The bass trombone has the smallest tessitura of the three parts, being limited to a minor sixth-from $d$ to $b^{b}$. The tenor part has the widest range - though it is still inside an octave-from $b^{b}$ to $a^{1}$. The alto range is just a half-step wider than the bass, from $d$ to $b^{1}$. The parts are simpler-almost sketchy—as compared to other works that included trombones written approximately the same time. There are two kinds of scoring in It Is Accomplished: either the outer parts are written in octaves with the inner tenor voice doubling one of the outer voices, or the section plays a chord. Doubling is similar to other Beethoven works: the bass trombone doubles the bass and bassoon (though not as closely as in previous works), and the tenor and alto trombones double the clarinets or the oboe. The first entrance of the trombones is below:

Example 85: It Is Accomplished, measures 63-69

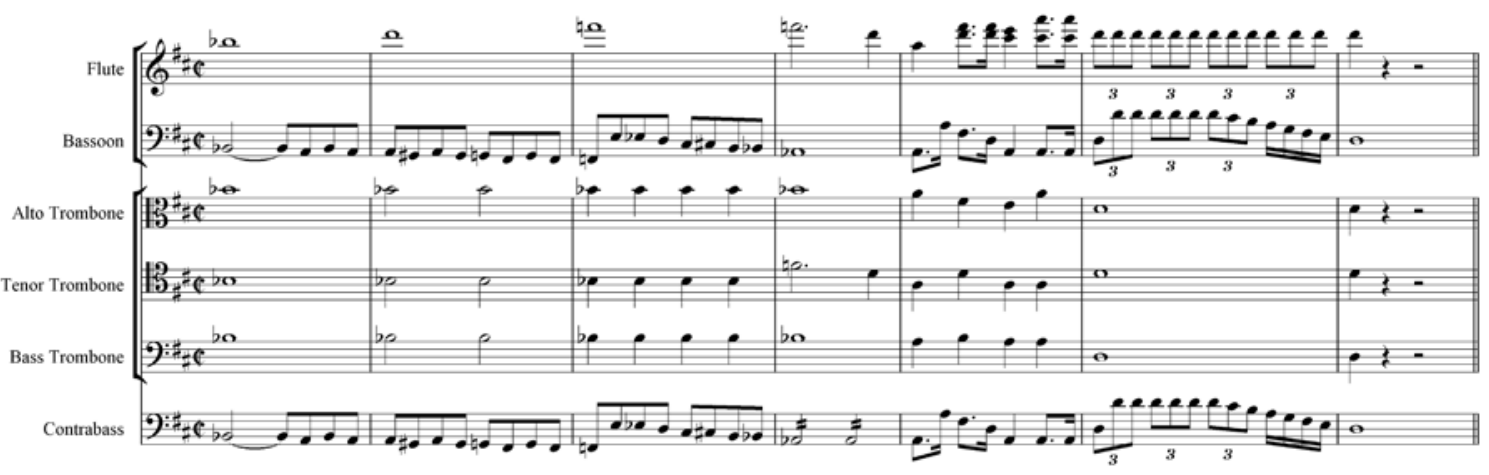

The second and third measures of the example indicate a technique Beethoven used in Christ on the Mount of Olives, seen in Example 10. The trombones repeat a note while the other instruments hold the note through. The result in Christ on the Mount of Olives was a soft rhythmic interchange between the trombones and the other instruments. The It Is Accomplished example is loud, resulting in the repeated notes of the trombones being brought out over the tutti orchestra, with less interplay and more rhythmic punctuation. Also, the fifth measure of the example shows the rhythmic abbreviation common in Beethoven trombone parts. The final nine bars of the work show the same technique: 
Example 86: It Is Accomplished, measures 157-165

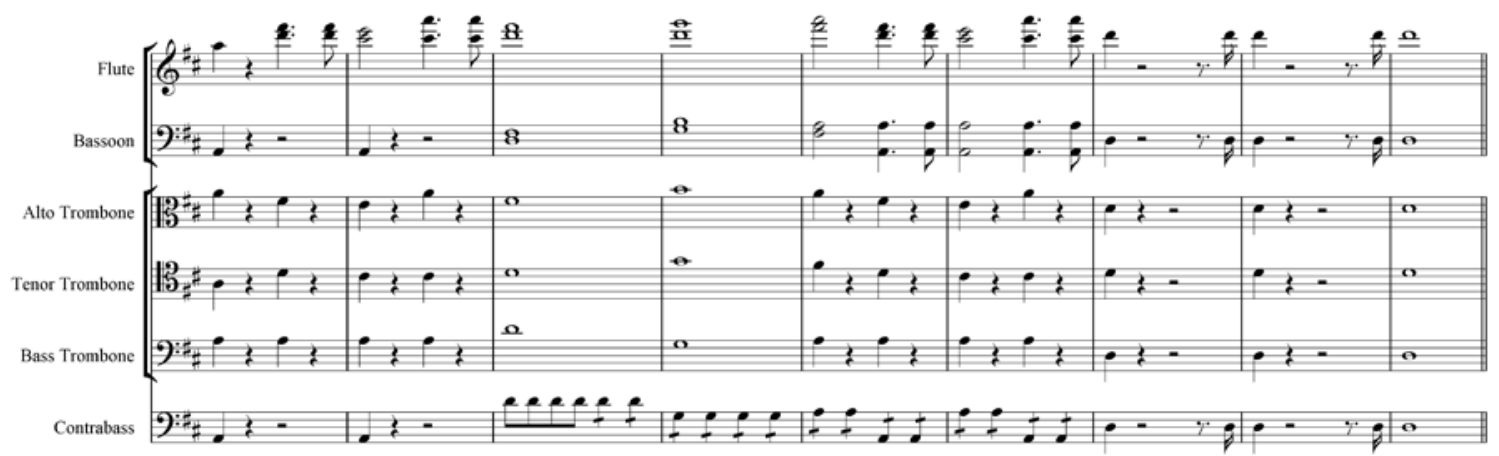

The first and second measures of the example show the simpler rhythm of the trombone parts, as do the last five measures. Each of the sixteenth note pickups in the winds, upper strings, and high brass (not shown) are omitted in the trombone parts.

In conclusion, It Is Accomplished is a short piece with limited trombone writing. The tessiturae of the three parts is more limited than most works already studied. The actual number of measures played is reduced as well. The trombone parts comprise simple doubling of other orchestral parts for the sake of buttressed downbeats in tutti loud sections. However, one new variation of an older technique can be seen where the trombones repeat a note over other instruments holding the same note. The result is a strong repetitive pulse from the trombone section, which would probably be playing a little more powerfully than the rest of the orchestra, and therefore would be slightly prominent.

\begin{tabular}{|c|l|c|l|l|c|c|c|}
\hline \multicolumn{6}{|c|}{ Table 15: Trombone Statistics for It is Accomplished, WoO97 } \\
\hline \multicolumn{2}{|c|}{ Movements } & \multicolumn{3}{c|}{ Measures } & \multicolumn{4}{c|}{ Ranges } \\
\hline Total & \#Played & Total & \#Played & \%Played & Alto & Tenor & Bass \\
\hline 1 & 1 & 165 & 23 & 14 & ${\text { d to } b^{1}}$ & $\mathrm{~B}^{b}$ to a & d to $b^{b}$ \\
\hline
\end{tabular}




\section{Chapter VI}

\section{Late Works}

\section{Missa Solemnis, Opus 123}

The beginnings of Missa Solemnis can be traced as far back as 1819, when it was announced that Beethoven's longtime pupil and benefactor, Archduke Rudolph, would be installed as Archbishop of Moravia on March 19, $1820{ }^{257}$ Upon learning of the announcement, an excited Beethoven wrote to the Archduke that "The day on which a High Mass composed by me will be performed during the ceremonies solemnized for Your Imperial Highness will be the most glorious day of my life," and that "I hope to complete the Mass and in good time too, so that, if the arrangement still stands, it can be performed on the $19^{\text {th }} .{ }^{258}$ Beethoven completed the Kyrie and Gloria in 1819, and began the Credo in early $1820,{ }^{259}$ completing it — as well as beginning the Benedictus—by Autumn that same year. ${ }^{260}$ As was often the case with Beethoven's compositions, the project grew to massive proportions, and the original projected date of completion passed by, leaving the work incomplete. ${ }^{261}$ At the time of writing Missa Solemnis, Beethoven was suffering from health problems $^{262}$ and legal battles over custody of his nephew Karl $^{263}$ (both which distracted him

\footnotetext{
${ }^{257}$ William Drabkin, Missa Solemnis (Cambridge: Cambridge University Press, 1991), 11. Schindler claims that the original announcement (and therefore the commencement of composition) was in 1818 (see Schindler, Beethoven as I Knew Him, 228), but Thayer contends that the announcements-the first being Rudolph's promotion to Cardinal, the second to Archbishop of Moravia-did not occur until April 24, 1819, and June 4, 1819, respectively (see Alexander W. Thayer, Life of Beethoven, 719). Therefore, the commencement of composition could not have occurred until after these two 1819 dates.

${ }^{258}$ William Kindermann, Beethoven (New York: Oxford University Press, 2009), 237-238.

259 Maynard Solomon, Beethoven, 322.

${ }^{260}$ Ibid., 343.

${ }^{261}$ One possible reason for the immense growth of his compositions was that he tended to offer his projected works for very high prices. Then as the work progressed, he was obligated to produce extraordinary works to justify the high asking price (see Kinderman, Beethoven, 238-239).

${ }^{262}$ Kinderman, Ibid., 239.

263 Thayer has detailed descriptions of the legal battles Beethoven fought over custody of his nephew. (See Alexander Thayer, Life of Beethoven [Princeton: Princeton University Press, 1964], 694-717.)
} 
from completing the Mass). With the increasing legal fees, Karl's tuition payments, and his other daily expenses, Beethoven began to slip into debt. ${ }^{264}$ In an effort to ameliorate his obligations, he offered Missa Solemnis for publication to Simrock in Bonn and settled on a fee to be held in escrow. Beethoven then managed to talk Franz Brentano (who helped negotiate the deal with Simrock) into an advance-from his own pocket—on the escrowed funds, while at the same time offering Missa Solemnis to at least six other publishers, including C.F. Peters in Leipzig and Schott in Mainz (who eventually published Missa Solemnis in 1825). ${ }^{265}$ In an effort to play these publishers against each other, Beethoven delayed releasing the Missa Solemnis score, during which time he would revise and add to the work, thus making an already full work more ponderous. Beethoven even informed the two original publishing companies with a stake in Missa Solemnis (Simrock and Peters) that he was actually working on two (or even three) Masses. ${ }^{266}$ Beethoven's dishonesty was eventually discovered, and being unable to repay Brentano his advance, he defaulted on the loan and effectually ended an 11-year friendship. ${ }^{267}$

The publishing difficulties surrounding Missa Solemnis serve as an illustration of the type of emotional (and sometimes physical) exertion and anguish that surrounded the work from its inception. Solomon says:

Indeed, there is a sense in which the Missa Solemnis came to be regarded by Beethoven as a talismanic composition, whose value to him was so great that...he embarked on a unique series of financial negotiations and manipulations in respect to its publication, which cost him several friendships

\footnotetext{
${ }^{264}$ Solomon, Beethoven, 354.

${ }^{265}$ William Drabkin, Missa Solemnis (Cambridge: Cambridge University Press, 1991$), 17$.

${ }^{266}$ Drabkin says that Beethoven's claims of multiple masses "led some biographers to suggest that at least one Mass may have been left unfinished at the time of his death...[but] the actual composition of these works could only have been wishful thinking on Beethoven's part, and the sketchbook entries represent no more than a halfhearted attempt to unburden a guilty conscience.” (See William Drabkin, Missa Solemnis [Cambridge: Cambridge Univeristy Press, 1964], 109, fn. 3.)

${ }^{267}$ Drabkin, Ibid., 355.
} 
and gave him an unpleasant, but deserved, reputation for sharp business practice. ${ }^{268}$

Legal and health battles notwithstanding, the composition of Missa Solemnis consumed Beethoven to a depth not seen by his friends before. According to Solomon, it even replaced “...Fidelio as the great 'problem work' of his career." ${ }^{269}$ Schindler referred to it as “...a colossal work, in which the composer concentrated his entire musical wealth.”270 He also relates this bizarre and amusing report:

From behind the closed door of one of the parlours we could hear the master working on the fugue of the Credo, singing, yelling, stamping his feet. When we had heard enough of this almost frightening performance and were about to depart, the door opened and Beethoven stood before us, his figures distorted to the point of inspiring terror. He looked as though he had just engaged in a life and death struggle with the whole army of contrapuntists, his everlasting enemies. His first words were confused, as if he felt embarrassed at having been overheard. Soon he began to speak of the day's events and said, with noticeable self-control, "What a mess! Everyone has run away and I haven't had anything to eat since yesterday noon.”271

Schindler concludes by exclaiming, "Never has such a great work of art been created under such adverse living conditions as this Missa Solemnis!”272

Other events surrounding the premiere of Missa Solemnis also contributed to the notion that the work grew to become "Beethoven’s Bane.” In the midst of all his publisher negotiations, Beethoven, still dreadfully short of funds, sent out letters to heads of state and prominent artists, musicians, and writers, offering them their own personal handwritten copies of Missa Solemnis in full score. Ten acceptances were returned to Beethoven, and he wrote out ten copies of the Mass—no doubt with some help—in 1823. One such subscriber was Prince Nikolai Galitzin, who organized the premiere of Missa Solemnis. The original

\footnotetext{
${ }^{268}$ Solomon, Ibid., 400.

${ }^{269}$ Ibid.

${ }^{270}$ Schindler, Beethoven as I Knew Him, 229.

${ }^{271}$ Schindler, Ibid., 229.

272 Ibid.
} 
concert was scheduled in St. Petersburg for Christmas, 1823, but due to the late delivery of the score, coupled with the difficulty of the work, the premiere of the Mass did not occur until April 7, 1824. ${ }^{273}$ The Vienna premiere of Missa Solemnis, held on May 7, 1824, only included the Kyrie, Credo, and Agnus Dei. The main attraction of that concert was Symphony \#9, and the events surrounding the premiere of that work will be discussed below.

Some have argued that Missa Solemnis has no place in a liturgical setting, ${ }^{274}$ or at best that the work does not settle in either a secular or sacred venue. ${ }^{275}$ However, Hanslick probably has the more reasonable argument when he says that “...one must be careful about accepting the often repeated objection that it is 'unchurchly.' ...[Beethoven] obviously began the work, intending, for all its immensity of concept, that it should meet the requirements of the church...” ${ }^{277}$ at the installation of his friend and benefactor Archduke Rudolf, to whom Beethoven dedicated the work. Furthermore, in an effort to ensure the ecclesiastical legitimacy of Missa Solemnis, while he was composing the Mass, Beethoven reportedly sought out friend and theologian Friedrich August Kanne (editor of the journal Weiner Allegemeine musikalische Zeitung) for his assistance with interpreting the Catholic liturgy. In addition, in order for the three movements from Missa Solemnis to be performed at the premiere of Symphony \#9, they had to be re-named as hymns. ${ }^{278}$ Had the Catholic Church not accepted Missa Solemnis as legitimate, the name change would not have been required. However, Beethoven himself did not necessarily view the work as specifically Catholic, and was known to opine that Missa Solemnis might best be performed as an oratorio, which

\footnotetext{
273 Drabkin, Ibid., 17-18.

${ }^{274}$ Vincent D’Indy, “Missa Solemnis, in Beethoven Companion, ed. Thomas Scherman and Louis Biancolli (Garden City: Doubleday, 1972), 951-952.

275 Solomon, Beethoven, 400.

${ }^{277}$ Eduard Hanslick, "Missa Solemnis,” in Beethoven Companion, ed. T. Scherman and L. Biancolli, 957.

278 Thayer, Life of Beethoven, 906.
} 
actually turned out to be its form at the premiere in St. Petersburg. ${ }^{279}$ This more ecumenical view of the work is buttressed by Beethoven's own words concerning the Mass: "My chief aim was to awaken and permanently instill religious feelings not only into the singers but also into the listeners.” 280

Missa Solemnis has in the score parts for three trombones: alto, tenor, and bass. Given the ecclesiastical ancestry of the trombone, it is appropriate that Beethoven chose to include them in the score of the Mass. In fact, Solomon says Beethoven scored trombones in the "judicare" section of the Credo "to symbolize divine power." ${ }^{281}$ As has been seen in several other works, the trombone parts were not part of the original autographs but were added later, ${ }^{282}$ only showing up in the official corrected scores, such as the dedication copy given to Archduke Rudolph, and the copy sent to Schott for publication. ${ }^{283}$ Because of this practice of adding the trombone parts at a later time, there were significant discrepancies in the various Missa Solemnis scores sent to subscribers. Thayer says:

In the autograph, and also in the copy which Beethoven gave to the Archduke, the trombones do not enter till the words "judicare vivos et mortuous." There are no trombones in the Gloria. The trombone passage which now appears just before the entrance of the chorus on "judicare" was formerly set for the horns. After the words "et mortuous" the trombones are silent until the end of the Credo in the autograph; they enter again in the beginning of the Sanctus, but are silent in the next allegro. They occur in the Benedictus, but are wanting in the Agnus Dei. ${ }^{284}$

The inconsistencies in the trombone parts were a substantial worry for Beethoven. In one particular letter to Schindler, he expressed great concern for the trombone parts to the Gloria, which as Thayer noted above, were not included in some editions:

\footnotetext{
${ }^{279}$ Solomon, Beethoven, 400.

${ }^{280}$ Ibid., 401.

${ }^{281}$ Maynard Solomon, Late Beethoven (Berkeley: University of California Press, 2003), 198.

${ }^{282}$ Wilfrid Mellers, Beethoven and the Voice of God (New York: Oxford University Press, 1982), 299.

${ }^{283}$ Hanslick, Ibid., 16. Also missing from the autographs were parts for contrabassoon, double bass, and organ.

${ }^{284}$ Thayer, Life of Beethoven, 819.
} 
How about the trombone part? It is certain that the fellow still has it-as he did not return it when he brought back the Gloria. There was so much to do in looking over the wretched scribbling that we forgot to take back the trombone part. If necessary I shall come to Vienna to the police-_ ${ }^{285}$

Beethoven's keen interest in the trombone part to the Gloria could be understood, based on the fact that the part did not as yet exist in the score. His use of the term "wretched scribbling” is most likely a reference to the labor of one of his copyists, whom he had to increasingly rely upon as he aged. His chronic stomach disorders were quite significant at this time, ${ }^{286}$ and he was having difficulties with his eyesight as well. ${ }^{287}$ Because the disposition of his eyesight affected the legibility of his handwriting — which already tended to fluctuate based on his physical condition, ${ }^{288}$ and because his need for copyists had already increased due to the ten scores of Missa Solemnis distributed to his subscribers, his need for (and therefore his complete frustration with) his copyists reached a peak. ${ }^{289}$

The trombone parts in Missa Solemnis are more extensive, more participatory, and more interesting than any of Beethoven's works written up to that time. Silent only in the opening Kyrie, they then play all four following movements, with fairly extensive parts. Even the ranges tend to be more extensive: the alto spans from $g$ to $\mathrm{d}^{2}$, the tenor is from c to

${ }^{285}$ Thayer, Ibid., 858.

${ }^{286}$ Ibid, 836.

${ }^{287}$ The letter to Schindler notes that his "eyes are still worse rather than better” (Thayer, Ibid., 859).

${ }^{288}$ Tyson, "Steps to Publication—and Beyond," in Beethoven Companion, ed. Denis Arnold and Nigel Fortune, (London: Faber and Faber, 1971), 473.

${ }^{289}$ Beethoven was especially abusive to some of his copyists. One particular copyist, Ferdinand Wolnak (most of Beethoven's copyists tended to be Bohemian), sent a letter to Beethoven explaining why he did not copy certain works. Thayer writes concerning Beethoven's reply—never sent-to this letter:

In letters two inches long he scrawled over the writing the words: "Stupid, Conceited, Asinine Fellow.” That was not enough. There was a wide margin at the bottom of the sheet, just large enough to hold Beethoven's next ebullition: Compliments for such a good-for-nothing, who pilfers one's money? - Better to pull his asinine ears!” Then he turned the sheet over. A whole page invited him—and he filled it up the middle with "Dirty Scribbler! Stupid Fellow! Correct the blunders which you have made in your ignorance, insolence, conceit and stupidity, this would be more to the purpose than to try to teach me, which is as if a Sow were to try to give lessons to Minerva." The margins were still available: on the right- "Do you do honor to Mozart and Haydn by never mentioning their names." On the left; "It was decided yesterday and even before then not to have you write any more for me." (See Thayer, Life of Beethoven, 937. 
$\mathrm{a}^{1}$, and the bass is from $\mathrm{D}$ to $\mathrm{f} \#^{1}$. The range of the bass trombone is especially interesting. Although the trombone parts may say, "alto, tenor, bass," according to Weiner, the actual instruments played were probably three tenors. ${ }^{290}$ However, in the case of the bass trombone part to Missa Solemnis, the low D is only playable on a true bass instrument. Beethoven was aware of the bass trombone with its lower tessitura, and probably specifically called for it in this case. While it has been suggested by Weiner that performances of this part-at least in Vienna-would still have been on a tenor trombone and would entail the performer playing the low D as a "false" tone, ${ }^{291}$ it is more likely, in the event the part were played on a tenor, that this one low note would have simply been played up an octave.

The first entrance of the trombones in the Gloria has the trombones playing a long chord with the tutti orchestra. (The only instruments with rhythmic activity are the strings, playing arpeggiated sixteenth notes.) It is reminiscent of the first entrance in Symphony \#6:

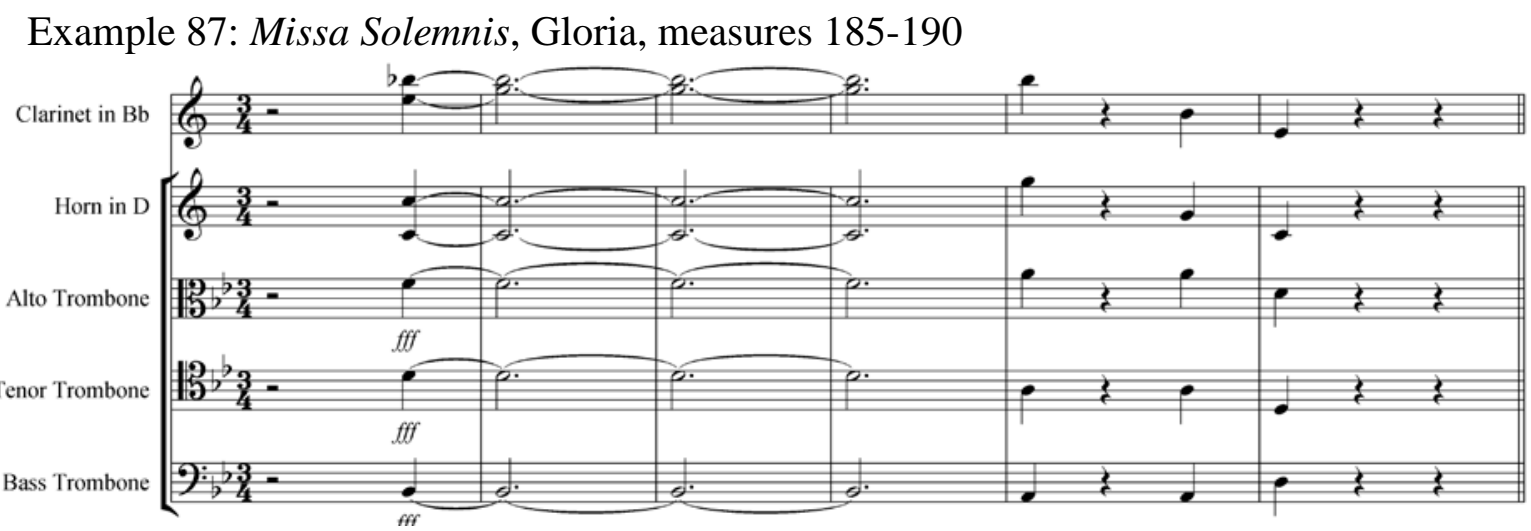

Instead of a loud diminished chord as in Symphony \#6, in this case it is a Dominant $7^{\text {th }}$ chord. In Symphony \#6, the trombones entered at the height of the storm scene. In Missa Solemnis, the first entrance of the trombones accompanies the text "Pater omnipotens" (omnipotent

\footnotetext{
${ }^{290}$ See Howard Weiner, "When is an Alto Trombone an Alto Trombone? When is a Bass Trombone a Bass Trombone?-The Makeup of the Trombone Section in Eighteenth- and Early Nineteenth-Century Orchestras," Historic Brass Society Journal 17 (2005), 37-79.

${ }^{291}$ For more discussion on this issue, refer above to the section analyzing Ruins of Athens.
} 
Father). Pointing to the ecclesiastical ancestry of the trombone, here the instruments are scored "to symbolize divine power." ${ }^{292}$ Roger Fiske says that at this point "Beethoven goes so far as to mark both chorus and orchestra fff to show that he wanted something quite exceptional, and for the first time in the Missa Solemnis he brings in his trombones.”293

Beethoven at once establishes the trombone section as rhythmic equals to the rest of the orchestra sections. Throughout Missa Solemnis, the occasions where Beethoven employs rhythmic abbreviation are comparatively rare; for the most part the trombones and the other sections are rhythmic equals. Only the strings in this passage have more complex rhythms:

Example 88: Missa Solemnis, Gloria, measures 292-295

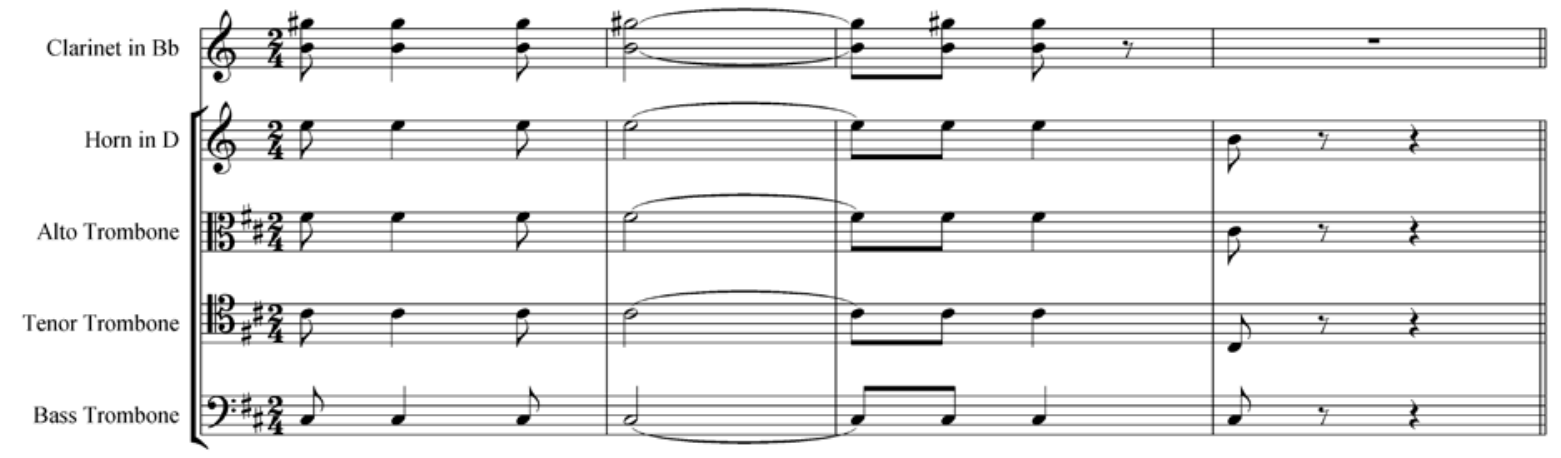

In this case, the clarinets, usually a section having the more complicated rhythms, actually drop out before the trombones do, creating a slight momentary prominence for the trombones (shared with the horns). The lack of rhythmic abbreviation represents a step forward in the evolution of Beethoven's orchestration techniques for trombones, especially in choral music. In some phrases, the trombones actually have rhythms more complex than other sections. While the strings and bassoons (not shown) in the example below have sixteenth notes and eighth notes, the rest of the winds and brass have rhythms similar to those represented in the clarinet and horn parts shown:

\footnotetext{
${ }^{292}$ Maynard Solomon, Late Beethoven (Berkeley: University of California Press, 2003), 198.

${ }^{293}$ Roger Fiske, Beethoven's Missa Solemnis (London: Paul Elek, 1979), 40.
} 
Example 89: Missa Solemnis, Credo, measures 11-15

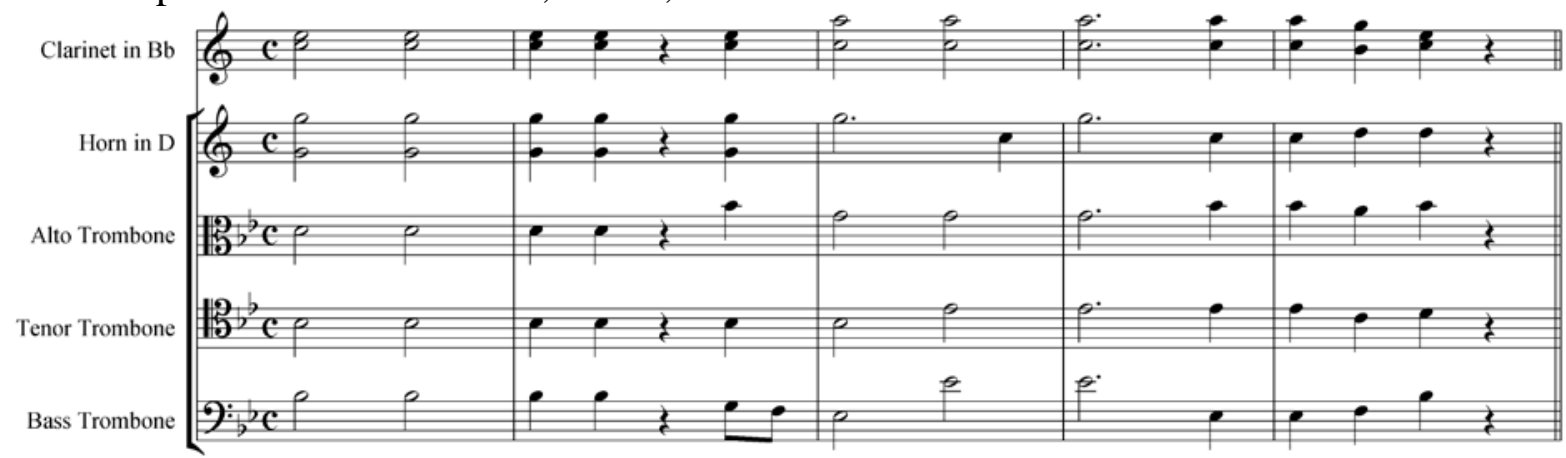

The bass trombone's passing tones in the second measure are a variation of the momentary prominence technique already seen in other works. Throughout Missa Solemnis, there are passing tones in the trombone parts. Most likely these passing tones are evidence of Beethoven hearkening back to liturgical music from the Renaissance, which were rich with such conventions. The same technique was seen in Three Equali: ${ }^{294}$

Example 90: Missa Solemnis, Gloria, measures 345-349

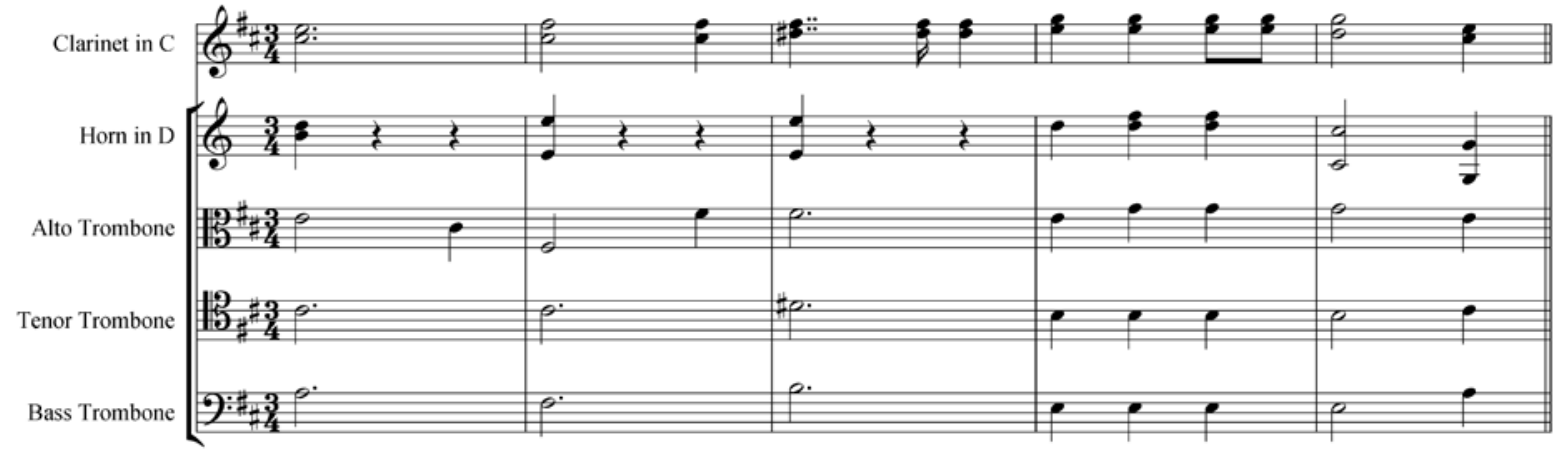

This particular example not only has a prominent passing tone for the alto trombone (no other instrument or choral part moves when the alto trombone does), but the third measure of the example includes a rare rhythmic abbreviation, or what might better be called simplified doubling. The trombones hold the chord, while the woodwinds (represented in this example again by the clarinet) double the rhythm of the chorus. The strings-not shown-have arpeggiated sixteenth notes, as was the case in Example 87.

\footnotetext{
${ }^{294}$ Kinderman, Beethoven, 268.
} 
Another orchestrational technique already seen in other works-especially in Symphony \#5-is the “downbeat only” technique:

Example 91: Missa Solemnis, Agnus Dei, measures.155-161

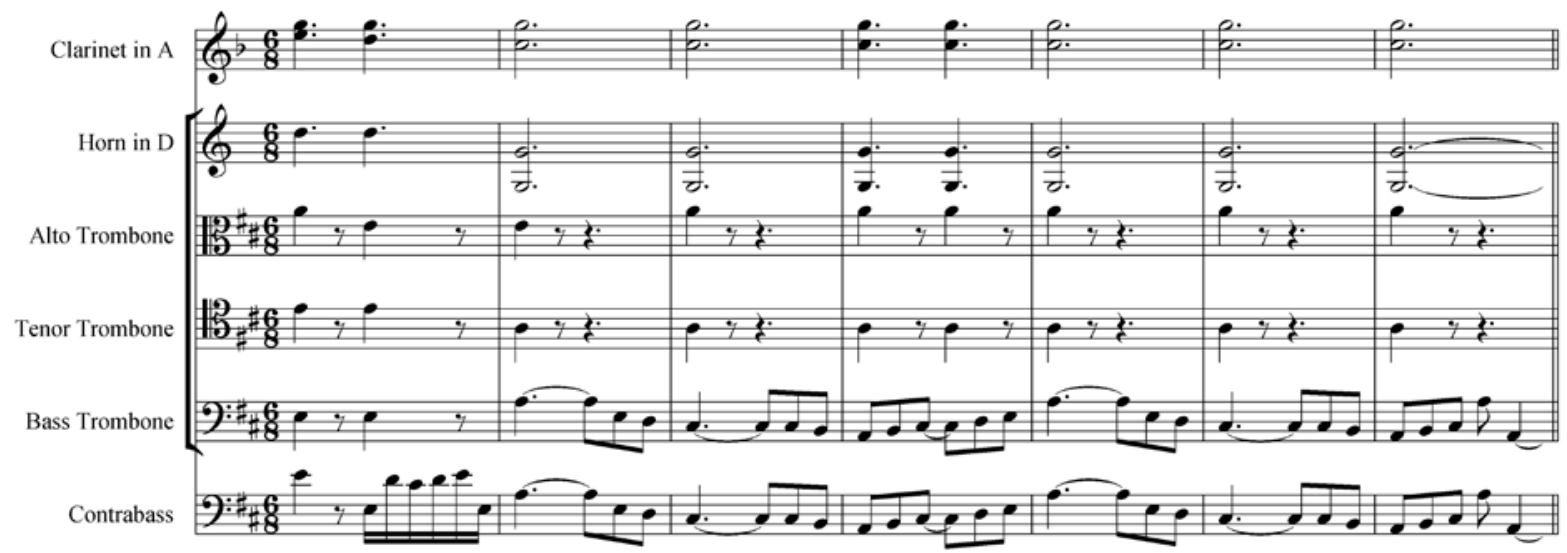

Here the alto and tenor trombones play only on the downbeats. The bass trombone, after the first measure of the example, doubles the string bass. When the trombones are not acting independently — which is significantly less in the Mass than in other works — or doubling the chorus, the instruments doubled are typical of what has already been encountered: the alto trombone tends to double the clarinet, the tenor tends toward the bassoon, and the bass trombone usually doubles the cello and bass. There are also examples of the entire trombone section — not just the bass trombone-doubling the various strings. The alto follows the first violins and the tenor follows the seconds. The bass trombone stays with the bass and cello:

Example 92: Missa Solemnis, Sanctus, measures 170-175

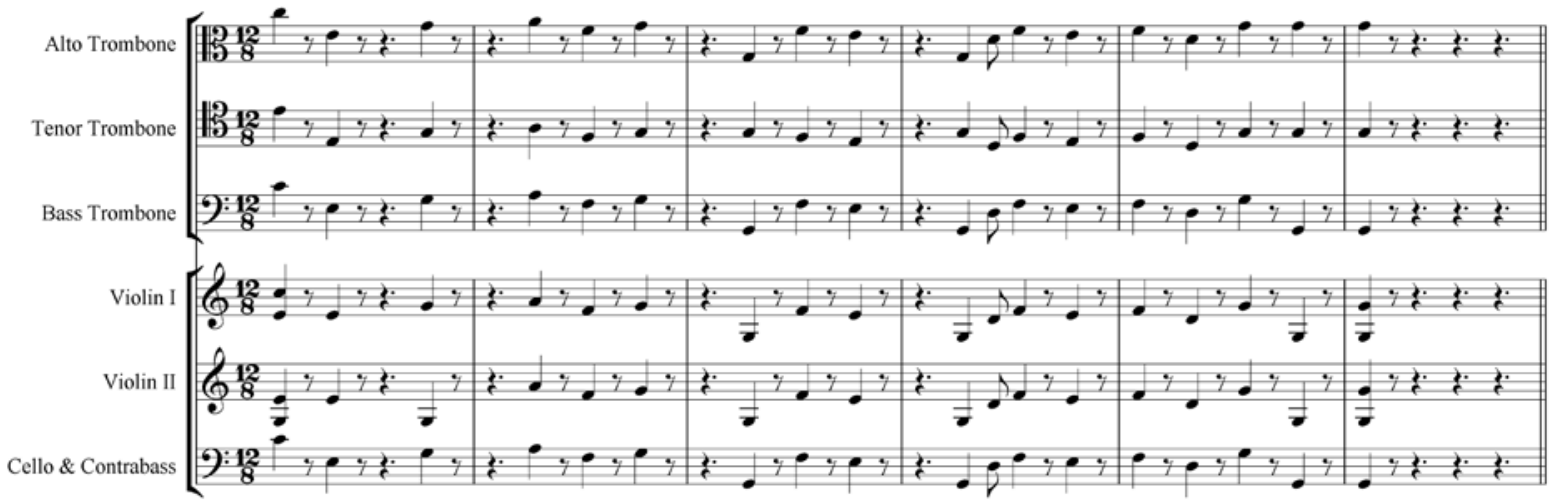


There are also examples of the trombones working in conjunction with the trumpet section and timpani, as will be seen in Consecration of the House:

Example 93: Missa Solemnis, Sanctus, measures 119-122 ${ }^{295}$

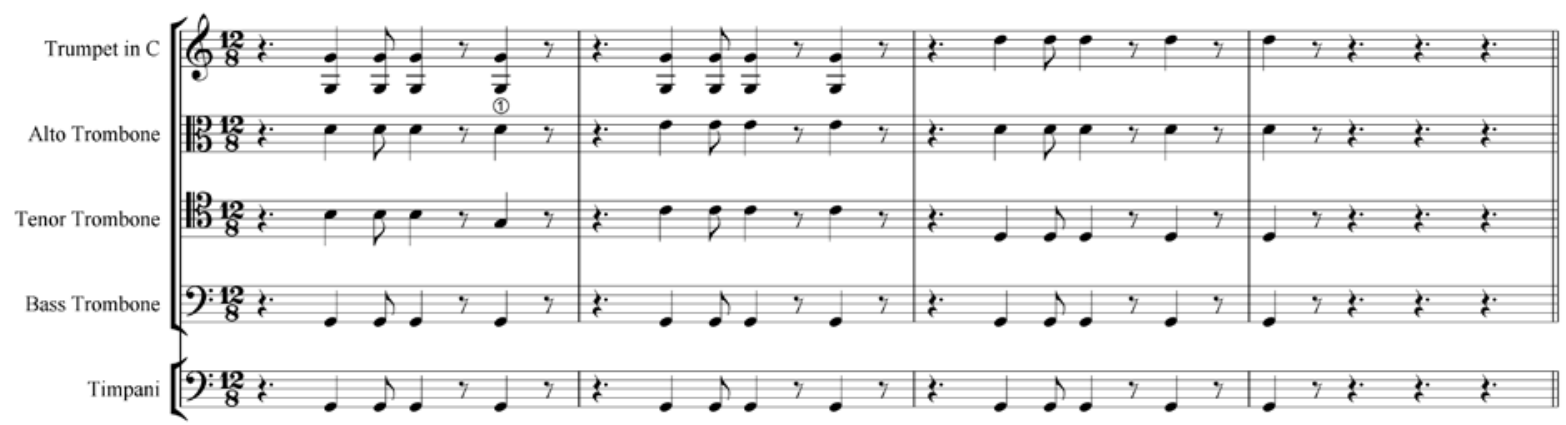

The trombones also have several passages that are probably best called section soli, as the example below shows. The trombones contribute a soft rhythmic background pulse, similar to the section soli from the beginning of Consecration of the House:

Example 94: Missa Solemnis, Sanctus, measures 9-20

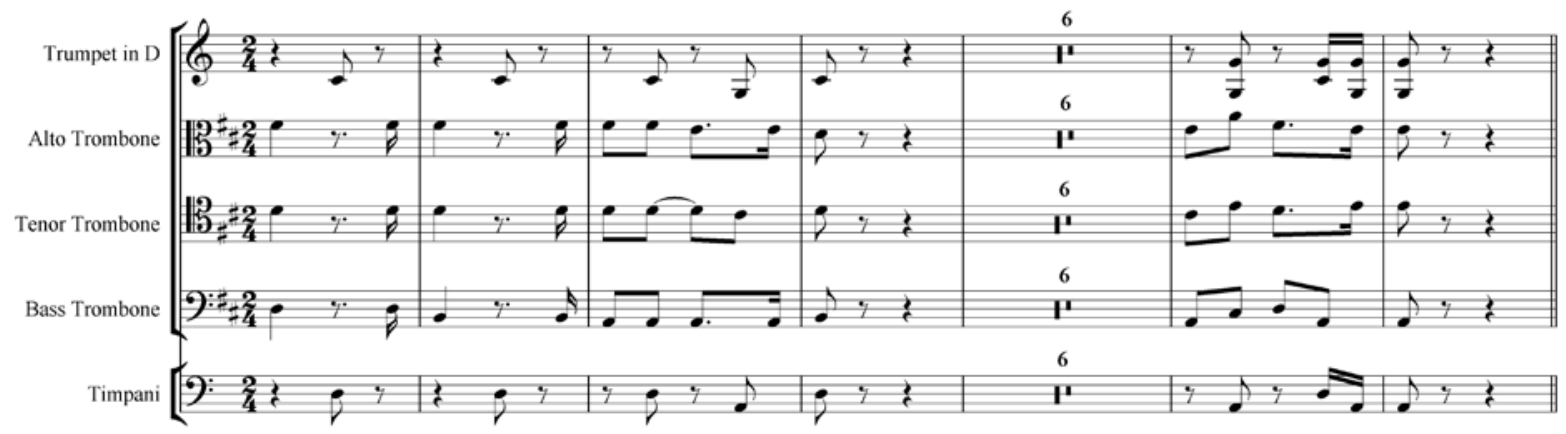

In this passage, the low strings and low woodwinds (not shown) have a fugue-like flowing melody while the other sections either have background chords or are resting.

The subject of doubling the chorus in Missa Solemnis warrants particular discussion. In Christ on the Mount of Olives, there are a few examples of the trombones doubling the chorus in a limited fashion, such as the first entrance of the individual voices. This is also the case with Ruins of Athens and King Stephen, where most of the choral doubling involves the

\footnotetext{
${ }^{295}$ The alto trombone note with the (1) above it was a g in earlier editions. The note was overwritten in some manuscripts and was difficult to determine. Cleaner manuscripts show this note to be a $\mathrm{d}^{1}$, which is reflected in the Critical Edition. (See Beethoven Werke VIII; 3, Missa Solemnis [Munich: Henle, 2000], 184, 326.)
} 
trombones loosely doubling the chorus. This is the style followed by Handel, Haydn, and Gluck, who then influenced Beethoven in his "French Revolutionary" style. ${ }^{296}$ However, in Missa Solemnis, the trombone section's doubling follows more closely the Austrian church music tradition, such as was seen in the liturgical music of Fux and Mozart. While it is likely that Beethoven was generally more influenced in his trombone writing by Handel, perhaps in yet another effort to make Missa Solemnis more ecclesiastically appealing, Beethoven not only added trombones_-frequently included in Austrian church music_-but also scored them in the Austrian church style, as did Mozart. ${ }^{297}$ Mozart's Requiem was especially dear to Beethoven—particularly while writing Missa Solemnis—as will be discussed in detail below.

When the trombones double the chorus in Missa Solemnis, it is usually note-for-note:

Example 95: Missa Solemnis, Gloria, measures 360-373
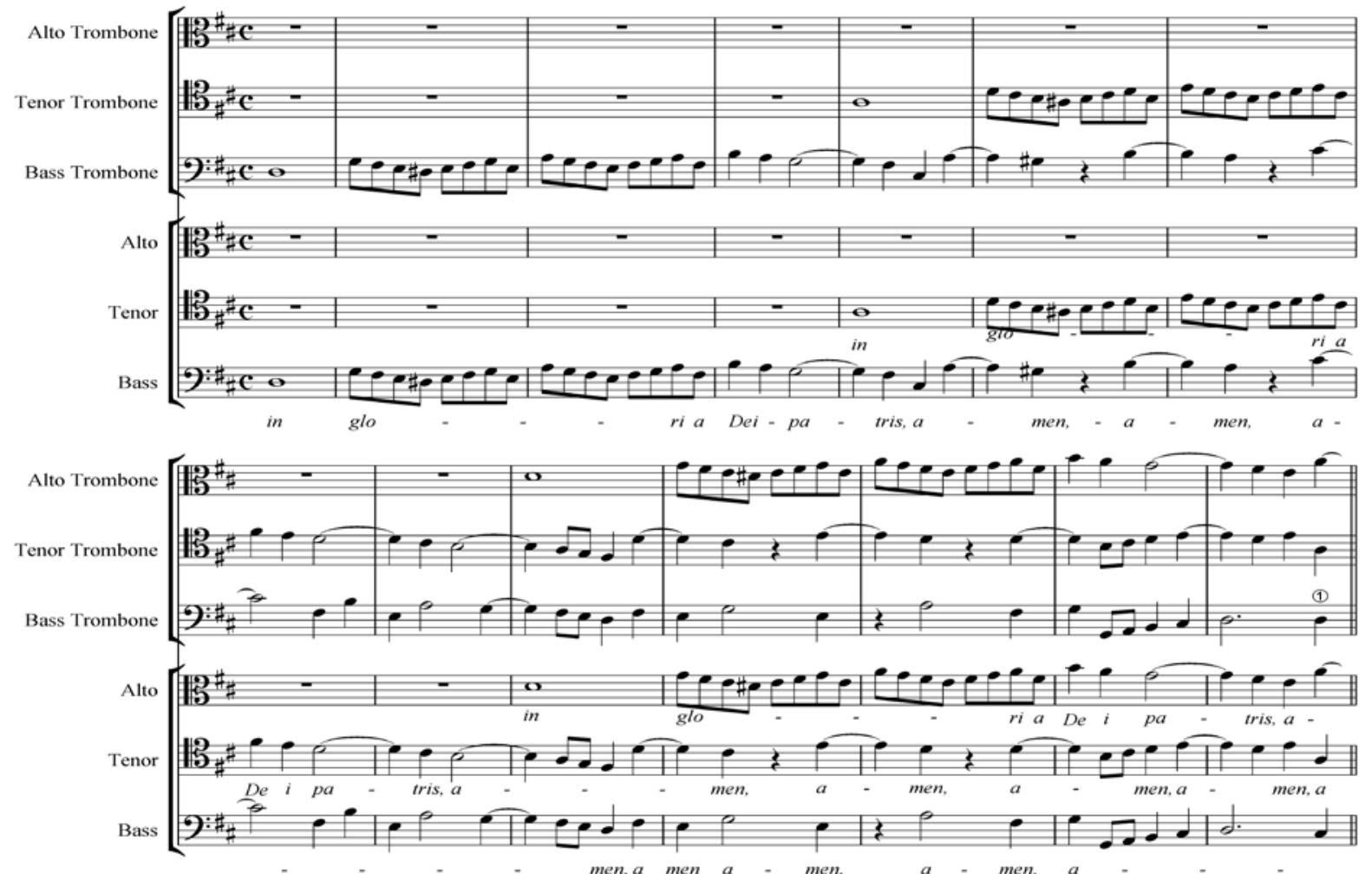

\footnotetext{
${ }^{296}$ See David M. Guion, "What Handel taught the Viennese about the Trombone," Historic Brass Society Journal 15 (2003), 291-321.

${ }^{297}$ For more information on the subject of Mozart's influence on Beethoven, see the discussion of Christ on the Mount of Olives above.
} 
This example is one of many where the trombones exactly double the chorus, typical of the traditional style of writing found in Viennese church music. This sometimes involves passages that are technically challenging for the trombones. Not only must they play the passage cleanly, in tune, and with a good sound quality, but they must at the same time beware of playing too loud for the chorus, particularly in the moving passages. In the example above, it is especially challenging to play at a low volume sufficient to properly support the chorus, partly because of the other instruments (not shown) that are playing at the same time. The bassoons, celli, and organ have the same passage as the bass trombone and tenor trombone, and the clarinet and horn play the same passage as does the alto trombone. These particular instruments—celli, bassoons, clarinet, horn, and especially organ—double the chorus along with the trombones throughout Missa Solemnis. Since Missa Solemnis utilizes the Viennese church music style of trombones doubling the choir, the trombones have a certain level of prominence by their presence alone. However, all decisions of orchestral balance should be made with the overarching prominence of the chorus in mind. The style of trombone writing followed by Handel and Haydn is certainly easier for the trombonist to execute. However, the particular sound the choir can achieve through the Viennese church music style is unique, full, sonorous, and worth the effort when done correctly. Unfortunately, the Viennese church style executed incorrectly tends to sound ponderous and bombastic, especially in heavily-orchestrated works such as Missa Solemnis. Perhaps this is one reason most composers abandoned the Viennese style of trombone writing by the middle of the Nineteenth Century.

Beethoven, in Missa Solemnis, creates a new level of rhythmic complexity in the Viennese-style trombone parts. In the example below, the trombones double the chorus 
along with bassoons, celli, organ, violas, and second violins (all not shown):

Example 96: Missa Solemnis, Agnus Dei, measures 216-229
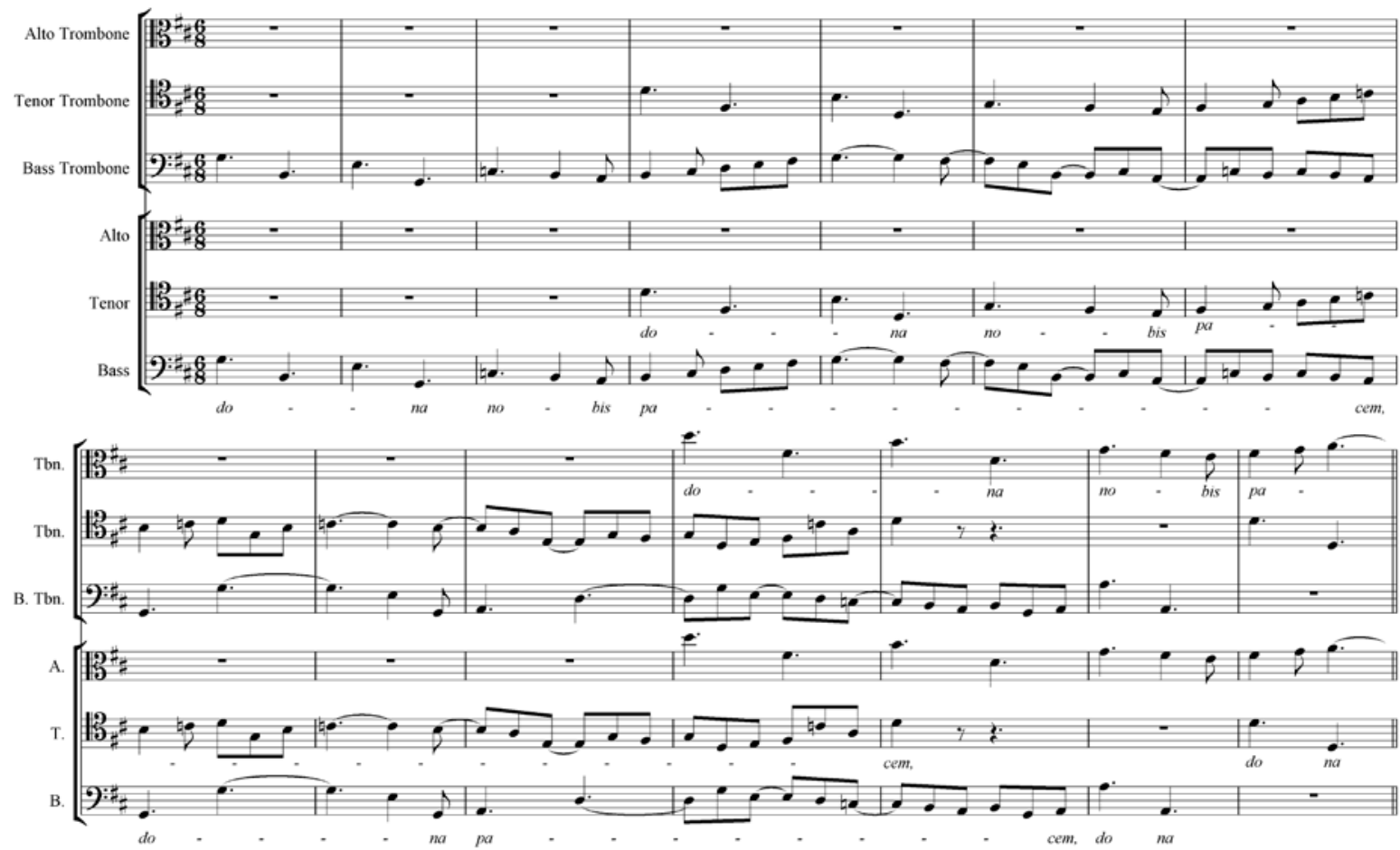

The complex rhythmic activity in this example presents challenges to the trombone section.

As was the case in Example 95, not only must they play cleanly enough to make the rhythm clear for the choir, but they must also do it in such a way as to not play too loudly for the choir as well. The same issues of volume occur in this example as did in Example 95, since other instruments double the choir along with the trombones. As was mentioned above, the organ, bassoon and clarinet tend to double the chorus, as well as cello, horn, and (on occasion) the first and second violins. Fortunately, these more agile instruments can actually help the trombones avoid playing with too much volume. The trombone section can play lightly beneath them and still have prominence, providing their weight and color, creating the traditional Viennese church music sound and style without burying the chorus.

In some Missa Solemnis passages, the trombone section's doubling of the chorus is not shared with the other lighter instruments: 
Example 97: Missa Solemnis, Gloria, measures 429-440

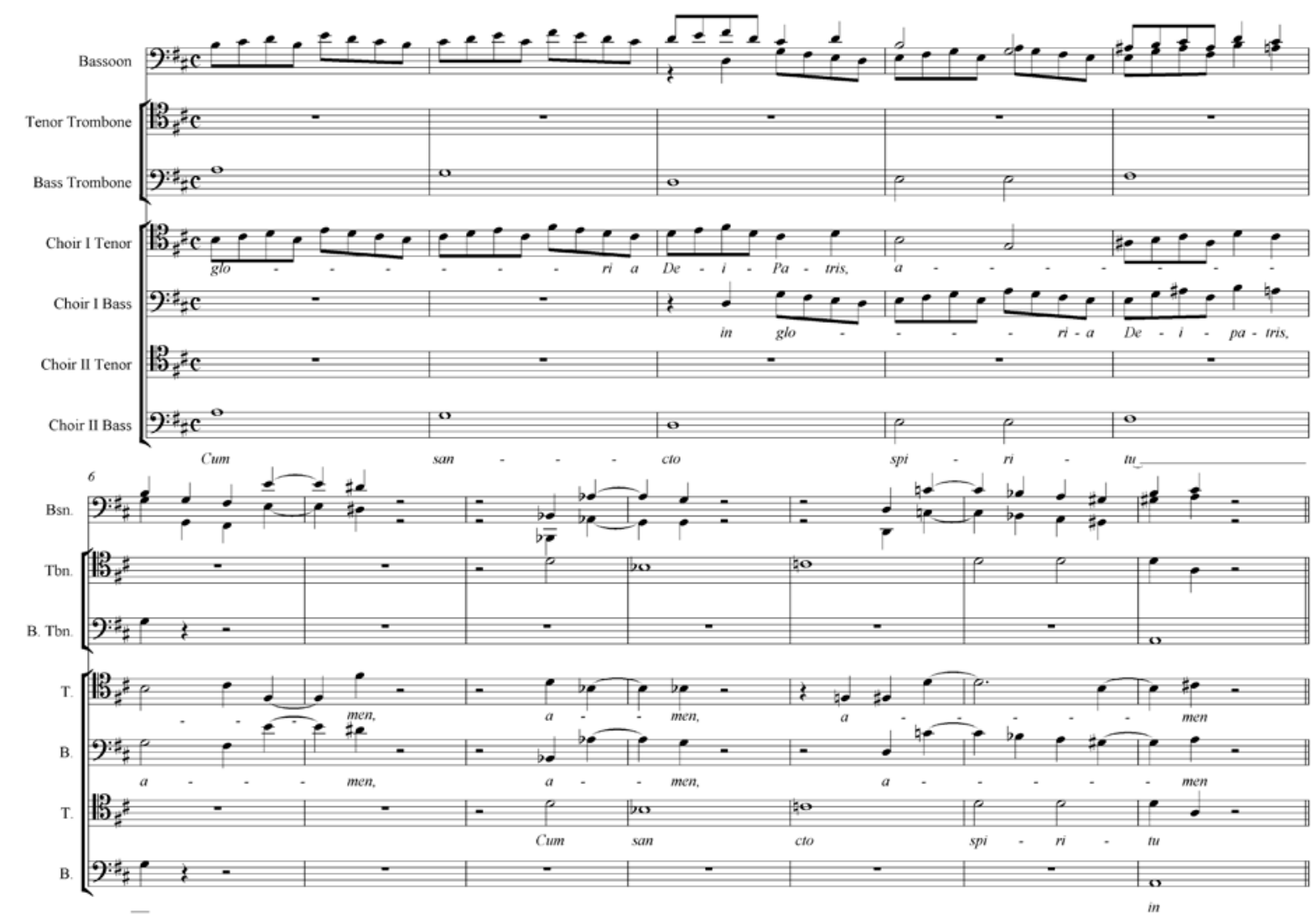

Only the tenor and bass trombones double the tenor and bass voice parts of Choir II; no other instrument also doubles, as was the case in the other examples shown above. One other example is fascinating because of the rhythmic play between the trombones, the other winds and brass, and the chorus:

Example 98: Missa Solemnis, Credo, measures 250-255

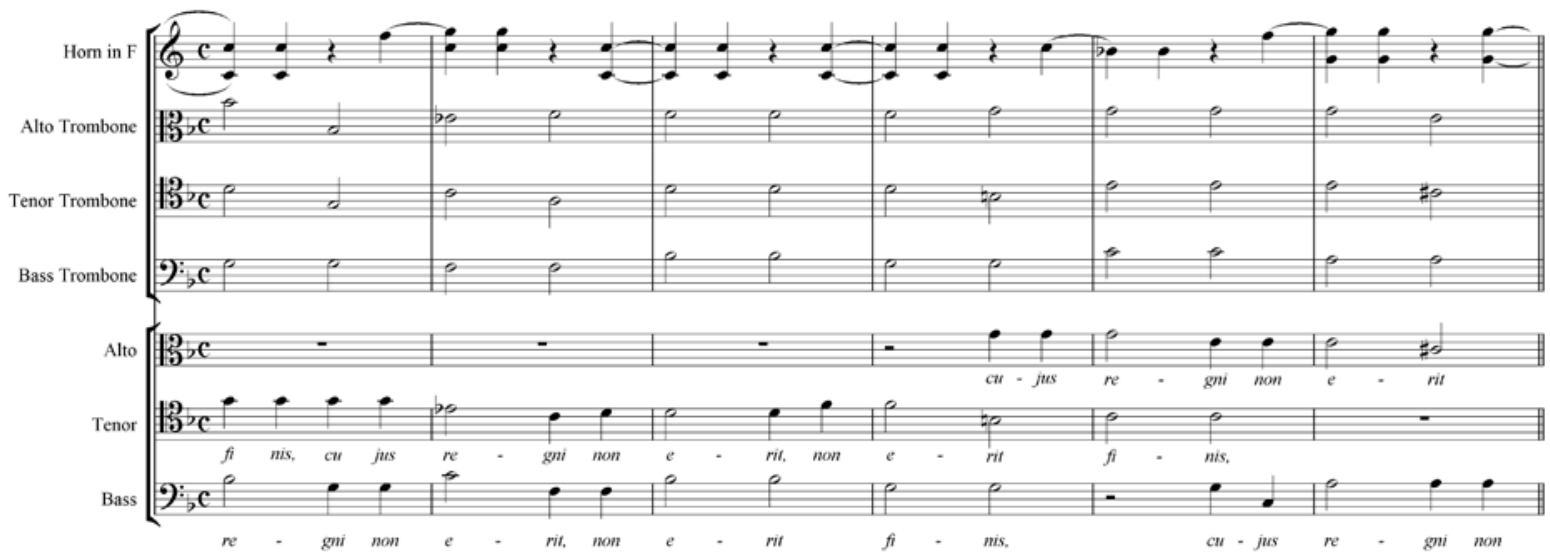


The trombones hold half notes which track the chorus loosely, over a syncopated rhythm played by the rest of the winds, represented in this example by the horn part. The strings play eighth notes throughout the example. There is a similar passage in Christ on the Mount of Olives, shown in Example 3 on page 27. The style of the accompanying trombone parts is peculiar to this section of the Credo. They truly act independently of any other section, sometimes supporting the choir, sometimes acting completely on their own. When the trombones support the chorus in this section, it is sometimes with unison doubling, at other times playing a related chord member, and still other times with no doubling at all. The unique musical result is akin to a momentary prominence, but with less emphasis on prominence and more on accompanying, while at the same time being independent of all others. This rhythmic play between the independently-acting trombones, the choir, and the other orchestral sections continues for several measures:

Example 99: Missa Solemnis, Credo, measures 256-261

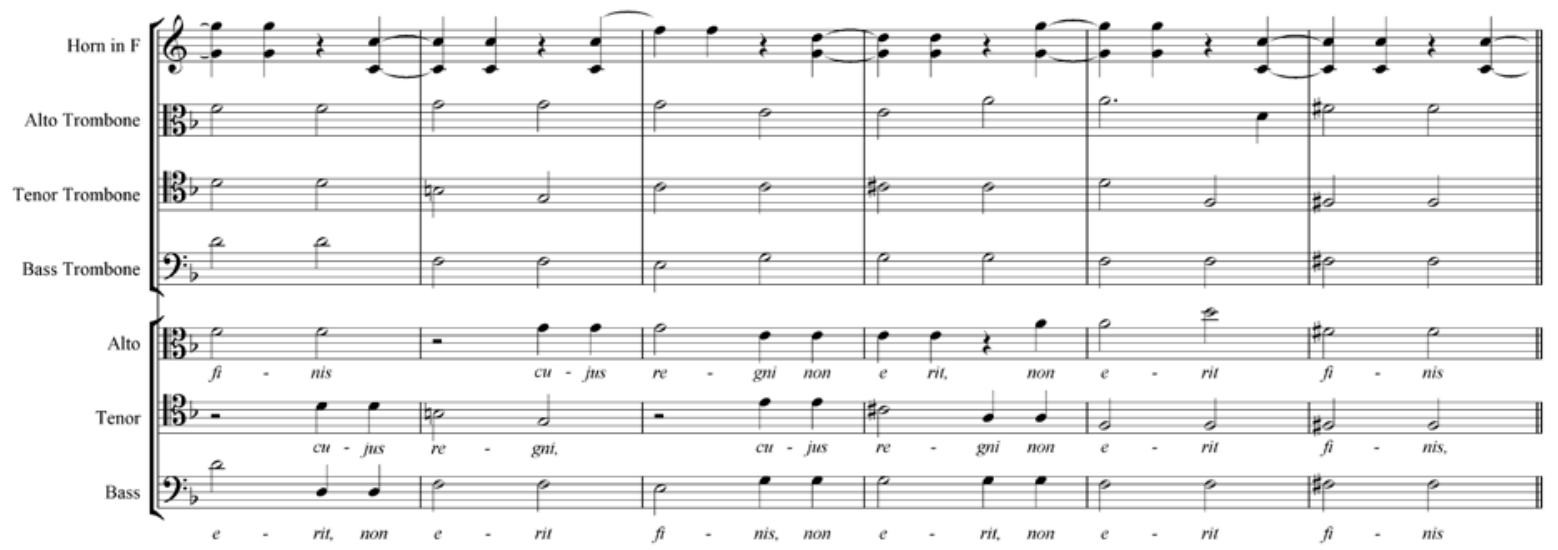

In the fifth measure of the example, the alto trombone part deviates from the alto voice part with a passing tone, again reflecting Renaissance compositional techniques. The alto trombone passing tone also serves to circumvent doubling the high $\mathrm{d}^{2}$ in the alto voice part, which Beethoven, despite having used higher notes in previous works (Symphony \#5, The Glorious Moment), seemed to avoid when writing the Missa Solemnis alto trombone part. 
In the last measure of Example 95 (above) the bass voice in the chorus descends from a $\mathrm{D}$ to a C\# on the fourth beat. However, the bass trombone does not: it remains on the $\mathrm{D}$ (a (1) is above the note). This is an example of the many mistakes found in the original Missa Solemnis scores. Even the latest edition of the Missa Solemnis score has this mistake in the bass trombone part. ${ }^{298}$ The other instruments playing the same $\mathrm{D}$ to $\mathrm{C} \#$ as the bass voice in measure 373 are second bassoon, cello, bass, and organ. Only the bass trombone stays on the errant D, which sounds undeniably wrong when played as written. Since the trombone parts were most likely written separately before they were included in the score, the mistake is in the bass trombone part as well. The first complete score and set of parts of the Mass was released in the spring of 1827, probably days before the death of Beethoven. Therefore, unlike most of his other works, Beethoven was not able to proofread the final score to Missa Solemnis. That issue — coupled with the large number of early sources available (because of the multiple handwritten copies of the Mass sent to Beethoven's various subscribers), and the fact that before Missa Solemnis was published Beethoven's favorite copyist had died—is the reason the original score of the Mass contains so many errors and other textual problems. ${ }^{299}$

The next example is the only bona fide trombone solo that Beethoven ever wrote:

Example 100: Missa Solemnis, Credo, measures 221-228

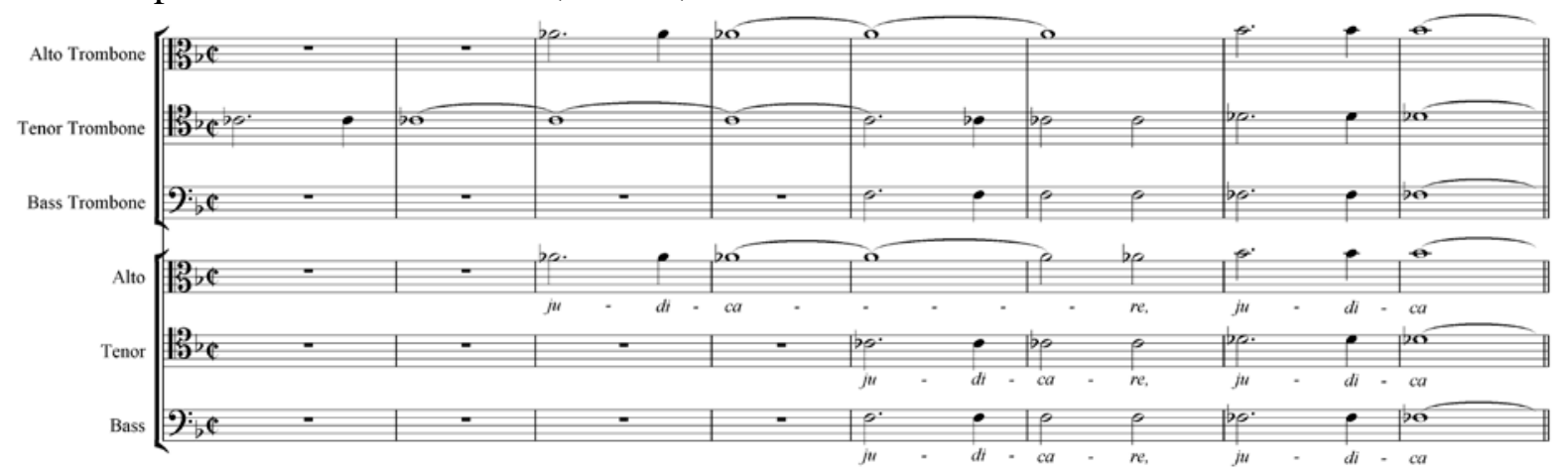

\footnotetext{
${ }^{298}$ There is not even any discussion of the measure in question in the end notes of the latest edition of Missa Solemnis. (See Beethoven Werke VIII; 3, Missa Solemnis [Munich: Henle, 2000], 68.) It is clearly a mistake. ${ }^{299}$ William Drabkin, Missa Solemnis, 18.
} 
The tenor trombone enters four measures earlier than the tenor voices, creating a solo for the tenor trombone. The tenor trombone plays the two measures entirely alone (except for the downbeat of the first measure), and when the alto and bass trombones play their similar passages several measures later-doubling alto and bass voices—other instruments (organ, bassoon, horn) play the same notes as well. ${ }^{300}$ The text accompanying the voices at this point reads "et iterum venturus est cum gloria judicare vivos et mortuous," which translated means "and he shall come again with glory to judge the living and the dead." The tenor trombone solo is similar to the solo written in the Tuba Mirum section of the Mozart Requiem, which describes the judgment of the world. As was discussed above, Beethoven, while writing Missa Solemnis, was most likely influenced by the Requiem. To quote Drabkin again:

But the sacred work which [Beethoven] seems to have cherished above all was Mozart's Requiem; he staunchly defended it when rumors of its doubtful authenticity reached Vienna in the mid-1820's. Recently, a Beethoven sketchleaf came to light on which the Kyrie of the Requiem is written out in short score, with extensive annotations of its themes and formal sections. It is the only such "analysis" by Beethoven, and probably dates from the period of work on the "et vitam venture" fugue of the Missa Solemnis. ${ }^{301}$

The "et vitam venture" section of the text comes from the end of the Credo, not far from the text accompanying the tenor trombone solo. It could very well be that Beethoven, having

300 The Critical Edition of Missa Solemnis (Beethoven Werke VIII; 3, Missa Solemnis [Munich: Henle, 2000], 316) has an alternate rendering of the trombone parts in this passage:

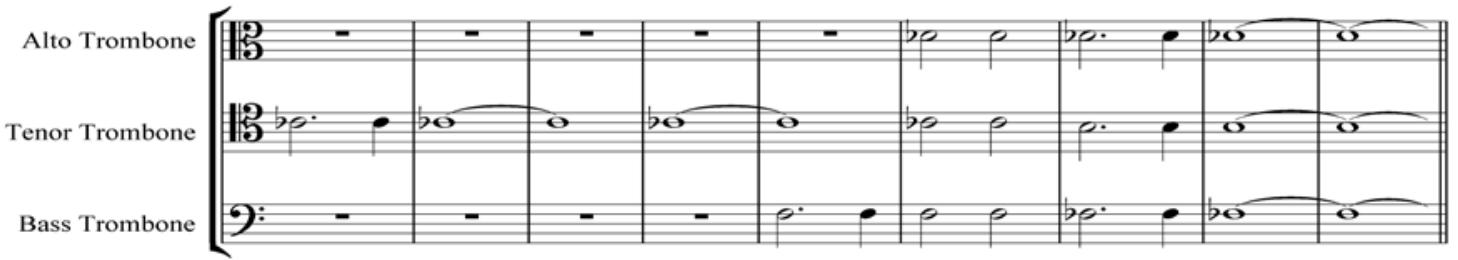

This fragment is from a different version of the Credo, and the first three bars-the tenor trombone solo-were added by Beethoven at a later date (see text accompanying fragment). The $\mathrm{C}^{b}$ in the second and fourth measures of the tenor trombone part, the $\mathrm{D}^{b}$ in the third measure of the alto trombone part, and the $\mathrm{F}^{b}$ in the fourth measure of the bass trombone part were all missing a flat sign in the fragment from the Critical Edition. They were added in this example because it is clear from the main score of the Critical Edition that they belong. The flat signs were not in the endnote fragment probably because they were not in the original manuscript fragment, but were understood by the copyists at the time that they should be included in the parts. (See Beethoven Haus-Bonn Website, http://www.beethoven-haus-bonn.de, 2009, accessed 1 July 2009.)

${ }^{301}$ William Drabkin, Missa Solemnis, (Cambridge: Cambridge University Press, 1991), 21. 
been studying the Mozart Requiem at the point he was writing the Credo to Missa Solemnis, wrote the short tenor trombone solo as a tribute to Mozart and the Requiem. The two texts are similar, with both describing judgment of the world. Furthermore, the voice of the trombone was at the time "ordained to pronounce the last judgment." 302 Even the choice of instrument is the same (and appropriate) in both cases. Therefore, the tenor trombone solo was both an example of the traditional apocalyptic proclamatory role for the instrument, as well as a musical tribute to Mozart.

One peculiar byproduct (or unintended consequence) of Beethoven’s utilization of the Austrian church music style of doubling is that there are occasions when the tessitura of the alto voice reaches into the extreme upper register of the alto trombone. When this occurred, Beethoven's solution was to simply omit the alto trombone part during the particular notes that extended above the instrument's tessitura:

Example 101: Missa Solemnis, Gloria, measures 381-392

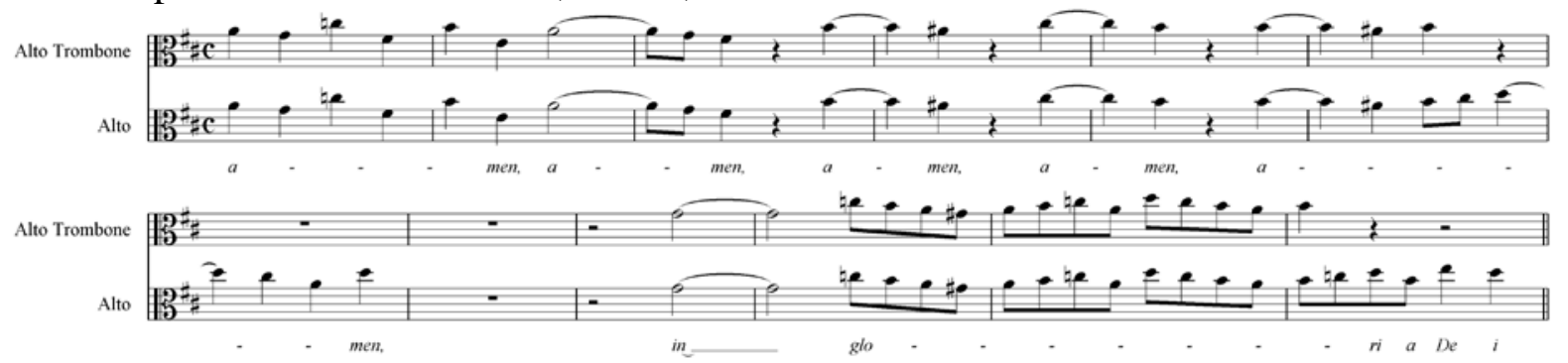

The harmonic activity and rests in the alto voice part in the above example cause the omissions in the alto trombone part to be reasonably smooth in this particular case. However, in another example, the omissions are more striking and even awkward:

Example 102: Missa Solemnis, Agnus Dei, measures 235-240

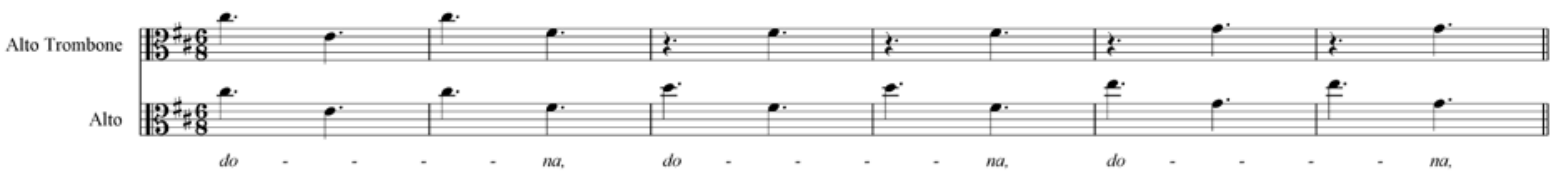

302 Timothy Howe, Ibid., 27. 
Fiske has this to say about the notes omitted from the alto trombone part in Example 101:

For 67 bars the Gloria fugue is continuously fortissimo. To make it even louder than it was already Beethoven added trombones at the last moment; their parts do not occur in either the autograph or in the copy sent to the Archbishop. They double the altos, tenors, and basses almost throughout, and though Beethoven left these trombone parts to his copyist he must have realized that unless care was taken the alto trombone might sometimes be faced with the impossible. On 28 September 1823 he was visited by a publisher, Tobias Haslinger, and an Englishman, Edward Schulz, who four months later described the meeting in the London Harmonicon. 'He asked Haslinger about the highest possible note on the trombone but was dissatisfied with the answer to which he received.' The question must have been prompted by the trombone parts being added in the Missa Solemnis, probably by those being added to the Gloria fugue. Perhaps as a result of Beethoven's advice the copyist left out the high Ds and Es in the alto trombone part...but a high D slipped by in bar 391. It cannot often have been played. ${ }^{303}$

Fiske’s final comment is ignorant of the alto trombone part from Symphony 5, which not only has the high D and E, but the high $\mathrm{F}$ as well. Some passages from Symphony \#9 are even more awkward than the above Example 102, as will be seen below.

In one case, instead of omitting notes, Beethoven had the alto trombone play a different chord member-in the fifth measure- then down an octave in the next measures:

Example 103: Missa Solemnis, Sanctus, measures 216-222

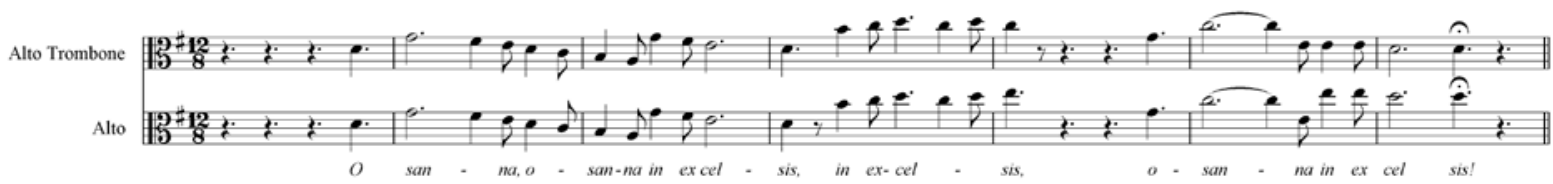

This technique of substituting a different member of the chord (or even the octave) due to tessitura issues has been called compensatory harmony, a technique continued and expanded by Berlioz. ${ }^{304}$ Compensatory harmony is a better solution to the tessitura problem than simply omitting the note, but there are many other instances besides the ones given above

\footnotetext{
${ }^{303}$ Roger Fiske, Ibid., 48.

${ }^{304}$ Berlioz used the compensatory harmony technique not as much when he was writing for trombones, but more when he was writing for non-chromatic instruments such as horns and trumpets. For more details about compensatory harmony, as well as an enlightening treatise on the brass orchestration techniques of Berlioz, see C.B. Wilson, “Berlioz’ Use of Brass Instruments,” Ph.D Dissertation, Case Western Reserve University, 1971.
} 
where the alto trombone part should simply be edited to include more notes from the alto voice part, thereby creating a less awkward musical line.

In conclusion, Missa Solemnis represents Beethoven’s most mature, complicated, and extensive writing for the trombone section yet encountered. The parts are robust, active, and challenging, both musically and physically. The treatment of the trombones in relation to the brass section, orchestra, and choir, shows a step forward in Beethoven's understanding of how to write for the instrument. Rhythmically, the trombone section mostly plays the same notes as both the chorus and the orchestra; there are very few examples of rhythmic abbreviation found in the work. The trombones come to the fore throughout Missa Solemnis, in the form of momentary prominences, passing tones, and even one outright solo in the tenor trombone. The range of the section is wider than in most of his works, with one particular note in the bass trombone part indicating that Beethoven specifically scored for a true bass trombone. The dynamics of the trombone section are more varied than has become typical: usually the trombones only play the louder tutti sections; however in Missa Solemnis, there are soft section solo passages, bringing to remembrance the soft chords from Christ on the Mount of Olives. There are veiled allusions to Consecration of the House Overture in the passages where the trumpets, timpani, and trombones play together. Other composers after Beethoven would develop this relationship between the trumpets and trombones (and horns)—especially after the trumpets (and horns) became chromatic — eventually creating the brass section that truly worked together as a unit. The choral doubling techniques in Missa Solemnis represent a unique integration of, and balance between, the traditional Viennese church music style of closely doubling the choir, and the independent trombone scoring found in the works of Handel and Haydn. This same hybrid style would be carried on by 
Schubert and Mendelssohn. The only criticism, if that is what it can be called, is the overly conservative treatment of the alto trombone, especially compared to how it was scored in Symphony \#5 and the Critical Edition of The Glorious Moment. There are passages where the alto trombone doubles the alto voice, but the trombone part is so redacted that it is nearly impossible to execute a clear melodic line. These sections could have included more notes from the alto voice part, making more musical sense without excessive increased difficulty.

\begin{tabular}{|c|l|c|l|l|c|c|c|}
\hline \multicolumn{6}{|c|}{ Table 16: Trombone Statistics for Missa Solemnis, Opus 123 } \\
\hline \multicolumn{2}{|c|}{ Movements } & \multicolumn{3}{|c|}{ Measures } & \multicolumn{3}{c|}{ Ranges } \\
\hline Total & \#Played & Total & \#Played & \%Played & Alto & Tenor & Bass \\
\hline 5 & 4 & 1932 & 559 & 29 & g to d $^{2}$ & c to a $^{1}$ & D to f\# \\
\hline
\end{tabular}

\section{Overture, Consecration of the House, Opus 124}

With the completion—or as near to completion as he would ever permit—of Missa Solemnis in 1822, Beethoven was able to turn his attention to other projects. The Josephstadt Theatre in Vienna had been recently renovated, and the director-Carl Friedrich Henslerwho was also director of a theater in Baden, approached Beethoven (while he was visiting Baden) for a new work to dedicate the newly refurbished theater. ${ }^{305}$ Beethoven chose a previous work written to dedicate a new theater-in this case excerpts from Ruins of Athens. The text was re-arranged to match the current occasion, and Beethoven wrote a new overture to accompany the older music, because he had felt that the Overture to Ruins of Athens was inappropriate for the occasion. ${ }^{306}$ According to Schindler, Beethoven struggled with poet Carl Meisl over the new text to Ruins of Athens, ${ }^{307}$ and as a result, according to Solomon, Consecration of the House was not altogether ready for the dedication concert, which took

\footnotetext{
305 Thayer, Life of Beethoven, 806.

${ }^{306}$ Schindler, Beethoven as I Knew Him, 234.

307 Schindler, Ibid.
} 
place on October 3, 1822. ${ }^{308}$ Despite the work's unfinished state, Consecration of the House was enthusiastically received, and was repeated over the next three nights. ${ }^{309}$ It was also performed at the Academie which featured the premiere of Symphony \#9 on May 7, $1824 .{ }^{310}$

Consecration of the House is basically an homage to Georg Frideric Handel. When asked (in 1817) who in his opinion were the greatest composers of the past, Beethoven was reported to have placed Handel at the top of his list. ${ }^{311}$ Schindler said that Beethoven had a “...long cherished idea of writing an overture specifically in the style of Handel."312 In Consecration of the House, Beethoven was able to fulfill that desire. Some have made the mistake of assuming that Consecration of the House was a caricature of Handel. However, Beethoven held him in too high regard to write a work which mocked him. In fact, Schindler cautions that Beethoven "...never intended to produce an imitation of Handel; he merely wished to invoke the style of his great predecessor." ${ }^{313}$ That being said, there are some passages from Consecration of the House that sound so much like passages from Handel's King Saul that they might be considered by some as bordering on parody.

Since music from March and Chorus from Ruins of Athens (see below)—which has trombones in the score-was included in this dedication concert, it stands to reason that the new overture would include trombones as well. Ruins of Athens calls for three trombones: alto, tenor, and bass; and Consecration of the House also called for the same. With the exception of the bass trombone, the tessiturae of the parts is more limited than even those of It Is Accomplished. The bass trombone's range is a twelfth, from G to c, the tenor's range is

\footnotetext{
${ }^{308}$ Solomon, Beethoven, 348.

${ }^{309}$ Ibid.

310 Thayer, 908.

${ }^{311}$ Kinderman, 279.

${ }^{312}$ Schindler, Ibid.

${ }^{313}$ Ibid., 235.
} 
a ninth, from c to $\mathrm{d}^{1}$, and the alto—with the most limited range of the three-spans a fifth, from $c^{1}$ to $g^{1}$. The parts themselves - in terms of actual measures played-are also more limited than It Is Accomplished. In fact, in Consecration of the House the trombones only play in seventeen out of 287 measures. However, the style of the trombone parts differs significantly from any other works studied, with the possible exception of a few passages from Christ on the Mount of Olives and the Finale of Act Two of Leonore (see Examples 7 and 18). Rhythmically, the trombone parts are not abbreviated: the rhythm that the trombones play is the same as that of the trumpets and timpani:

Example 104: Consecration of the House, measures 1-5

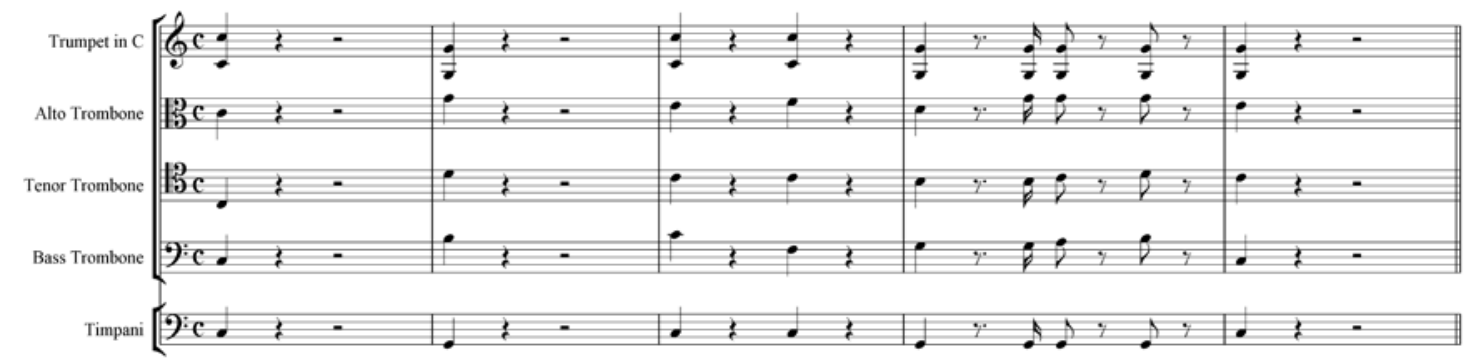

The rhythms in measure four are an example of the rhythmic equality of the brass throughout the opening of Consecration of the House. Beethoven wrote the trumpet and trombone parts to work together as one larger brass unit-something he had begun to do in Missa Solemnis (see Example 93). This technique could be considered another step toward the development of the orchestral brass section, which was further advanced by composers following Beethoven, especially Germanic composers of the late Nineteenth Century. ${ }^{314}$

After the opening chords (the only other instance besides The Glorious Moment where the entire trombone section plays the first notes of a work), the trombone partsdespite the small number of measures they play-are significant. In fact, every passage played by the trombones is either a momentary prominence or a section solo:

\footnotetext{
${ }^{314}$ See Guion, p. 279 for more discussion of Beethoven and the completion of the orchestral brass choir.
} 
Example 105: Consecration of the House, measures 8-21

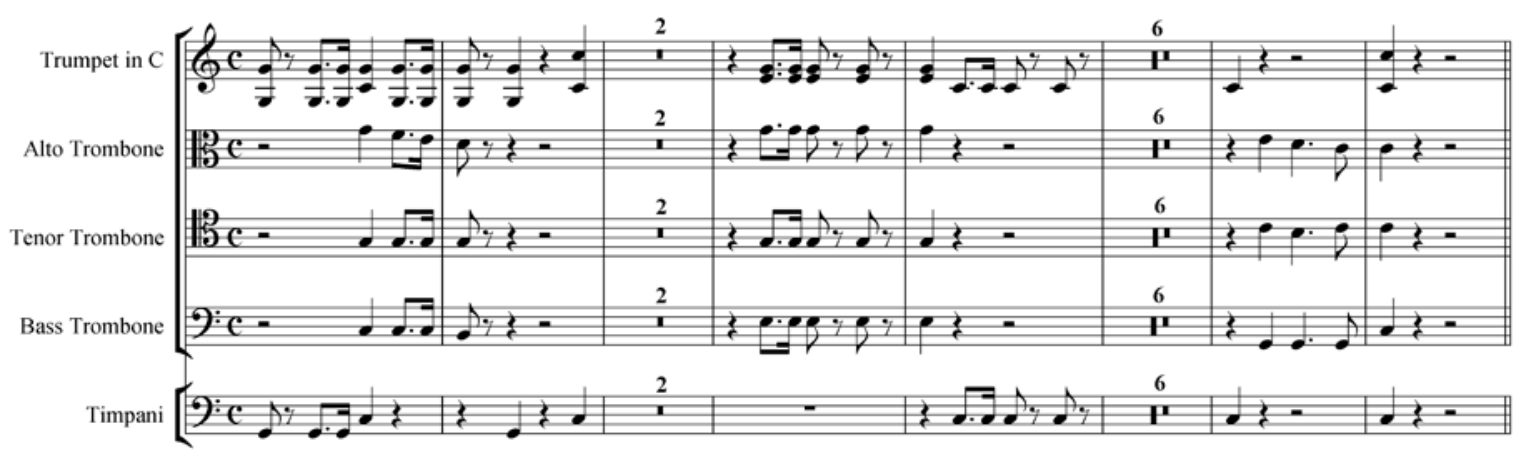

The trombones basically repeat the above passage, then after measure 37 remain silent for the rest of the overture. However, in the original corrected score, the trombone parts continue in the score as empty bars (with rests marked in) for the remainder of the work. ${ }^{315}$ Usually in a modern score, within a page of the last notes an instrument plays, the space the instrument(s) part(s) occupied is taken away and used for other instruments. The implication here is that in Consecration of the House, since the entire work retained the trombone lines, there was more that would have been written for the trombones. It is known that Beethoven wrote Consecration of the House in a hurry, and that it was not complete at its premiere. ${ }^{316}$ Since he was in the habit of adding trombone parts at the last minute, ${ }^{317}$ it is quite likely that he meant to fill in more notes for the trombones to play but simply ran out of time, retaining empty measures for later completion. However, once the work was reasonably completed and premiered, instead of returning to the score and adding more trombone parts, Beethoven turned to other projects. The problem of "missing" trombone parts is especially noticed in measures 37-53, which includes material derivative of Handel's King Saul:

\footnotetext{
${ }^{315}$ Beethoven Haus-Bonn, "Overture, Consecration of the House," < http://www.beethoven-hausbonn.de/sixcms/detail.php?id=\&template=dokseite_digitales_archiv_en\&_eid=\&_ug=\&_werkid=126\&_dokid= wm53\&_opus=op.\%20124\&_mid=Works\%20by\%20Ludwig\%20van\%20Beethoven\&_seite=1>, 2009, accessed 1 July, 2009.

${ }^{316}$ Solomon, Ibid., 348.

${ }^{317}$ For examples of this see discussion of Christ on the Mount of Olives and Leonore above, and see discussion of Symphony \#9 below.
} 
Example 106: Consecration of the House, measures 37-40

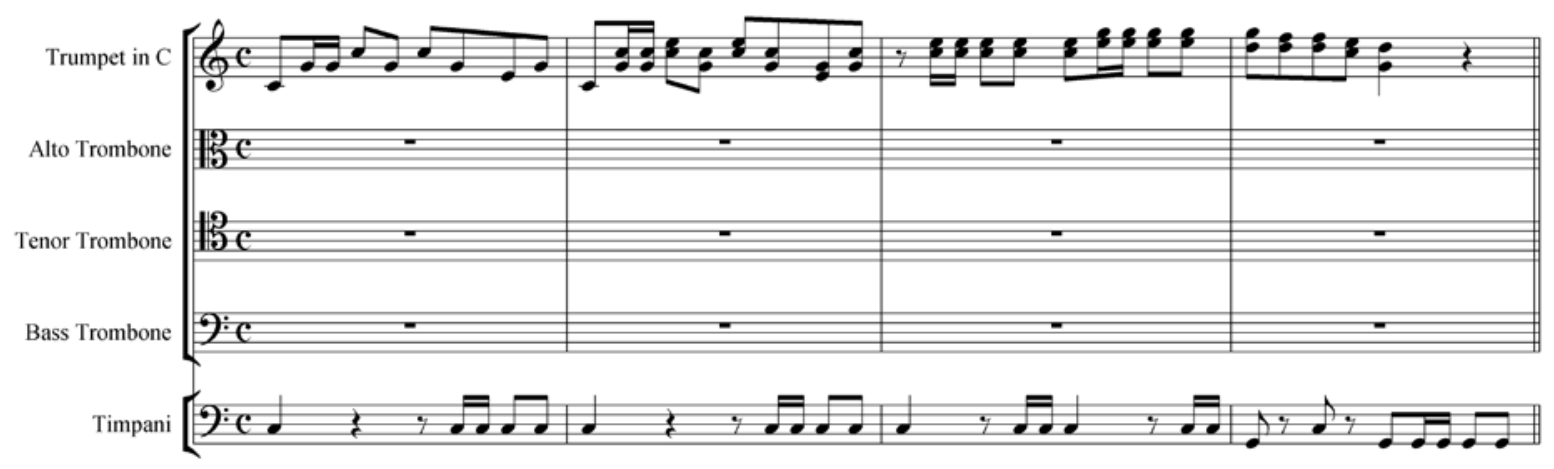

The corresponding passage from King Saul is below. Note the similarities between the trumpet parts in the first and second measures of the Consecration of the House example directly above, and the second and fourth measures of the King Saul example directly below. The King Saul passage in question includes trombones, and it is probable that Beethoven would have included trombones in the corresponding Consecration of the House section had there been more time for him to complete the overture:

Example 107: Handel, King Saul, Number 1, measures 18-23

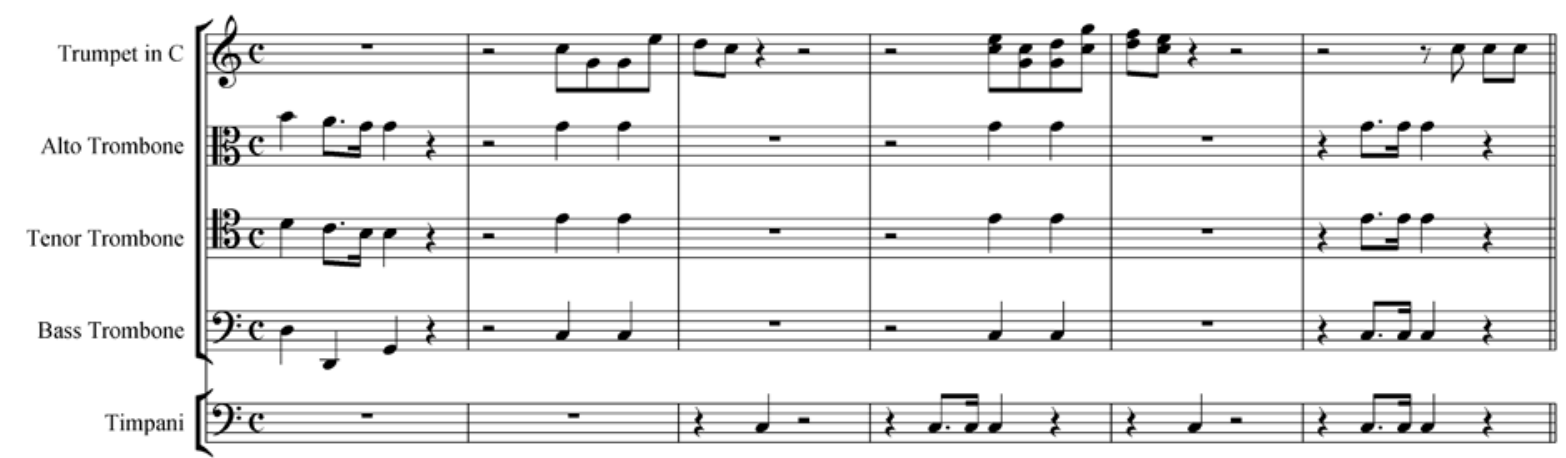

To conclude Consecration of the House, Beethoven most likely incorporated trombone parts because the other work performed (March and Chorus from Ruins of Athens) also included trombones. However, the measures which include trombones, though few in number, are orchestrated differently than in most of his other works. They reflect a style of composition that is a throwback to an earlier compositional period and style, specifically that 
of Handel. The trombones follow the melodic and rhythmic lines of the trumpets and timpani, with little or no rhythmical abbreviation. There are section soli for them as well. It seems clear that more would have been written for the trombones in Consecration of the House if Beethoven had had the time to complete the work. However, since it was his habit to add trombone parts last, in this particular work he obviously never went back to add them.

\begin{tabular}{|l|l|c|l|l|c|c|c|}
\hline \multicolumn{6}{|c|}{ Table 17: Trombone Statistics for Consecration of the House, Opus 124} \\
\hline \multicolumn{2}{|c|}{ Movements } & \multicolumn{5}{c|}{ Ranges } \\
\hline Total & \#Played & Total & \#Played & $\%$ Played & Alto & Tenor & Bass \\
\hline 1 & 1 & 278 & 17 & 6 & d to $b^{1}$ & $\mathrm{~b}^{b}$ to $\mathrm{a}^{1}$ & $\mathrm{~d}$ to $\mathrm{b}^{b}$ \\
\hline
\end{tabular}

\section{March and Chorus from the Ruins of Athens, Opus 114}

This piece was included in the same dedication program for the Josephstadt Theatre as the premiere of Consecration of the House. The March and Chorus from the Ruins of Athens is simply a redux of Number \#6 from the original Ruins of Athens. Though Beethoven claimed the work was new, as Thayer has said, “...not a measure had been added.”318 This work was also performed at various concerts in the years following the Josephstadt Theatre performance, including one particular benefit concert on May 11, 1826. The piece was published that same year, as a separate Opus, and is performed occasionally (unlike the complete work from which it is taken). All trombone-related comments regarding the March and Chorus can be found in the Ruins of Athens section in the previous chapter.

\begin{tabular}{|c|l|c|l|l|c|c|c|}
\hline \multicolumn{2}{|c|}{ Table 18: Trombone Statistics for March and Chorus from Ruins of Athens, Opus 114 } \\
\hline \multicolumn{2}{|c|}{ Movements } & \multicolumn{3}{|c|}{ Measures } & \multicolumn{4}{c|}{ Ranges } \\
\hline Total & \#Played & Total & \#Played & \%Played & Alto & Tenor & Bass \\
\hline 1 & 1 & 165 & 47 & 28 & $\mathrm{~b}^{b}$ to c & $\mathrm{e}^{b}$ to $\mathrm{b}^{b^{1}}$ & $\mathrm{~B}^{b^{0}}$ to e $b^{1}$ \\
\hline
\end{tabular}

\footnotetext{
${ }^{318}$ Thayer, Life of Beethoven, 807.
} 


\section{Symphony \#9, Opus 125}

Symphony \#9 was the final work Beethoven wrote that included trombones. The ideas for the work can be traced back to 1793—Beethoven's early days in Bonn—where he voiced intent to set Schiller's Ode to Joy to music. ${ }^{319}$ The first true fragments and sketches of Symphony \#9 appeared in his sketchbooks from 1816-1817, perhaps as early as $1815 .{ }^{320}$ In 1817, Beethoven received a commission from the London Philharmonic Society for a new symphony but did not begin any serious efforts at expanding his sketches into a complete composition, possibly due to distractions caused by the "raging litigation" over custody of his nephew Karl. ${ }^{321}$ Beethoven tended to compose his symphonies in pairs. Such was the case with Symphony \#5 and \#6, which were both premiered on the same concert in 1807—as well as Symphony \#7 and \#8, which were both premiered within months of each other in 1813. With Symphony \#9, Beethoven "was again contemplating the almost simultaneous production of two symphonies.”322 While a few sketches remain of what would have been the Tenth Symphony, Beethoven did not stay with the dual symphony project this time but instead seemed to replace the fragments of a tenth symphony with Missa Solemnis as the Ninth's counterpart. However, there was less simultaneous composition going on in this case; most of Beethoven's energy turned towards finishing Symphony \#9 only after the completion of Missa Solemnis in $1823 .{ }^{323}$ So, while ideas and seeds of Symphony \#9 go back thirty years, and sketches go back probably six years, it can be asserted, as Thayer aptly said, that “...1823 saw the birth of the Symphony, though work was carried over into 1824.”"324

\footnotetext{
${ }^{319}$ Solomon, Beethoven, 56.

${ }^{320}$ Nicholas Cook, Beethoven Symphony \#9 (Cambridge: Cambridge University Press, 1993), 9.

${ }^{321}$ Ibid., 322.

${ }^{322}$ Thayer, Life of Beethoven, 889.

${ }^{323}$ Thayer, Ibid., 879.

${ }^{324}$ Ibid., 890.
} 
Beethoven, in a foul disposition towards the musical life of Vienna (and its love at that time for Rossini), had contemplated premiering Symphony \#9 in Berlin. ${ }^{325}$ The Viennese dignitaries responded with a letter reiterating their loyalty to and appreciation of Beethoven, proposing an Academie concert to benefit him, both artistically and financially. At first, several Vienna theatres sparred for the privilege of hosting the Academie. It appeared as if the concert would take place in late April at the Theatre an-der-Wein, but due to lack of competent soloists at that venue, ${ }^{326}$ it was finally booked at the Kärntnertor Theater. ${ }^{327}$ Even though the new location was approved, because of the complexity and difficulty of the Symphony, settling upon a date proved more difficult. At one point Beethoven actually pulled out of the entire production-mainly due to the singers constantly begging him to simplify the solo parts. ${ }^{328}$ Thayer reports that there were only two full rehearsals, ${ }^{329}$ but as Cook says, the statement is misleading. There may have been two full rehearsals, but there were other separate section rehearsals for the strings, rehearsals for the chorus, and coaching sessions—led by Beethoven—for the soloists. ${ }^{330}$ Finally the concert was scheduled for May 7, 1824. The program, as mentioned in the discussion of Missa Solemnis above, included Consecration of the House Overture, three movements (Kyrie, Credo, and Agnus Dei) from Missa Solemnis-titled "Three Grand Hymns" to satisfy the church authorities—and the premiere of Symphony \#9, called "A Grand Symphony with Solo and Chorus." The Kärntnertor Theater was filled to capacity, except for the Kaiser’s box seat, for he and his wife (as well as Archduke Rudolph) were not in Vienna at the time. The concert-and

\footnotetext{
${ }^{325}$ Thayer, Ibid., 896-897.

${ }^{326}$ Ibid., 906-907.

${ }^{327}$ Nicholas Cook, Ibid., 20.

${ }^{328}$ Schindler, Beethoven as I Knew Him, 277. Beethoven chided the chorus and soloists for becoming soft due to singing too much Italian music, which was also a swipe at the currently popular Rossini (see Nicholas Cook, Beethoven Symphony \#9 [Cambridge: Cambridge University Press, 1993], 20-21).

${ }^{329}$ Thayer, Ibid, 907.

${ }^{330}$ Cook, Ibid.
} 
especially Symphony \#9—-was received with the highest enthusiasm by the loyal Viennese audience, despite numerous performance difficulties on the part of the orchestra. ${ }^{331}$ Because of the extreme emotion surrounding the event, there are discrepancies in the details of personal accounts. However, Schindler, who acted as concert manager for the premiere of the symphony, ${ }^{332}$ probably described the situation best:

As for the musical success of this memorable evening, it could be favorably compared to any event ever presented in that venerable theatre. Alas! the man to whom all this honor was addressed could hear none of it, for when at the end of the performance the audience broke into enthusiastic applause, he remained standing with his back to them. Then it was that Caroline Unger [contralto soloist] had the presence of mind to turn the master towards the proscenium and show him the cheering crowd throwing their hats into the air and waving their handkerchiefs. He acknowledged his gratitude with a bow. This set an almost unprecedented volley of jubilant applause that went on and on as the joyful listeners sought to express their thanks for the pleasure they had just been granted. ${ }^{333}$

Unfortunately, the amount of the proceeds from the concert threw Beethoven "into a fuming ill-humor." ${ }^{334}$ He tended to grossly overestimate his earnings from performances, as was discussed earlier concerning Leonore, and in this case, his brother Johann encouraged Beethoven's overestimation of the profits. ${ }^{335}$ He met several of his regular companions, including Schindler, at a restaurant after the concert, and after ordering his meal, flew into a rage, accusing Schindler of swindling him, claiming a "credible informant" had reported to him Schindler's thievery. Thayer opines that Johann “...was jealous of Schindler’s participation in the composer's business affairs..." and took advantage of the opportunity to

\footnotetext{
${ }^{331}$ Many of those present later recollected the difficulties the orchestra members had during the performance. Critic Freidrich August Kanne said that the weaker violinists simply put their bows down during the Scherzo, and Leonore librettist Leopold Sonnleithner referred to the string bass Recitative in the fourth movement as "gruff rumbling." (See Nicholas Cook, Beethoven Symphony \#9 [Cambridge: Cambridge Univ. Press, 1993], 22-23.)

${ }^{332}$ Thayer, Ibid., 911.

${ }^{333}$ Ibid., 208.

${ }^{334}$ Ibid., 911.

${ }^{335}$ Solomon, Beethoven, 352.
} 
drive a wedge of suspicion between Beethoven and Schindler. ${ }^{336}$ That Schindler re-wrote this particularly unpleasant experience in his biography of Beethoven to read that upon learning of the box office report Beethoven had collapsed at his home, ${ }^{337}$ shows not only Schindler's loyalty to his mentor but also his ability to forgive. (However, after this episode, Schindler did “...disappear from the foreground of Beethoven's activities until late in 1826.” ${ }^{338}$ ) A second concert with Symphony \#9 on the program took place at the Great Redoutensaal Theatre on May 23 in the afternoon, but due to the beautiful weather the house was at less than half capacity. ${ }^{339}$ The London Philharmonic Society—-the original commissioner of the work—did not premiere Symphony \#9 until March 21, 1825. The British reviews were mixed at best, with little understanding (or charity) concerning the new ideas of the work, such as inclusion of a choir or a Recitative by the basses at the beginning of the fourth movement. ${ }^{340}$ Since that time, however, Symphony \#9 has come to be recognized as one of the greatest symphonic works ever composed. Some, like Schindler, venture even further and describe the work as "the highest triumph of orchestral music perhaps of all time." ${ }^{341}$

Symphony \#9 has in the score three trombones: alto, tenor, and bass. By this time in Beethoven's compositions, the three-trombone section had become the standard; the twoinstrument teams of Symphony \#6 and Fidelio had been cast aside for the more versatile three-trombone section. This size section became the standard ${ }^{342}$ for symphonic composers

\footnotetext{
${ }^{336}$ Solomon, Ibid.

337 Schindler, Ibid., 280.

${ }^{338}$ Solomon, Ibid.

339 Ibid.

${ }^{340}$ Nicholas Cook, Ibid., 42-43.

${ }^{341}$ Schindler, Ibid., 297.

342 The type of instruments scored does change around the middle of the Nineteenth Century, however, from the alto, tenor, and bass section common to Beethoven, to a two tenor and one bass section-although Berlioz did tend to write for three tenors in most of his works (except Symphonie Fantastique). The other composer who might be considered an exception to the three trombone section in a symphonic work rule was Richard Wagner, whose Ring called for four trombones (one being a Contrabass trombone). While The Ring is not a symphonic
} 
following Beethoven, with few variations on that number until Mahler and his Symphony \#2 (Resurrection), which calls for four trombones. ${ }^{343}$ The tessiturae of the three trombone parts in Symphony \#9 is typical, though the bass trombone's low range is reduced somewhat. The alto ranges from $g$ to $d^{2}$, the tenor ranges from $d$ to $a^{1}$, and the bass is from $G$ to $f \#^{1}$. The trombone section in this work has very clearly delineated roles, based on the particular context and dynamic. For example, the trombones have a purely accompanying role in the Scherzo, and in that movement, the span of the parts tends to be wider, hovering around tenths, twelfths, and even as wide as two octaves. In the ending of the Finale, the trombones have more of a tutti supporting role, and the intervals tend to be closer, including sixths, fifths, and even unisons. The chords are all in close position, with the final chords in a tight root position triad, which, as was discussed earlier, has excellent projection qualities.

The first entrance of the trombone section occurs in the trio of the Scherzo, where the bass trombone begins, joined later by the alto and tenor. The entrance is musically surprising, since the bass trombone is the only brass instrument to hold the sustained note. It is joined by the oboes and clarinets, which then continue the melody:

Example 108: Symphony \#9, Scherzo, measures 412-415

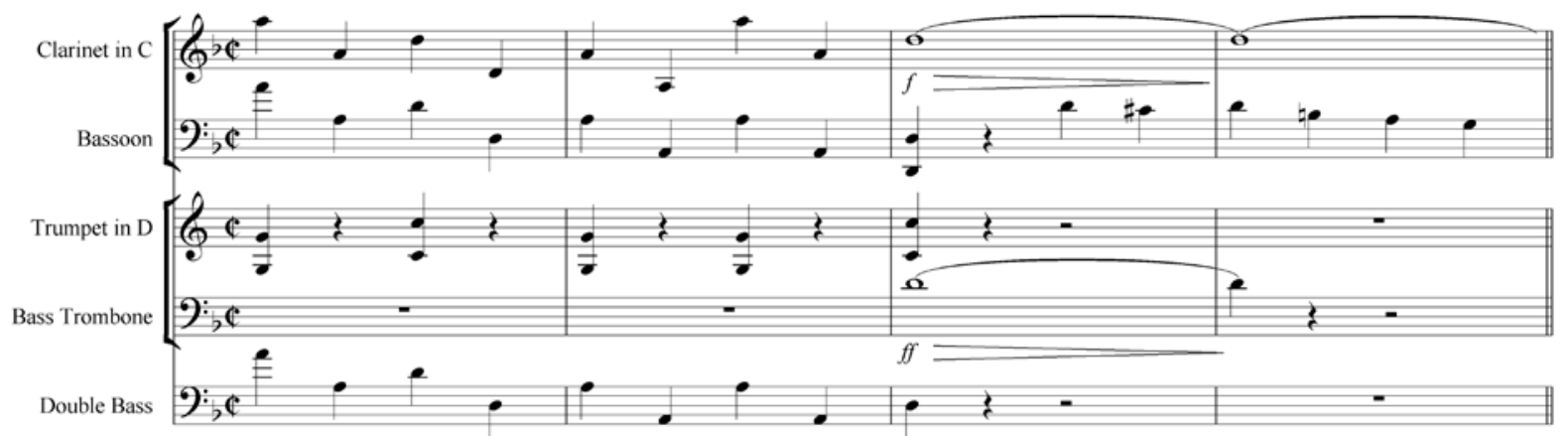

work per se, Wagner's operas, especially The Ring, could be categorized as orchestral, or even symphonic. His assigning thematic importance to trombones is a treatment of the instrument that is more symphonic than any other Nineteenth Century operatic composer, most of whom scored for trombones mainly as extra tutti forces.

${ }^{343}$ Mahler did not consistently score for four trombones. His Symphonies 5, 7, and 9 call for three trombones (Symphony \#7 also includes a part for Tenor horn—an instrument similar to the modern Baritone Horn). He scored for four trombones in Symphonies 2, 3, 6, and 8, with extra antiphonal trombones in Symphony 8. 
Aside from this one sustained D (and the same note at the end of the movement), the bass trombone for the most part doubles the string basses. The doubling is not exact, as is often the case when the bass trombone doubles the choir. In this instance, the bass trombone's doubling follows the celli and basses in a much more loose fashion:

Example 109: Symphony \#9, Scherzo, measures 475-484

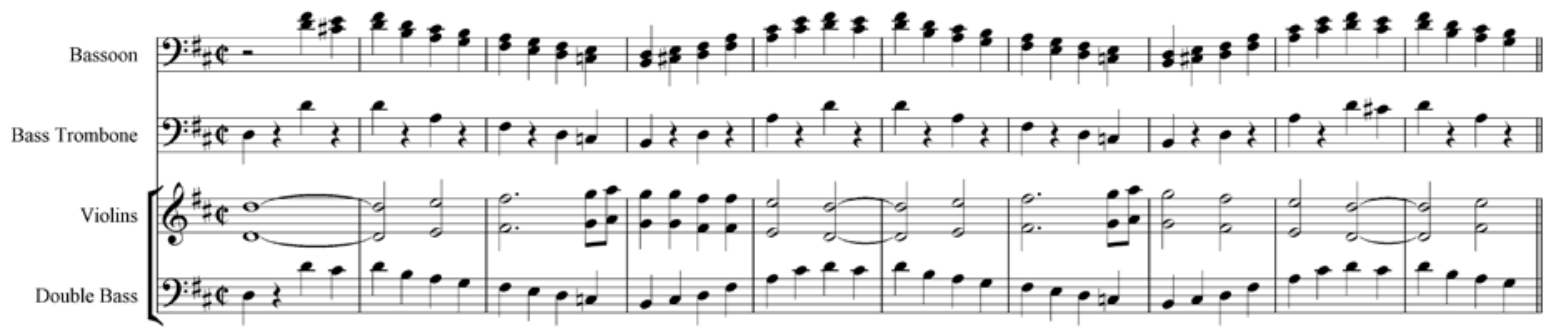

The bass trombone basically plays the note for each downbeat, leaving out the upbeats. It is the only instrument that plays this part. All others are either playing the melody, the full bass line, or holding out soft whole notes. The lone bass trombone part in this movement is reminiscent of that in the Victory March from King Stephen, discussed previously, where the bass trombone-without the alto or tenor-loosely doubles the cello and bass line. The bass trombone is then eventually joined by the alto and tenor:

Example 110: Symphony \#9, Scherzo, measures 496-507

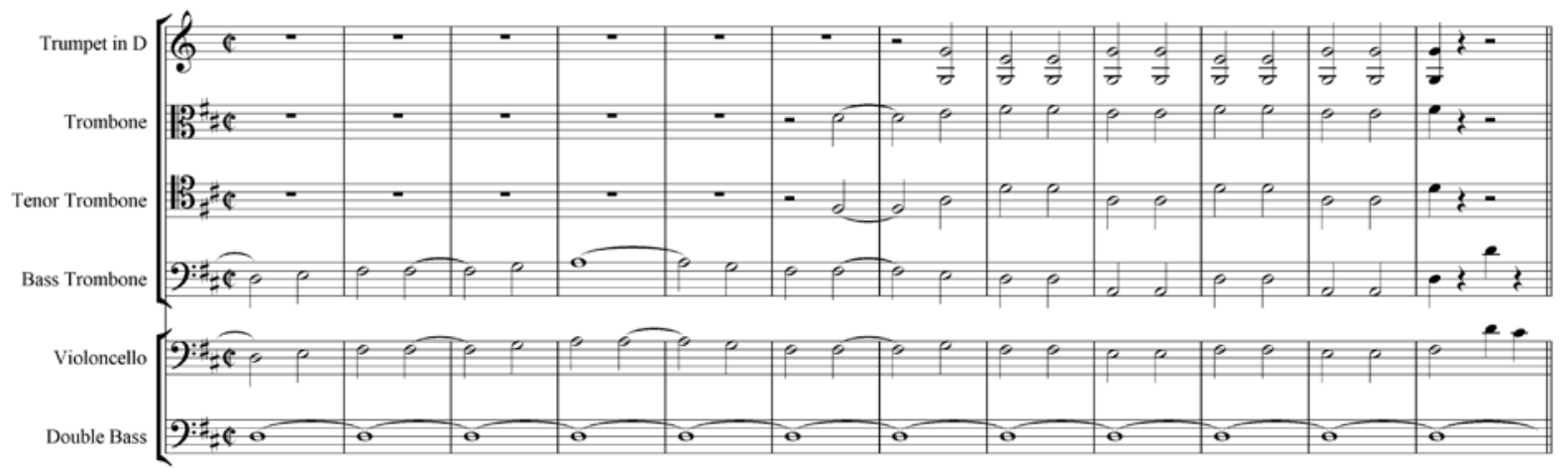

The bass trombone at this point doubles the celli instead of the bass, until the eighth measure of the example, where the part is more or less independent-in octaves with the tenor trombone, while the alto trombone carries the cello notes up the octave. The trumpets also 
join in at this section, which is reminiscent of the few passages from Consecration of the House where the trumpets and trombones worked together as a section. The same idea is repeated several bars later, with most of the voices one chord member higher:

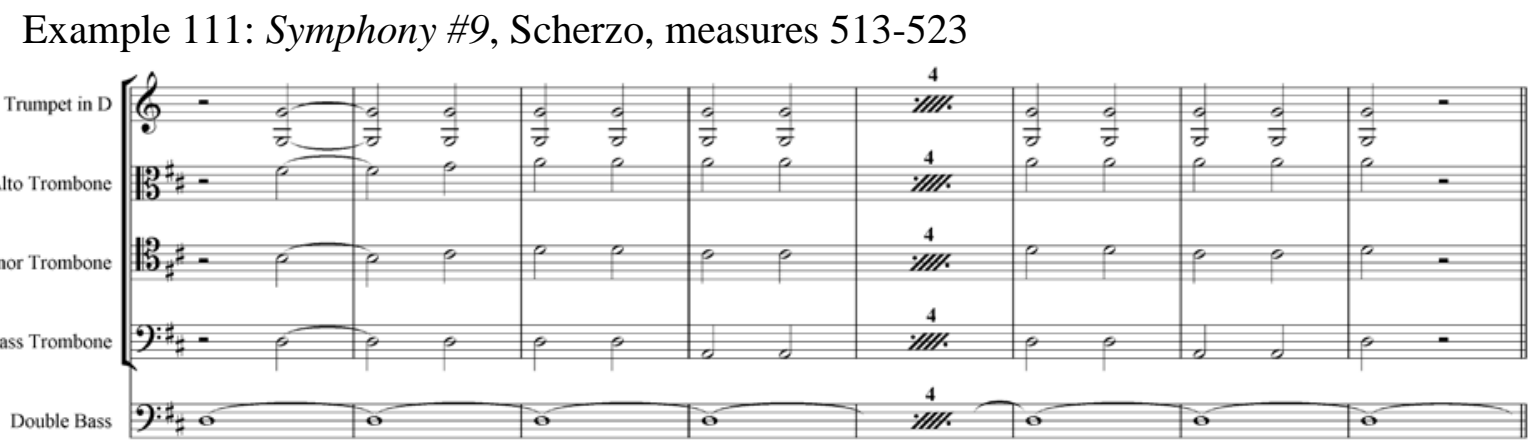

After the Da Capo, the Coda includes the bass trombone without the alto and tenor again:

Example 112: Symphony \#9, Scherzo, measures 944-954

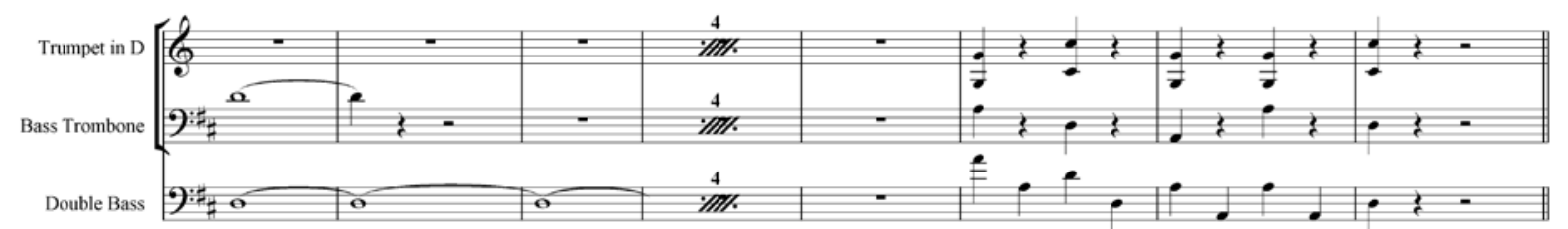

Here again the bass trombone is written using rhythmic abbreviation, this time joined by the trumpets. Thayer notes that the trombone parts to the Scherzo were not in the original score- similar to the trombone parts for other works such as Christ on the Mount of Olivesand that "these parts contained also Beethoven's instructions to the copyist as to where to introduce them in the score.”344

The trombones remain silent for the third movement, as was the case with the opening movement of the symphony. They finally play again well into the Finale, beginning with the bass trombone doubling the tenor and bass voices. Kinderman describes the passage as archaic and modal ${ }^{345}$-hearkening back to the Renaissance and the ecclesiastical role of

\footnotetext{
344 Thayer, Life of Beethoven, 329, fn. 5.

${ }^{345}$ Kinderman, Beethoven, 304.
} 
the trombones at that time-similar to their role in Missa Solemnis. Berlioz described the effect of the trombones in this particular section as "religious, solemn, and immense:" 346

Example 113: Symphony \#9, Finale, measures 595-610

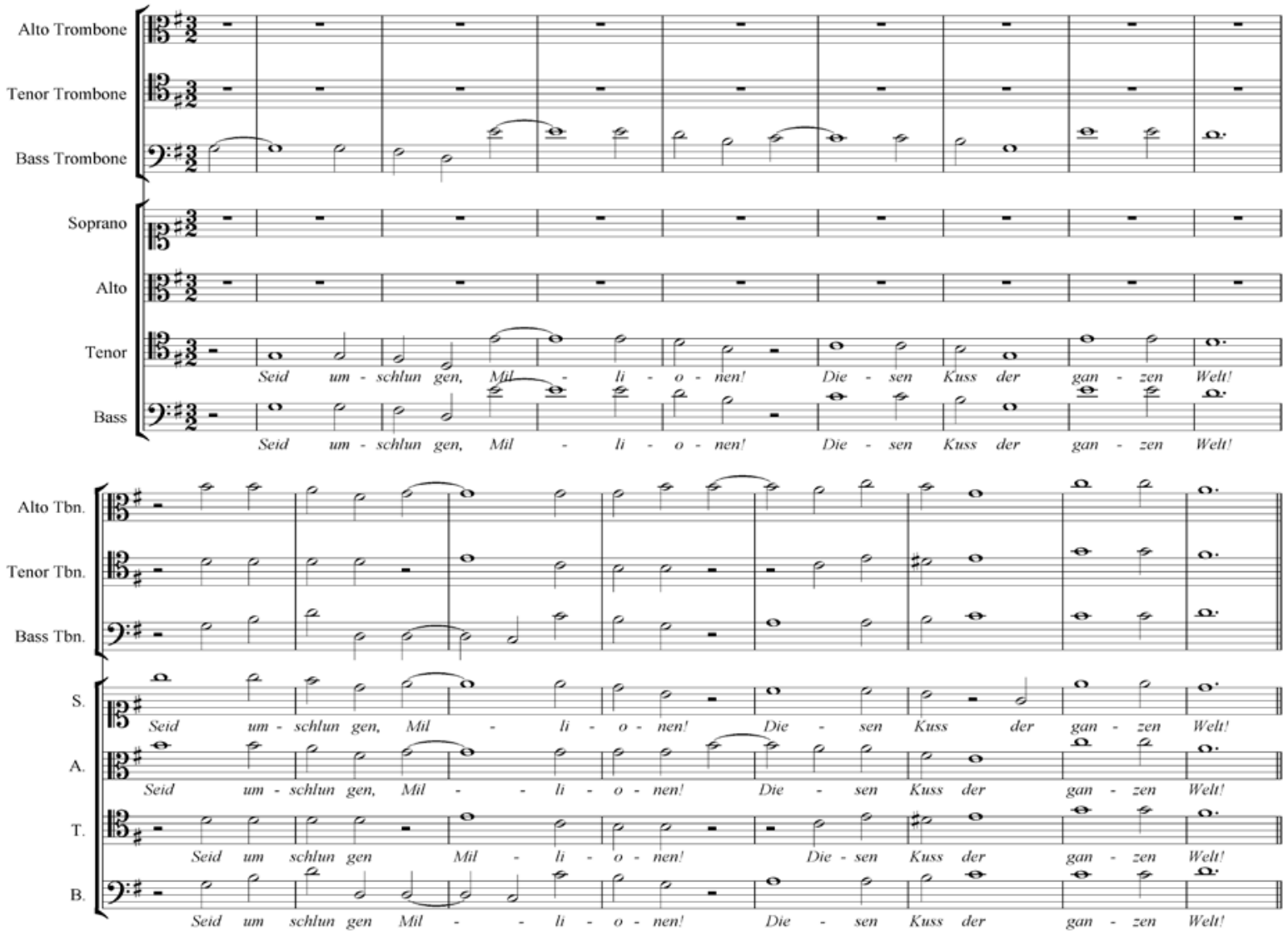

The bass trombone plays alone again as in the Scherzo, but doubling both the basses and tenors at this point. Though not as intense as the solo tenor trombone in the Credo of Missa Solemnis, (and accompanied by the celli and string basses), the solo entrance of the bass trombone acts like an intonation of an organ to alert a cantor to introduce the new text:

"Seid umschlungen, Millionen! Diesen Kuss der ganzen Welt! Brüder-überm Sternenzelt Muss ein lieber Vater wohnen.”

Which being translated means:

Be embraced, you millions! Here's a kiss for all the world! Brothers! Above the canopy of the stars there must dwell a loving Father!

${ }^{346}$ Hector Berlioz, Beethoven (Boston: Crescendo Publishing Company, 1975), 47. 
The particular religious belief outlined in these words - the Brotherhood of Man and the Fatherhood of God—was one firmly held by Beethoven throughout his life. ${ }^{347}$ It is fitting that he chose trombones—with their ancient religious and ecclesiastical associations— to be prominent in this portion of the work. The section continues:

Example 114: Symphony \#9, Finale, measures 611-626

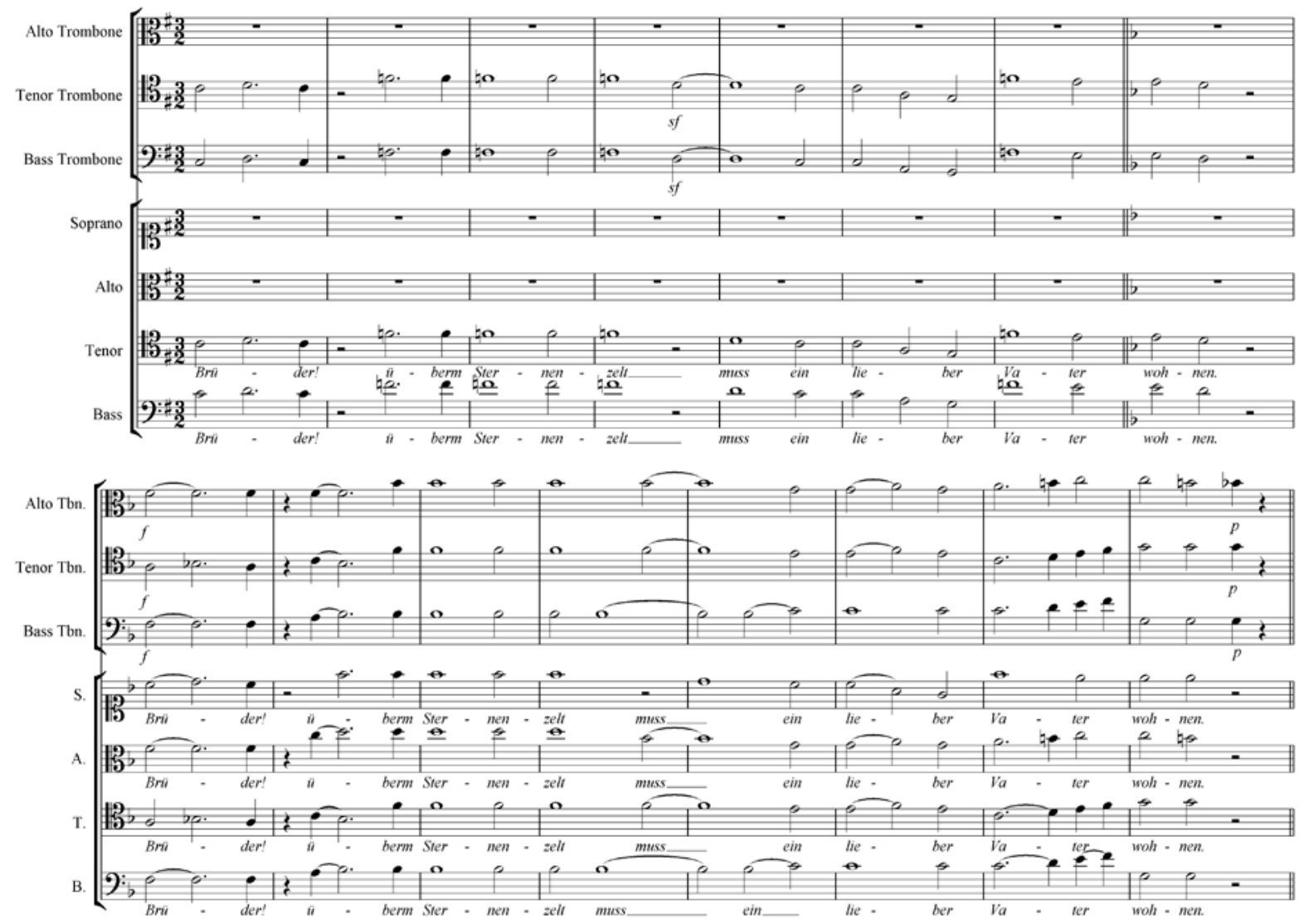

The doubling techniques of Example 114 differ from Example 113 considerably. Example 113 has the trombones doubling the voice in the more traditional manner: the alto trombone matching the alto voice, the tenor trombone matching the tenor voice (after the initial opening which is played only by the bass trombone), and the bass trombone doubling the bass voice. However, in Example 114 (shown directly above), right away the techniques are different. First, the tenor trombone doubles the basses and tenors at the proper octave, while

${ }^{347}$ Solomon, Beethoven, 404-405. 
the bass trombone doubles at the lower octave. The octave "D's" in the fourth measure of the example had particular significance to Beethoven, who noted in his sketches, "On Welt Sternenzelt forte trombone blasts.”348

After the full choir enters at the key change, the bass trombone continues doubling at pitch, while the tenor and alto trombones - in the tenth measure of the example, switch doubling voices momentarily. The example continues for two more measures with the alto trombone doubling, not at pitch, but a third lower than the alto voice: instead of the high $\mathrm{d}^{2}$, the alto is lowered to the $b^{b^{1}}$. This is most likely another example of "compensatory harmony," such as what was seen briefly in Missa Solemnis. Why Beethoven would consider a $\mathrm{d}^{2}$ to be too high for the alto trombone in this case but not in other cases such as in Missa Solemnis or Symphony \#5 will be addressed below. After the compensatory harmony, the entire section doubles the choir at pitch, until the final note, where the trombones play a subito piano chord with the tutti orchestra. Fortunately, the fact that the note is with tutti orchestra makes it easier to execute than if it were the trombones alone.

The next example comes from the beginning of the choral fugue. Beethoven has involved trombones in choral fugues since Christ on the Mount of Olives. In the case of the oratorio, the trombones only doubled the chorus parts as they each entered with the fugue subject (see Example 5, Christ on the Mount of Olives). In Missa Solemnis, the trombones double the chorus for extended sections of the fugue subjects. The same goes for the grand fugue in the Finale of Symphony \#9. In fact, it seemed that, at least in the mind of one Beethoven historian, fugues were innately associated with trombones. Thayer describes a page from Beethoven's sketches which includes the remark, “Or perhaps instead of a new

\footnotetext{
${ }^{348}$ Thayer, Life of Beethoven, 891.
} 
symphony, a new overture on Bach, well fugued with 3 ."349 The Beethoven historian

Gustav Nottebohm had filled in the blank area on the sketch page with "Trombones? Subjects?»350 The fugue begins in the alto voice part:
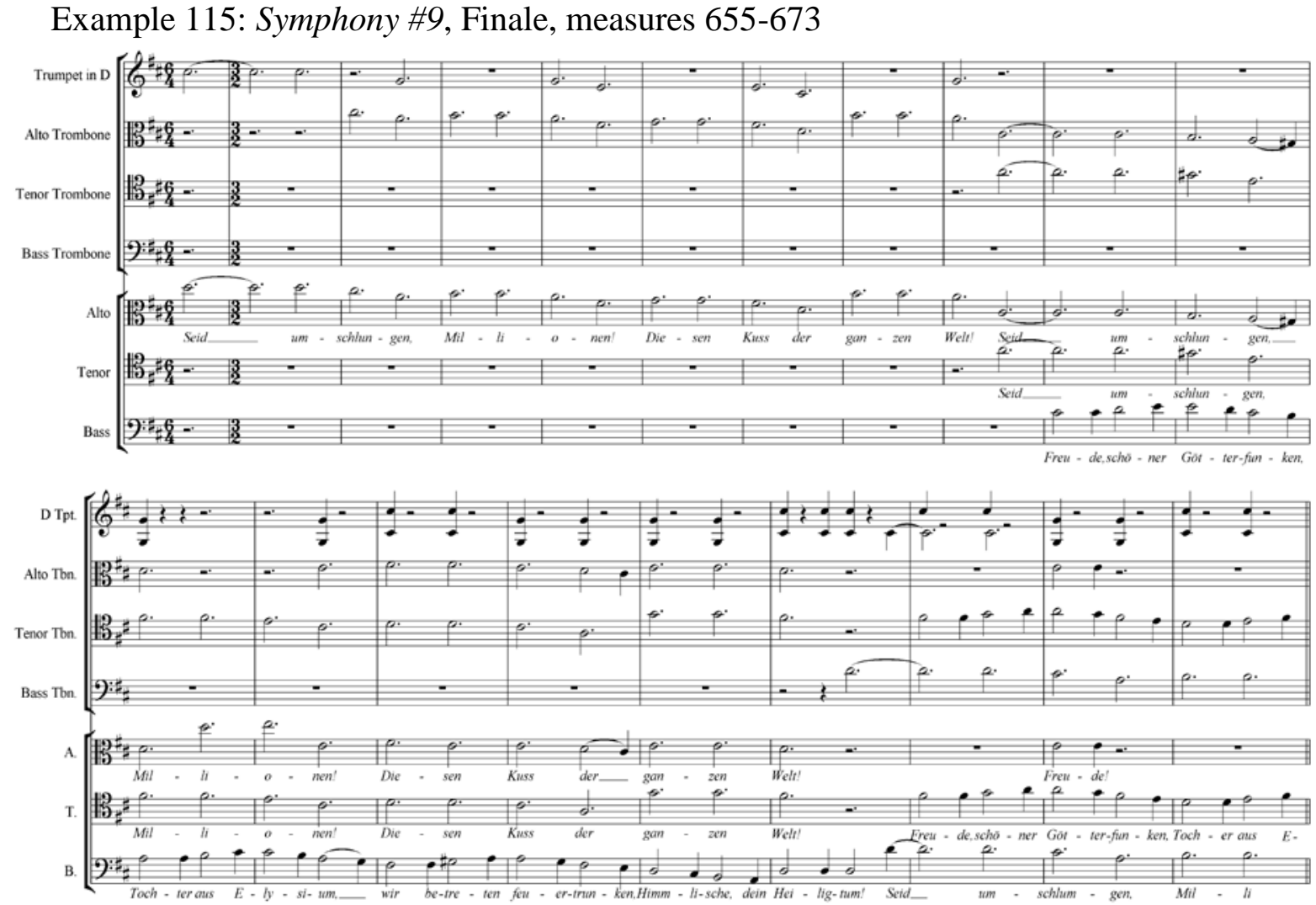

For the most part, the three trombones exactly double their voice counterparts. However, the alto trombone has exceptions throughout the fugue-with instances of those exceptions in the first, second, twelfth and thirteenth measures of the example-where Beethoven apparently thought the alto voice part went too high for the alto trombone to follow. In those cases, the trumpet (first and second measures) and clarinet (twelfth and thirteenth measures, not shown) were substituted for the alto trombone. The result is a piecemeal melody distributed among instruments of significantly varying tone colors, which presents the challenge of blending the

349 Thayer, Life of Beethoven, 889.

${ }^{350}$ Ibid., fn. 15. 
diverse tone colors of those dissimilar instruments to create a cohesive melodic line. Another compensatory technique in the alto trombone part, also seen in Missa Solemnis, is the dropping down of one octave. In cases where the octave shift is written to make musical sense, this shift—if executed properly—is not noticeable. However, there is one octave change which makes no musical sense, found in the alto trombone part in the choral fugue:

Example 116: Symphony \#9, Finale, measures720-729

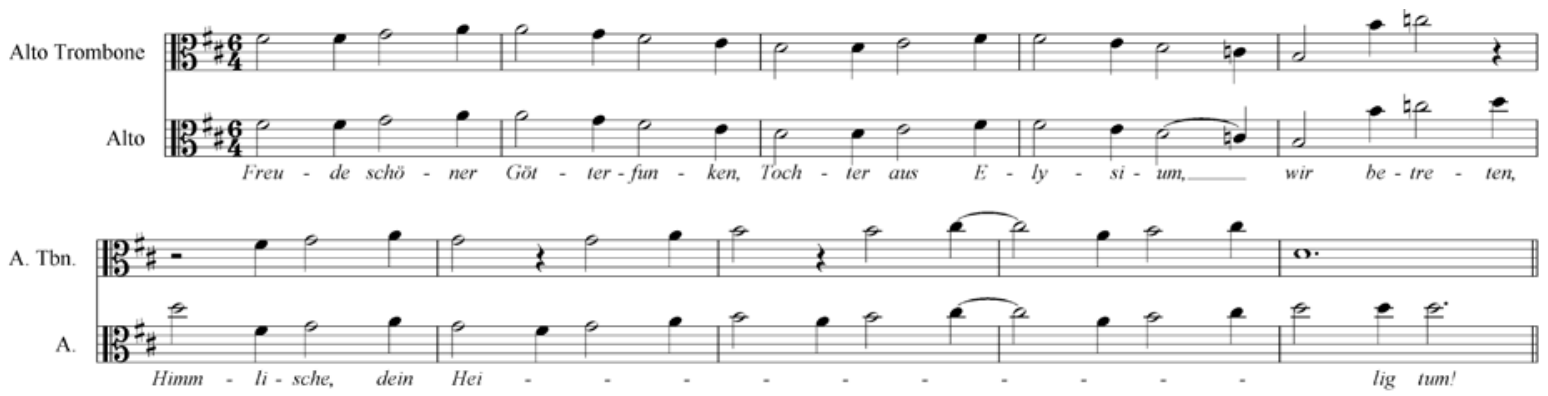

The final measure of the example, with its completely unmusical major seventh drop on a resolution that demands an upwardly-moving half-step, represents the epitome of musical awkwardness. Why would Beethoven write such a thing? Forsyth might have suggested that it was due to Beethoven's deafness—-total by the time of Symphony \#9-which is how he explained the unorthodox contrabassoon part in the work. ${ }^{351}$ However, there may be a more plausible explanation for such a strange interval: one that could explain many of the odd alto trombone omissions and compensations encountered, especially in late works such as Missa Solemnis and Symphony \#9. Throughout Beethoven’s career he employed various copyists to assist him in preparing scores for publication and parts for performances. Not only did these copyists copy the scores and parts, but at times they took it upon themselves to correct the mistakes in the autographs. ${ }^{352}$ Although there were several whose names are known, the

\footnotetext{
${ }^{351}$ Cecil Forsyth, Orchestration (London: MacMillan and Co., 1926), 249.

${ }^{352}$ A logical deduction based on Schünemann's comment about a score of Symphony \#5, where a particular copyist specifically did not correct any of Beethoven's mistakes, but copied the score exactly as Beethoven had
} 
copyist who was without peer in Beethoven’s eyes was Wenzel Schlemmer, Beethoven’s chief copyist for nearly 25 years. $^{353}$ Some of Beethoven's germane works (those with trombone parts) bearing Schlemmer's hand included Christ on the Mount of Olives, Ruins of Athens, King Stephen, ${ }^{354}$ and The Glorious Moment. ${ }^{355}$ However, Schlemmer died in August 1823, which meant that he was not involved in the later stages of Missa Solemnis and most of Symphony \#9. This is borne out by Beethoven’s 1825 complaint in a letter to the publisher Schott: "I have no intelligent copyist...the copyist I had and upon whom I could depend has been in the grave for eighteen months.” ${ }^{356}$ In fact, Beethoven might have relied on Schlemmer for specific information on trombones, for he asked his friend, music publisher Tobias Haslinger, in September, 1823 (one month after Schlemmer's death), what "the highest possible note on the trombone” was, and apparently received an unsatisfactory answer. ${ }^{357}$ Furthermore, as mentioned before, as Beethoven’s health deteriorated, he had to rely more and more on copyists. ${ }^{358}$ Based on these points, it is probable that the particular note under consideration in measure 729 of the alto trombone part was not written by Beethoven, but more likely by a copyist—in this case probably Wenzel Rampl. Rampl, or “Rampel,” as Beethoven usually spelled it, ${ }^{359}$ was Schlemmer’s apprentice and had worked with Beethoven off and on for almost as many years as Schlemmer. Beethoven was not as fond of Rampl as he was Schlemmer, probably referring to Rampl as "a very indifferent

written it. (See Alan Tyson, "Notes on Five of Beethoven's Copyists," Journal of the American Musicological Society 23, Nº 3 [Autumn, 1970], 458-459.)

${ }_{353}$ Alan Tyson, "Steps to Publication—and Beyond," in Beethoven Companion, ed. Denis Arnold and Nigel Fortune (London: Faber and Faber, 1971), 470.

${ }^{354}$ Alan Tyson, “Notes on Five of Beethoven’s Copyists,” Ibid., 445.

${ }^{355}$ Tyson, "Steps to Publication—and Beyond," Ibid., 471.

${ }^{356}$ Tyson, Ibid., 472.

${ }^{357}$ Thayer, Life of Beethoven, 870.

${ }^{358}$ Tyson, Ibid., 473. Apparently, the legibility of Beethoven’s writing fluctuated with his illnesses (see Tyson, "Steps to Publication-and Beyond, p. 473, fn. 1).

${ }^{359}$ Tyson, “Notes on Five of Beethoven’s Copyists,” Ibid., 450. 
worker,”360 and not completely trusting him to "produce an accurate copy of his own.”361 While the handwriting idiosyncrasies of Rampl resemble those of his teacher Schlemmer, Beethoven scholar Alan Tyson has been able to determine through handwriting analysis that Symphony \#9—and therefore the offending wrongly-placed alto trombone note-was most likely copied out by Rampl. Unfortunately, due to either health issues or time constraints, Beethoven was not able to fix the error. Whether Rampl—in a misguided attempt to correct Beethoven - wrote the note in the wrong octave on purpose or by mistake is not known.

The last allegro section of the Finale has the trombones in their traditional symphonic tutti downbeat role, as was seen in Symphony \#5. They no longer double the chorus:

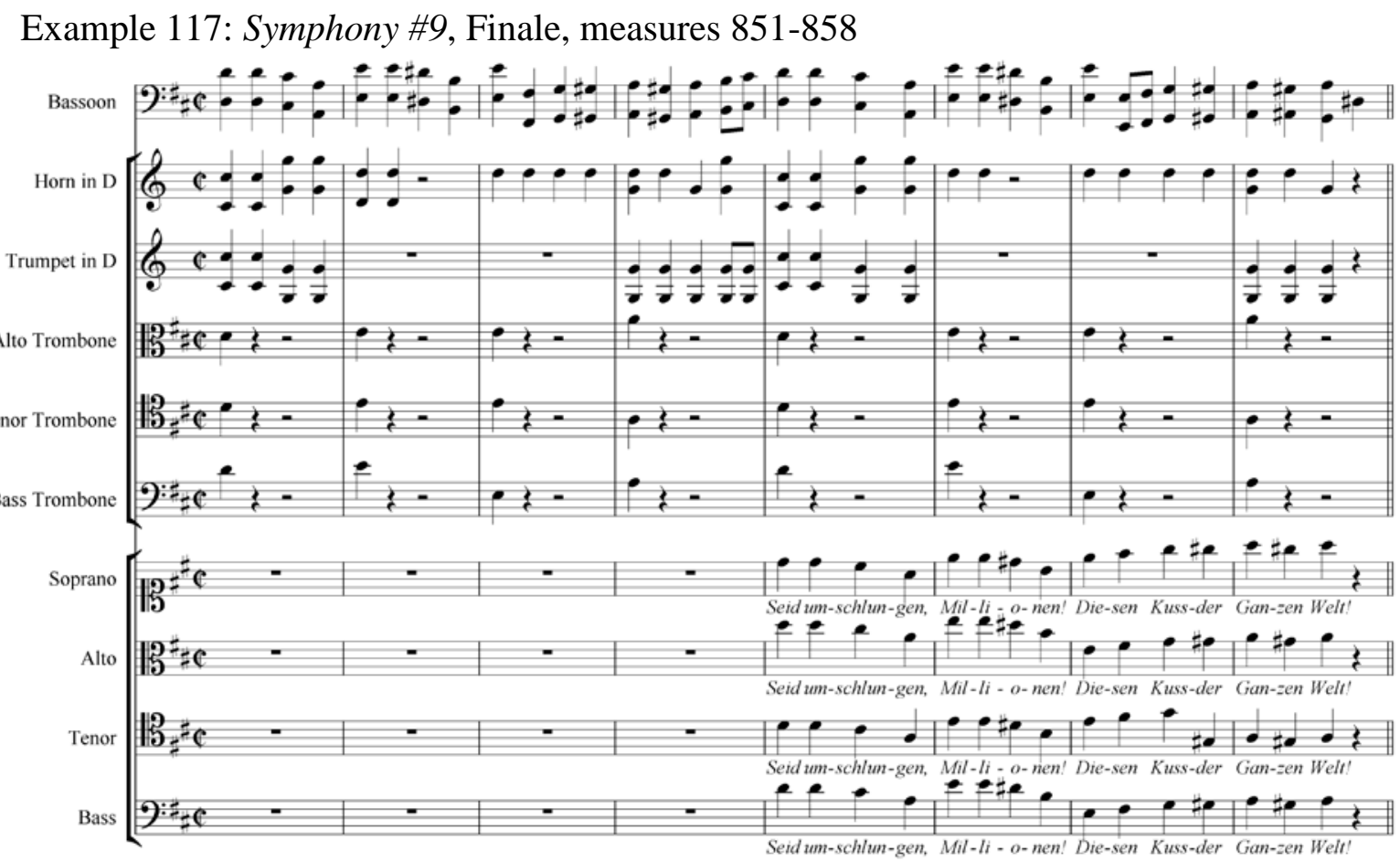

The chorus parts are doubled by the tutti horns, woodwinds, and strings. Some horns play the same rhythm as the chorus but only play the notes that fall on their harmonic series (still the tradition despite the invention of valves in 1814). The trumpets follow the rhythm of the

\footnotetext{
${ }^{360}$ Ibid., 442.

${ }^{361}$ Ibid., 450, fn. 15.
} 
timpani, while the trombones play only the downbeat, or in the following measures, the pickup and the downbeat. The rest of the winds and horns have the full rhythmic passage:

Example 118: Symphony \#9, Finale, measures 861-864

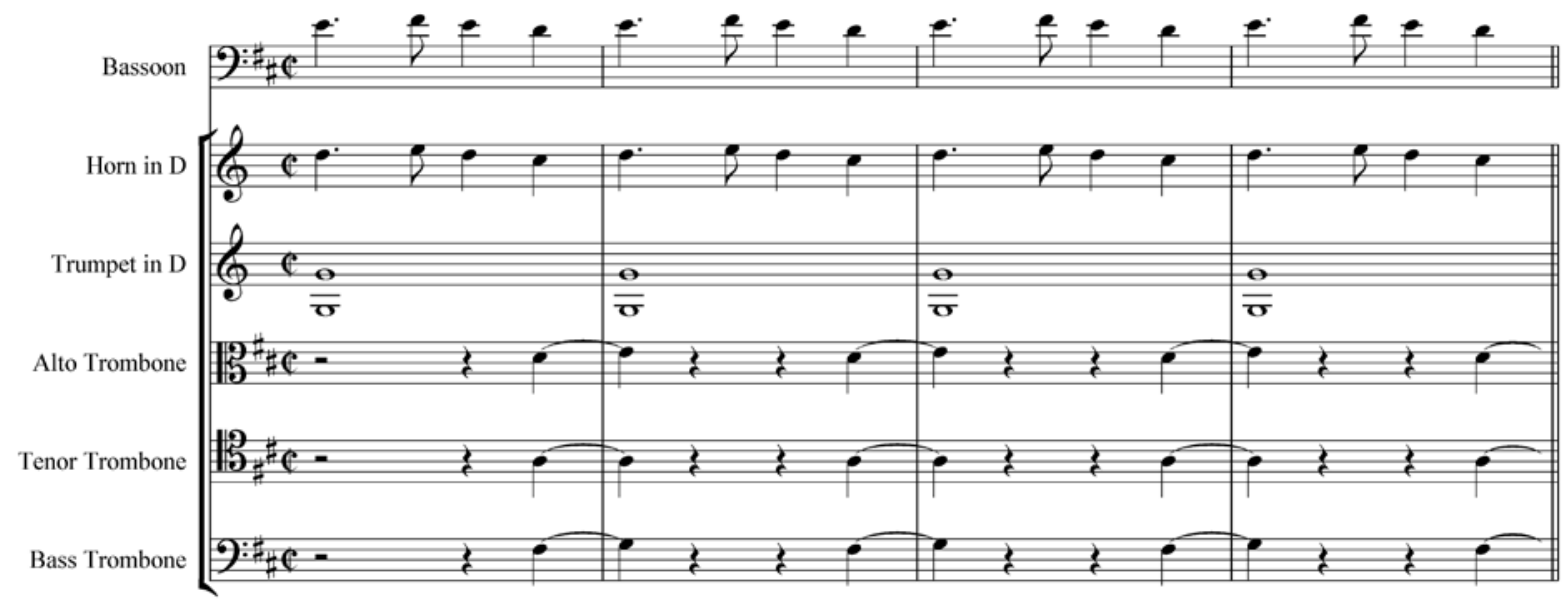

In the next two examples, it is the trombone section that provides the only rhythmic difference — at least in the winds and brass_-between the two passages. In the first example, the trombones play half notes, as do the chorus and tutti winds and high brass. While sections such as this usually have the trombones abbreviated rhythmically, Beethoven chose to write the trombone parts with the same half notes as the rest of the orchestra and chorus:

Example 119: Symphony \#9, Finale, measures 880-886

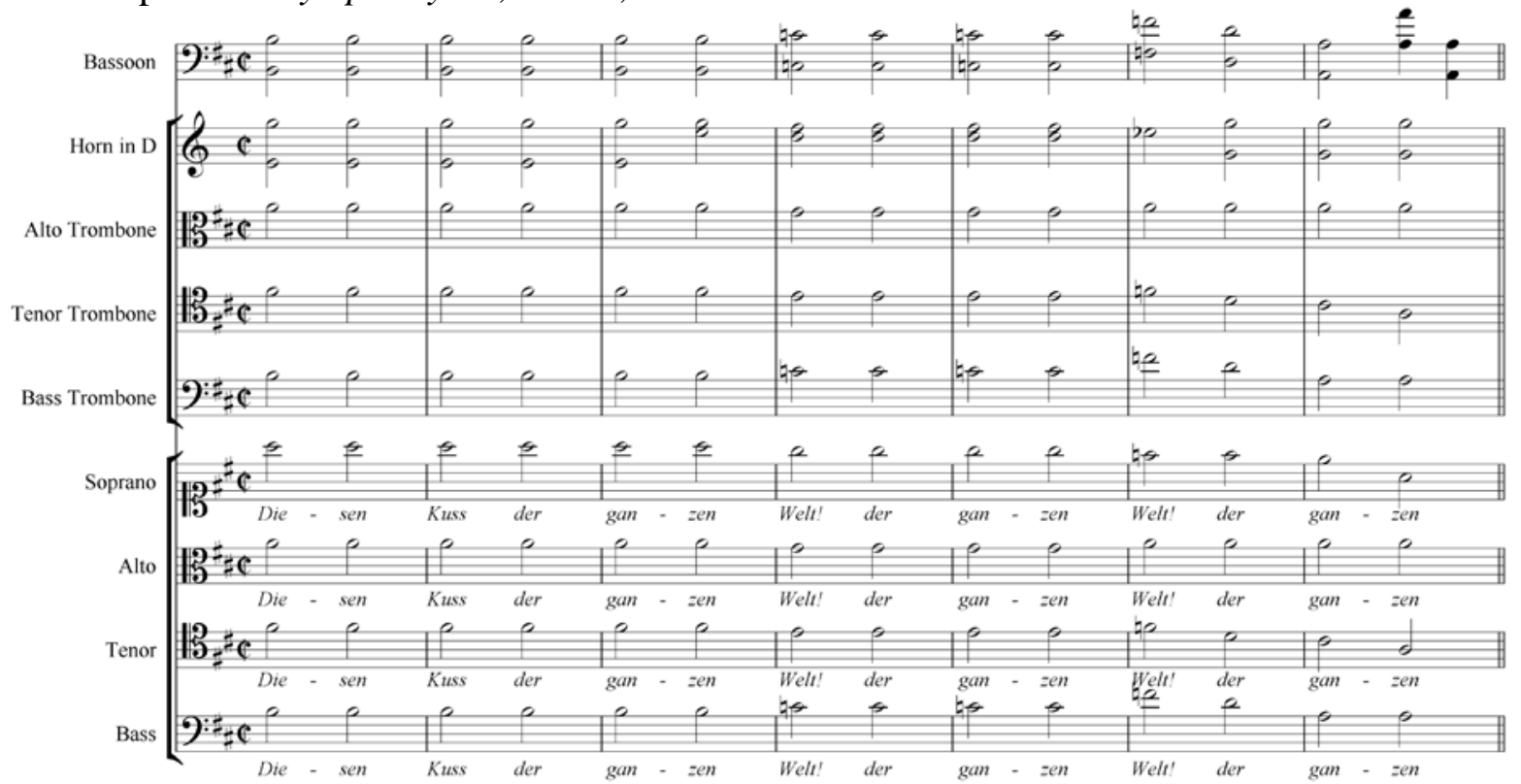


However, in the next example, while the chorus, winds and high brass continue playing half notes, the trombone section switches to quarter notes:

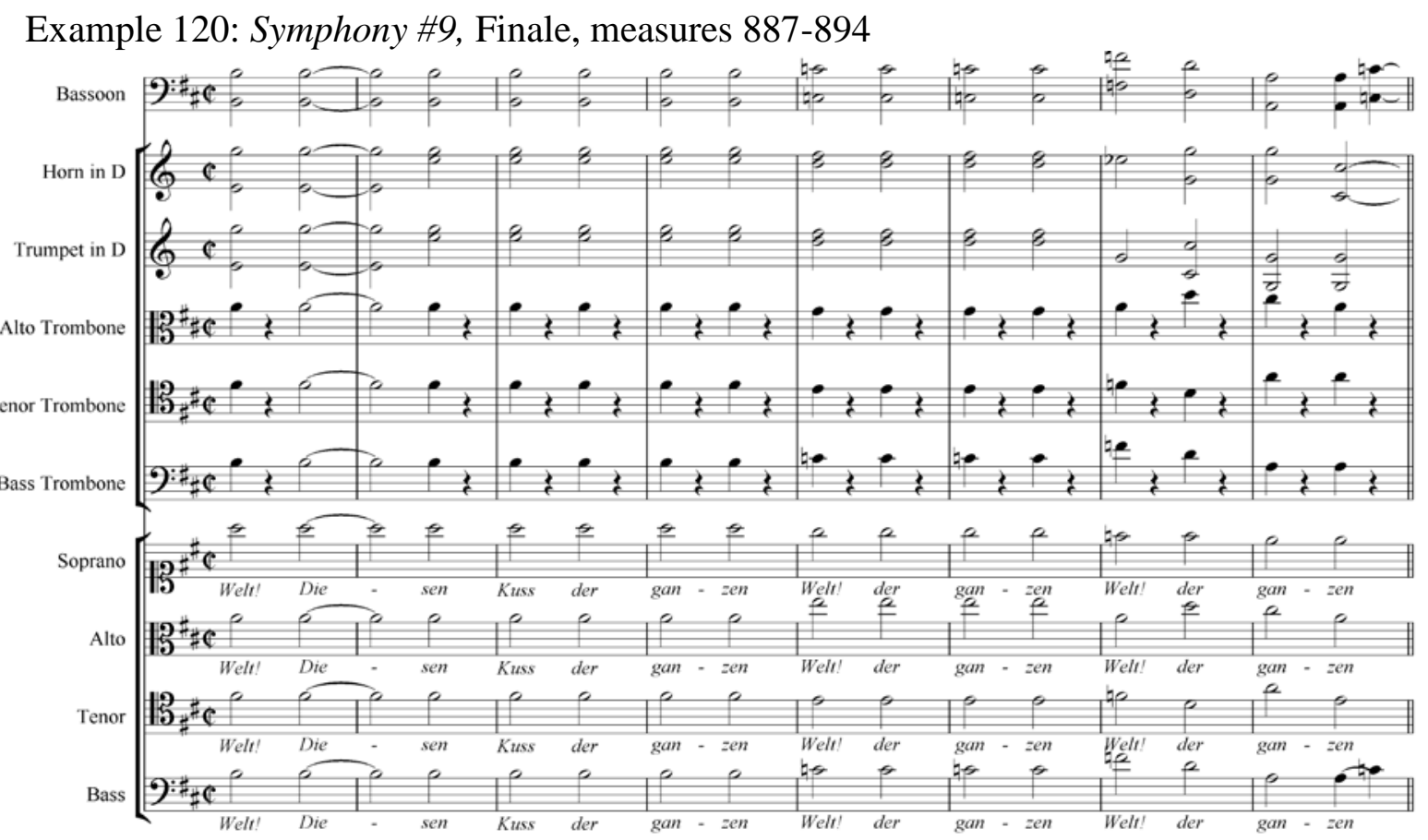

The reason for the change might have been another copyist error, but more likely the trombone notes were shortened to create musical variety between the two passages, which otherwise are practically identical. Throughout this section, the trombones mostly double their corresponding voice parts. The exception is in the fifth and sixth measures of the example, where the alto voice goes up to an $\mathrm{e}^{2}$ but the alto trombone stays on the same $\mathrm{g}^{1}$ as the previous excerpt (doubling the soprano one octave lower). This is another example of compensatory harmony, first encountered in Missa Solemnis. In addition, notice in the seventh measure the alto trombone has its only $\mathrm{d}^{2}$ of the entire work. This could be another case of a Rampl copying error (assuming it was Rampl who was doing the copying at this point). If it was an error, then Rampl was indeed trying to avoid the high $\mathrm{d}^{2}$ altogether and wrote it here by accident. This then logically makes the awkward major seventh drop in the alto trombone part in measure 729 (discussed above) a deliberate act on the part of the 
copyist, as opposed to a mistake. (If that is the case, then Rampl in measure 729 evidenced a fantastic lack of understanding of proper musical phrasing.) Another possible explanation was that the passage shown directly above was copied by someone other than Rampl, and he chose to write the alto trombone to the customary high $\mathrm{d}^{2}$. Probably the most satisfying explanation was that the lone $\mathrm{d}^{2}$ could be written at this point because of the context: the entire orchestra and chorus are at full volume, and perhaps Beethoven (or the copyist) felt that the high $\mathrm{d}^{2}$ was allowable, due to the thick orchestration and loud dynamic. In any case, as with Missa Solemnis, the alto trombone part to Symphony \#9 could undergo some editing to create more cohesive musical lines-especially in measure 729, where the phrase needs to be properly resolved up the half step to the high $\mathrm{d}^{2}$.

The work concludes with a short Maestoso section followed by the final Prestissimo:

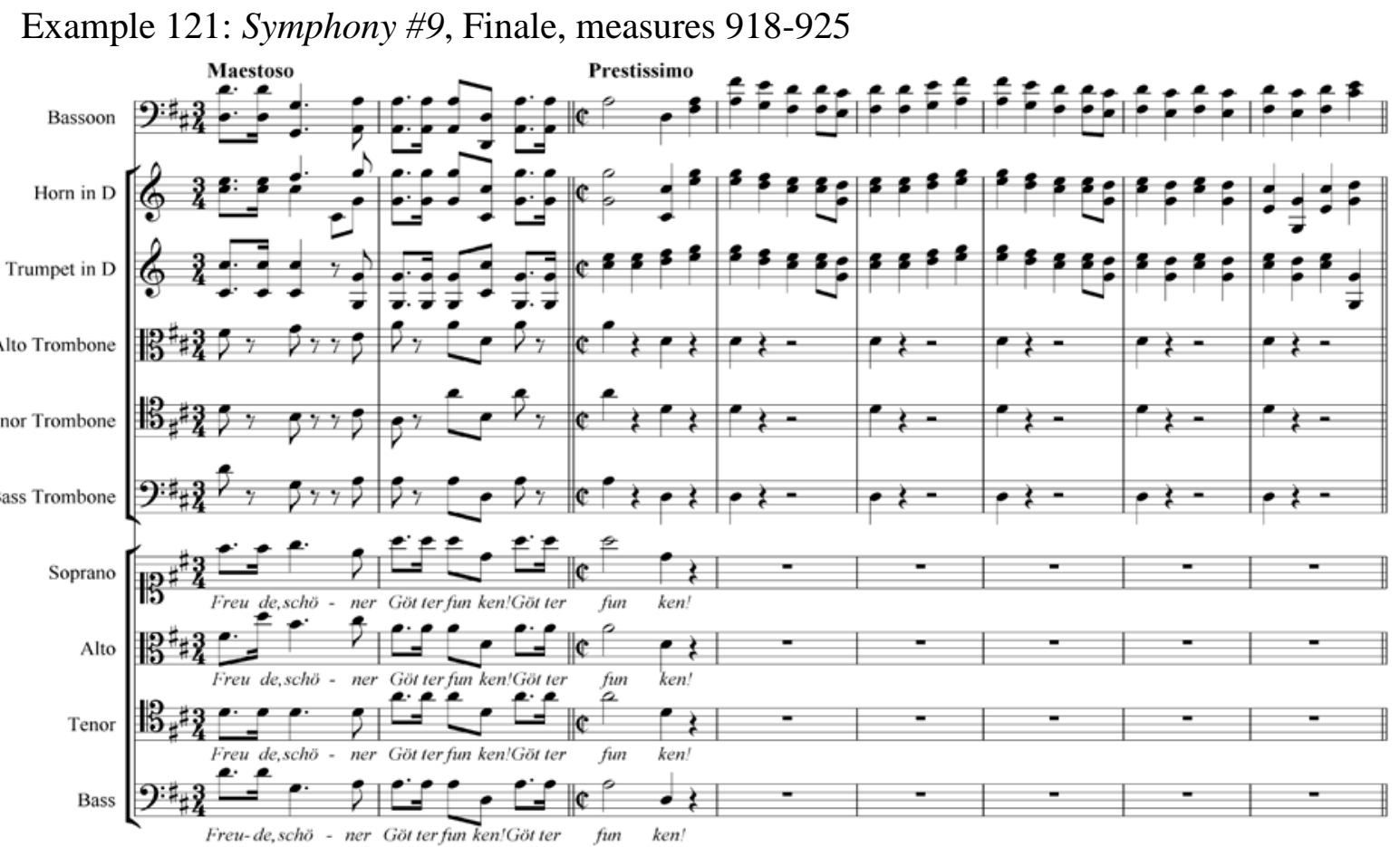

The trombones at this point play only on the downbeats through the end of the work. The final chords played by the trombones begin several measures before the end and are written 
in the section's most effective and loudest-sounding close triadic harmony:

Example 122: Symphony \#9, Finale, measures 928-935

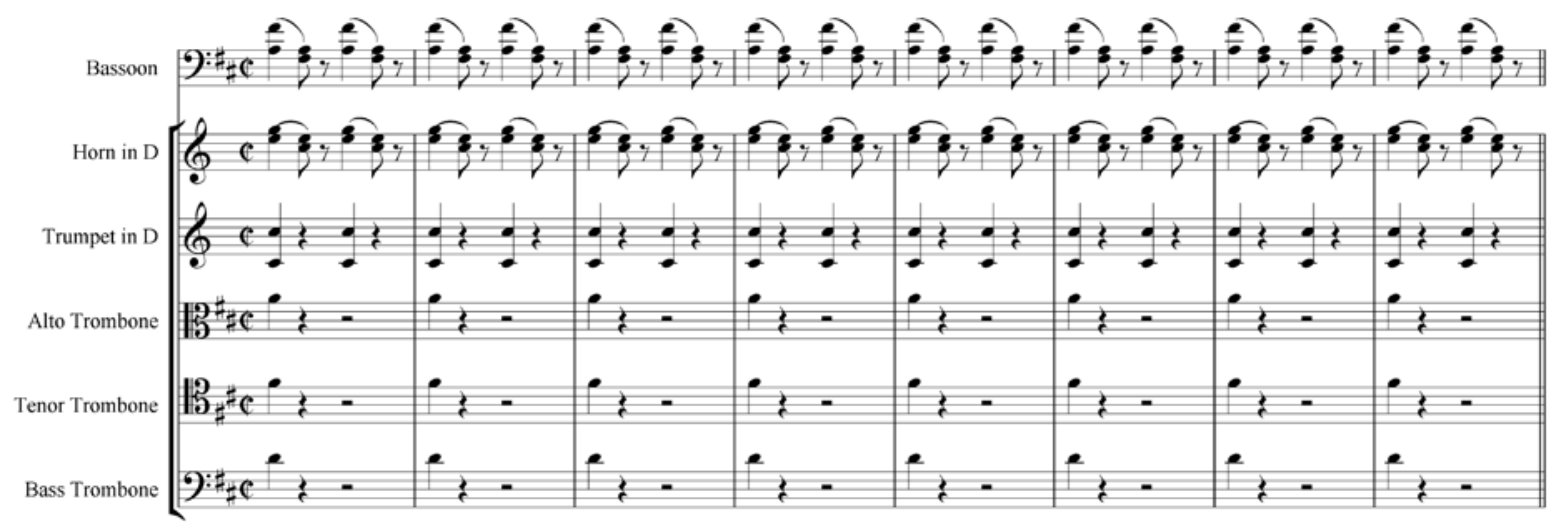

While it is true that in these last measures the trombones are just three more voices playing along in a loud tutti section, the close position of the triad, coupled with the natural loudness of the instrument, creates a sound that significantly increases the overall dynamics of the entire orchestra. The words of Forsyth—used to describe an ending by a different composer where the trombones also played in close triadic harmony-are appropriate here: "Nothing could be simpler on paper: nothing could be more effective in sound.” 362

To conclude, while Missa Solemnis probably represents Beethoven’s most expansive trombone writing, Symphony \#9 represents his most versatile. The trombone section displays the widest variety of roles in Symphony \#9. They quietly support the winds and strings in the Scherzo, with the bass trombone playing extended simplified doubling passages alone, as was the case in King Stephen and The Glorious Moment. The bass trombone also plays a solo note with the male voices in the Finale, joined by the tenor trombone in the next solo passage. In this same passage the trombone section hearkens back to its ancient ecclesiastical role, supporting the chorus as it intones Beethoven's fundamental religious beliefs. There are passages where the trombones create a larger brass section with the

${ }^{362}$ Cecil Forsyth, Orchestration, (London: MacMillan And Co., 1926), 147. 
trumpets, as was touched upon in Consecration of the House. In the choral fugue, by this time a regular place for the trombones to appear, the section plays its traditional Austrian church music role and doubles the chorus note for note-with the exception of the alto trombone, which is omitted at certain points because of range issues. The alto trombone part is peculiar, scored lower than it had been in the past by Beethoven, almost as if he had forgotten the range of the instrument. His asking a friend about this very subject is an indication that he may truly have forgotten the range. Copyist intervention may have been another factor contributing to the idiosyncrasies of the alto trombone part. The dynamics of the trombone section are more extreme than was previously written, with drastic volume shifts over just one beat. The trombone parts also reflect some more typically traditional roles, such as rhythmic abbreviation and playing only the downbeat while the rest of the orchestra continues through the measure. The section also is written in closer harmonies than in earlier works, creating a brighter, more projecting sound-especially when close triads are played_-as in the final Prestissimo section. Overall, like Missa Solemnis, the parts are robust and musically interesting. However, the difference is that while the trombone section plays less in Symphony \#9-almost by a third as compared to Missa Solemnis - the parts in the symphony have a more varied role. Because of the dual nature of Symphony \# 9-it being both a symphonic work and a choral work - the trombones fulfill more varied purposes than in a work written in strictly an orchestral or choral genre.

\begin{tabular}{|c|c|c|c|c|c|c|c|}
\hline \multicolumn{8}{|c|}{ Table 19: Trombone Statistics for Symphony \#9, Opus 125} \\
\hline \multicolumn{2}{|c|}{ Movements } & \multicolumn{3}{|c|}{ Measures } & \multicolumn{3}{|c|}{ Ranges } \\
\hline Total & \#Played & Total & \#Played & \%Played & Alto & Tenor & Bass \\
\hline 4 & 2 & 2598 & 262 & 10 & g to $\mathrm{d}^{2}$ & d to $a^{1}$ & $\mathrm{G}$ to $\mathrm{f} \#^{1}$ \\
\hline
\end{tabular}




\section{Chapter VII}

\section{Comparisons and Conclusion}

\section{Comparisons between Genres}

Before discussing the next section, it is necessary to elaborate on the issue of how to categorize Beethoven's works within their various genres. Some works are more easily placed in a genre than others. For example, Leonore/Fidelio is obviously placed in the operatic genre, and Three Equali is obviously a chamber quartet. However, where would Symphony \#9 be placed? Does it belong in symphonies, or in choral works with orchestra? Should Missa Solemnis be categorized as an oratorio, as Beethoven had suggested, ${ }^{363}$ or should it be listed as a mass? In addition, should Fidelio Overture and the two overtures to Leonore which include trombones also be placed in the genre of overture, since these works have always been more often performed as individual overtures than as introductions and/or additions $^{364}$ to the opera? While some of the answers to these questions are debatable, the table below represents one effort to categorize the works into genres that most clearly define their salient properties, in order of increased playing frequency, from left to right:

\begin{tabular}{|c|l|l|l|l|l|c|c|}
\hline \multicolumn{7}{|c|}{ Table 20: Genres of Beethoven's Works which Include Trombones, by Opus } \\
\hline Opera & Symph. & Choral $^{\text {365 }}$ & Sacred & Overture & Orch. $^{366}$ & Band & Chamber \\
\hline 72 & 67 & 113 & 85 & $72 \mathrm{a}$ & 91 & WoO 24 & WoO 30 \\
\hline \multirow{3}{*}{} & 68 & 117 & 123 & $72 \mathrm{~b}$ & 114 & & \\
\cline { 2 - 6 } & 125 & 136 & & $72 \mathrm{c}$ & & & \\
\cline { 2 - 3 } & & WoO 97 & & 124 & & & \\
\hline
\end{tabular}

\footnotetext{
${ }^{363}$ Solomon, Beethoven, 400.

${ }^{364}$ Gustav Mahler established the tradition of inserting Leonore Overture \#3 after the Dungeon scene to provide music during the extra time needed for the stage change. There is some debate as to whether Mahler truly was the first to do this. (See Michael Kennedy, Mahler [London: Aldine, 1974], 22-23.)

365 The full name of this genre is Choral Works with Orchestra. Grove's Music Online lists WoO 97 as an Opera, but it probably best fits in the genre of choral works with orchestra.

${ }^{366}$ The full name of this genre is Miscellaneous Orchestral work.
} 
The operatic genre represents the most limited trombone scoring, both in terms of frequency of playing and musical complexity. While there were signs of progress, predominantly the trombone parts in Leonore/Fidelio are limited to tutti orchestra support, backup chords, and simplistic doubling. The most musically complex passages are in the Recitatives of the 1805-06 productions, and while they are rhythmically equal to the other instruments, they are still limited usually to just a handful of measures. Furthermore, the trombone parts in the 1814 production are reduced to only two trombones and are restricted to only a handful of musical numbers, with note values no shorter than a quarter note. Thematically, in Leonore/Fidelio the trombone section mostly continues its traditional Viennese operatic role of depicting religious or underworldly scenes and characters. ${ }^{367}$

The next genre in increasing frequency of playing is the symphony. Obviously, Symphonies 5 and 6 fall into this category. Symphony \#9 has also been included to avoid too many genres, though there are some differences in scoring techniques in Symphony \#9 that will be noted. For the most part, in all the orchestral sections of the three works, the trombone section plays a tutti support role, with an emphasis on loud dynamics. Rhythmic abbreviation is quite common, though probably not because of any feared inability of trombonists to play fast notes, but more likely to encourage a strong downbeat while at the same time retaining clarity and forward motion. Vocal passages from Symphony \#9 incorporate some of the techniques that will be described when discussing the choral genres, but primarily the trombone parts tend to be pared down slightly, probably in an effort to avoid overbalancing the choir. Symphony \#6 possibly has one technique not seen in any other work, where the trombone section starts a melody which is then completed by the

\footnotetext{
${ }^{367}$ There is an excellent chart and accompanying discussion in Timothy Howe's dissertation showing how Gluck and Mozart scored for trombones whenever depicting such subjects. (See Howe, Ibid., 7.)
} 
horns. The fact that this specific technique never showed up in any other of Beethoven's works is revealing. Since every other orchestrational technique Beethoven used for trombones does show up in other works, it is unlikely that he abandoned the "melody completion” technique without attempting it at least one additional time. A more plausible reason the "melody completion" technique did not show up again is because Beethoven did not write the trombones to complete (or start) a melody in the Symphony \#6 passage in question. Referring again to Example \#38 on page 65, it is more likely that in this particular passage Beethoven was simply using the "tutti downbeat" technique. This scoring technique has been encountered in many of his works that include trombones, especially symphonies. The horns do not complete the melody; they play the entire melody, which is one that begins after the downbeat. This is borne out by the last two measures of the example, where the trombones begin to play the downbeats of both beat one and beat four (in 6/8 time), but the horn melody stays the same. If the trombones indeed were written in this case to begin a melody, the horn melody in these two measures would have been altered to match the change in the trombone downbeats. Therefore, it is probably best to say that in this example in Symphony \#6, the scoring technique employed by Beethoven was another instance of tutti downbeats—a common technique seen in many other cases in his other works.

In the next genre-choral works with orchestra-the trombone section begins to enjoy a more important role in the orchestra, especially when scored in conjunction with the choir. While the orchestrational techniques employed by Beethoven in this genre are typical—such as tutti orchestral support, choral doubling, and momentary prominences—the trombone parts tend to be more imaginative than in previous genres. There are creative scoring techniques designed to incorporate new "tonal colors," as well as Beethoven’s first 
scoring for the trombone section of one (in King Stephen). The trombones tend to be more active in Recitatives—as they were in the 1805-06 productions of Leonore-and the section becomes established as a regular part of choral fugues. Overall, the trombone section's participation is elevated as compared to the previous genres.

The next genre is the overture. While Consecration of the House is Beethoven's only "stand-alone" overture containing trombone parts, the three Leonore and Fidelio overtures need to be included in this section as well, mainly because-as mentioned above-these three pieces have always appeared in concert programs apart from full productions of the opera. In the three overtures, the trombones (alto, tenor, and bass in Leonore Overtures \#2 and \#3; tenor and bass in Fidelio Overture) play a considerable percentage of the total measures, more so with the two Leonore overtures:

\begin{tabular}{|l|l|l|l|l|l|l|l|l|}
\hline \multicolumn{7}{|c|}{ Table 21: Trombone Statistics for Leonore and Fidelio Overtures } \\
\hline Leonore Ov. \#2, Op. 72a & \multicolumn{4}{|l|}{ Leonore Ov. \#3, Op. 72b } & \multicolumn{3}{|c|}{ Fidelio Overture, Op. 72c } \\
\hline Total & \# Play & \% Play & Total & \# Play & \% Play & Total & \# Play & \% Play \\
\hline 530 & 145 & 27 & 628 & 190 & 30 & 308 & 47 & 15 \\
\hline
\end{tabular}

The trombone section in the overture genre tends toward tutti support, rhythmic abbreviation, and loud sounds—as seen in the symphony genre—but the frequency of measures played is significantly higher than in the symphonic genre. Furthermore, the section has more soli than has been seen in other genres. Although Consecration of the House does have a much lower playing frequency percentage, the measures that the trombones do play are significant in their musical content and filled with prominences and section soli.

The next genre is sacred music. While the two works listed under this genre are usually classified differently—one an oratorio and the other a mass—-to approach each work 
as a separate genre creates too many one-work genres and skews the orchestrational trend line. In addition, the role of the trombone section is quite similar in both works. Therefore they have been combined into one genre. The trombone parts in the sacred genre represent the most sophisticated and musically involved orchestration techniques Beethoven employed for the instrument. The section has diverse roles, though due to the early composition date of Christ on the Mount of Olives, the parts are more primitive than in the later Missa Solemnis. The trombones support the choir and make use of other more interesting techniques such as passing tones, momentary prominences, section soli, and even one short solo. The section also has the more traditional roles seen in the other orchestral genres, such as tutti support, rhythmic abbreviation, and loud section dynamics. The percentage of measures played is higher, indicating a more advanced level of involvement on the part of the trombone section.

The final orchestral genre is the miscellaneous orchestral piece. The two works in this category are Wellington's Victory and March and Chorus from Ruins of Athens. The trombone parts in both these works tend to have the typical orchestrational techniques already encountered in the symphonic genre. They usually play tutti sections, with loud dynamics and (generally) abbreviated rhythms. However, the trombone section in this genre tends to play more measures than in the symphonic and other orchestral genres. There tend to be more prominences and section soli. So, while the sophistication of the trombone parts is reduced-especially as compared to the choral and sacred genres, the trombones play a lot more of the time.

The frequency of measures played in the various orchestral genres is indicated in the chart below. Musical sophistication and frequency of measures played are not synonymous: 


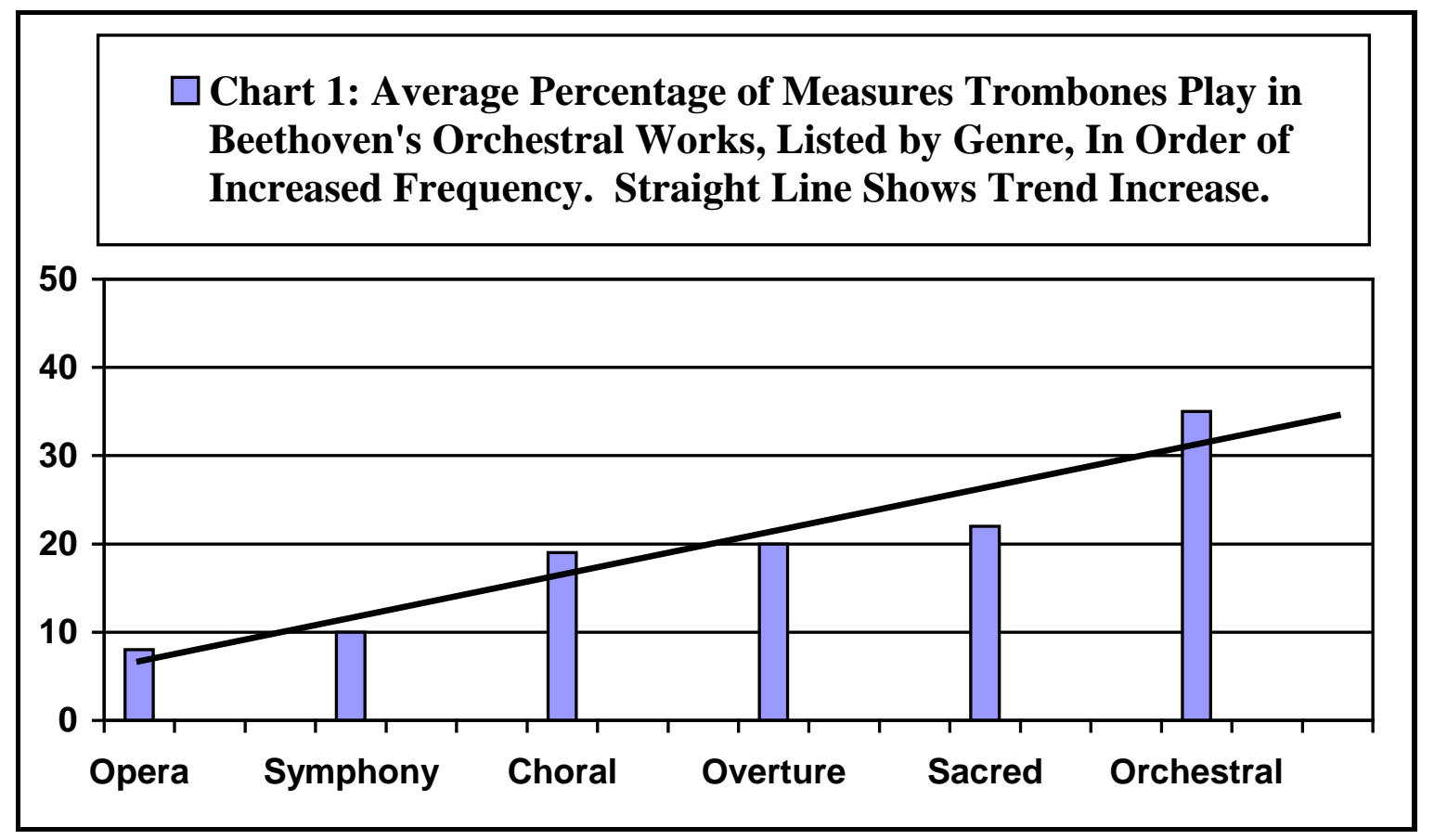

There are two other non-orchestral genres to be discussed. The first is march for military band. Due to the dissimilarity of this genre, the Military March in $D$ cannot be combined with any other. This work carries the orchestrational techniques of the miscellaneous orchestral piece considerably further. The two trombones (tenor and bass) play almost all the time, yet the parts are completely tutti, loud, and rhythmically abbreviated. In this case, the more the trombones play, the more simplistic the music. However, it is the nature of military music to be simplistic, since its purpose is to serve a specific function, in this case to accompany soldiers in marching ceremonies and parades.

The final genre is the chamber quartet, Three Equali. For the most part the four individual parts are equal in importance (hence the name), though in Equale 1 the first trombone does have a semblance of a melody for most of the movement. Since the orchestration is exclusively for trombones, the instrument obviously plays in 100 percent of the measures. The parts are less complex rhythmically than most of the other genres-except 
for opera - and none of the usual techniques are encountered. Dynamically, the chamber quartet represents the softest overall playing, though there are softer notes occasionally in the other genres, especially those where the frequency of played measures is below 20 percent. The range is more limited than the other genres, except military band. Since Three Equali is written for four trombones (not three), the instruments finally play in true four-part harmony, complete with full chords, often with doubled root. Overall, the parts are significantly easier to play than the parts from most of the other genres, again except military band and perhaps opera. The parts, though simple, are clearly the most musically interesting of all the genres.

A chart showing all works of Beethoven which include trombones, listed in increasing frequency of measures played, is below. As with Chart 1, musical sophistication and frequency of measures played are not necessarily synonymous:

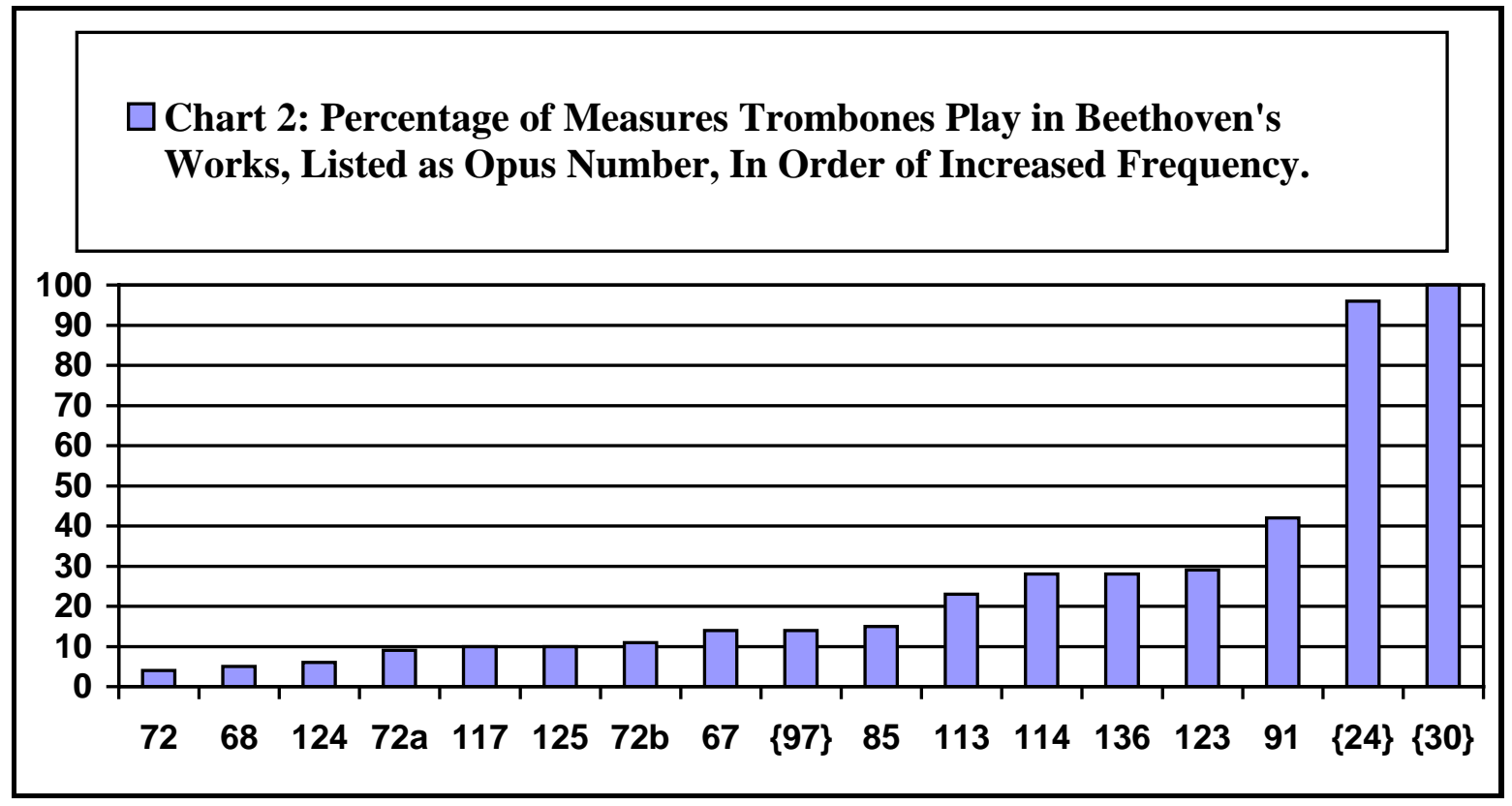




\section{Comparisons across Time}

While categorizing Beethoven's works into genres is interesting and makes for some helpful comparisons, it is somewhat artificial in that the method of categorization is rather subjective and therefore prone to contrivance and manipulation. Time, however, is an objective phenomenon, and therefore it is not nearly as susceptible to exploitation as are man-made forms of classification such as genres. With this in mind, what types of changes to Beethoven's orchestration of the trombone can be observed over the course of time?

Beethoven's first work that included trombones, Christ on the Mount of Olives, is an example of the accepted and established orchestrational techniques commonly found in trombone parts from sacred genres in the late Eighteenth and early Nineteenth Centuries. Beethoven was influenced by the works of his teacher Haydn, as well as Handel, especially through The Seasons, The Creation ${ }^{368}$ and King Saul, all of which include trombones in the score. So, Beethoven started his trombone scoring on this familiar ground, following in his mentors' footsteps. However, as Thayer has said, it was the ambition of Beethoven "to surpass his contemporaries..."369 Beethoven's orchestration of trombones in Christ on the Mount of Olives surpasses Haydn's orchestration in some aspects, especially in the momentary prominences and the rather intimate role the trombones play in several passages. On the other hand, to Haydn's credit, the bass trombone part in The Creation is still one of the most complicated pieces in the orchestral bass trombone literature. ${ }^{370}$ Another area where Haydn held the advantage over Beethoven's earliest trombone scoring efforts was in writing

\footnotetext{
${ }^{368}$ Kinderman, Beethoven, 94-95.

${ }^{369}$ Thayer, Life of Beethoven, 437.

${ }^{370}$ There is, however, some debate surrounding the bass trombone part from The Creation. There are those who assert that the part commonly used today is not authentic, and that the original part was on the same level of simplicity as the alto and tenor parts. (See Edward Solomon, "Creating Problems," British Trombone Society Website, http://www.britishtrombonesociety.org/resources/archived-articles/creating-problems.html.)
} 
for the alto trombone. In Christ on the Mount of Olives, the alto part does not have the level of sophistication or musical interest that the tenor and bass parts possess.

The next work in which Beethoven scored trombones—Leonore-is, in some ways, a step backward in sophistication from the level seen in Christ on the Mount of Olives. In other ways, however, Leonore is a microcosm—within one work—of musical evolution. Again, the presence of trombones in the operatic genre was not novel: other composers who were known influences on Beethoven, such as Gluck and Mozart, had already scored operas to include trombones. As in Christ on the Mount of Olives, Beethoven took an alreadyestablished tradition and expanded upon it. The two early productions of Leonore-in 1805 and 1806-show the micro-evolution and expansion of tradition mentioned above: the trombone parts in the 1806 version (with Leonore Overture \#3) and most likely expanded parts from the opera (such as Example 19) are more extensive and prominent than those of just the year before. A comparison of Tables 4 and 5 (on pages 51 and 52) indicates a 22\% increase in the frequency of trombone measures played from the 1805 production to the 1806 production of the opera. (Table 21 above also shows the increase in the overtures associated with the two productions, listed as Opus 72a and Opus 72b; 1805 and 1806, respectively) Had Beethoven continued on a course of opera composition, the trombone section most likely would have further increased in importance and frequency of measures played.

The next two works including trombones were Symphony \#5 and Symphony \#6. These were composed almost simultaneously and premiered on the same concert. Some scholars view the two works as an opposed pair. Kinderman says, “...the Fifth and Sixth Symphonies represent disparate musical worlds that ultimately complement one another.” ${ }^{371}$ In similar fashion, the trombone parts in the two symphonies differ significantly, yet when

\footnotetext{
${ }^{371}$ Kinderman, Ibid., 146.
} 
taken as a whole, represent a full spectrum of playing styles. In Symphony \#5, the trombone parts are all in the loud tutti style, with trombones-while having only one bona fide section solo-playing a prominent role throughout by sheer volume. In Symphony \#6, with the exception of the Storm scene, the trombone parts are much more relaxed and supportive of other sections and have no prominences or other techniques designed to bring the section into the foreground. The technique of working in conjunction with the horns in completing a melody, as mentioned above, is more likely another example of the trombones providing tutti downbeats, which was a common technique used by Beethoven. While not being the first symphony to include trombones, Symphony \#5 was the first symphony written by a wellknown composer whose compositions became part of the standard orchestral repertoire. The simplicity with which Beethoven wrote for the alto trombone in Christ on the Mount of Olives was completely reversed in Symphony \#5. The alto trombone part is legendary in its tessitura, and the trombone parts in general are extensive and active. In fact, in the one movement the trombones play, they play in almost half the measures. The increased musical interest in the trombone parts from this pair of symphonies represents another step forward in trombone orchestration by Beethoven.

Chronologically, the next two works—Ruins of Athens and King Stephen—were also composed simultaneously, and again are best taken as a pair. Of the two works, Ruins of Athens is the more adventuresome in terms of orchestration techniques, though King Stephen is not without interest. Both works show more creativity and sophistication in the trombone parts, thereby continuing the upward direction of evolution. As was the case with Symphony \#5 and Symphony 6, in the Ruins of Athens/King Stephen pair, it is the latter that has less for the trombones to play, with far fewer interesting passages. In Ruins of Athens, Beethoven 
scored the trombones in new combinations, probably in search of new "tonal colors" to reflect the Turkish style of the music. He also extended the range of the bass trombone down to $\mathrm{B}^{b^{0}}$, the lowest note-as far as can be determined—in the trombone repertoire up to that time. King Stephen, while more conservative in the complexity of the parts and the amount of measures played by the trombones, still has interesting recitatives, as well as scoring for a single bass trombone (where it serves as a trombone section of one) in the Victory March.

The next work—Three Equali—is not placed on the timeline represented by Chart 3, because it is neither an orchestral work, nor does it fit with any of the other genres; it is in its own genre of chamber quartet. The other reason Three Equale is not represented on Chart 3 is because it is an exception to the slow upward trend of sophistication of trombone parts, shown by frequency of measures played. (Since the work obviously features trombones in $100 \%$ of the measures, including it in Chart 3 would skew the trend line.) The work is an example of Beethoven looking back to the Renaissance, scoring the work for the trombones in their traditional ecclesiastical role. It is a sublime work of significant importance to the trombone quartet genre, and unfortunately, due to its deceptive intricacies, it is often performed quite poorly. Those works composed after Three Equali-with the exception of the 1814 production of Fidelio - continue to show a steady progress of complexity. ${ }^{372}$

Wellington's Victory follows next, and there can be seen two main points of progress in this work. The first is the position of the chords and the overall intervallic span of the three parts. The section tends to play most of its chords in close position, with a majority of them being in root position. This technique, though used occasionally in the past, comes to the fore in this work. This could possibly be one point of influence from Three Equali, since

\footnotetext{
${ }^{372}$ It does not appear that after composing Three Equali Beethoven suddenly began scoring trombones in new and innovative ways. Works composed after Three Equali do not evidence a quantum leap in sophistication. This is contrary to one of the anticipated conclusions in the original Prospectus for this Research Project.
} 
a majority of chords in that work tend to be in close position. However, it could also be simply because Beethoven was writing to make the trombone section have more projection, which close position will create. The other point of progress is the total number of measures the trombones play. Wellington's Victory has trombones playing in 42 percent of the measures, which is 38 percent higher than the next highest work, Missa Solemnis. The frequency of trombone notes and the close position chords contribute to the overall military style of the work, as well as its general loudness and bombast.

Chronologically following Wellington's Victory, the 1814 production of Fidelio comes next. While the work is essentially the same as the aforementioned Leonore, because of the significant difference in the trombone parts between the 1805-06 and the 1814 productions, it is necessary to include the 1814 production of Fidelio as its own entry in Chart 3. As was discussed in the historical background of Leonore, Beethoven borrowed an early version of the Leonore score to revise the opera for the 1814 production of Fidelio. This score had only limited trombone parts in it, and therefore the 1814 version of Fidelio represents a step backward in the overall sophistication of Beethoven's trombone parts (though a smaller step backward when exclusively considering the Leonore/Fidelio evolutionary microcosm). The 1814 production, with Beethoven's reversion to an older, unmodified (as far as trombone parts are concerned) score of the opera, created trombone parts with a $63 \%$ decrease in bars played, accompanied by a $33 \%$ decrease of section size versus the 1806 version. Without the 1814 production of Fidelio, the steady rise in trombone frequency indicated in Chart 3 would have been more pronounced.

The next two works—The Glorious Moment and It Is Accomplished-represent, in comparison to Fidelio, a significant step forward in sophistication. However, if Fidelio is 
omitted from the timeline, the two works most likely represent a very slight upward trendor even a flat line-in terms of complexity in the trombone parts. As was the case with previous works, while they were not concurrently composed, The Glorious Moment and It Is Accomplished are probably best taken as a pair. Whereas both works are generally more conservative in trombone scoring, The Glorious Moment represents the more detailed of the pair in terms of orchestrational interest, while It Is Accomplished represents the more rudimentary. The Glorious Moment has the trombones supporting the chorus in fugal sections, further establishing this practice as customary for Beethoven. The trombone parts are musically interesting and at times brilliantly scored in terms of how the section interacts with the choir. It Is Accomplished includes several standard orchestrational techniques, including one particular method of creating momentary prominences: the trombone section rearticulates chords while the rest of the orchestra holds longer valued notes below the rearticulated chords. The result is a pulsing of the beat, creating forward motion.

Chronologically the next work is the Military March in D, which, like Three Equale, is not represented on Chart 3. The reason for excluding this work from the timeline is the same as that of Three Equali: the genre (in this case march for military band) differs significantly from the other genres represented in the timeline. The trombone parts in the Military March in D are typical of the military band genre: unimaginative, supportive of the low woodwinds (usually in the form of doubling), mostly loud, often rhythmically abbreviated, and tutti. The trombones play in 96 percent of the measures. One noteworthy aspect of the work —indirectly related to the trombone-is that as far as can be determined, the Military March in D is the only work of Beethoven that includes a part for Serpent.

Although the next work (with trombones) that Beethoven completed—probably in 
late 1821 or early 1822 — was Missa Solemnis, its premiere was not until 1824, the same year as Symphony \#9. These two works are again best approached as a pair, and so Missa Solemnis will be discussed below. The other two works premiered in 1822, at a dedication concert in November, were Consecration of the House and March and Chorus from Ruins of Athens. Both of these works represent deviations from the steady rise in the complexity of Beethoven's trombone orchestration. In Consecration of the House-which was an homage to Handel—-the trombone parts are quite similar to those in Handel's King Saul, but the overture only includes trombones in the first 37 measures of the work. The few measures that do have trombone parts are interesting and prominent (there are several short section soli), but the fact that there are so few measures in which the trombones play skews the statistical results in Chart 3 downward. The other half of this pair-March and Chorus from Ruins of Athens-is simply recycled material of one number from The Ruins of Athens. The trombone parts are interesting and active (and includes the aforementioned low $\mathrm{B}^{0}$ in the bass trombone), but are present in more measures than is usual for Ruins of Athens, thereby skewing the statistical results upward slightly. As a result, these two works mostly cancel each other out in their influence on the steady rise of frequency of measures played.

Finally, the remaining pair of Beethoven's works which included trombones in the score, as mentioned above, was Missa Solemnis and Symphony \#9. These two works represent Beethoven's most advanced, sophisticated, and creative scoring for the trombone. In Missa Solemnis, the trombone section serves a prominent role in several capacities. They almost always have the same rhythm as the rest of the orchestra. The parts are infused throughout with passing tones, momentary prominences, section soli, and one bona fide solo in the tenor trombone part. The trombone section is a vital part of the orchestration: they 
play in almost 30 percent of the measures. The trombones serve a crucial role in supporting the choir-especially in fugue sections—and are essential to the ecclesiastical nature of the work. In Symphony \#9, the trombone section plays less of the time than in Missa Solemnis, and the parts tend to be somewhat more conservative. This has been seen with other of Beethoven’s works that are best taken in pairs, such as Symphony \#5 and \#6, and Ruins of Athens and King Stephen. Nevertheless, in Symphony \#9 the trombones fulfill an important role, especially in support of the choir. Not only do the trombones usually double the choir outright in fugue sections, but they also support and double the choir in the passage that is often considered to be the high point of the symphony — and therefore the high point of Beethoven's entire compositional output: the intonation of his firmly-held belief that "above the starry host, a Heavenly Father must surely dwell.”373

A chronological chart showing Beethoven's orchestral works that include trombones, with the increasing number of measures played by the trombone section over time, is below:

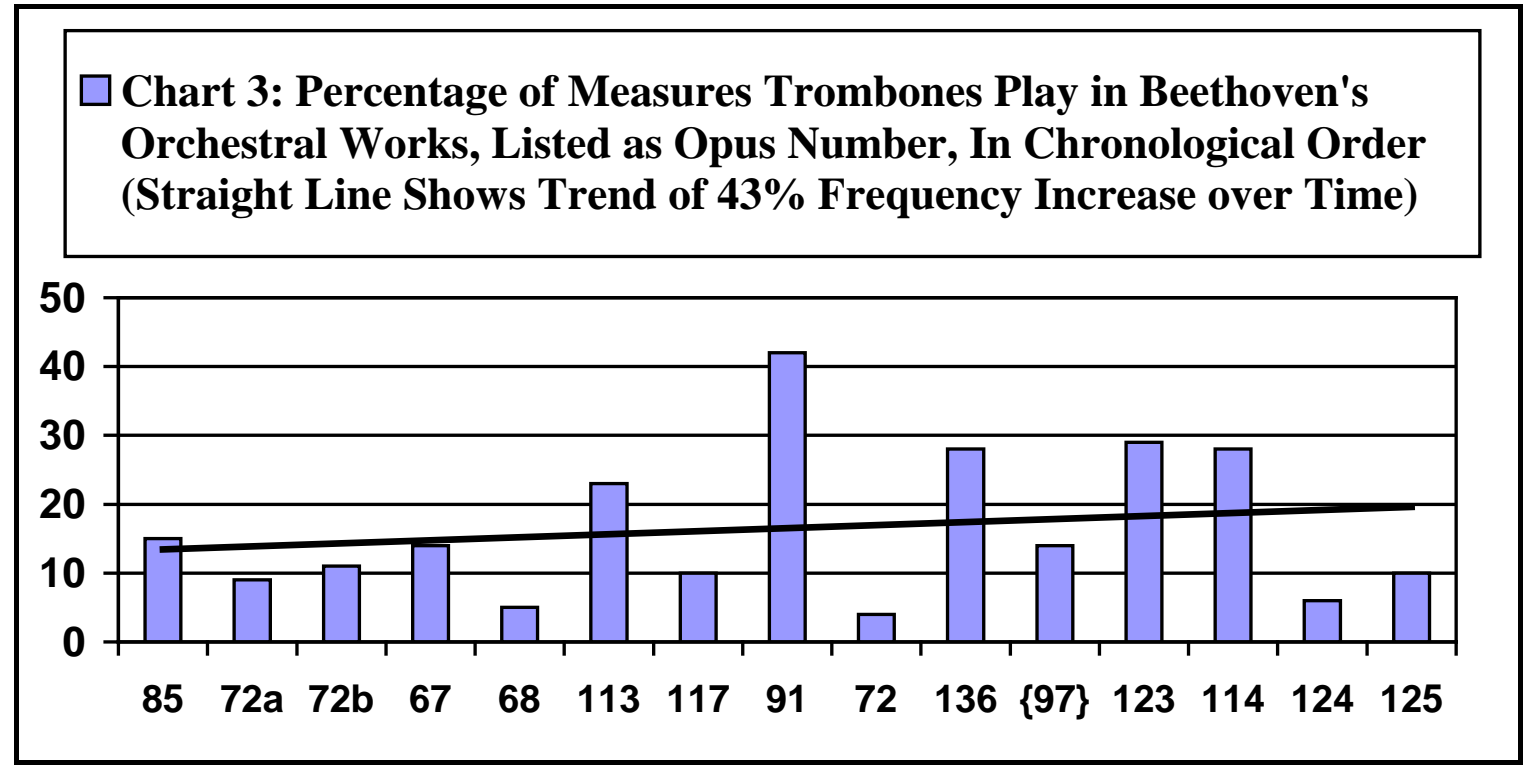

\footnotetext{
${ }^{373}$ Kinderman, 305.
} 


\section{Conclusions}

When Beethoven's works which include trombones are organized into genres, a trend of increasing frequency of playing can be seen. Most of the time, this increased frequency is indicative of increased complexity and musical sophistication as well. The trombone parts in the operatic genre are the least complex, progressing through the symphonic and choral genres to sacred music. In the sacred music genre the trombones not only have more measures to play than most of the other genres, but the parts are increasingly interesting, musically rewarding, and are vital to the integrity of the overall score. Two genres that do not follow the trend line are miscellaneous orchestral work and military band. The trombone section in these genres, while having the most measures to play, has parts that are unsophisticated and musically primitive. Finally, the chamber quartet genre sits outside the other genres as the exception, mostly defying categorization, because the work is scored for trombones only.

If Beethoven's works that include trombones are examined chronologically, a similar upward trend in complexity becomes apparent. Over the course of 21 years of Beethoven's compositional career, his orchestration of the trombone evolved from an innovative modeling of Handel and Haydn to an exceptional and unique synthesis of the best qualities of both the Handel/Haydn-based independent trombone section, and the Austrian church music-based trombone section that fully supported the choir. The frequency of trombone playing in his orchestral works increased over the 21 years, as Chart 3 indicates. The melodic content, range, and harmonic interest in the trombone parts also increased over the same time span. Beethoven's reliance on the power-and versatility — of the trombone section increased throughout his career. 


\section{Closing Remarks}

As was stated in the Introduction, this paper was devoted mostly, with a few exceptions, to material not previously studied in significant detail. Therefore, many subjects related to Beethoven's orchestration of the trombone were left unexplored. Some specific subjects that come to mind include a study of those composers who were influences on Beethoven’s compositional process-Bach, Handel, Mozart, Gluck, Haydn, Cherubini and others—and how they specifically influenced Beethoven in his trombone orchestration. ${ }^{374}$ Along the same lines, another subject would be a study of those composers from the generations following Beethoven—especially those immediately subsequent to him: names such as Berlioz, Schubert, Mendelssohn, Schumann, Wagner, Liszt, and Brahms—and how Beethoven specifically influenced them in his trombone writing. Furthermore, while the statistical charts throughout this paper serve as broad markers to show the frequency of the trombone parts, they are quite limited and of little genuine informational value insofar as quantifying other more significant musical properties of the trombone parts such as prominence, section soli, melodic content, and level of importance to the overall work in question. More specific and statistically-based studies of Beethoven's works that include trombone ${ }^{375}$ would be welcome contributions to the trombone literature, and well worth the effort. The broad spectrum of this paper did not allow for such detailed research. The foundational character of this research project should serve as just that: a foundation. Hopefully others will, in a response to this paper, devote their energy to detailing some of the other subjects and ideas spawned by Beethoven's orchestration of the trombone.

\footnotetext{
${ }^{374}$ Guion did this in some detail, (see David Guion, The Trombone: Its History and Music, 1697-1811), but there is room for more research, especially in light of recently discovered documents pertaining to the subject. ${ }^{375}$ Such as a paper along the lines of H. Keith Jackson's excellent research on selected compositions by Gustav Holst. (See H. Keith Jackson, “The Low Brass Orchestration of Gustav Holst,” D.M.A. Dissertation, Arizona State University, 1995.)
} 


\section{Bibliography}

Adler, Samuel. The Study of Orchestration. New York: W.W. Norton and Company, 1989.

Arnold, Denis, and Nigel Fortune, Editors. Beethoven Companion. London: Faber and Faber, 1971.

Baines, Anthony, Arnold Myers, and Trevor Herbert, “Trombone,” Grove Music Online ed. L. Macy, <http://www.grovemusic.com>. 2008; accessed 18 February, 2008.

Bate, Philip. Trumpet and Trombone: An Outline of their History, Development, and Construction. London: Earnest Benn, Ltd., 1978.

Beethoven Haus-Bonn Website. <http://www.beethoven-haus-bonn.de/sixcms/detail.php// portal_en>. 2008; accessed18 February, 2008

Beethoven, Ludwig van. Christ on the Mount of Olives [1890]. Mineola: Dover, 1996.

. Christ on the Mount of Olives. Beethoven Werke VIII, 1. Selections translated by Richard Scruggs. Edited by Beethoven-Archiv, Bonn. Munich: Henle, 1961-

. Fidelio. Huntington Station: Edwin F. Kalmus.

. Incidental Music to King Stephen. Leipzig: Breitkopf and Härtel.

. Incidental Music to Ruins of Athens. Leipzig: Breitkopf and Härtel.

. It Is Accomplished. Beethoven Werke X, 2. Edited by Beethoven-Archiv, Bonn. Munich: Henle, 1998.

. Leonore. Weisbaden, Breitkopf and Härtel, 1967.

. Leonore Overture \#3 [1862]. New York: Dover, 1985.

. March and Chorus from Ruins of Athens. Leipzig: Breitkopf and Härtel,

. Military March in D. Leipzig: Breitkopf and Härtel.

. Missa Solemnis. Beethoven Werke VIII, 3. Selections translated by Richard

Scruggs. Edited by Beethoven-Archiv, Bonn. Munich: Henle, 2000.

. Missa Solemnis [1864]. New York: Dover, 1991.

. Missa Solemnis. Original manuscript available on Beethoven Haus-Bonn Website

<http://www.beethoven-haus-bonn.de>. 2009, accessed 1 July 2009. 
. Overture: Consecration of the House [1864]. Mineola: Dover, 1999.

. Overture, Consecration of the House. Original manuscript available on Beethoven

Haus-Bonn Website <http://www.beethoven-haus-bonn.de>. 2009, accessed 1 July 2009.

. Symphony \#3. New York: Edwin F. Kalmus.

. Symphony \#5. New York: Edwin F. Kalmus.

. Symphony \#6. New York: C. F. Peters Corporation, 1980.

. Symphony \#9. New York: Edwin F. Kalmus.

. The Glorious Moment. Miami: Edwin F. Kalmus \& Co., Inc, 1990.

. The Glorious Moment. Beethoven Werke X, 1. Selections translated by Lorraine

DiSimone. Edited by Beethoven-Archiv, Bonn. Munich: Henle, 1996.

. Three Equali. Beethoven Werke VI, 1. Selections translated by Richard Scruggs.

Edited by Beethoven-Archiv, Bonn. Munich: Henle, 2008.

. Three Equali. Leipzig: Breitkopf and Härtel.

. Three Equali. Original manuscript available on Beethoven Haus-Bonn Website

<http://www.beethoven-haus-bonn.de>. 2009, accessed 15 July 2009.

. Wellington’s Victory [1864]. Mineola: Dover, 2002.

Bellingham, Jane. “Equale.” The Oxford Companion to Music. Ed. Alison Latham. Oxford Music Online. <http://www.oxfordmusiconline.com/subscriber/article/opr/t114/e2296>. 2009; accessed 12 June 2009.

Berlioz, Hector. Beethoven's Nine Symphonies, Fidelio-His Only Opera, and its Overtures. Translated by Ralph De Sola. Boston: Crescendo Publishing, 1975.

- The Memoirs of Hector Berlioz. Translated by David Cairns. New York: Alfred A. Knopf, 2002.

Berlioz, Hector, and Richard Strauss. Treatise on Instrumentation. Translated by Theodore Front [1948]. Mineola: Dover Publications, 1991.

Blatter, Alfred. Instrumentation and Orchestration. New York: Schirmer Books, 1997.

British Trombone Society Website. <http://www.trombone-society.org.uk/index.php>. 2008; accessed 18 February 2008. 
Cook, Nicholas. Beethoven Symphony \#9. Cambridge: Cambridge University Press, 1993.

Cooper, Barry. Beethoven and the Creative Process. Oxford: Clarendon, 1990.

Del Mar, Jonathan, ed. Ludwig van Beethoven, Symphony Nr. 5 in C minor, a Critical Commentary. Kassel: Bärenreiter, 1999.

- Ludwig van Beethoven, Symphony Nr. 6 in F Major, a Critical Commentary. Kassel: Bärenreiter, 1998.

- Ludwig van Beethoven, Symphony Nr. 9 in D minor, a Critical Commentary. Kassel: Bärenretier, 1996.

Drabkin, William. Beethoven Missa Solemnis. Cambridge: Cambridge University Press, 1991.

Drew, John, "The Emancipation of the Trombone in Orchestral Literature." Journal of the International Trombone Association 9, (March 1981): 2-4.

Fiedler, Andre. "The Equale.” Journal of the International Trombone Association 19 (January 1991), 40-41.

Fiske, Roger. Beethoven’s Missa Solemnis. London: Paul Elek, 1979.

Forsyth, Cecil. Orchestration. London: The Macmillan Company, 1926.

Fulmer, Cassandra R. 'The Role of the Bass Trombone in Haydn’s 'Die Schöpfung,' Beethoven's 'Ninth Symphony', and Brahms' 'Fourth Symphony': A Tutorial Focusing on Historical Background and Preparation Suggestions.” DMA Dissertation, Louisiana State University, 1998.

Gleason, Bruce. “A Guide to Teaching Beethoven’s Marches.” Music Educators Journal, Vol. 82, No. 4 (Jan., 1996), pp. 17-19+50.

Gordon, Sarah. "Das sinfonische Werk von Franz Beck,” British Trombone Society Website, $<$ http://www.britishtrombonesociety.org/resources/archived-articles/das-sinfonische-werk -von-franz-beck.html>. 2009, accessed 9 June, 2009.

Gregory, Robin. The Trombone: The Instrument and its Music. London: Faber and Faber, 1973.

Guion, David M. The Trombone: Its History and Music, 1697-1811. New York: Gordon and Breach Publishers, 1988. 
—. "A Brief History of the Trombone. Online Trombone Journal, <http://www. trombone.org/articles/library/viewarticles.asp?ArtID=254>. 2008; accessed 20 February 2008.

— . "What Handel Taught the Viennese about the Trombone." Historic Brass Society Journal 15 (2003), 291-321.

Herbert, Trevor. The Trombone. New Haven: Yale University Press, 2006.

Howe, Timothy E. "Developing a historical model for trombone performance practice in German and Austrian orchestral works from the period 1785-1830.” DMA Dissertation, University of Nebraska, 2002.

John, Nicholas, Editor. Beethoven Fidelio. New York: Riverrun Press, 1980.

Jones, David Wyn. The Symphony in Beethoven’s Vienna. New York: Cambridge University Press, 2006.

Kallai, Avishai, “Joachin Eggert: Trombone Pioneer.” Ludwig van Beethoven Website, $<$ http://lvbeethoven.com>. 2008; accessed 18 February, 2008.

Kelly, Thomas Forrest. First Nights: Five Musical Premieres. New Haven: Yale University Press, 2000.

Kennedy, Michael. Mahler. London: Aldine, 1974.

Kimball, Will. “Alto Trombone History Timeline.” http://www.kimballtrombone.com/altotrombone/alto-trombone-history-timeline. 2009; accessed 23 October, 2009.

Kinderman, Willliam. Beethoven. New York: Oxford University Press, 2009.

Lee, James D. "A Comparative Study of the Symphonic Trombone Scoring of Beethoven, Brahms, and Berlioz.” Master’s Thesis, Kent State University, 1974.

MacArdle, Donald. Beethoven Abstracts. Detroit: Information Coordinators, Inc., 1974.

Macdonald, Hugh. Berlioz's Orchestrational Treatise: A Translation and Commentary. New York: Cambridge University Press, 2002.

Mellers, Wilfrid. Beethoven and the Voice of God. New York: Oxford University Press, 1982

Montgomery, Jim. "The Use of Trombone by G.F. Handel." Journal of the International Trombone Association XIII/3 (July 1985), 32-34. 
Parsons, Anthony. "Symphonic Birth Pangs of the Trombone,” Ludwig van Beethoven Website <http://www.britishtrombonesociety.org/resources/archived-articles/first-nightnerves.html >. 2008; accessed 18 February, 2008.

Piston, Walter. Orchestration. New York: W.W. Norton and Company, 1955.

Rauscher, Donald. Orchestration: Scores and Scoring. New York: The Free Press of Glencoe, 1963

Rimsky-Korsakoff, Nikoli. Principles of Orchestration, Edited by Maximilian Steinberg [1922]. Translated by Edward Agate. New York: Dover Publications, 1964

Shapiro, Nat. An Encyclopedia of Quotations about Music. New York: Doubleday, 1978.

Scherman, Thomas K., and Biancolli, Louis, Editors. Beethoven Companion. Garden City: Doubleday, 1972.

Schindler, Anton Felix. Beethoven as I Knew Him. Ed. Donald W. MacArdle, Translated by Constance S. Jolly. London: Faber and Faber, 1966.

Shifrin, Ken. "The Alto Trombone in the Orchestra: 1800-2000.” British Trombone Society Website <http://www.britishtrombonesociety.org/resources/shifrin/the-alto-trombone-inthe-orchestra-1800-2000.html>. 2009; accessed 26 May, 2009.

Solomon, Edward. "Creating Problems.” British Trombone Society Website $<$ http://www.britishtrombonesociety.org/resources/archived-articles/creatingproblems.html>. 2009, accessed 23 August, 2009.

Solomon, Maynard. Beethoven. New York: Schirmer Books, 2001. Late Beethoven: Music, Thought, Imagination. Berkeley: University of California Press, 2003.

Streeter, Thomas W., "Survey and Annotated Bibliography on the Historical Development of the Trombone." Journal of the International Trombone Association 7 (January 1979): 27-32.

Thayer, Alexander Wheelock. Thayer's Life of Beethoven, Volume I. Edited by Elliot Forbes. Princeton: Princeton University Press, 1964.

. Thayer's Life of Beethoven, Volume II. Edited by Elliot Forbes. Princeton: Princeton University Press, 1964.

Tomaschek, Johann Wenzel, and Abram Loft. "Excerpts from the Memoirs of J. W. Tomaschek.” The Musical Quarterly, Vol. 32, No. 2 (April 1946), 244-264. 
Tucker, Wallace. "The Trombone Quartet: Its Appearance and Development Throughout History.” Journal of the International Trombone Society VII (January 1979), 2-7.

Tyson, Alan. “The 1803 Version of Beethoven's Christus am Oelberge.” The Musical Quarterly 56 (1970), 551-584.

. "Notes on Five of Beethoven's Copyists." Journal of the American Musicological Society 23 (1970), 439-471.

Wagner, Joseph. Orchestration: a Practical Handbook. New York: McGraw-Hill, 1959.

Weiner, Howard. “Beethoven’s Equali (WoO 30): A New Perspective.” Historic Brass Society Journal 14 (2002), 215-277.

- "When is an alto an alto trombone? When is a bass trombone a bass trombone? The makeup of the trombone section in eighteenth- and early nineteenth-century orchestras.” Historic Brass Society Journal 17 (2005), 37-79. 